National Bureau or Standards

NBS Special Publication 722

A User's Guide for RAPID,

Reduction Algorithms for the

Presentation of

Incremental Fire Data

Breese and Peacock

NBS NBS NBS NBS NBS NBS NBS NBS. WBS

IS NBS NBS NBS NBS NBS NBS NBS NBS NBS NBS NBS NBS NBS NBS NBS NBS NBS NBS NBS NBSA 3S NBS NBS NBS NBS NBS NBS NBS NBS NBS NBS NBS NBS NBS NBS NBS NBS NBS NBS NBS NBS IS NBS NBS NBS NBS NBS NBS NBS NBS NBS NBS NBS NBS NBS NBS NBS NBS NBS NBS NBS NGS
IS NBS NBS NBS NBS NBS NBS NBS NBS NBS NBS NBS NBS NBS NBS NBS NBS. NBS NBS NBS NBS
iS NBS NBS NBS NBS NBS NBS NBS NBS NBS NBS NBS NBS NBS National Bureau of Standards NBS NBS iS NBS NBS NBS NBS NBS NBS NBS NBS NBS NBS NBS NBS NBS NBS NBS NBS NBS NBS NBS

QC BS NBS NBS NBS NBS NBS NBS NBS NBS NBS 100 .457 \# 722 BS NBS NBS NBS NBS NBS NBS NBS NBS NBS 1986 
he National Bureau of Standards' was established by an act of Congress on March 3, 1901. The Bureau's overall goal is to strengthen and advance the nation's science and technology and facilitate their effective application for public benefit. To this end, the Bureau conducts research and provides: (I) a basis for the nation's physical measurement system, (2) scientific and technological services for industry and government, (3) a technical basis for equity in trade, and (4) technical services to promote public safety. The Bureau's technical work is performed by the National Measurement Laboratory, the National Engineering Laboratory, the Institute for Computer Sciences and Technology, and the Institute for Materials Science and Engineering

\section{The National Measurement Laboratory}

Provides the national system of physical and chemical measurement; coordinates the system with measurement systems of other nations and furnishes essential services leading to accurate and uniform physical and chemical measurement throughout the Nation's scientific community, industry, and commerce; provides advisory and research services to other Government agencies; conducts physical and chemical research; develops, produces, and distributes Standard Reference Materials; and provides calibration services. The Laboratory consists of the following centers:
- Basic Standards ${ }^{2}$

- Radiation Research

- Chemical Physics

- Analytical Chemistry

\section{The National Engineering Laboratory}

Provides technology and technical services to the public and private sectors to address national needs and to solve national problems; conducts research in engineering and applied science in support of these efforts; builds and maintains competence in the necessary disciplines required to carry out this research and technical service; develops engineering data and measurement capabilities; provides engineering measurement traceability services; develops test methods and proposes engineering standards and code changes; develops and proposes new engineering practices; and develops and improves mechanisms to transfer results of its research to the ultimate user. The Laboratory consists of the following centers:
- Applied Mathematics

- Electronics and Electrical Engineering ${ }^{2}$

- Manufacturing Engineering

- Building Technology

- Fire Research

- Chemical Engineering ${ }^{2}$

\section{The Institute for Computer Sciences and Technology}

Conducts research and provides scientific and technical services to aid Federal agencies in the selection, acquisition, application, and use of computer technology to improve effectiveness and economy in Government operations in accordance with Public Law 89-306 (40 U.S.C. 759), relevant Executive Orders, and other directives; carries out this mission by managing the Federal Information Processing Standards Program, developing Federal ADP standards guidelines, and managing Federal participation in ADP voluntary standardization activities; provides scientific and technological advisory services and assistance to Federal agencies; and provides the technical foundation for computer-related policies of the Federal Government. The Institute consists of the following centers:
- Programming Science and Technology

- Computer Systems Engineering

\section{The Institute for Materials Science and Engineering}

Conducts research and provides measurements, data, standards, reference materials, quantitative understanding and other technical information fundamental to the processing, structure, properties and performance of materials; addresses the scientific basis for new advanced materials technologies; plans research around cross-country scientific themes such as nondestructive evaluation and phase diagram development; oversees Bureau-wide technical programs in nuclear reactor radiation research and nondestructive evaluation; and broadly disseminates generic technical information resulting from its programs. The Institute consists of the following Divisions:
- Ceramics

- Fracture and Deformation ${ }^{3}$

- Polymers

- Mctallurgy

- Reactor Radiation 


\section{A User's Guide for RAPID, Reduction Algorithms for the Presentation of Incremental Fire Data}

J. Newton Breese and Richard D. Peacock

Center for Fire Research

National Engineering Laboratory

National Bureau of Standards

Gaithersburg, MD 20899

August 1986

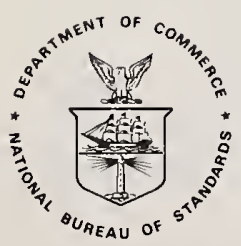

U.S. Department of Commerce Malcolm Baldrige, Secretary

National Bureau of Standards

Emest Ambler, Director 
Library of Congress

Catalog Card Number: 86-600565 Washington: 1986

National Bureau of Standards

Special Publication 722

Natl. Bur. Stand. (U.S.),

Spec. Publ. 722

195 pages (Aug. 1986)

CODEN: XNBSAV
U.S. Government Printing Office For sale by the Superintendent of Documents,

U.S. Government Printing Office, Washington DC 20402 


\section{TABLE OF CONTENTS}

TABLE OF CONTENTS . . . . . . . . . . . . . . . . . . . . . . . . . i

LIST OF TABLES . . . . . . . . . . . . . . . . . . . . . . . . . . . iv

Abstract . . . . . . . . . . . . . . . . . . . . . . 1

1. INTRODUCTION . . . . . . . . . . . . . . . . . . . . . . . . . . 1

2. Part A: Input and Output Control . . . . . . . . . . . . . . . . . . 4

3. Part B: Test and Instrument Descriptions . . . . . . . . . . . . . . 8

4. Part C: Input Formats for Data Acquisition Systems Not Pre-Defined

in RAPID.......................... . . . . 10

5. Part D: Skipping Data Records on Input . . . . . . . . . . . . . . . 14

6. Part E: Input Data in Data-Acquisition-System-Dependent Formats . . . 17

7. Part F: Input Data in Data-Acquisition-System-Independent Format . . 18

8. Part G: Corrections to the Data Matrix . . . . . . . . . . . . . . 20

9. Part H: Non-Trivial Transformations of the Data Matrix . . . . . 21

10. Part I: Plotting... . . . . . . . . . . . . . . . . 22

11. Notes on the Preparation of Data Inputs (NPDI) Read by RAPID . . . 25

12. Transformation Control Commands for Part H . . . . . . . . . . . . . 36

12.1 Available Transformation Control Commands . . . . . . . . . . 37

12.1.1 Utility Commands . . . . . . . . . . . . . . . . 37

12.1.2 Basic Commands . . . . . . . . . . . . . . . 38

12.1.3 Complex Commands . . . . . . . . . . . . . . . . . . . 39

12.2 Data Input for Transformation Control Commands . . . . . . . . 40

13. Data Input for Utility Commands . . . . . . . . . . . . . . . . . . . 44

13.1 Part H, Class U, Subpart a: Input Specified by Utility
Command AMBIENTS . . . . . . . . . . . . . . . . . . 45

13.2 Part H, Class U, Subpart b: Input Specified by Utility
Command AVERAGE . . . . . . . . . . . . . . . . . . 47

13.3 Part H, Class U, Subpart $c$ : Input Specified by Utility 52

13.4 Part H, Class U, Subpart d: Input Specified by Utility
Command COMPUTE . . . . . . . . . . . . . . . . . . . 55 
13.5 Part H, Class U, Subpart e: Input Specified by Utility Command DELAY . . . . . . . . . . . . . . . . . 58

13.6 Part H, Class U, Subpart f: Input Specified by Utility Command DELTA . . . . . . . . . . . . . . . . . 60

13.7 Part H, Class U, Subpart $\mathrm{g}$ : Input Specified by Utility Command E119...... . . . . . . . . . . .

13.8 Part H, Class U, Subpart h: Input Specified by Utility Command INTEGRATE .. . . . . . . . . . . . . . . . . . . . . 64

13.9 Part H, Class U, Subpart $i$ : Input Specified by Utility Command RENAME . . . . . . . . . . . . . . . . . . . . . . 66

13.10 Part H, Class U, Subpart j: Input Specified by Utility Command SEPARATE...................... . 68

13.11 Part H, Class U, Subpart k: Input Specified by Utility Command SMOOTH ....................... . . 72

13.12 Part H, Class U, Subpart 1: Input Specified by Utility Command SPECIFY .. . . . . . . . . . . . . . . . . 75

13.13 Part H, Class U, Subpart m: Input Specified by Utility

13.14 Part H, Class U, Subpart n: Input Specified by Utility Command TIME

14. Data Input for Basic Commands

14.1 Part H, Class B, Subpart a: Input Specified by Basic Command GAS 8 . . . . . . . . . . . . . . . . . . . . .

14.2 Part H, Class B, Subpart b: Input Specified by Basic Command PRESSURE .. . . . . . . . . . . . . . . . .

14.3 Part H, Class B, Subpart c: Input Specified by Basic Command SMOKE

14.4 Part H, Class B, Subpart d: Input Specified by Basic Command THERMOCOUPLE . . . . . . . . . . . . . . .

14.5 Part H, Class B, Subpart e: Input Specified by Basic Command VELOCITY $\cdot \cdot \cdot \cdot \cdot \cdot \cdot \cdot \cdot \cdot \cdot \cdot \cdot \cdot \cdot \cdot \cdot \cdot$

14.6 Part H, Class B, Subpart f: Input Specified by Basic Command WT-LOSS

15. DATA INPUT FOR COMPLEX COMMANDS . . . . . . . . . . . . . . . . . 105

15.1 Part H, Class C, Subpart a: Input Specifiéd by Complex Command BALANCE ..................... 106

15.2 Part H, Class C, Subpart b: Input Specified by Complex Command FLOW-RATE . . . . . . . . . . . . . . . . . 108

15.3 Part H, Class C, Subpart c: Input Specified by Complex

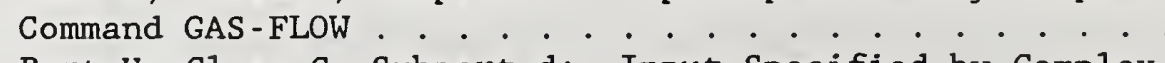

15.4 Part H, Class C, Subpart d: Input Specified by Complex

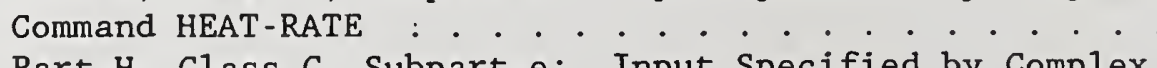

15.5 Part H, Class C, Subpart e: Input Specified by Complex Command HEAT-RATE- 2

15.6 Part H, Class C, Subpart f: Input Specified by Complex

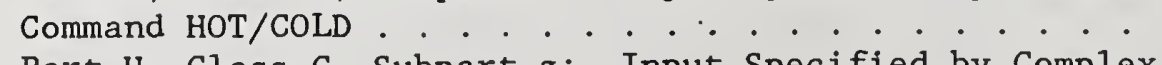

15.7 Part H, Class C, Subpart g: Input Specified by Complex Command MASS-FLOW 
15.8 Part H, Class C, Subpart h: Input Specified by Complex Command MASS-FLOW-2 . . . . . . . . . . . . . . . . . . . . . 142

15.9 Part H, Class C, Subpart i: Input Specified by Complex Command MASS-FLOW-3 . . . . . . . . . . . . . . . . . . . . . 145

15.10 Part H, Class C, Subpart $\mathrm{j}$ : Input Specified by Complex. Command STATIC . . . . . . . . . . . . . . . . . . . . . 147

15.11 Part H, Class C, Subpart k: Input Specified by Complex Command SURFACE . . . . . . . . . . . . . . . . . . . . . . . 154

15.12 Part H, Class C, Subpart 1: Input Specified by Complex Command VENT-LOSS . . . . . . . . . . . . . . . . . . . . 157

15.13 Part H, Class C, Subpart m: Input Specified by Complex Command WT-RATE . . . . . . . . . . . . . . . . . . 159

15.14 Part H, Class C, Subpart $n$ : Input Specified by Complex Command ZERO-TC....................... 162

Appendix A . . . . . . . . . . . . . . . . . . . . . . . . . . . 164

Sample Set of Input Data for RAPID . . . . . . . . . . . . . . . . . 164

Listing of Input Data Set for RAPID . . . . . . . . . . . . . . . . 174

Appendix B . . . . . . . . . . . . . . . . . . . . . . . . 178

Using RAPID on the CFR Minicomputer . . . . . . . . . . . . . . 178 Using the Program . . . . . . . . . . . . . . . . . . . . 179

But, It Can Be Easier Than That . . . . . . . . . . . . . . . 180 Other Niceties to Make Your Life With RAPID Easier . . . . . . 182

Appendix C . . . . . . . . . . . . . . . . . . . . . . . . . . 185

Selected Listings from the Program. . . . . . . . . . . . . . 185 PROGRAM RAPID .. . . . . . . . . . . . . . ....... . 186 BLOCK DATA CRVFIT . . . . . . . . . . . . . . . . . . . . . 188 


\section{LIST OF TABLES}

Table 1. Pre-Defined Data Formats for Input to RAPID . . . . . . . . . 35

Note: Certain commercial equipment is identified in this paper in order to illustrate adequately certain device specific characteristics. Such identification does not imply recommendation or endorsement by the National Bureau of Standards, nor does it imply that the equipment is necessarily the best available for the purpose. 


\title{
A Users Guide for RAPID,
}

Reduction $\mathbf{A l g o r i t h m s ~ f o r ~ t h e ~}_{\text {resentation of }} \mathbf{I}_{\text {ncremental fire }} \mathbf{D}_{\text {ata }}$

Version 86.0602

J. Newton Breese and Richard D. Peacock

\begin{abstract}
The voluminous amount of data that can be collected by automatic data acquisition systems during large scale fire tests requires the use of a digital computer for the reduction of data. RAPID is a stand-alone program specifically designed to convert raw instrument voltages collected during such tests into meaningful units. The reduced data can also be used alone or in combinations to obtain quantities that require more than minimal data reduction. The program is written with the ability to accept data from a user defined data acquisition system, with the ability to check the correctness of data included. Through the use of input data provided by the user, the data can be converted into meaningful scientific units. The data can then be presented in tabular or printer plot form, or stored for further processing.

This user's guide provides detailed instructions for the use of the program.
\end{abstract}

Key Words: Computer program; data acquisition; data reduction; fire tests

\section{INTRODUCTION}

In 1968, the Building Research Division of the National Bureau of Standards (NBS) approached the Computer Services Division of NBS with a proposal concerning the design of a series of computer programs to facilitate the analysis of automatically recorded data. During the following two years, a system of programs called SPEED (Systematic Plotting and Evaluation of Enumerated Data) was developed and tested. This system was announced at the 
Ninth Annual Technical Symposium of the Association for Computing Machinery and in an article in Computer Graphics. The following paragraphs, quoted from the Computer Graphics article, which indicated the need for SPEED are still valid:

\begin{abstract}
"The use of digital scanning systems offers several advantages to the research scientist. First, their rapid recording capabilities allow for more complete data sampling. Second, automatically recorded data is more accurate than data that has been recorded manually.

These advantages are however, to some extent, counterbalanced by several problems which arise. Two problems are caused by the large volume of recorded data. First, it is difficult, if not impossible, to process large volumes of data by hand. Thus, the scientist finds it necessary to make use of the computer.

Unfortunately, he is often unfamiliar with the capabilities and limitations of this device. Second, when presented with a large volume of data, it is often difficult for the scientist to rapidly interpret the broad characteristics of general trends that may be present. Two other problems arise in the form in which the data are recorded. The data are generally recorded in millivolts rather than standard units. Thus some conversion process, usually a linear transformation, is required. Furthermore, the recorded data are not usually directly compatible with computers. In order for a computer to read this data some special computer program must be used to read this data in the recorded form and translate it into the internal computer representation."1
\end{abstract}

During the years since its announcement, SPEED has been widely used at NBS and other computer installations and has been rewritten once to provide new features and a standardized system of programs with current documentation ${ }^{2}$. RAPID (Reduction Algorithms for the Presentation of Incremental Fire Data) is

1 Smith, John M., Automatic Data Evaluation, Manipulation, Display, and Plotting with SPEED, Computer Graphics, Vol. 4, No. 2, 41-53 (Fal1 1970).

2 Peacock, R. D., and Smith, John M., SPEED2, A Computer Program for the Reduction of Data from Automatic Data Acquisition Systems, Nat1. Bur. Stand. (U. S.), NBSTN 1108 (September 1979). 
a stand-alone program that employs the software developed for the PLOT2 phase of SPEED2. In addition, it has been expanded and designed specifically designed to convert raw fire test data into meaningful units. The reduced data can be used alone or in combinations to obtain quantities that require more than minimal data reduction.

This report provides detailed instructions for the use of the program and describes the implementation of the various calculations available. 


\section{Part A: Input and Output Control}
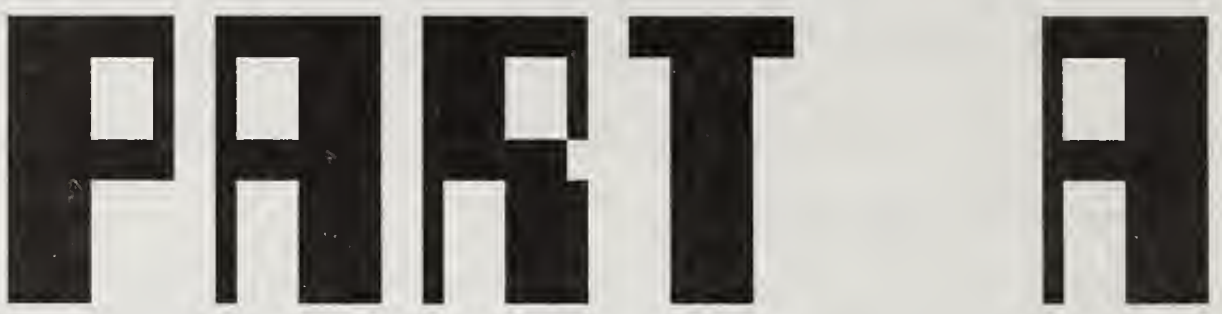

\begin{tabular}{|c|c|c|c|}
\hline Input & Variables & Format & Comments \\
\hline Al & $\begin{array}{l}\text { INTYPE, INPRT, INPNCH, } \\
\text { INSTOP, INERR, INSKIP, } \\
\text { INSAVE, INTEST }\end{array}$ & $8 I 5$ & 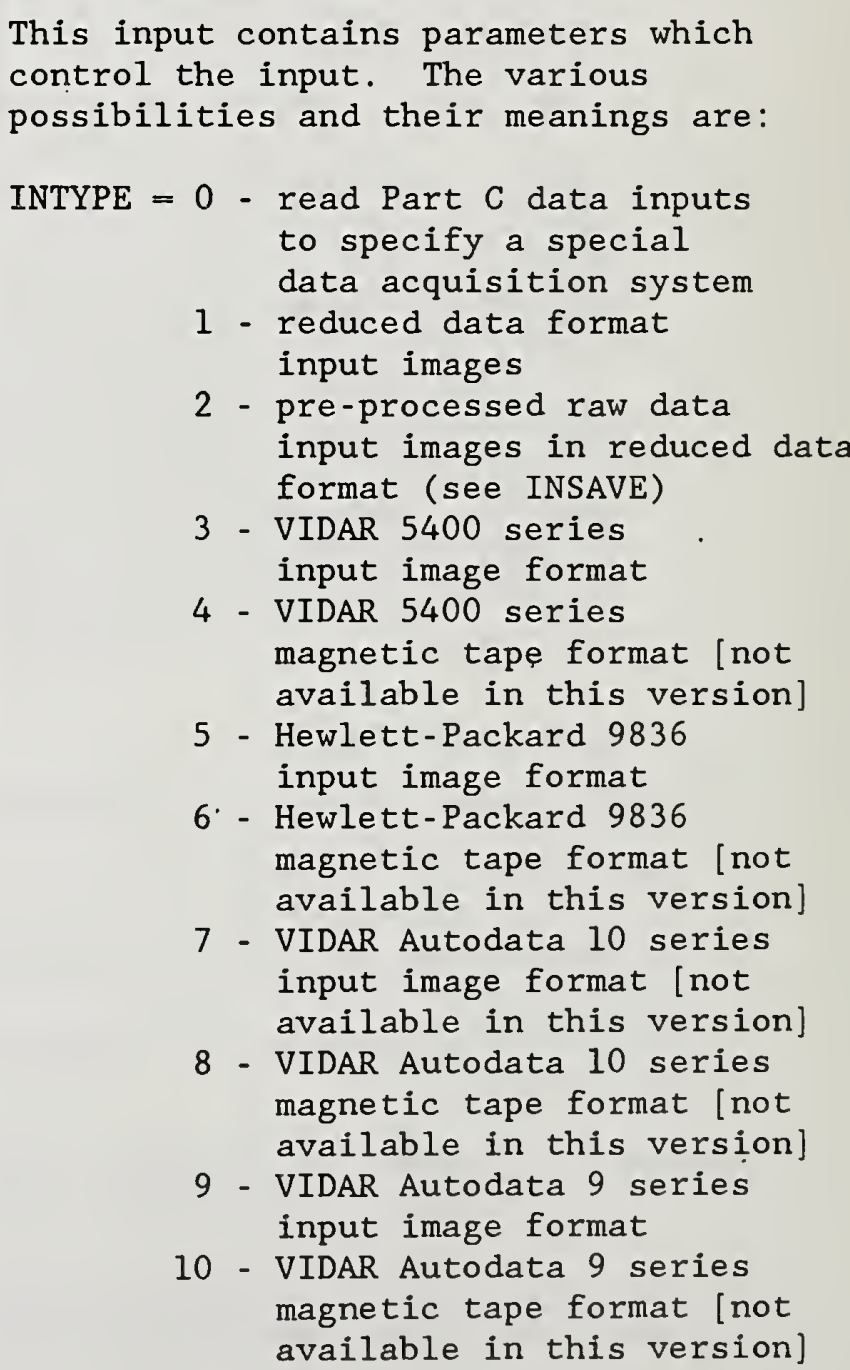 \\
\hline
\end{tabular}


INPRT - Directs printing of data as recorded by a data acquisition system. If INPRT is equal to zero, no data is printed. If INPRT is greater than zero, INPRT specifies the maximum number of data records to be printed. If INPRT is equal to -1 , all data records are printed. If INPRT is equal to -2 , only data records that contain errors are printed.

INPNCH - Directs the output of the data as recorded by a data acquisition system to secondary storage. If INPNCH is greater than zero, all data records are written to the unit specified by INPNCH. The user may assign this unit to any storage media.

INSTOP -. If INSTOP is non-zero, directs RAPID to stop execution after processing the input data recorded by the data acquisition system.

INERR - Specifies the maximum number of error messages to be printed during processing of data recorded by a data acquisition system.

INSKIP - If INSKIP is non-zero, read Part $D$ data inputs to specify records of input data to be skipped. 


\begin{tabular}{|c|c|c|c|}
\hline & & & $\begin{array}{l}\text { INSAVE - Directs the output of } \\
\text { interpreted raw data to mass } \\
\text { storage, magnetic tape, etc. } \\
\text { If INSAVE is greater than zero, } \\
\text { all data records not skipped } \\
\text { (see INSKIP) are written to the } \\
\text { unit specified by INSAVE. The } \\
\text { user may assign this unit to } \\
\text { any storage media. This } \\
\text { "formatted raw data" may be } \\
\text { identified and used as input to } \\
\text { subsequent runs by setting } \\
\text { INTYPE equal to } 2 \text {. The format } \\
\text { of the raw data saved is the } \\
\text { same as any reduced data saved } \\
\text { by setting NPNCH greater than } \\
\text { zero (see input A2 below). } \\
\text { See NPDI [4]. } \\
\text { See NPDI [5] } \\
\text { INTEST - include the test number (if } \\
\text { it exists) on input } \\
<0 \text { - delete the test number (if } \\
\text { it exists) on input }\end{array}$ \\
\hline Input & Variables & Format & Comments \\
\hline A2 & $\begin{array}{l}\text { NTEST, NPRT, NPNCH, } \\
\text { NPLOT, NCORR, NERR }\end{array}$ & $6 \mathrm{I} 5$ & $\begin{array}{l}\text { This input contains certain parameters } \\
\text { which control actions concerning the } \\
\text { transformed data matrix. The } \\
\text { possibilities are: } \\
\begin{aligned} \text { NTEST - See NPDI [5] } \\
\text { - between } 1 \text { and } 999 \text {, inclusive - } \\
\text { specifies a test number to } \\
\text { be prefixed to reduced data } \\
\text { instrument numbers output } \\
\text { by setting NPNCH greater } \\
\text { than zero. } \\
=0 \text { - on saved output (see NPNCH) } \\
\text { only include the test } \\
\text { number if it already exists } \\
\text { (from input). }\end{aligned}\end{array}$ \\
\hline
\end{tabular}




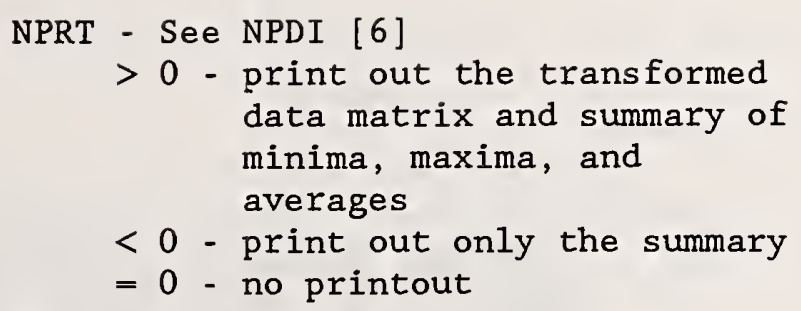
data matrix and summary of minima, maxima, and averages

$<0$ - print out only the summary $=0$ - no printout

NPNCH - Directs the output of the transformed data matrix to card punch, mass storage, or magnetic tape. If $\mathrm{NPNCH}$ is greater than zero, all data records are written to the unit specified by NPNCH. The user may assign this unit to any storage media.

NPLOT - If NPLOT is non-zero, Part I data inputs are read to generate printer plots of selected instruments.

NCORR - If NCORR is non-zero, Part G data inputs are read to correct readings of the data matrix.

NERR - Specifies the maximum number of error messages to be generated by any one data reduction subroutine. 


\section{Part B: Test and Instrument Descriptlons}
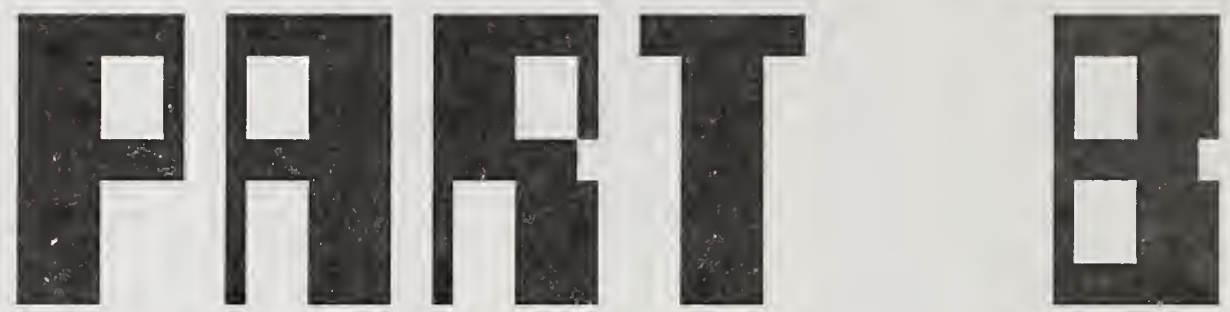

\begin{tabular}{|c|c|c|c|}
\hline Input & Variables & Format & Comments \\
\hline $\mathrm{B} 1, \mathrm{~B} 2$ & $\begin{array}{l}\text { TITLE }(1: 80), \text { TITLE } \\
(81: 120)\end{array}$ & $\begin{array}{l}\mathrm{A} 80 / \\
\mathrm{A} 40\end{array}$ & $\begin{array}{l}\text { These two inputs specify the title of } \\
\text { the experiment, printed at the top of } \\
\text { all pages of output. }\end{array}$ \\
\hline Input & Variables & Format & Comments \\
\hline B3 & $\begin{array}{l}\operatorname{KH}(i), \operatorname{ITYPE}(i) \\
\operatorname{NAME}(i), \operatorname{KHPRT}(i)\end{array}$ & $\begin{array}{l}\mathrm{I} 6, \mathrm{I} 2 \\
\mathrm{~A} 66, \mathrm{~A} 3\end{array}$ & $\begin{array}{l}\text { For each instrument included in the data } \\
\text { matrix, there must be a input of this } \\
\text { form defining the instrument number, } \\
\mathrm{KH}(i) \text {; the instrument type, ITYPE(i); } \\
\text { and the instrument name, NAME(i). The } \\
\text { instrument number, KH(i), is either the } \\
\text { channel number assigned by the data } \\
\text { acquisition system, or, for user created } \\
\text { instruments, a unique number assigned by } \\
\text { the user. NAME(i) is broken into two } \\
\text { parts: a } 6 \text {-character abbreviated ID that } \\
\text { is printed when listing or plotting } \\
\text { data and a } 60 \text {-character description. } \\
\text { If KHPRT is non-blank, the transformed } \\
\text { instrument values will NOT be printed. } \\
\text { Note that all the channels may be } \\
\text { skipped by setting NPRT <= 0 on PLOT2 } \\
\text { Data Input A2. The number of inputs is } \\
\text { variable, with the end signalled by a } \\
\text { input B4, below. }\end{array}$ \\
\hline Input & Variables & Format & Comments \\
\hline B4 & IEND & $77 \mathrm{X}, \mathrm{A} 3$ & $\begin{array}{l}\text { If IEND is equal to } 999 \text {, this input } \\
\text { signals the end of the set of instrument } \\
\text { defining inputs, B3 above. }\end{array}$ \\
\hline
\end{tabular}




\begin{tabular}{|c|c|c|c|}
\hline Input & Variables & Format & Comments \\
\hline B5 & $C(1), \operatorname{ADD}(i), \operatorname{POWER}(i)$ & $\begin{array}{l}1 \mathrm{X} \\
3 \mathrm{~F} 15.6\end{array}$ & $\begin{array}{l}\text { Each } C(i), \operatorname{ADD}(i) \text {, and POWER }(i) \\
\text { represent the conversion coefficients } \\
\text { for all instruments of type } i \text {. There } \\
\text { are as many B5 inputs as there are } \\
\text { different types of instruments as } \\
\text { defined in the set of instrument inputs, } \\
\text { B3 above. (See NPDI [7]). }\end{array}$ \\
\hline Input & Variables & Format & Comments \\
\hline B6 & IEND & $77 \mathrm{X}, \mathrm{A} 3$ & $\begin{array}{l}\text { If IEND is equal to } 999 \text {, this input } \\
\text { signals the end of the set of conversion } \\
\text { coefficient inputs, B } 5 \text { above. }\end{array}$ \\
\hline
\end{tabular}


4. Part C: Input Formats for Data Acquisition Systems Not Pre-Defined in RAPID
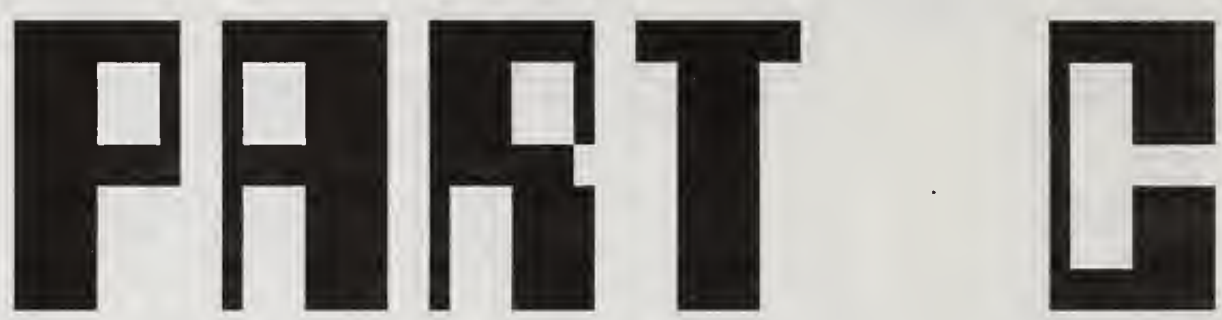

If the data acquisition system is not one of the pre-defined types (see Table 1), the user may have to define the formats the program will need for the input media, the time and data readings, and the end-of-file marker.

At this time, there is only one format for specifying the input media. The syntax for the format is below:

\section{INPUT=DATA IMAGES, CHANNELS PER LINE $=<\mathrm{n}>$}

where $\mathrm{n}$ is any integer number $>=1$ and where the number is the maximum number of channels found on a single input image.

As is noted, the format is a specification for data images. Data added from mass storage or tape files, and data transferred from remote terminals are considered DATA IMAGES.

The syntax for defining the data readings, time readings, and end-of-record and end-of-file markers is the same for all four: 


$\begin{array}{ll}\text { READING }=<\text { pattern }> & \text { or } \\ \text { TIME }=<\text { pattern }> & \text { or } \\ \text { EOR=<pattern }> & \text { or } \\ \text { EOR=EOR } & \text { or } \\ \text { EOF }=<\text { pattern }> & \text { or } \\ \text { EOF }=\text { EOF } & \end{array}$

where pattern is defined by

$$
\left[N_{1}\right] *\left(C_{1}\right)\left[N_{2}\right] *\left(C_{2}\right)\left[N_{3}\right] *\left(C_{3}\right) \ldots\left[N_{m-2}\right] *\left(C_{m-2}\right)\left[N_{m-1}\right] *\left(C_{m-1}\right)\left[N_{m}\right] *\left(C_{m}\right)
$$

and

$$
\begin{aligned}
& \mathrm{N}_{1}, \mathrm{~N}_{2}, \mathrm{~N}_{3} \ldots \mathrm{Nm}-2, \mathrm{Nm}-1, \mathrm{~N}_{\mathrm{m}}=\begin{array}{l}
\text { any integer greater than or } \\
\text { equal to } 1 .
\end{array} \\
& \mathrm{C}_{1}, \mathrm{C}_{2}, \mathrm{C}_{3} \ldots \mathrm{Cm}-2, \mathrm{Cm}-1, \mathrm{C}_{\mathrm{m}}=\begin{array}{l}
\text { one or more of the following } \\
\text { character specifications: }
\end{array}
\end{aligned}
$$

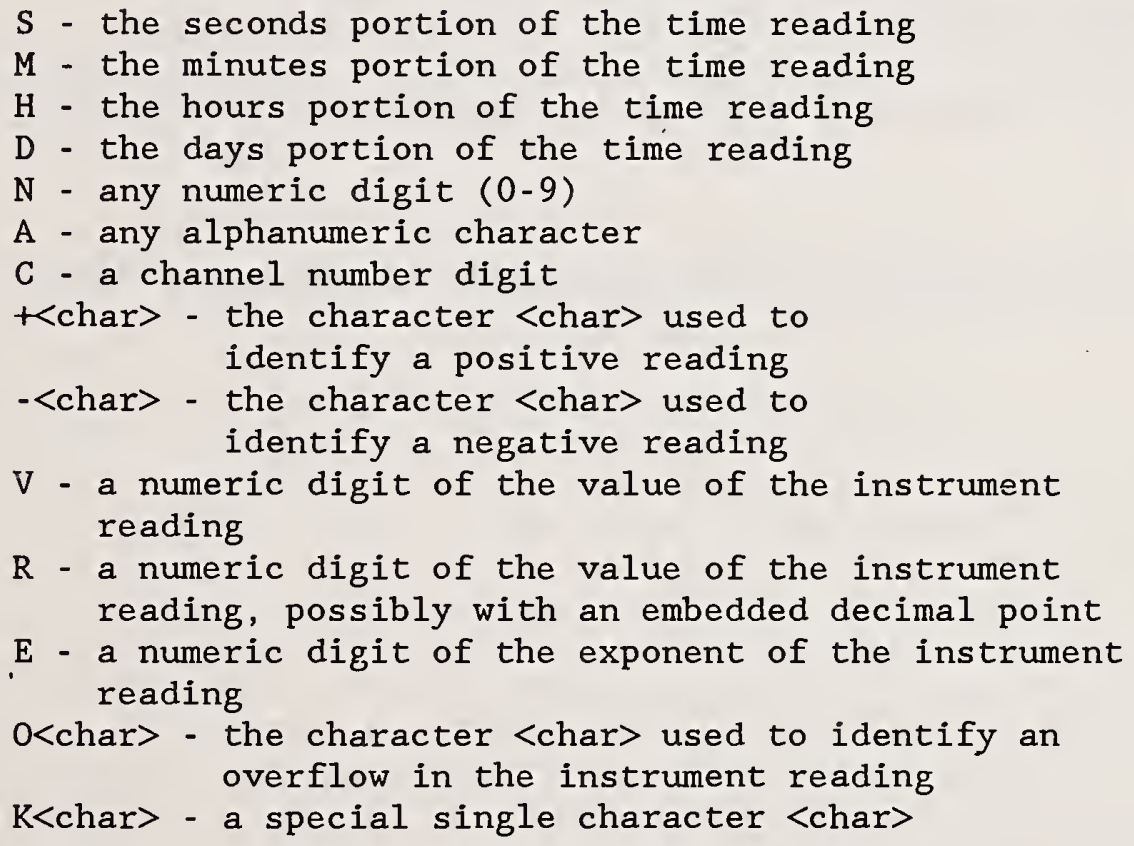

If several possibilities exist for a single character, then all possibilities are placed within the parentheses. For instance, if a single character is used to indicate,+- , or overflow, it might be coded as (+1-209) defining the plus indicator as 1 , the minus indicator as 2 , and the overflow indicator as 9 . 
Consider a reading as follows: three digits of channel, a single indicating the sign of the reading or overflow, five characters indicating the value of the reading, a single character exponent and two spaces. It could be coded as:

$\operatorname{READING}=(C)(C)(C)(+1-209)(V)(V)(V)(V)(V)(E)(K)(K)$

or equally

READING $=3 *(C)(+1-209) 5 *(V)(E) 2 *(K)$

The forms $E O R=E O R$ and $E O F=E O F$ are used for magnetic tape media and indicate, respectively, that the data records are separated by physical record gaps on the tape and that there is a physical end-of-file mark on the tape.

Data Inputs C1 through C5 are only entered if parameter INTYPE (Data Input A1) is zero. 


\begin{tabular}{l|ll|l|l}
\hline Input & \multicolumn{2}{|c|}{ Variables } & Format & Comments \\
\hline C1 & IN & A80 & IN - the input media definition \\
\hline Input & & Variables & Format & Comments \\
\hline C2 & IN & A80 & IN - the reading definition \\
\hline Input & & Variables & Format & Comments \\
\hline C3 & IN & & A80 & IN - the time definition \\
\hline Input & & Variables & Format & Comments \\
\hline C4 & IN & & A80 & IN - the end-of-record (EOR) \\
definition
\end{tabular}




\section{Part D: Skipping Data Records on Input}
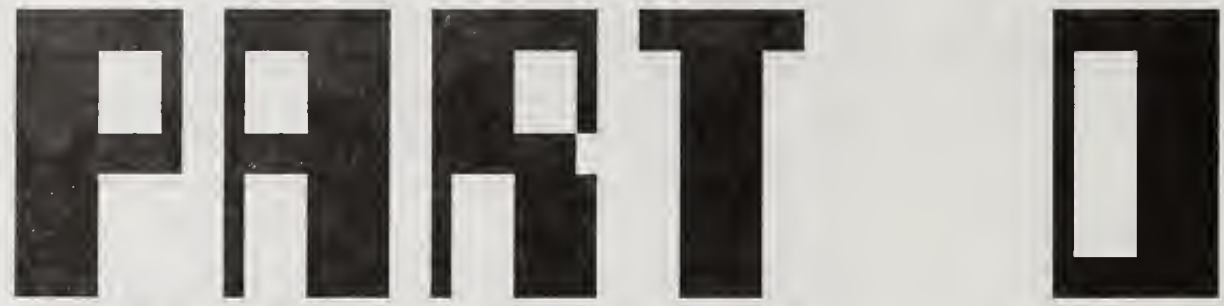

Part D specifies the records to be skipped during the processing of data recorded by a data acquisition system. The records identified to be skipped are ignored on input; no translation of the skipped records is done.

There are two methods of describing which records are to be skipped:

1. Up to 16 different records can be enumerated by entering the scan number of the record to be skipped.

2. A "skip/keep" pattern, defining the records to be skipped and kept can be input.

For method 2, the input form is defined as follows:

$$
\operatorname{SKIP}=\left(C_{1} N_{1}\right) R_{1} \quad\left(C_{2} N_{2}\right) R_{2}^{\prime} \quad \cdots \quad\left(C_{m-1} N_{m-1}\right) R_{m-1}\left(C_{m} N_{m}\right) R_{m}
$$

where 


$$
\begin{aligned}
C_{1}=S \text { or } K & \text { or } F \\
\text { where, } & S \text { stands for Skip } \\
& K \text { stands for Keep } \\
& F \text { stands for Final record }
\end{aligned}
$$

$\mathrm{N}_{1}=$ any number $>=1$

where the number is an integer indicating the number of times the preceding $C$ is to be repeated

$R_{1}=$ any number $>=1$

where the number is an integer indicating the last record number on which the $\mathrm{CN}$ pair is impacted

Like the data system format specifications, if several combinations exist for a single $C_{i} N_{i}$ pair, than all possibilities are placed within the parenthesis. For example, if the user wishes to skip two records and one record from record 1 to record 200, it would be coded as (S2K1) 200 .

Consider the coding for the following requirements - The user wishes to keep records 1 to 5; skip 2 records and keep 1 record for records 6 to 150; and keep every record for records 151 to 599 ; record 600 is to be the last record processed:

$$
\mathrm{SKIP}=(\mathrm{K} 1) 5 \quad(\mathrm{~S} 2 \mathrm{~K} 1) 150(\mathrm{~K} 1) 599 \quad(\mathrm{~F} 1) 600
$$

Note that care should be taken to ensure that no overlaps or conflicts exist in the pattern. If conflicts exist, the first encountered sepcification that applies to a given input record will be used, leading to potentially unpredictable results. 
Part D should only be entered if parameter INSKIP (Data Input Al) is greater than zero.

\begin{tabular}{|c|c|c|c|}
\hline Input & Variables & Format & Comments \\
\hline $\mathrm{D} 1 \mathrm{a}$ & $\begin{array}{l}\operatorname{ISKIP}(1), \operatorname{ISKIP}(2) \\
\ldots, \operatorname{ISKIP}(i) \\
1<=i<=16\end{array}$ & $16 I 5$ & $\begin{array}{l}\text { This is method } 1 \text {. } \\
\text { ISKIP - the number of the record to } \\
\text { be skipped }\end{array}$ \\
\hline Input & Variables & Format & Comments \\
\hline $\mathrm{D} 1 \mathrm{~b}$ & IN & A80 & $\begin{array}{l}\text { This is method } 2 . \\
\text { IN - the skip/keep pattern as } \\
\text { described above }\end{array}$ \\
\hline
\end{tabular}




\section{Part E: Input Data in Data-Acquisition-System-Dependent Formats}
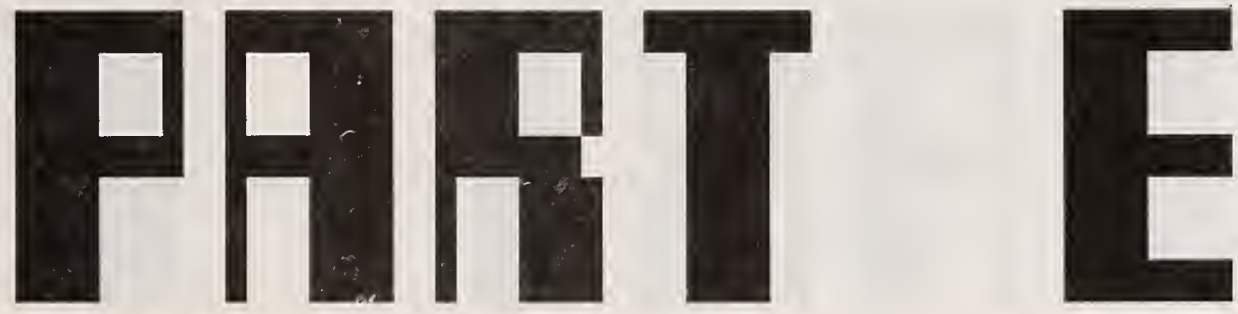

Part E data images are the data recorded by the data acquisition system prepared in the format recorded by a data acquisition system. Different formats, such as those described in Table 1 or as defined using Part C data images, are possible. If the data images were prepared by an earlier run of RAPID (by setting INPNCH greater than zero), the set of data images produced should be in the proper format for insertion at this point. 


\section{Part F: Input Data in Data-Acquisition-System-Independent Format}
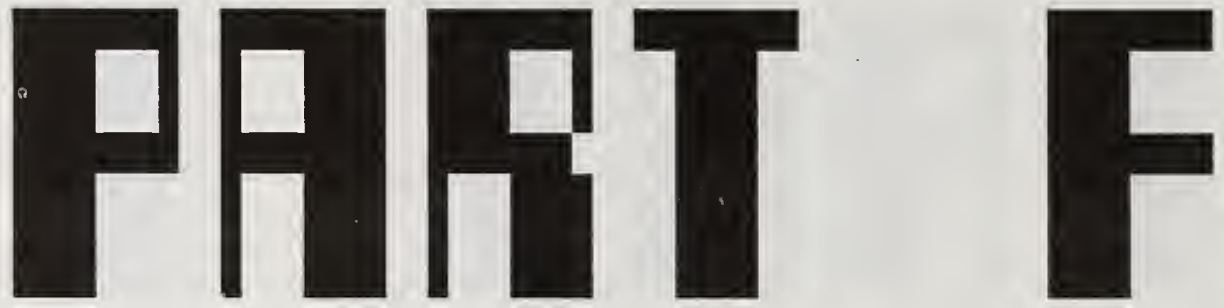

Part $\mathrm{F}$ data images are the data recorded by the data acquisition system or by and earlier run of RAPID in a format that is generated when INSAVE and/or NPNCH are greater-than zero. If the data being input were created in one of those two ways, it already should be in the correct format for insertion at this point.

If the data are being generated in some other way, the format of the inputs is as described below. One set of $F 1$ and F2 inputs should be prepared for each instrument.

Part $\mathrm{F}$ data inputs are read only if parameter INTYPE (Data Input A1) is equal to 2 or 4.

\begin{tabular}{|c|c|c|c|}
\hline Input & Variables & Format & Comments \\
\hline $\mathrm{F} 1$ & $\begin{array}{l}\text { NPTS , KH , NAME1 , *, } \\
\text { NAME } 2\end{array}$ & $\begin{array}{l}2 \mathrm{I} 6, \\
\mathrm{~A} 6, \mathrm{~A} 1, \\
\mathrm{~A} 60\end{array}$ & $\begin{array}{l}\text { NPTS - the number of data points for } \\
\text { this instrument } \\
\text { KH - the instrument number } \\
\text { NAME1 - a six character abbreviated ID } \\
* \text { - ' } * \text { ' } \\
\text { NAME2 - a } 60 \text { character description of } \\
\text { the instrument } \\
\text { Note that the string ' } 999 \text { ' in columns } \\
78-80 \text { terminates the reading of Part F } \\
\text { data inputs. }\end{array}$ \\
\hline
\end{tabular}




\begin{tabular}{l|l|l|l}
\hline Input & \multicolumn{1}{|c|}{ Variables } & Format & \multicolumn{1}{c}{ Comments } \\
\hline F2 & $\begin{array}{l}\text { REED }(1), \operatorname{REED}(2), \ldots, \\
\operatorname{REED}(i) \\
1<i<=\text { NPTS }\end{array}$ & $7 E 11.5$ & $\begin{array}{l}\text { Note that as many F2 inputs as necessary } \\
\text { should be entered until al1 NPTS data } \\
\text { points have been entered. } \\
\text { REED - a data point }\end{array}$ \\
\hline
\end{tabular}




\section{Part G: Corrections to the Data Matrix}
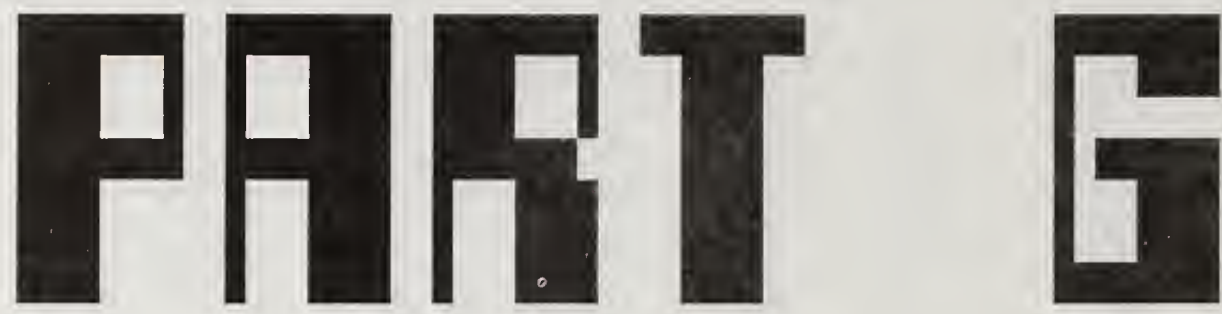

Part G data inputs are read only if parameter NCORR (Data Input A2) is non-zero. As many additional sets of $\mathrm{G} 1$ and $\mathrm{G} 2$ inputs as are required may be included at this point to make the necessary corrections.

\begin{tabular}{|c|c|c|c|}
\hline Input & Variables & Format & Comments \\
\hline G1 & IRL , IRH , ICL, ICH & 415 & $\begin{array}{l}\text { The variables define a low row index } \\
\text { (IRL), a high row index (IRH), a low } \\
\text { column index (ICL), and a high column } \\
\text { index (ICH) to define the portion of the } \\
\text { data matrix to be corrected. See NPDI } \\
\text { [9]. } \\
\text { Note that setting IRL less than zero } \\
\text { terminates the reading of Part G data } \\
\text { inputs. }\end{array}$ \\
\hline Input & Variables & Format & Comments \\
\hline G2 & $\begin{array}{l}\operatorname{REED}(i, j), i=I R L, I R H, \\
\text { or } j=I C L, I C H\end{array}$ & $8 \mathrm{~F} 10.0$ & $\begin{array}{l}\text { These are the corrections to the matrix. } \\
\text { The number of inputs required depends on } \\
\text { the number of corrections: } \\
\qquad G_{\text {Int }}\left[\frac{(\text { IRH-IRL })+(\text { ICH-ICL })+1}{8}\right]+1 \\
\text { where } G_{\text {Int represents the greatest }} \\
\text { integer function. }\end{array}$ \\
\hline
\end{tabular}




\section{Part H: Non-Trivial Transformations of the Data Matrix}
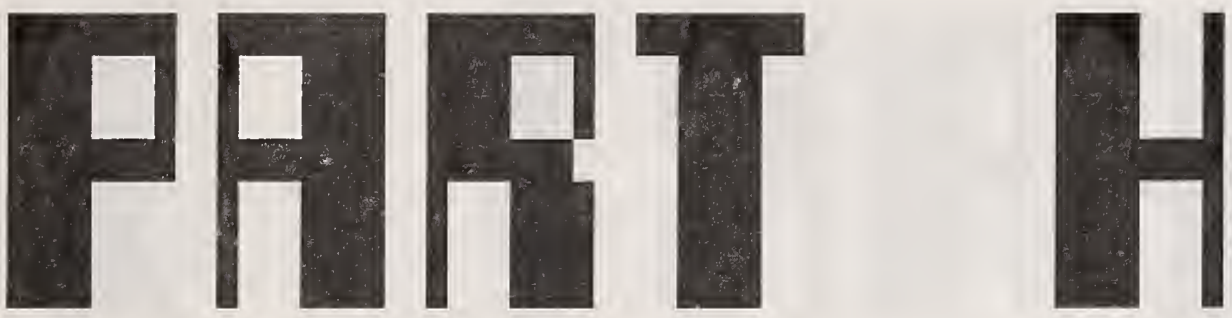

In Part B, above, it is possible to identify conversion constants for each instrument that allow the user to multiply, add to, and raise to a power, the value of each instrument by those constants.

However, in many cases the use of those constants is not sufficient to transform the raw data into values of use to the test analyst. Therefore, a large set of subroutines is included at this point to allow the conversion and manipulation of not only raw data, but also the combinations of converted data needed to produce the complex variety of values required for good fire test analysis.

The description of the input for Part $\mathrm{H}$ is rather extensive, so, in order to preserve the continuity of this document, it is included after Table 1 . 


\section{Part I: Plotting}
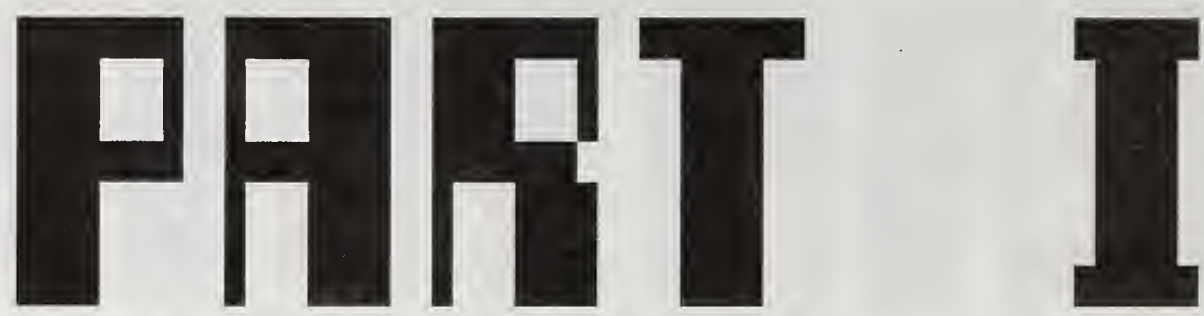

Although not always precise in the conveyance of information, printer plots can be a useful tool to the test analyst.

Three forms of plots can be used here:

1. PLOT Nx Ny1 Ny2 .. Nym where $\mathrm{Ny} 1, \mathrm{Ny} 2, \ldots, \mathrm{Nym}$ are any number of instrument numbers representing the $\mathrm{y}$-axis values being plotted versus instrument number $\mathrm{Nx}$, the $\mathrm{x}$-axis values.

2. PLOT $\mathrm{Nx} 1, \mathrm{Ny} 1 \quad \mathrm{Nx} 2, \mathrm{Ny} 2 \quad \ldots \quad \mathrm{Nxm}, \mathrm{Nym}$ where $\mathrm{Ny} 1, \mathrm{Ny} 2, \ldots, \mathrm{Nym}$ are any number of instrument numbers representing the $\mathrm{y}$-axis values being plotted versus instrument numbers $\mathrm{Nx} 1, \mathrm{Nx} 2, \ldots$ Nxm (respectively), the $x$-axis values.

\section{PROFILE}

where, typically, values are plotted versus position rather than versus time. 
Part I data inputs are read only if parameter NPLOT (Data Input A2) is non-zero.

\begin{tabular}{|c|c|c|c|}
\hline Input & Variables & Format & Comments \\
\hline II & IN & A80 & $\begin{array}{l}\text { IN - one of the three forms of plots } \\
\text { described above. If form } 1 \\
\text { or } 2 \text { is used, and there is not } \\
\text { enough room on one input to } \\
\text { identify all the instrument } \\
\text { numbers required, this input } \\
\text { may be continued by placing a } \\
\text { semicolon (;) on the input. } \\
\text { See NPDI [3]. }\end{array}$ \\
\hline Input & Variables & Format & Comments \\
\hline I2 & GTITL & A80 & $\begin{array}{l}\text { GTITL - the } 80 \text { character graph title } \\
\text { printed above the graph. If } \\
\text { Form } 3 \text { of input I1 was used, } \\
\text { GTITL is concatenated with the } \\
\text { string } \\
\text { ' PROFILE OF THE FOLLOWING } \\
\text { CHANNELS:' }\end{array}$ \\
\hline Input & Variables & Format & Comments \\
\hline I3 & $\begin{array}{l}\operatorname{JCHAN}(1), \operatorname{JCHAN}(2) \\
\ldots, \operatorname{JCHAN}(i) \mathrm{x} \\
1<=i<=20\end{array}$ & $\begin{array}{l}\text { EVALU8 } \\
\text { (NPDI } \\
[2])\end{array}$ & $\begin{array}{l}\text { Read this input only if Form } 3 \text { of input } \\
\text { I1 is used. } \\
\text { JCHAN - the instrument number of the } \\
\text { values to be plotted in the } \\
\text { profile (see NPDI [3]). These } \\
\text { values are the } \mathrm{x} \text {-axis values. } \\
\mathrm{X}=\text { ' } \mathrm{X} \text { ' - the end-of-set mark }\end{array}$ \\
\hline Input & Variables & Format & Comments \\
\hline I4 & $\begin{array}{l}\operatorname{POS}(1), \operatorname{POS}(2), \ldots \\
\operatorname{POS}(j) x \\
j=i\end{array}$ & $\begin{array}{l}\text { EVALU8 } \\
\text { (NPDI } \\
[2])\end{array}$ & $\begin{array}{l}\text { Read this input only if Form } 3 \text { of input } \\
\text { Il is used. } \\
\text { POS - the position of instruments } \\
\text { identified with input I2; } \\
\text { these values are the } y \text {-axis } \\
\text { values. } \\
\text { X }=\text { ' } \mathrm{X}^{\prime} \text { - the end-of-set mark }\end{array}$ \\
\hline
\end{tabular}




\begin{tabular}{|c|c|c|c|}
\hline Input & Variables & Format & Comments \\
\hline I5 & $\begin{array}{l}\operatorname{JTIME}, \operatorname{ISCAN}(1) \\
\operatorname{ISCAN}(2), \ldots \ldots \\
\operatorname{ISCAN}(k) \mathrm{X} \\
1<=k\end{array}$ & $\begin{array}{l}\text { EVALU8 } \\
(\text { NPDI } \\
[2])\end{array}$ & $\begin{array}{l}\text { Enter this input only if Form } 3 \text { of input } \\
\text { Il is used. } \\
\text { JTIME - the time channel instrument } \\
\text { number (see NPDI [3]). } \\
\text { ISCAN - if ISCAN is an integer, it is } \\
\text { the scan number of the values } \\
\text { of the JCHAN to be used. } \\
\text { - if ISCAN is a real (has a } \\
\text { decimal point) it is the time } \\
\text { of the values of the JCHAN to } \\
\text { be used. If the time cannot be } \\
\text { exactly matched, the time } \\
\text { nearest without going over is } \\
\text { used. } \\
\mathrm{X}=\text { ' } \mathrm{X}^{\prime} \text { - the end-of-set mark }\end{array}$ \\
\hline Input & Variables & Format & Comments \\
\hline I6 & $\mathrm{XL}, \mathrm{XH}, \mathrm{YL}, \mathrm{YH}$ & $\begin{array}{r}\text { open } \\
(\text { NPDI } \\
[1])\end{array}$ & $\begin{array}{l}X L \text { - lower limit of the } X \text { axis } \\
X H \text { - upper limit of the } X \text { axis } \\
Y L \text { - lower limit of the } Y \text { axis } \\
Y H \text { - upper limit of the } Y \text { axis }\end{array}$ \\
\hline Input & Variables & Format & Comments \\
\hline I7 & XBUFF, YBUFF & $2 \mathrm{~A} 40$ & $\begin{array}{l}\text { XBUFF - the } 40 \text { character } x \text {-axis title. } \\
\text { XBUFF will be centered by the } \\
\text { program } \\
\text { YBUFF - the } 40 \text { character y-axis title. } \\
\text { YBUFF will be centered by the } \\
\text { program. }\end{array}$ \\
\hline
\end{tabular}




\section{Notes on the Preparation of Data Inputs (NPDI) Read by RAPID}
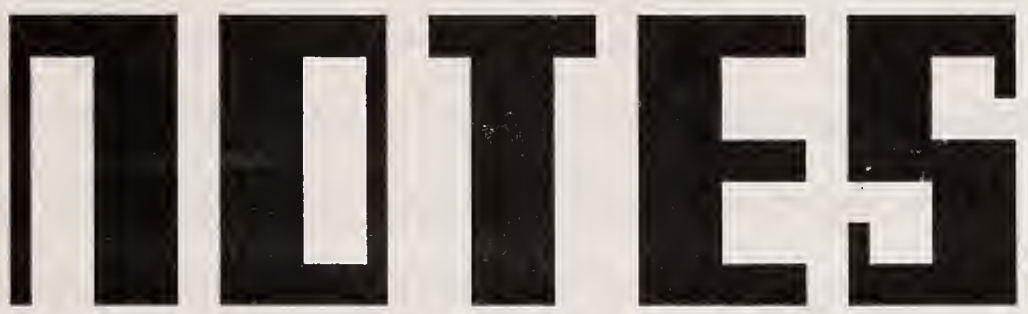

NPDI [1] Open (List Directed) Formats

When entering values using an open (list directed) format, the value of the variable being entered must match the variable type (e.g., when entering an integer, a value with a decimal point must not be found). Therefore, variable names used in this program follow the standard convention for typing:

unless otherwise noted -

variable names beginning with the letters $A$ through $\mathrm{H}$ or 0 through $\mathrm{Z}$ are real;

variable names beginning with the letters $I$ through $N$ are integer.

NPDI [2] Special Format Read by Subroutine EVALU8

Subroutine EVALU8 is a general purpose data input reading routine. It is called by many of the data reduction subroutines. It reads and counts the number of input values on the input, stores them and their types (integer or real) in data arrays, and returns the data and control to the calling subroutine. 
An input value is defined as the string of digits and/or characters found between spaces or commas on a data input. The end of the set of values is signaled by the characters ' $X^{\prime}$ (space, $X$ ) after the last value. When no limit is imposed by the calling subroutine, up to 100 values may be read in one set. If all the values cannot fit on one input, they may continue on to the next input. Inputs will continue to be read until ' $\mathrm{X}$ ' or an illegal character is encountered. If no digits or characters are encountered before the first comma or between commas, a real value of 0.0 is assumed.

The legal digits and characters are as follows:

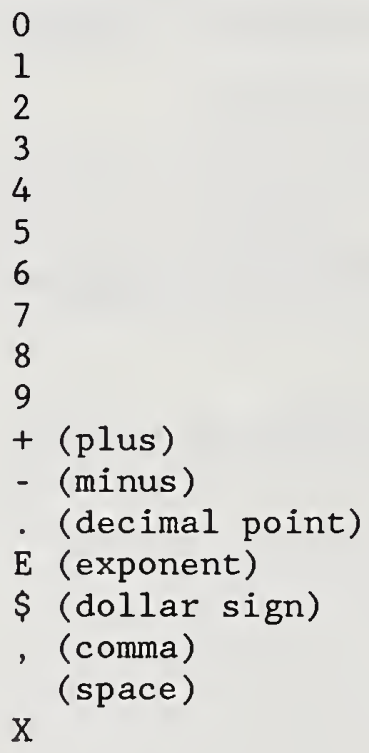

This subroutine will accept either integer or real values with the stipulation that the values must match the type of the variable being entered. (See NPDI [1] above). A real value must include a decimal point or " $E$ ". 
The dollar sign ( $\$$ ) has a special meaning to this subroutine. It signals that a channel created during execution of the program is to be used. The number following the dollar sign represents the order in which the channel was created. The dollar sign and the digits are automatically replaced by the channel number in which the values are stored. See NPDI [3], below.

Note that the format described here is almost identical to "open" (1ist directed) format. The difference is the limit on the number of values that can be read and the special characters: the dollar sign $(\$)$ and letter $\mathrm{X}$.

NPDI [3] Channels Created by the Program

This program creates new channels in which to store some of the calculated data. To identify a created channel for use by a data reduction subroutine or by the plot routine (data input II), only the order in which the channels were created need be known. For example, to plot the data stored in the fifth channel created, enter the number ' $\$ 5^{\prime}$ where the channel number is normally entered. The program automatically replaces the dollar sign $(\$)$ and the 5 with the proper channel number. This method of identifying a channel may be used in any of the subroutines when the input data are read using subroutine EVALU8. (See NPDI [2] above). It may also be used when entering channel numbers for plots or as noted in other specific command instructions.

The dollar sign method of identifying created channels can not be used if the channel was created in a previous execution of the program. In those cases, the 
channel must be handled in the normal manner, appearing in the instrument list (data input B3) and using the complete, right-justified, six-digit number.

The created channel numbers can be assigned for use in two ways: automatically by the program and by the user by means of the SPECIFY command. If the program chooses the channel number, the number is chosen such that the smallest available channel number from an unused series of channels is used. (Note: a channel series is a value from 0 to 9 and is identified by the first digit in the channel number (see NPDI [5] below). The program checks the original instrument list and determines the series which have channels used. The remaining series are put in the created channel pool for use as needed. The total number of channels that can be automatically drawn from the pool is then the number of empty series times 100. Also, for that reason, it is wise to choose a channel number for time in a series that is already being used.

NPDI [4] Saving Unreduced (Raw) Data in a Formatted Data Matrix

The option for saving raw, unreduced data in a formatted data matrix is input on Data Input Al (Variable INSAVE). By setting INSAVE to the appropriate value the first time the raw data set is used, a formatted raw data set can be saved. Since this new data set is in a data-collection-system-independent format, the program can (in subsequent executions) read the input data without having to interpret for format correctness (i.e., read numbers instead of reading character by character), which is significantly faster. 
NPDI [5] Instrument Numbers - Management of the Test Number Prefix

An instrument number is a six digit number whose first three digits represent a test number and whose last three digits represent a channel number. There are two variables, INTEST (Data Input A1) and NTEST (Data Input A2), that control the test number prefix part of the instrument numbers. INTEST controls the prefix during input, NTEST controls the prefix during output (when NPNCH (Data Input A2) is greater than zero).

INTEST can direct the program to either pass the test number through or to strip off the test number, leaving only the channel number (effectively it changes the test number prefix to 000 , which is insignificant). If the test number is passed through and it is NOT insignificant, it must be used when identifying instruments for data transformations and plotting.

NTEST can direct the program to pass the test number "as is" to the saved reduced data file or to replace the test number with a value between 1 and 999 inclusive. NTEST has no effect if NPNCH is zero, since no reduced data are saved.

NPDI [6] Output of the Transformed Data Matrix

The option for printing (or not printing) the transformed data matrix is input on Data Input A2. In the SPEED2 version, the matrix is either not printed (NPRT.EQ.0) or printed (NPRT.NE.0). The RAPID version is slightly different in 
that it prepares a table of minimums, maximums and averages for each channel and, consequently, the options for NPRT have also changed:

$$
\begin{aligned}
\text { NPRT } & =0 \text {, neither data matrix nor summary table is printed } \\
& <0 \text {, only the summary table is printed } \\
& >0 \text {, both the matrix and the summary table are printed. }
\end{aligned}
$$

This change is compatible with earlier versions of the program.

\section{NPDI [7] Constant Value Conversion Inputs}

In subroutine CONV, after all other conversions and calculations are done, the data undergo one final reduction before finally leaving the subroutine. In the SPEED2 version, this reduction is linear and of the form

$$
\operatorname{REED}=(\operatorname{REED} * \mathrm{C})+\mathrm{ADD}
$$

where $C$ and $A D D$ are constants entered with data input B5. The RAPID version is different in that it includes an exponential value:

$$
\text { REED }=((\text { REED *C) }+\mathrm{ADD}) * * \text { POWER }
$$

where $C, A D D$, and POWER are the constants entered.

Data input $\mathrm{B} 5$ is modified as follows to accommodate the change: 


\section{Variables: $\quad C(i), \operatorname{ADD}(i), \operatorname{POWER}(i)$ \\ Format: $1 \mathrm{X}, 3 \mathrm{~F} 15.6$}

The following default conditions exist to help avoid errors:

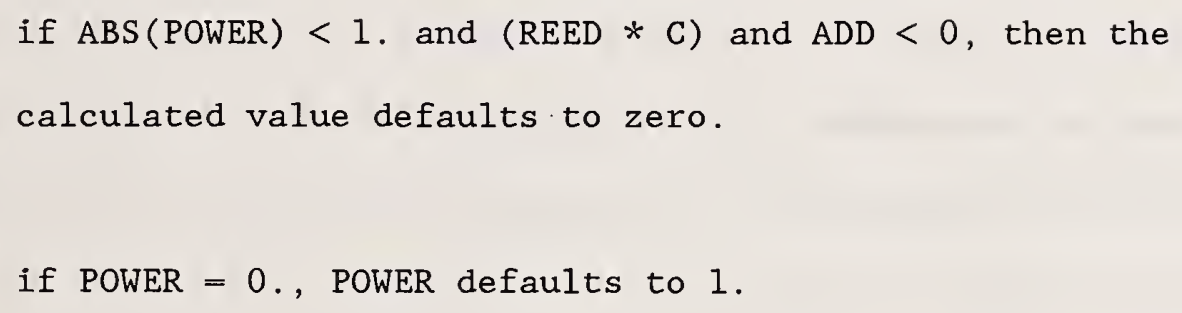

The automatically assigned constant values for channels created by the program are :

$$
\mathrm{C}=1.0 \quad \mathrm{ADD}=0.0 \quad \text { POWER }=1.0
$$

This change is compatible with earlier versions of the program.

NPDI [8] Variables in Brackets ([]) and Braces (\{\})

In the documentation above, some of the variables in the variable lists under each command appear within brackets ([]) or braces (\{\}). The variables within brackets are optional; the variables with braces are conditional. The options and/or conditions are specified to the right under the Comments. If the variable. 
is not used as an argument, the comma used to separate it from the other variables (if used) should also be omitted.

NPDI [9] Making Corrections to the Data Matrix

RAPID also provides the capability of modifying or correcting entries in the input matrix. Any number of corrections may be made; however, any single correction may apply only to one single entry, consecutive entries in a single column, or consecutive entries in a single row. Corrections are expected if and only if the parameter NCORR (Data Input A2) is set non-zero by the user.

Assuming NCORR is non-zero, RAPID will read a input containing the variables IRL (a low row index), IRH (a high row index), ICL (a low column index), and ICH (a high column index). The following restrictions apply:

a. Either IRL=IRH or ICL=ICH or both. Note, if IRL=IRH, all corrections apply to a single row. If $\mathrm{ICL}=\mathrm{ICH}$, all corrections apply to a single column. If $I R L=I R H$ and $I C L=I C H$, a single entry will be corrected.

b. IRL is greater than zero but less than or equal to IRH or IRL is less than zero. IRL less than zero signifies the end of the corrections.

c. ICL is greater than zero but less than or equal to ICH or both ICL and ICH are less than zero. Note that ICL and ICH must be both positive or both negative. If they are negative, they are interpreted to be instrument 
numbers rather than column numbers. In this case, the column $i$ in which instrument number ICL is stored is found. Similarly, the column $j$ in which instrument number ICH is stored is found. Then the values of ICL and ICH are replaced by $i$ and $j$ respectively. The restriction becomes $i$ is greater than zero but less than or equal to $j$.

Failure to satisfy any of the above restrictions will result in an error message being printed and may result in all following data inputs being out of order. Thus, particular care must be taken in the preparation of this input.

There are, in effect, only three valid combinations. They are:

a. IRL is equal to IRH and ICL is equal to ICH meaning correct entry $\operatorname{REED}(I R L, I C L)$.

b. IRL is less than IRH and ICL is equal to ICH meaning correct entries $\operatorname{REED}($ IRL, ICL) , REED (IRL+1, ICL) , . , REED (IRH - 1, ICL) and REED (IRH, ICL) .

c. IRL is equal to IRH and ICL is less than ICH meaning correct entries $\operatorname{REED}($ IRL , ICL), REED (IRL , ICL+1), . , REED (IRL, ICH-1) and REED (IRL , ICH) .

In any of the above cases, the number of entries to be corrected is

$$
(\text { IRH-IRL })+(\text { ICH-ICL })+1
$$


These entry corrections are read from a series of data images prepared in the format 8F10.0. 
Table 1. Pre-Defined Data Formats for Input to RAPID

1 - reduced data format input images

2 - pre-processed raw data input images in reduced data format

3 - VIDAR 5400 series input image format

4 - VIDAR 5400 series magnetic tape format

5 - Hewlett-Packard 9836 input image format

9 - VIDAR Autodata 9 series input image format

10 - VIDAR Autodata 9 series magnetic tape format

FORMAT

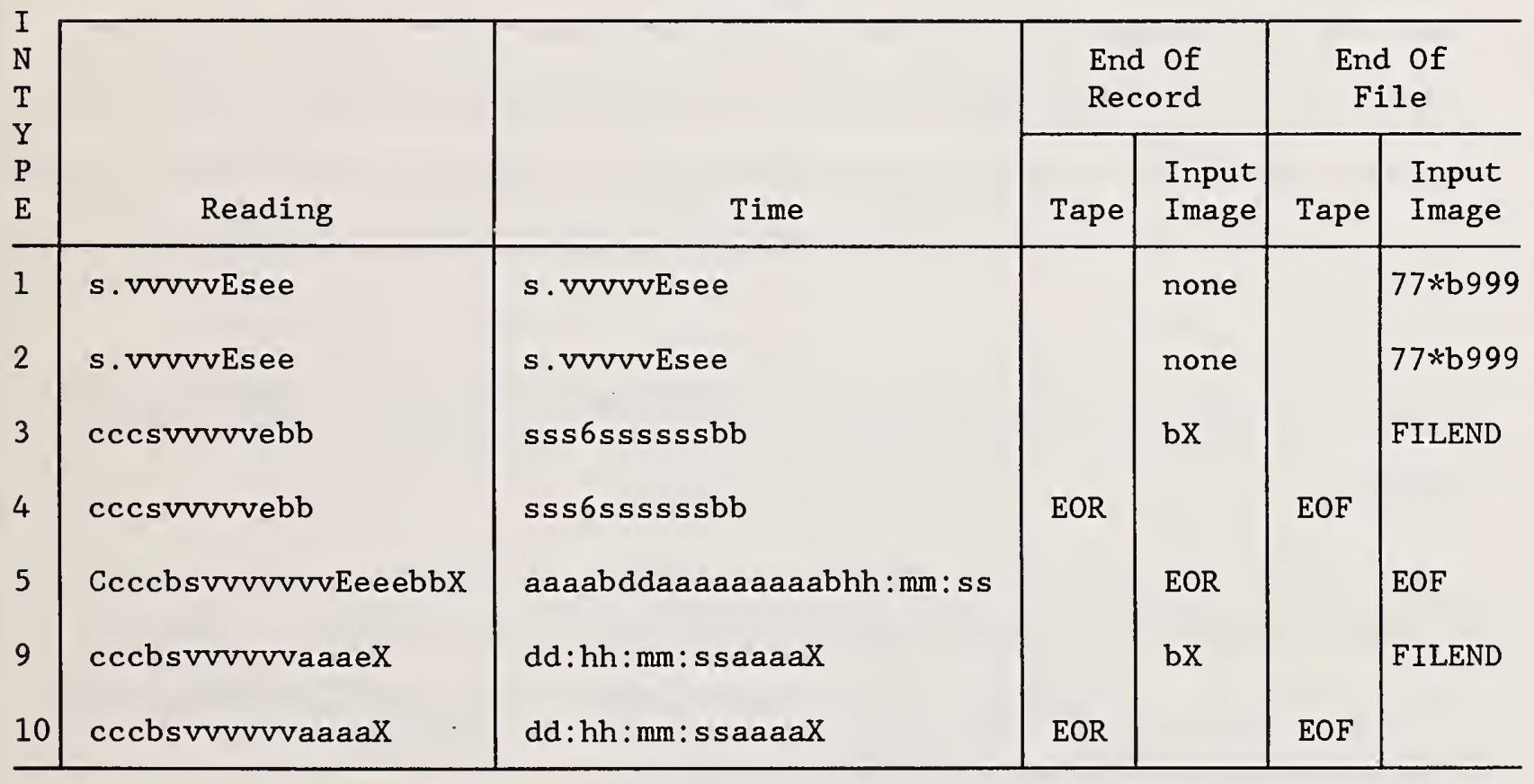
a - any character
$\mathrm{v}$ - magnitude of reading
$C$ - the character "C"
- an overflow indicator
e - exponent of a reading
$\mathrm{E}$ - the character "E"
c - a channel number digit
$\mathrm{n}$ - a numeric $(0-9)$
$X$ - the character "X"
$r$ - value of a reading
: - the character ":"
s - sign of a reading
b - blank
$\mathrm{d}, \mathrm{h}, \mathrm{m}, \mathrm{s}$ - days, hours, minutes, seconds of a time reading
EOR - magnetic tape end of record
EOF - magnetic tape end of file

If a number is followed by a star (*), the character immediately following the star is repeated that number of times. 


\section{Transformation Control Commands for Part $\mathrm{H}$}
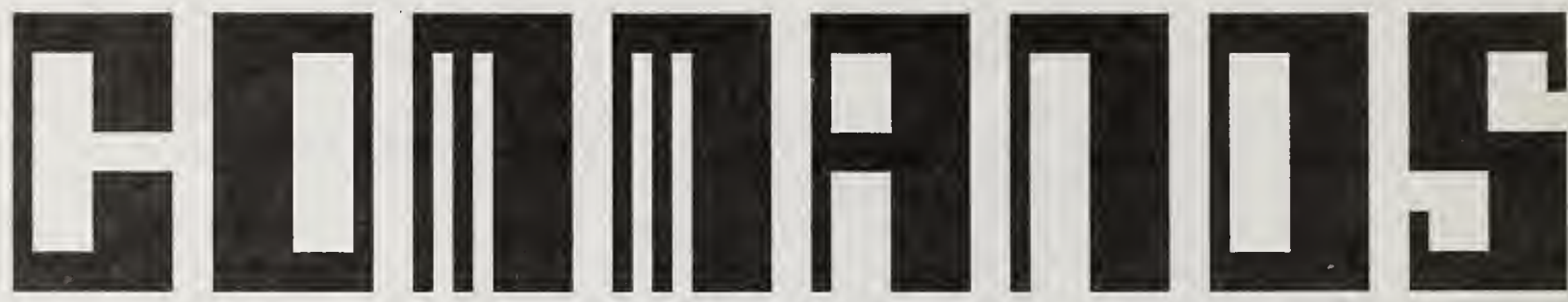

Data Reduction and Transformation Subroutines

There are 33 commands that the main conversion subroutine uses to call the subroutines needed to perform the data transformations routinely required for fire test data. For discussion and documentation purposes only, these commands and subroutines can be divided into three classes: utility, basic, and complex.

The utility class performs operations on reduced data such as integrating and averaging .

The basic class calculation is one in which, with the exception of temperature, only the values from one instrument are required. Typically, the basic class calculation does not create any new channels.

The complex class calculation requires at least two sets of instrument values or other information, such as instrument position. Typically, the complex class calculation creates one or more new channels in order to store the calculated results. 
The subroutines that actually perform the data reduction are invoked by entering a command (beginning in column 1) with data input $\mathrm{Hl}$. When a subroutine is called, it will look for the additional input information needed to perform the data transformation. When the data transformation is complete, control returns to the main conversion subroutine, which looks for the next command to be executed.

A brief description of each subroutine is shown in the following sections.

\subsection{Avallable Transformation Control Commands}

\subsubsection{UtIlity Commands}

\begin{tabular}{|c|c|c|c|}
\hline Class & Subpart & Command & Purpose \\
\hline \multirow[t]{6}{*}{$\begin{array}{l}\mathrm{U} \\
\text { (Utility) }\end{array}$} & a & AMBIENTS & $\begin{array}{l}\text { override default values of ambient } \\
\text { temperature, pressure and relative humidity }\end{array}$ \\
\hline & $\mathrm{b}$ & AVERAGE & $\begin{array}{l}\text { find the average of " } n \text { " channels; upper and/or } \\
\text { lower limits may be set for each channel and } \\
\text { the average may be weighted }\end{array}$ \\
\hline & c & COMBINE & $\begin{array}{l}\text { concatenate the values from more than one } \\
\text { channel over specific intervals of the complete } \\
\text { test in order to create a new, continuous, } \\
\text { channel. }\end{array}$ \\
\hline & $\mathrm{d}$ & COMPUTE & $\begin{array}{l}\text { find the result of any FORTRAN-like algebraic } \\
\text { expression; operations are add, subtract, } \\
\text { multiply, divide, raise to a power, } \\
\text { find minimum or maximum; operands may be } \\
\text { constants or channel numbers }\end{array}$ \\
\hline & e & DELAY & $\begin{array}{l}\text { adjust the values of specific channels } \\
\text { to account for a delay in response, etc. }\end{array}$ \\
\hline & $\mathrm{f}$ & DELTA & $\begin{array}{l}\text { find the difference between consecutive } \\
\text { readings of the same channel }\end{array}$ \\
\hline
\end{tabular}


g

E119

h INTEGRATE

i RENAME

j SEPARATE

k SMOOTH

1 SPECIFY

m

$\mathrm{n}$

TIME create a channel with the standard E119 temperature $\left({ }^{\circ} \mathrm{C}\right.$ or $\mathrm{F}$ ) for each time scan using an identified time channel

integrate a channel with respect to time

give meaningful names (other than the default names) to created channels

for channels that store information from more than one instrument, separate and store the individual results in individual channels

reduce the "noise" in a channel using a sliding least-squares straight line fit for small sections of the curve

specify the channel number that a created channel will receive

calculate various statistics regarding any particular channel: minimum, maximum, average, time to exceed a particular value, etc.

convert $\mathrm{h} / \mathrm{m} / \mathrm{s}$ to elapsed $\mathrm{s}$ and/or add a time shift to the existing, or a new, time channel

\subsubsection{Basic Commands}

\begin{tabular}{|c|c|c|c|}
\hline Class & Subpart & Command & Purpose \\
\hline \multirow{6}{*}{$\begin{array}{c}\mathrm{B} \\
(\mathrm{Basic})\end{array}$} & a & GAS 8 & calculate concentrations of different gases \\
\hline & $\mathrm{b}$ & PRESSURE & calculate static pressure \\
\hline & c & SMOKE & calculate smoke optical density \\
\hline & $\mathrm{d}$ & $\begin{array}{l}\text { THERMOCOUPLE } \\
\text { or TC }\end{array}$ & $\begin{array}{l}\text { convert voltage output to temperature for } \\
\text { various different types of thermocouples }\end{array}$ \\
\hline & e & VELOCITY & calculate gas velocity \\
\hline & $f$ & WT-LOSS & calculate total weight loss of monitored items \\
\hline
\end{tabular}




\subsubsection{Complex Commands}

\begin{tabular}{|c|c|c|c|}
\hline Class & Subpart & Command & Purpose \\
\hline \multirow[t]{8}{*}{$\begin{array}{c}\text { C } \\
\text { (Complex) }\end{array}$} & a & BALANCE & $\begin{array}{l}\text { calculate rate of heat release from total } \\
\text { energy balance }\end{array}$ \\
\hline & $\mathrm{b}$ & FLOW-RATE & $\begin{array}{l}\text { find neutral plane height and calculate volume } \\
\text { flow rate, mass flow rate, and convective } \\
\text { energy transport rate in and out of a chamber } \\
\text { using gas velocity }\end{array}$ \\
\hline & c & GAS-FLOW & $\begin{array}{l}\text { calculate the mass flow rate through an } \\
\text { opening of any gas whose concentration, } \\
\text { velocity, and temperature are known }\end{array}$ \\
\hline & $\mathrm{d}$ & HEAT-RATE & $\begin{array}{l}\text { calculate the rate of heat release from gas } \\
\text { concentration (oxygen depletion), gas } \\
\text { velocity, and gas temperature }\end{array}$ \\
\hline & e & HEAT-RATE-2 & $\begin{array}{l}\text { calculate the rate of heat release from } \\
\text { oxygen depletion, gas velocity, and gas } \\
\text { temperature; specifically designed for use } \\
\text { when only one of each type of instrument is } \\
\text { used (no profiles) }\end{array}$ \\
\hline & $f$ & HOT/COLD & $\begin{array}{l}\text { find the position of the hot/cold interface } \\
\text { as determined by the temperatures from an } \\
\text { identified profile }\end{array}$ \\
\hline & $g$ & MASS - FLOW & $\begin{array}{l}\text { calculate neutral plane height and mass flow } \\
\text { rate of gas through an opening using gas } \\
\text { temperature profiles }\end{array}$ \\
\hline & $\mathrm{h}$ & MASS - FLOW- 2 & $\begin{array}{l}\text { calculate the mass flow rate of gas through } \\
\text { an opening using temperature profiles and } \\
\text { a neutral plane height determined by another } \\
\text { source }\end{array}$ \\
\hline
\end{tabular}




\begin{tabular}{|c|c|c|}
\hline i & MASS - FLOW - 3 & $\begin{array}{l}\text { calculate the mass flow rate of gas through } \\
\text { an opening using a single gas velocity } \\
\text { measurement and the area of the vent } \\
\text { perpendicular to the gas flow }\end{array}$ \\
\hline j & STATIC & $\begin{array}{l}\text { find the neutral plane height, thermal } \\
\text { discontinuity height, pressure at the thermal } \\
\text { discontinuity height, opening gas velocities, } \\
\text { and interior temperatures from static pressure } \\
\text { inside chamber. }\end{array}$ \\
\hline k & SURFACE & $\begin{array}{l}\text { calculate average and total heat loss rate and } \\
\text { total incident heat flux to a surface } \\
\text { using surface temperature }\end{array}$ \\
\hline 1 & VENT -LOSS & $\begin{array}{l}\text { calculate radiative heat loss through an } \\
\text { opening using exhaust gas temperature }\end{array}$ \\
\hline & WT-RATE & $\begin{array}{l}\text { calculate percent weight loss, rate of weight } \\
\text { loss, and rate of heat release from total } \\
\text { weight loss }\end{array}$ \\
\hline & ZERO-TC & $\begin{array}{l}\text { calculate zero diameter thermocouple } \\
\text { temperatures from least squares fit of } \\
\text { temperatures from various sized thermocouples }\end{array}$ \\
\hline
\end{tabular}

\subsection{Data Input for Transformation Control Commands}

The commands may be given in any order and as many times as necessary. The end of.data transformation is signaled by entering the command "END".

Note that many of the subroutines called "create" new channels in which to store the calculated or transformed results. These channels must be included when counting the number of channels used. Make sure the parameter NCOL in the main program, RAPID, is large enough. Up to 1000 channels may be created by the program.

All units are metric for both input and output unless otherwise noted. 


\begin{tabular}{|c|c|c|c|}
\hline Input & Variables & Format & Comments \\
\hline $\mathrm{Hl}$ & CMD , COMENT & A80 & 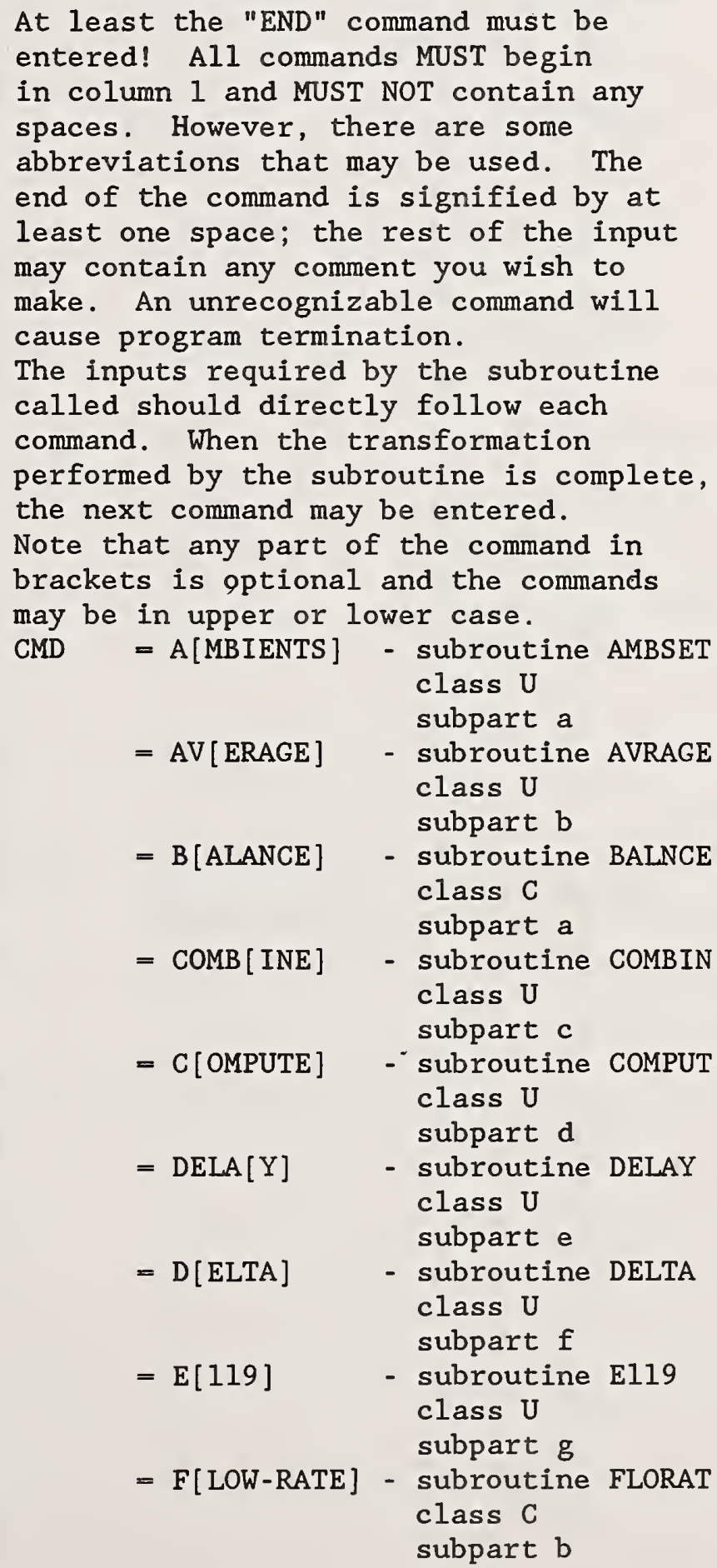 \\
\hline
\end{tabular}


$=G[A S \%] \quad$ - subroutine GASCON class B subpart a

= GAS-[FLOW $]$ - subroutine GASFLO class C subpart $c$

$=$ H[EAT-RATE ] - subroutine RHRDOX class $C$ subpart d

$=\mathrm{H}[\mathrm{EAT}-\mathrm{RATE}-] 2$ subroutine RHRDO2 class C subpart e

$=H O[T / C O L D]$ - subroutine HTNCLD class C subpart $f$

$=I$ [NTEGRATE] - subroutine INTGRT class U subpart $h$

$=\mathrm{M}[\mathrm{ASS}-\mathrm{FLOW}]$ - subroutine MASFLO class C subpart $\mathrm{g}$

$=\mathrm{M}[$ ASS - FLOW -$] 2$ -

subroutine MASFL2 class $C$ subpart $h$

$=\mathrm{M}[\mathrm{ASS}-\mathrm{FLOW}-]^{3}-$ subroutine MASFL3 class $\mathrm{C}$ subpart $i$

$=\mathrm{P}[\mathrm{RESSURE}]$ - subroutine PRESS class B subpart b

$=\mathrm{R}$ [ENAME] - subroutine NUNAME class U subpart $i$

$=S[$ EPARATE $]$ - subroutine SEPRAT class U subpart $j$

= SM[OKE $]$ - subroutine SMOKE class B subpart $C$

$=$ SMOO[TH] - subroutine SMOOTH class U subpart $k$

$=\mathrm{SP}[\mathrm{ECIFY}]$ - subroutine $\mathrm{SPECFY}$ class U subpart 1

$=\mathrm{ST}[\mathrm{ATIC}]$ - subroutine STATIC class C subpart j 


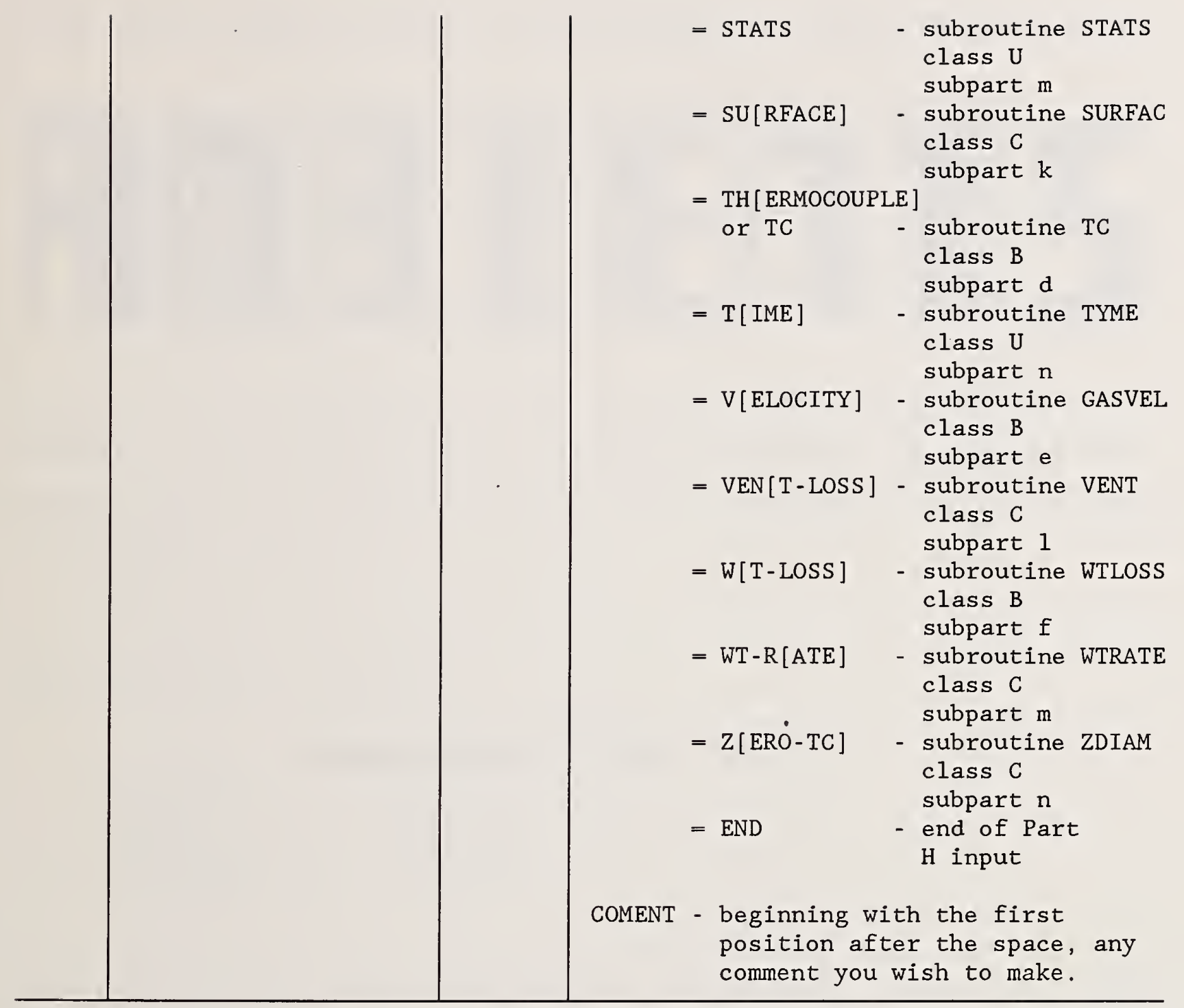

At this point enter the input specified under each command as it is given. 
13. Data Input for Utility Commands 


\subsection{Part H, Class U, Subpart a: Input Specifled by Utility Command AMBIENTS}
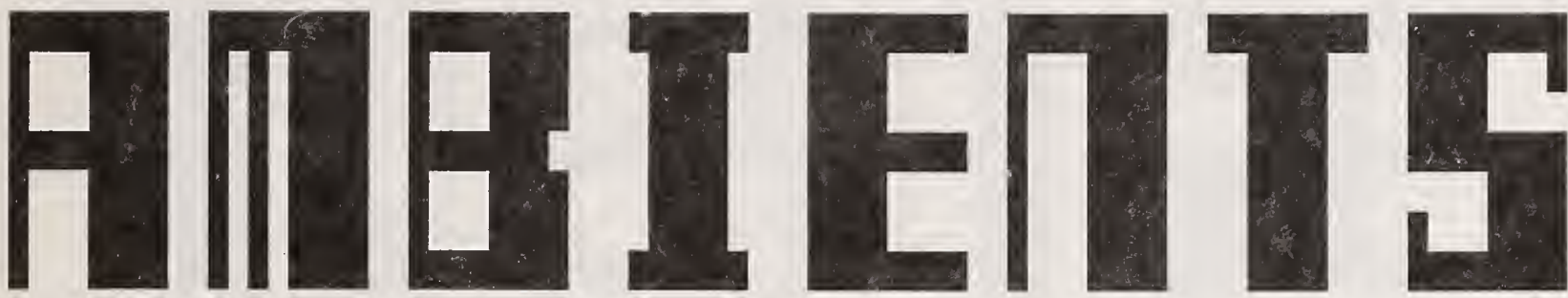

The subroutine can assign values other than default values to the ambient temperature $\left({ }^{\circ} \mathrm{C}\right)$, pressure $(\mathrm{kPa})$, and relative humidity $(\%)$. The ambient air density $(\mathrm{kg} / \mathrm{cu} \mathrm{m})$ is calculated using the ambient temperature and pressure and is not available to be set.

The default ambient values are:

$\begin{array}{ll}\text { Temperature } & =20{ }^{\circ} \mathrm{C} \\ \text { Pressure } & =101.3 \mathrm{kPa} \\ \text { Relative Humidity } & =50.8 \\ \text { Air Density } & =1.205 \mathrm{~kg} / \mathrm{cu} \mathrm{m}\end{array}$

It is possible to give the command AMBIENTS more than once. However, any ambient that is set using this subroutine, will remain at the value given until reset also using this subroutine. The values set here are in effect and are available throughout the program. Any other subroutine that is called that requires an ambient value will use the most current value of the ambient. It is not necessary to issue the command AMBIENTS if the default values are to be used. 


\begin{tabular}{|c|c|c|c|}
\hline Input & Variables & Format & Comments \\
\hline HUal & CTRL & $\mathrm{A} 80$ & $\begin{array}{l}\text { Only one of these inputs is read each } \\
\text { time the command AMBIENTS is given. The } \\
\text { program searches for each of the three } \\
\text { "key-words" that identify which ambient } \\
\text { value is to be set: } \\
\text { "AMBT=" - set ambient temperature, } \\
\text { "AMBP=" - set ambient pressure, kPa } \\
\text { "AMBRH=" - set ambient relative } \\
\text { humidity, percent } \\
\text { After each key-word, the next five char- } \\
\text { acters are assumed to be the value of } \\
\text { the ambient being set, in F format (e.g. } \\
\text { "AMBT= } 238.54 \text { " would assign the value } \\
238 \text {. }{ }^{\circ} \text { to the ambient temperature; } \\
\text { the } 5 \text { and } 4 \text { are ignored since they are } \\
\text { the sixth and seventh characters. } \\
\text { Any or all of the ambient values may be } \\
\text { set with this control input. If more } \\
\text { than one value is set, be sure that at } \\
\text { least } 5 \text { characters (including blanks) } \\
\text { separate each key-word. The key-words } \\
\text { may appear on the control input in any } \\
\text { order. }\end{array}$ \\
\hline
\end{tabular}

Enter Another Command (Data Input H1) 

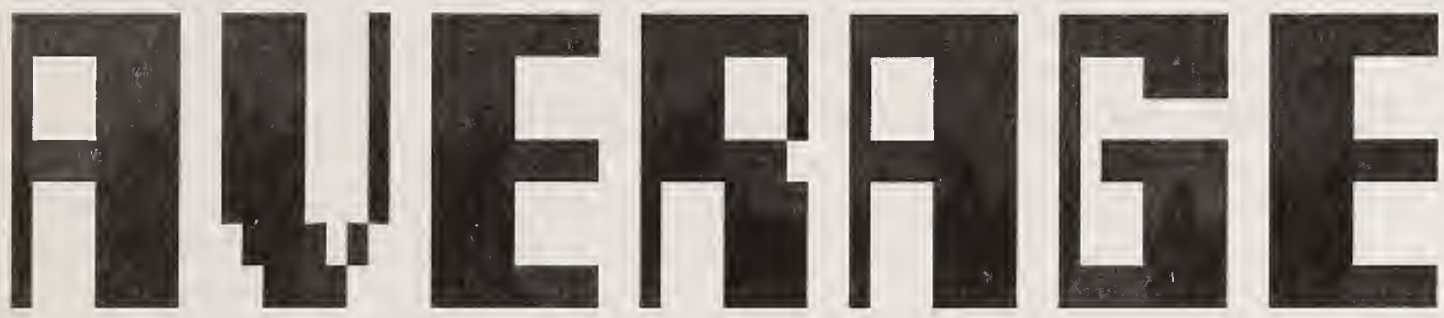

The subroutine finds the average of the values from up to 25 channels. The average may be a weighted average and lower and/or upper limits for the values may be specified.

The general format for entering the information for the average is as follows:

$$
\begin{aligned}
& [<\lim >] \operatorname{ch}(1)[w f(1)][<\lim >] \operatorname{ch}(2)[w f(2)] \ldots[<\lim \rangle] \operatorname{ch}(i)[w f(i)] x \\
& \text { for } 1<=1<=25 .
\end{aligned}
$$

In the format above, brackets (i.e., []) surround values that are optional inputs (the brackets themselves should not appear on the input input). Note that the limits (lim) appear within "limit delimiters" - $\diamond$ - and that, once set, apply to the values of all channels that follow until they are reset. You may specify a lower limit only, an upper limit only, both a lower and an upper limit, or no limits. Initially no values are set and, thus, no limits will be used unless specified. Conversely, the weighting factor (wf) only applies to the channel that it follows. If no weighting factor is specified, the weighting factor defaults to 1.0. The commas are optional. The "X" signals the end of the input and is strictly required. Often, one input will not allow sufficient space to enter all the input desired. Therefore, the input may appear on any number of 
inputs as long as not more than 500 characters are used (including spaces and the "X") .

The specific format for entering limits is as follows:

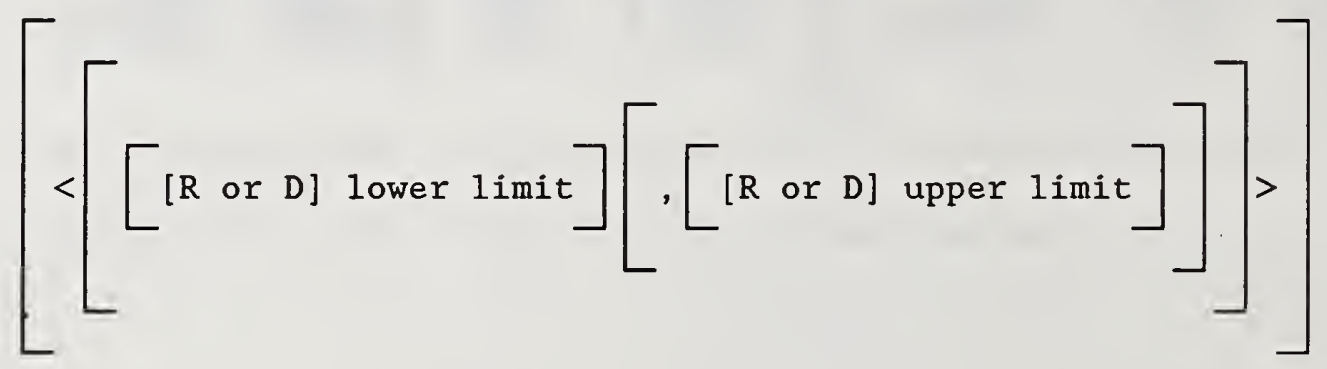

As in the general format above, values or characters within a set of brackets are optional. To identify that limits are being entered, a set of less-than $(<)$ and greater-than $(>)$ symbols (limit delimiters) must surround the limits. The limits themselves may be real or integer values; however, an integer value is assumed to be a channel number. If the limit is a real value, the value of the limit is constant. If the limit is a channel number, the value of the limit is the value stored in the channel at the time being averaged. If a channel number that does not exist is entered as a limit, the run terminates.

The "R" and "D" stand for REPLACE and DELETE, respectively. If a value is outside a limit that has an " $R$ " attached to it, the value being averaged is replaced by the limit value. If outside a limit that has a "D" attached, the value is not used to find the average and the population of the average is decreased by the weighting factor for that channel. If neither " $R$ " nor " $D$ " is entered, " $R$ " is assumed. 
A lower limit only, an upper limit only, both lower and upper limits, and no limits may be specified. The different combinations of limits is obtained as follows (- indicates a channel or constant value):

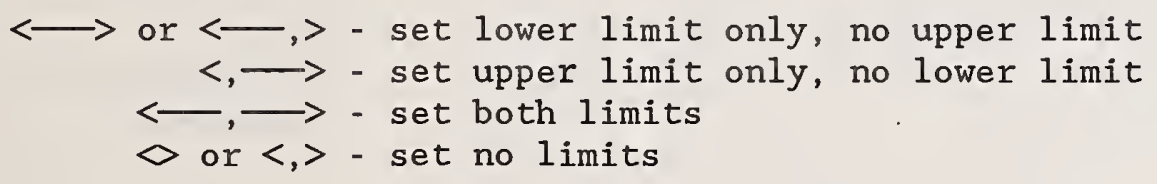

Note that an empty field is not the same as having a limit set to zero. Also note that a comma may appear if a lower limit is set but must appear if an upper limit is to be set (an error will occur if one is not found).

The specific format for entering a weighting factor is as follows:

$$
[*-]
$$

where stands for the weighting factor value.

The brackets again indicate that the weighting factor is an optional entry. To identify that a weighting factor is being entered, a "*" must be prefixed to the weighting factor value. The value itself may be a real or an integer, but will be treated by the program as a real.

Note that anywhere in this subroutine that a channel number is allowed as an entry, a created channel number can be specified by using the method described in the Notes on the Preparation of Data Inputs Read by RAPID (see NPDI [3]). 
Following is an example of a typical input record:

$$
321322 * 1.5323<320, \mathrm{D} 1000 .>324, * 2,325 \diamond 326<, \mathrm{R} 1000 .>327 \mathrm{X}
$$

The record above would be deciphered as follows:

\begin{tabular}{|c|c|c|c|c|c|c|c|c|c|c|}
\hline & & & & C & & & & & C & \\
\hline C & & & C & 0 & $\mathrm{R}$ & & & C & 0 & $\mathrm{R}$ \\
\hline $\mathrm{h}$ & W F & & $\mathrm{h}$ & $\mathrm{n}$ & e & D & & $\mathrm{h}$ & $\mathrm{n}$ & e \\
\hline a & e a & L L & a & $s$ & $p$ & e & U L & a & $s$ & $p$ \\
\hline $\mathrm{n}$ & $i c$ & o $i$ & $\mathrm{n}$ & $t$ & 1 & 1 & $p i$ & $\mathrm{n}$ & $t$ & 1 \\
\hline $\mathrm{n}$ & $g t$ & $\mathrm{w} \mathfrak{m}$ & $\mathrm{n}$ & a & a & e & $\mathrm{pm}$ & $\mathrm{n}$ & a & a \\
\hline e & $h \circ$ & e i & e 0 & $\mathrm{n}$ & c o & $t$ & e $i$ & e o & $\mathrm{n}$ & $c \circ t$ \\
\hline 1 & $t r$ & $r t$ & $1 \mathrm{r}$ & $t$ & e $\mathrm{r}$ & e & $r t$ & $1 \mathrm{r}$ & $t$ & e r e \\
\hline 321 & 1.0 & none & - & & - & & none & - & & - \\
\hline 322 & 1.5 & none & - & & - & & none & - & & - \\
\hline 323 & 1.0 & none & - & & - & & none & - & & - \\
\hline 324 & 2.0 & 320 & chan & & rep & & 1000 & cons & & de1 \\
\hline 325 & 1.0 & 320 & chan & & rep & & 1000 & cons & & de1 \\
\hline 326 & 1.0 & none & - & & - & & none & - & & - \\
\hline 327 & 1.0 & none & - & & - & & 1000 & cons & & rep \\
\hline
\end{tabular}

One channel is created by the program for each average found. 


\begin{tabular}{|c|c|c|c|}
\hline Input & Variables & Format & Comments \\
\hline HUb1 & NAVG & $\begin{array}{c}\text { open } \\
\text { (NPDI } \\
[1])\end{array}$ & $\begin{array}{l}\text { Only one of these inputs is read each } \\
\text { time the command AVERAGE is given. } \\
\text { NAVG - number of average calculations } \\
\text { to be made. Prepare NAVG } \\
\text { sets of HUb2 inputs. NAVG } \\
\text { channels will be created }\end{array}$ \\
\hline Input & Variables & Format & Comments \\
\hline HUb2 & IN & A80 & $\begin{array}{l}\text { Any number of these inputs may be used } \\
\text { for a single average (up to } 500 \\
\text { characters including spaces and } \\
\text { the "X"). } \\
\text { IN - the input record as described } \\
\text { in the discussion above }\end{array}$ \\
\hline
\end{tabular}

Enter Another Command (Data Input H1) 


\subsection{Part H, Class U, Subpart c: Input Specifled by Utility Command COMBINE}
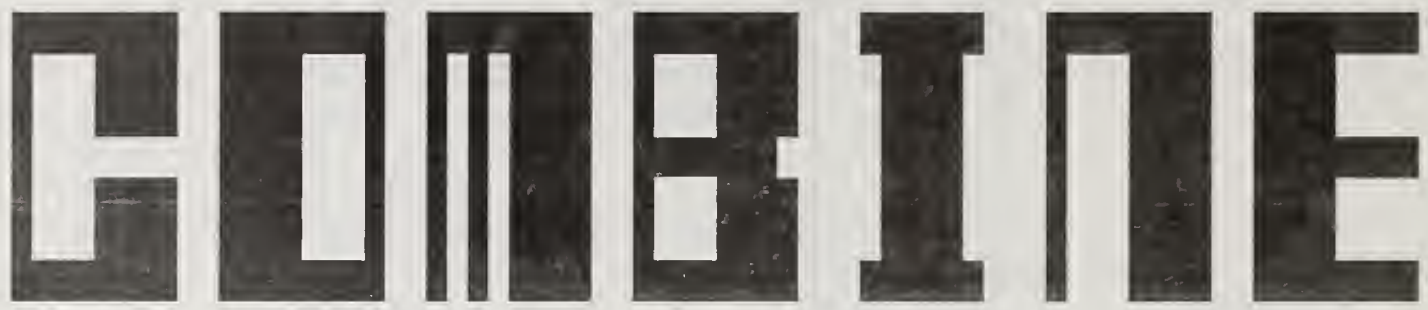

The subroutine concatenates values from identified channels over specified ranges. The resulting data vector is stored in a channel created by the program. It is useful for combining into one channel, the values from two or more channels, such as when two instruments with different ranges are used to measure the same phenomenon.

A time (in seconds) or a scan number may be used to identify when the values from a channel are to begin being included. If a time is used, the actual scan number $(j)$ is determined internally such that $t(j-1)<t$ ime $<=t(j)$, and where $t(i)$ is the time at the ith scan. The values from a channel continue to be included until the next beginning scan number is reached (if there is one). If desired, times and scan numbers can both be used (a time for one channel, a scan for the next, etc.).

If the range of the first channel begins sometime after the first scan, the scans of the created channel are undefined and arbitrarily set to zero.

The scan numbers (or times) need not be entered in any particular order except that they should match the same relative order in which the channel numbers to be combined were entered. Ordering of the scans is done internally. 
For example, if the combined channel were to be made up of three different data channels over four intervals, the inputs might look like this:

$\begin{array}{lllll}621 & 622 & 621 & 650 & \mathrm{X} \\ 0 . & 300 . & 600 & 250 & \mathrm{X}\end{array}$

This set of inputs instructs the subroutine to create a channel made up of the values from channel 621 from time 0 . up to, but not including, the value at time 300. seconds. From 300. up to, but not including, 600 , the values from channel 622. From 600. seconds up to, but not including, the value at scan 250 , the values from channel 621 again. And from scan 250 to the end, the values from channel 650.

\begin{tabular}{|c|c|c|c|}
\hline Card & Variables & Format & Comments \\
\hline $\mathrm{HUcl}$ & NCOMB [, JTIME] & $\begin{array}{l}\text { open } \\
(\text { NPDI } \\
[1])\end{array}$ & $\begin{array}{l}\text { Only one of these inputs is read each } \\
\text { time the command COMBINE is given. } \\
\text { NCOMB - number of combinations of } \\
\text { channels to be made. Prepare } \\
\text { NCOMB sets of HUc2 and HUc3 } \\
\text { inputs. NCOMB channels will } \\
\text { be created. } \\
\text { JTIME - the time channel number. } \\
\text { If times are to be used to } \\
\text { define the beginning of an } \\
\text { interval, this value must be } \\
\text { entered. }\end{array}$ \\
\hline Card & Variables & Format & Comments \\
\hline HUc2 & $\begin{array}{l}\operatorname{JCHAN}(i) X \\
1<=i<=20\end{array}$ & $\begin{array}{l}\text { EVALU8 } \\
\text { (NPDI } \\
[2])\end{array}$ & $\begin{array}{l}\text { JCHAN - channel number of values to be } \\
\text { included in the combination } \\
\text { (NPDI [3]). }\end{array}$ \\
\hline
\end{tabular}




\begin{tabular}{c|c|c|c}
\hline Card & Variables & Format & Comments \\
\hline HUc3 & $\begin{array}{l}\text { (IB }(\mathrm{i}) \text { or BTIME }(\mathrm{i})\} \\
\mathrm{X}<=\mathrm{i}<=20\end{array}$ & $\begin{array}{c}\text { EVALU8 } \\
\text { (NPDI } \\
[2])\end{array}$ & $\begin{array}{l}\text { These values are used to identify the } \\
\text { beginning of the interval corresponding } \\
\text { to the data channels above. } \\
\text { IB - a scan number. } \\
\text { BTIME - a time in seconds. BTIME } \\
\text { may not be used if JTIME is not } \\
\text { specified. }\end{array}$ \\
\hline
\end{tabular}

Enter Another Command (Data Card H1) 
13.4 Part H, Class U, Subpart d: Input Specifled by Utillty Command COMPUTE
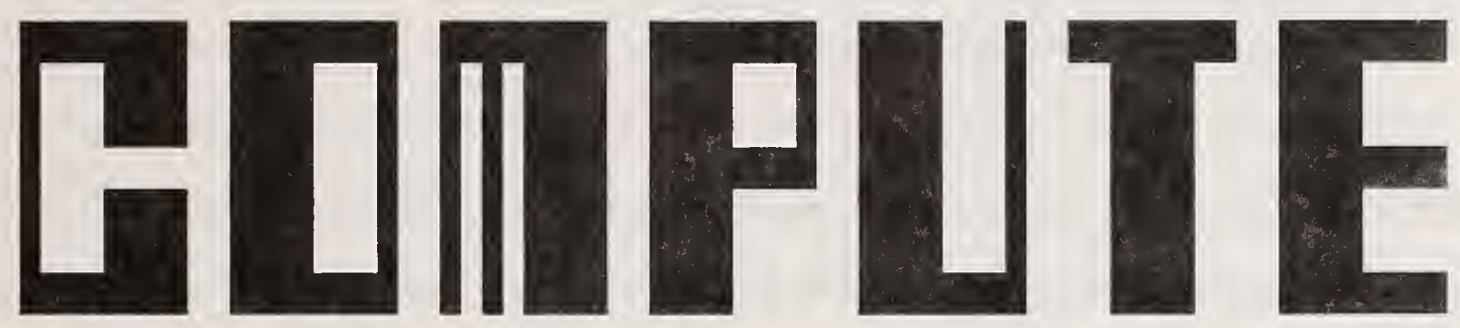

The subroutine deciphers a FORTRAN-type algebraic expression and calculates the results. The operations that can be handled are ADD (+), SUBTRACT (-), MULTIPLY $(*)$, DIVIDE $(/)$, RAISE TO A POWER $(* *)$, AVERAGE (A), FIND THE MINIMUM (<), and FIND THE MAXIMUM $(>)$. (Note that AVERAGE $(A)$, MINIMUM $(<)$, and MAXIMUM $(>$ ) have non-standard operator symbols). The operators and operands may be nested in parentheses in order to perform the operations in the desired sequence. The operators themselves have hierarchical ranks as follows:

\begin{tabular}{lccc} 
Function & Symbol & Rank \\
\cline { 2 - 2 } AVERAGE & A & 3 \\
RAISE TO A POWER & $* *$ & 2 \\
MULTIPLY or DIVIDE & $*$ or / & 1 \\
ADD or SUBTRACT & + or - & 0 \\
MINIMUM or MAXIMUM & $<$ or $>$ & 0
\end{tabular}

The AVERAGE function generates the appropriate ADDs, DIVIDEs, and nesting to insure the proper average is found. Note that, unlike the averaging algorithm employed when the command AVERAGE is given, no limits or weights can be used for this average.' 
When several AVERAGE operators are encountered in a string (unbroken by parentheses or other operators) all the values linked together by the A's are added before the average is found.

The MINIMUM operation finds and saves the smaller value of two values and the MAXIMUM operation does the same only for the larger value.

The operands may be either real constants or channel numbers. If an operand contains a decimal point, it is assumed to be a constant. Otherwise, the operand is assumed to be a channel number. If you wish to use channels which were created by the program, you may do so by using the method described in the Notes on the Preparation of Data Inputs Read by RAPID (see NPDI [3]). If an assumed channel is not found, the run will terminate.

A typical computation might be as follows:

$$
(301 \text { A } 302 \text { A } 303 *((20.9-(313<314)) / 100 .)) * * 2 . \quad X
$$

In the example above, the first step is to find the smaller value from channels 313 and 314 and then subtract that value from th constant 20.9. That result is then divided by $100 \ldots$ The average of the values from channels 301, 302, and 303 is then found and then multiplied by the result of the above division. Finally, that result is squared. The " $\mathrm{X}$ " indicates the end of the computation and must be present. Up to 500 significant (non-blank) characters may be used to enter one computation (including the "X"). 
In addition there are three so-called "channel operators". The three channel operators are H (for HIGH), L (for LOW), and M (for MEAN). These operators are used to find a single value within a single channel. The syntax is to use the operator (H, L, or M) followed by a channel number; e.g., H408, L16162, M\$03. The operator and its channel number are reduced to a single real number before any other calculation is done. Thus the channel operator/channel number may be used anywhere a real number may be used and must follow any syntax pertaining to real numbers.

H <channel number>

L <channel number>

$M<$ channél number> returns the highest value found in the channel. returns the lowest value found in the channel. returns the average of all the values found in the channel.

One channel is created by the program for each computation performed.

\begin{tabular}{|c|c|c|c|}
\hline Input & Variables & Format & Comments \\
\hline HUdl & NCOMP & $\begin{array}{l}\text { open } \\
\text { (NPDI } \\
{[1] \text { ) }}\end{array}$ & $\begin{array}{l}\text { Only one of these inputs is read each } \\
\text { time the command COMPUTE is given. } \\
\text { NCOMP - the number of computations } \\
\text { done. Prepare NCOMP sets of } \\
\text { HUd2 inputs. NCOMP channels } \\
\text { will be created. }\end{array}$ \\
\hline Input & Variables & Format & Comments \\
\hline HUd2 & IN & $\mathrm{A} 80$ & $\begin{array}{l}\text { As many inputs as needed may be used } \\
\text { but the total number of significant } \\
\text { (non-blank) characters may not } \\
\text { exceed } 500 \text {. } \\
\text { IN - the input computation as } \\
\text { described in the discussion } \\
\text { above. }\end{array}$ \\
\hline
\end{tabular}

Enter Another Command (Data Input HI) 


\subsection{Part H, Class U, Subpart e: Input Specified by Utility Command DELAY}
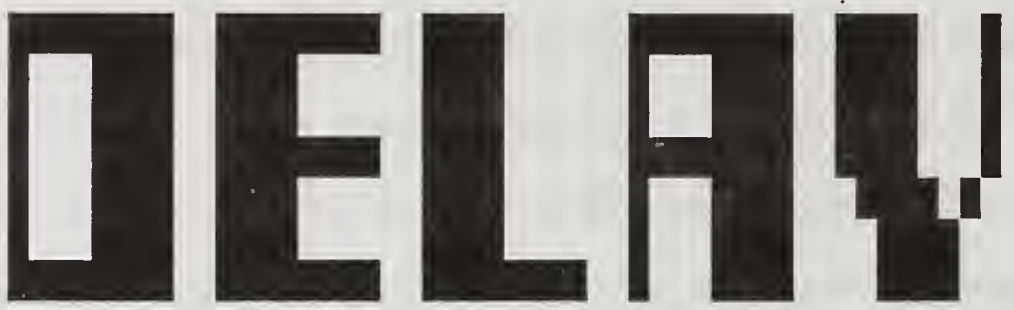

This subroutine accounts for any delay in the output due to the response time of an instrument. For any response time, $r$, a reading, $R$, at time, $t$, is defined as: $R(t)=R(t+r)$. If the response time is not an even multiple of the scan rate, a straight line interpolation of the data is done.

For time, $x<t+r<y$, the interpolation and redefinition is:

$$
R(t)=R(t+r)=\left[\frac{(t+r)-x}{y-x}\right] *[R(y)-R(x)]
$$

No new channels are created by this command. Any changes in the data matrix take place in the identified channel. 


\begin{tabular}{|c|c|c|c|}
\hline Input & Variables & Format & Comments \\
\hline HUel & NDLAY & $\begin{array}{l}\text { open } \\
\text { (NPDI } \\
[1])\end{array}$ & $\begin{array}{l}\text { NDLAY - the number of groups of } \\
\text { channels for which delays are } \\
\text { to be entered. } \\
\text { Enter NDLAY HUe2 inputs. }\end{array}$ \\
\hline Input & Variables & Format & Comments \\
\hline HUe2 & $\begin{array}{l}\operatorname{JCHAN}(1), \operatorname{JCHAN}(2) \\
\ldots, \operatorname{JCHAN}(\mathrm{i}), \mathrm{JTIME} \\
\operatorname{DLAY} \mathrm{X} \\
1<=i<=98\end{array}$ & $\begin{array}{l}\text { EVALU8 } \\
\text { (NPDI } \\
[3])\end{array}$ & $\begin{aligned} \text { JCHAN - the channel number of the } \\
\text { values which are delayed } \\
\text { (NPDI [3]). } \\
\text { JTIME - the time channel number, s. } \\
\text { DLAY - the amount of the delay, s. } \\
\text { X }=\text { ' } \mathrm{X}^{\prime} \text { - end-of-set mark }\end{aligned}$ \\
\hline
\end{tabular}

Enter Another Command (Data Input H1) 
13.6 Part H, Class U, Subpart $f$ : Input Specified by Utility Command DELTA
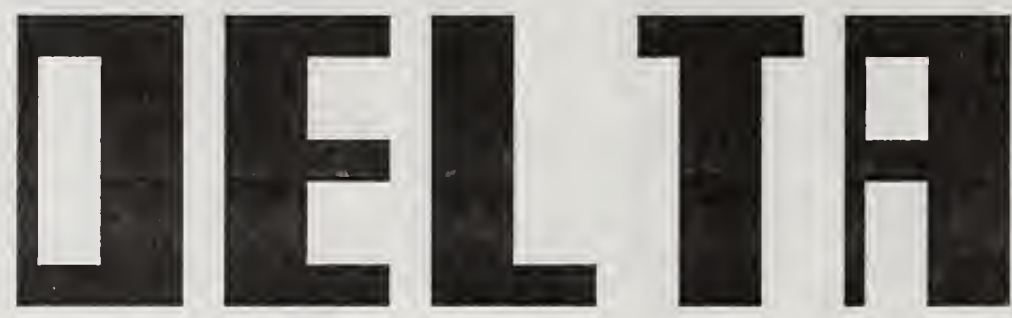

The subroutine calculates the difference between sequential values of any particular channel. The results are stored in a channel created by the program. Any channel number may be used as input. If you wish to use a channel which was created by the program, you may do so by using the method described in the Notes on the Preparation of Data Inputs Read by RAPID (see NPDI [3]).

There are two methods of calculation and storage of results as follows:

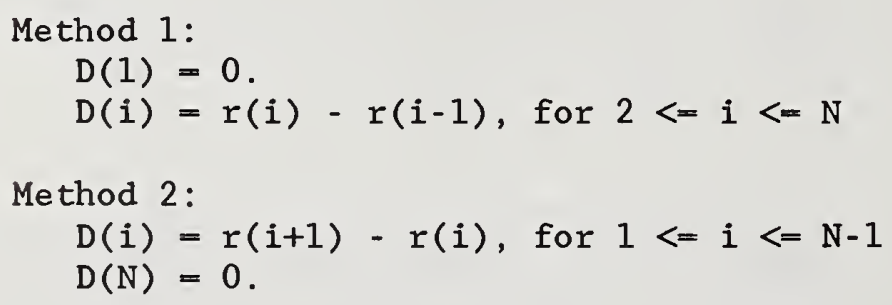

where $D$ is the resulting difference, $r$ is the value stored in the channel, and $N$ is the total number of scans. 


\begin{tabular}{|c|c|c|c|}
\hline Input & Variables & Format & Comments \\
\hline HUfl & NCHAN & $\begin{array}{l}\text { open } \\
\text { (NPDI } \\
[1])\end{array}$ & $\begin{array}{l}\text { NCHAN - the number of channels for } \\
\text { which the incremental } \\
\text { differences between adjacent } \\
\text { values are calculated. } \\
\text { Prepare NCHAN HUf2 inputs. } \\
\text { NCHAN channels are created. }\end{array}$ \\
\hline Input & Variables & Format & Comments \\
\hline HUf2 & JCHAN, [ ICALC] X & $\begin{array}{c}\text { EVALU8 } \\
\text { (NPDI } \\
[2])\end{array}$ & $\begin{aligned} \text { JCHAN - } & \text { the channel number containing } \\
& \text { the values between which the } \\
& \text { differences are calculated } \\
& (\text { NPDI }[3]) . \\
\text { ICALC = } & 0 \text {, method } 1 \text {, above. } \\
\diamond & 0 \text {, method } 2 \text {, above. } \\
& \text { Note that the default for a } \\
& \text { missing value is Method } 1 . \\
\mathrm{X}= & \text { ' } \mathrm{X} \text { ' - end-of-set mark }\end{aligned}$ \\
\hline
\end{tabular}

Enter Another Command (Data Input H1) 


\subsection{Part H, Class U, Subpart g: Input Specifled by Ut1lity Command E119}
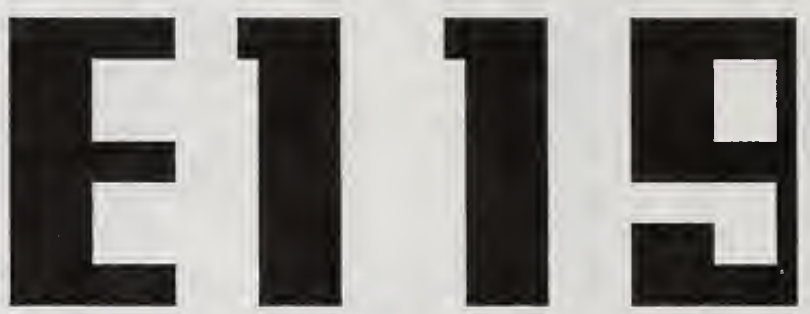

The subroutine calculates the standard E119 temperature for each time from an identified time channel. The temperature may be stored as either degrees Celsius or Fahrenheit in a channel created by the program. This subroutine will only calculate values for one channel at a time and thus, it must be called each time a channel is to be created.

The equations used to calculate the temperature are as follows:

$$
\begin{aligned}
& \text { for time less than zero - } \\
& \mathrm{T}=70 . \\
& \text { for time less than } 2 \text { hours - } \\
& \mathrm{T}=1044 . * \operatorname{Tanh}(0.8429 * t)-498.2 * \operatorname{Tanh}(0.9736 * t) \\
& +1286 * \operatorname{Tanh}(8.9100 * t)+70 \text {. } \\
& \text { for time equal to or greater than } 2 \text { hours - } \\
& \mathrm{T}=1632 .+75 . * t+70 \text {. }
\end{aligned}
$$

where,

Tanh is the hyperbolic tangent function, $\mathrm{T}$ = temperature in degrees Fahrenheit, and $t=$ time in hours 
Note that the calculation is made in degrees Fahrenheit and is converted to Celsius, if necessary.

One channel is created each time the command E119 is given.

\begin{tabular}{|c|c|c|c|}
\hline Input & Variables & Format & Comments \\
\hline HUg1 & JTIME, ITCODE & $\begin{array}{l}\text { open } \\
\text { (NPDI } \\
{[1] \text { ) }}\end{array}$ & 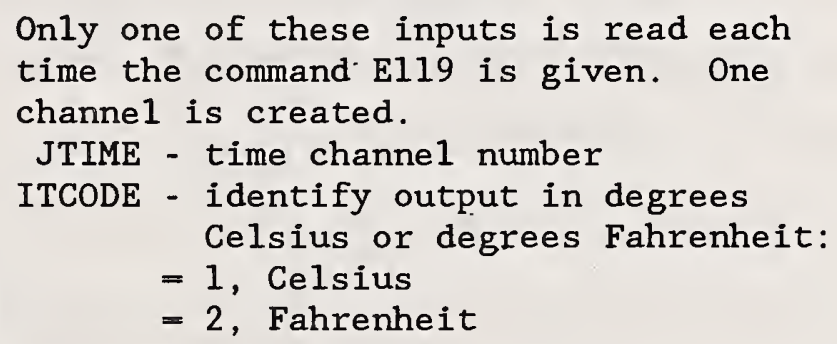 \\
\hline
\end{tabular}

Enter Another Command (Data Input H1) 
13.8 Part H, Class U, Subpart h: Input Specified by Utility Command INTEGRATE
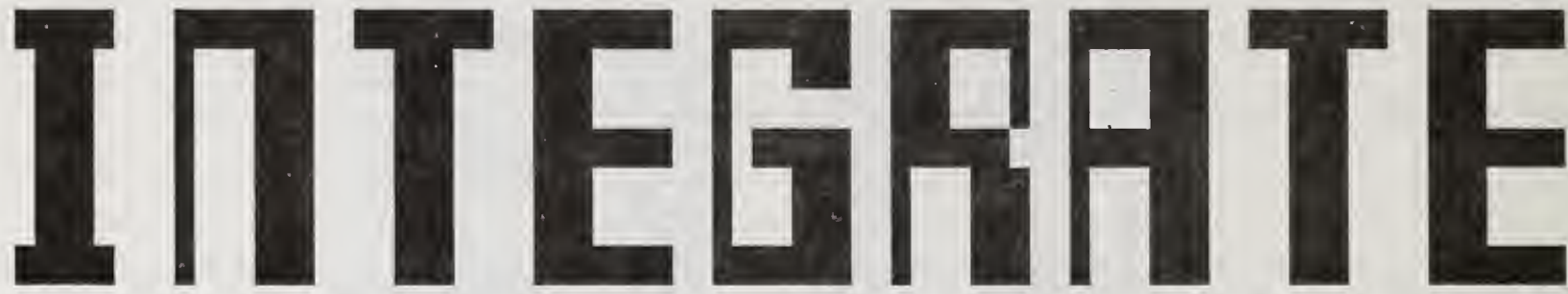

The subroutine calculates the area under the curve with respect to time. The area is calculated using a geometríc algorithm (the sum of the trapezoids defined by the segment of the curve between two points and the time axis). The calculated values are stored in a channel created by the program.

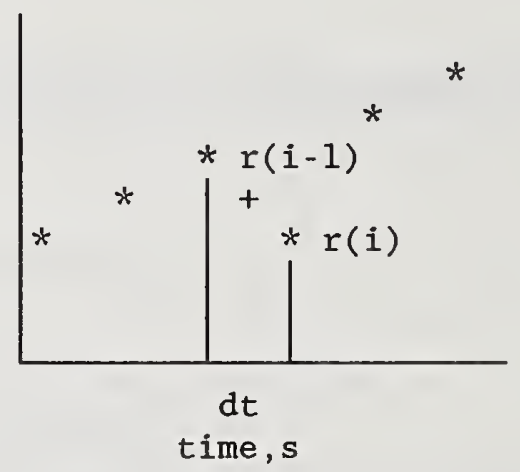

$$
A(i)=\operatorname{SUM}[a(i), i=1, n]=\operatorname{SUM}[(r(i-1)+r(i)) * d t(i) / 2, i=1, n]
$$

where $A(i)$ is the total area under the curve up to point $i, a(i)$ is the area of the "ith" trapezoid, and SUM is the summation function.

Note that the values being integrated have already been transformed using the conversion coefficients input on PLOT2 data input B5 for the original channel. 
The conversion coefficients for the created channels are the default values of $\mathrm{C}=1.0, \mathrm{ADD}=0.0$, and POWER $=1.0$.

\begin{tabular}{|c|c|c|c|}
\hline Input & Variables & Format & Comments \\
\hline HUhl & NINT & $\begin{array}{l}\text { open } \\
\text { (NPDI } \\
[1])\end{array}$ & $\begin{array}{l}\text { Only one of these inputs is read each } \\
\text { time the command INTEGRATE is given. } \\
\text { NINT - number of curves to be } \\
\text { integrated. Prepare NINT HUh2 } \\
\text { inputs. NINT channels will be } \\
\text { created. }\end{array}$ \\
\hline Input & Variables & Format & Comments \\
\hline HUh2 & JCHAN, JTIME X & $\begin{array}{c}\text { EVALU8 } \\
\text { (NPDI } \\
[2])\end{array}$ & $\begin{aligned} \text { JCHAN - channel number of curve to be } \\
\text { integrated (NPDI [3]) } \\
\text { JTIME - reference time channel number } \\
\text { with respect to which JCHAN } \\
\text { is integrated, s } \\
\mathrm{X}=\text { ' } \mathrm{X}^{\prime} \text {-' end-of-set mark }\end{aligned}$ \\
\hline
\end{tabular}

Enter Another Command (Data Input H1) 
13.9 Part H, Class U, Subpart 1: Input Specifled by Utility Command RENAME
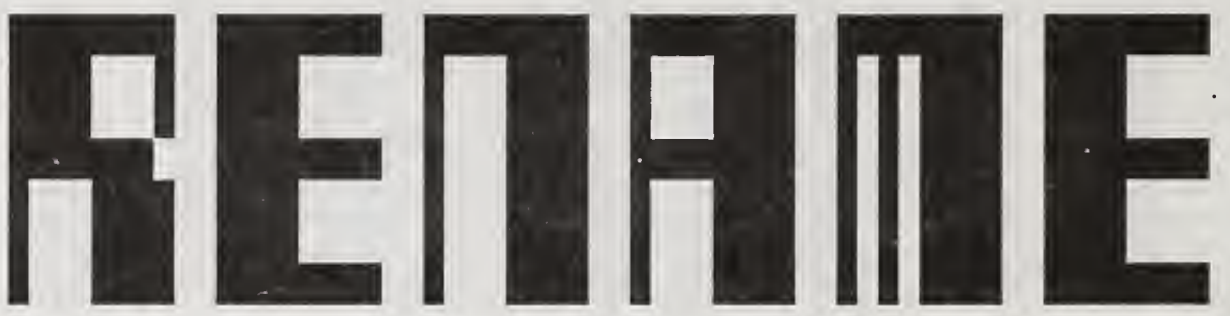

The subroutine allows the user to provide descriptions of the channels created by the program other than the descriptions generated by the program when a channel is created. The format used is the same as that for data inputs B3 and B4 except that the "\$" signifying a created channel is recognized and the instrument type need not be identified. 


\begin{tabular}{|c|c|c|c|}
\hline Input & Variables & Format & Comments \\
\hline HUil & CHAN, ID 1, ID 2, KHPRT & $\begin{array}{l}\mathrm{A} 6,2 \mathrm{X}, \\
\mathrm{A} 6, \mathrm{~A} 60, \\
\mathrm{~A} 3\end{array}$ & $\begin{array}{l}\text { The number of HUil inputs is variable. } \\
\text { The end of HUil format inputs is } \\
\text { signaled by entering one HUi2 input. } \\
\text { CHAN - the channel number being } \\
\text { identified, right justified and } \\
\text { including the "\$" (if desired) } \\
\text { in the left-most significant } \\
\text { position. } \\
\text { ID1 - a six-character, abbreviated ID. } \\
\text { ID2 - the } 60 \text {-character description. } \\
\text { KHPRT = ' (blank field) - print out } \\
\text { the values of this column on } \\
\text { output } \\
\text { out the values of this column } \\
\text { out (non-blank) - do not print }\end{array}$ \\
\hline Input & Variables & Format & Comments \\
\hline $\mathrm{HUi} 2$ & IEND & $77 \mathrm{X}, \mathrm{A} 3$ & $\begin{aligned} \text { IEND }=1999^{\prime}- & \text { end of the set of } \\
& \text { HUil inputs }\end{aligned}$ \\
\hline
\end{tabular}

Enter Another Command (Data Input H1) 
13.10 Part H, Class U, Subpart J: Input Specifled by Ut1lity Command SEPARATE
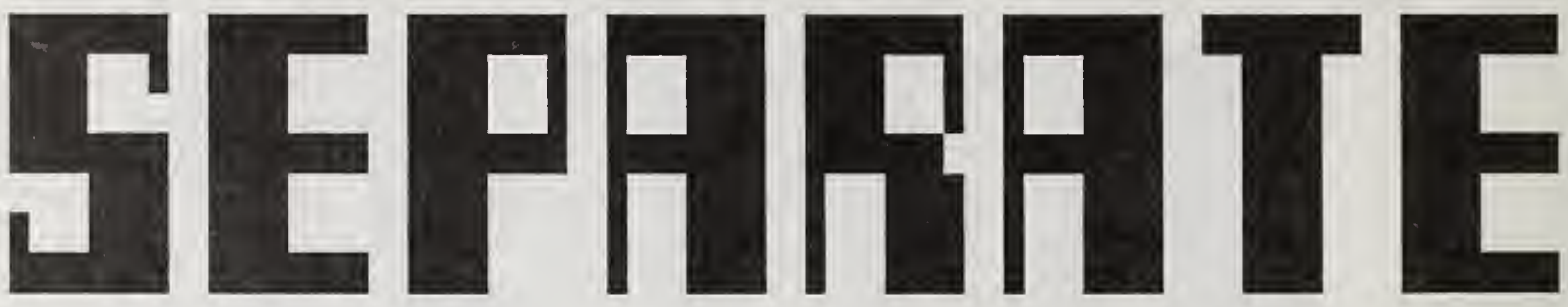

Often times one channel will be used to collect the data from more than one instrument by manually or automatically stepping a switch, etc. In order to plot, or otherwise compare, the individual values, it is necessary to resolve the channel into its separate parts. Since the time at which the "nth" value of each part is recorded is different, the time channel must also be resolved into separate parts.

The subroutine resolves both the data and time channels into parts according to a pattern, or "separation code", provided by the user. Various, repeatable patterns may be needed to identify which scans belong to which instrument. The separation code format allows for an infinite number of variations.

In general, the separation code consists of the "skip/keep" pattern in parentheses followed by the scan number of the last scan to which the pattern applies:

([skip/keep pattern]) [scan number] ([skip/keep pattern]) [scan number] ...

The skip/keep pattern is repeated until the scan number is reached. The pattern itself consists of a series of letters and numbers signifying skip or keep and 
how many scans of each. The letter ' $S$ ' stands for skip; the letter ' $K$ ' stands for keep. Any number of alternating skips and keeps may appear in the pattern.

\section{Example 1}

The channel has the values from three instruments stored in it and each instrument is recorded every third scan. There were 295 scans taken. The separation codes for the three instruments would be:

$\begin{array}{lll}\text { Instrument } 1: & \text { (K1S2) } 295 & \text { (keep scans } 1,4,7, \ldots, 295) \\ \text { Instrument 2: } & \text { (S1K1S1)295 } & \text { (keep scans } 2,5,8, \ldots, 293 \text { ) } \\ \text { Instrument 3: } & \text { (S2K1)295 } & \text { (keep scans } 3,6,9, \ldots, 294)\end{array}$

Example 2

One set of instruments' values stored in the channel was recorded such that, to recover them, every first, third, fourth and sixth scans are skipped and every second and fifth are kept, up to scan 100. From scan 101 to 295 (end of test), every other scan is kept. The separation code would be:

(S1 K1 S2 K1 S1) 100 (S1 K1) 295

Alternatively, the letter ' $E$ ' may be used to signify the last scan recorded:

(S1 K1 S2 K1 S1)100 (S1 K1)E 
Spaces in the code are ignored except that if a space follows a number, the whole number is assumed to be to the left of the space:

\section{(S1K1S $2 \mathrm{~K} 1 \mathrm{~S} 1) \quad 100(\mathrm{~S} 1 \mathrm{~K} 1) \mathrm{E}$}

is the same as the code above.

The following syntax rules should be used when preparing the separation code:

1. A '(' should be the first significant character on the input and should be the first significant character, if any, after a scan number.

2. An ' $S$ ' or a ' $K$ ' must be the next significant character after '('

3 A "repeat" number must follow ' $S$ ' or ' $K$ ' even if it is 1

4. An ' $S^{\prime},{ }^{\prime} K^{\prime}$, or ')' must be the next significant character following a repeat number.

5. A scan number or ' $E$ ' must be the next significant character(s) following ')'.

6. Spaces are ignored except that if a space follows a number, the whole number is assumed to be to the left of the space.

Note that if an ' $E$ ' is not used and the last scan number given is not greater than or equal to the number of scans in the channel, all scans past the last scan number given are skipped. If the last scan number given is greater than the number of scans used, the "skip/keep" pattern is repeated until the last scan used is reached. 
The conversion coefficients of the original channel (identified by ITYPE on data input B3 and entered with data input B5) are also used by the newly created channe1.

Both the separated values and the separated time are stored in new channels created by the program.

\begin{tabular}{|c|c|c|c|}
\hline Input & Variables & Format & Comments \\
\hline HUj1 & JTIME, JCHAN, NPART X & $\begin{array}{c}\text { EVALU8 } \\
\text { (NPDI } \\
[2])\end{array}$ & $\begin{array}{l}\text { Only one of these inputs is read each } \\
\text { time the command SEPARATE is given. } \\
\text { JCHAN - channel number of data to be } \\
\text { separated into parts (NPDI [3]) } \\
\text { JTIME - reference time channel number } \\
\text { NPART - number of parts into which data } \\
\text { is to separated. Prepare NPART } \\
\text { HUj2 input(s) } \\
\text { X - ' } \mathrm{X}^{\prime} \text { - end-of-set mark. }\end{array}$ \\
\hline Input & Variables & Format & Comments \\
\hline $\mathrm{HUj} 2$ & PAT & A80 & $\begin{array}{l}2 \text { channels created for every HUj2 input } \\
\text { read: first is for data, second is for } \\
\text { time. } \\
\text { PAT - } 80 \text { character separation code: } \\
\text { 1) first character must be '(' } \\
\text { 2) 'S' or ' } K \text { ' must follow ' (' } \\
\text { 3) "repeat" number must follow } \\
\text { ' } S \text { ' or ' } K \text { ' } \\
\text { 4) ' } S \text { ', ' } K \text { ', or ')' must follow } \\
\text { "repeat" number } \\
\text { 5) scan number or 'E' must } \\
\text { follow ')' } \\
\text { 6) spaces are ignored except } \\
\text { they must not be in the } \\
\text { middle of numbers }\end{array}$ \\
\hline
\end{tabular}

Enter Another Command (Data Input H1) 
13.11 Part H, Class U, Subpart k: Input Specified by Utility Command SMOOTH
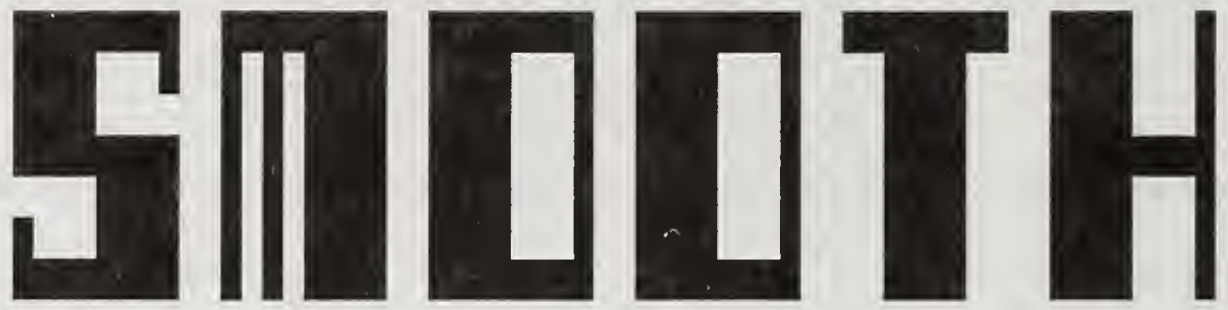

The subroutine will smooth "noisy" data by finding the least squares straight line fit for small sections, or "windows", of the curve. The window is an odd number of adjacent values from the channel being smoothed along with the corresponding values from the time channel. The smoothed value at the center of the window is calculated from the equation of the fit line and stored in a new channel created by the program. After the smoothed point is calculated and stored, the window slides up, dropping the "oldest" value and adding a new one. A new straight line is determined and the point calculated and stored. The process is repeated until the entire curve is smoothed.

Note that any odd number of points may be used, but a small number is preferable when the trend of the curve shows a rapid increase or decrease.

It is possible to re-smooth a curve simply by entering the created channel number of a previously smoothed curve as the channel to be smoothed (see NPDI [3]).

The equation of the line is of the form: $S(i)=A * x(i)+B$, where $S(i)$ is the calculated "ith" smooth point, $x(i)$ is the "ith" time value, and A and B are determined by: 


$$
\begin{aligned}
& A=\frac{n * \operatorname{SUM}[x(i) * y(i), i=a, b]-\operatorname{SUM}[x(i), i=a, b] * \operatorname{SUM}[y(i), i=a, b]}{n * \operatorname{SUM}[(x(i) * * 2), i=a, b]-(\operatorname{SUM}[x(i), i=a, b]) * * 2} \\
& B=\frac{\operatorname{SUM}[y(i), i=a, b]-A * \operatorname{SUM}[x(i), i=a, b]}{n}
\end{aligned}
$$

where $\mathrm{n}$ is the number of points in the window between point a and point $b, \mathrm{x}(\mathrm{i})$ is the "ith" time reading, $y(i)$ is the "ith" value from the curve being smoothed, and SUM is the summation function.

Note that the values being smoothed have already been transformed using the conversion coefficients input on data input B5 for the original channel. The conversion coefficients for the created channels are the default values of $\mathrm{C}=$ $1.0, \mathrm{ADD}=0.0$, and $\mathrm{POWER}=1.0$ 


\begin{tabular}{|c|c|c|c|}
\hline Input & Variables & Format & Comments \\
\hline HUk1 & NCHAN & $\begin{array}{c}\text { open } \\
\text { (NPDI } \\
[1])\end{array}$ & $\begin{array}{l}\text { Only one of these inputs is read each } \\
\text { time the command SMOOTH is given. } \\
\text { NCHAN - number of channels to be } \\
\text { smoothed. Prepare NCHAN HUk2 } \\
\text { inputs. NCHAN channels will } \\
\text { be created. }\end{array}$ \\
\hline Input & Variables & Format & Comments \\
\hline HUk2 & $\begin{array}{l}\text { JCHAN , JTIME [, NPTS ] } \\
X\end{array}$ & $\begin{array}{c}\text { EVALU8 } \\
\text { (NPDI } \\
[2])\end{array}$ & $\begin{aligned} & \text { JCHAN - channel number of data to be } \text { smoothed (NPDI [3]) } \\
& \text { JTIME - time channel number } \\
& \text { NPTS - number of values in "window" } \\
& \text { (default value is } 3 \text { ) } \\
& \mathrm{X}=' \mathrm{X}^{\prime} \text { - end-of-set mark }\end{aligned}$ \\
\hline
\end{tabular}

Enter Another Command (Data Input H1) 
13.12 Part H, Class U, Subpart 1: Input Specified by Utility Command SPECIFY
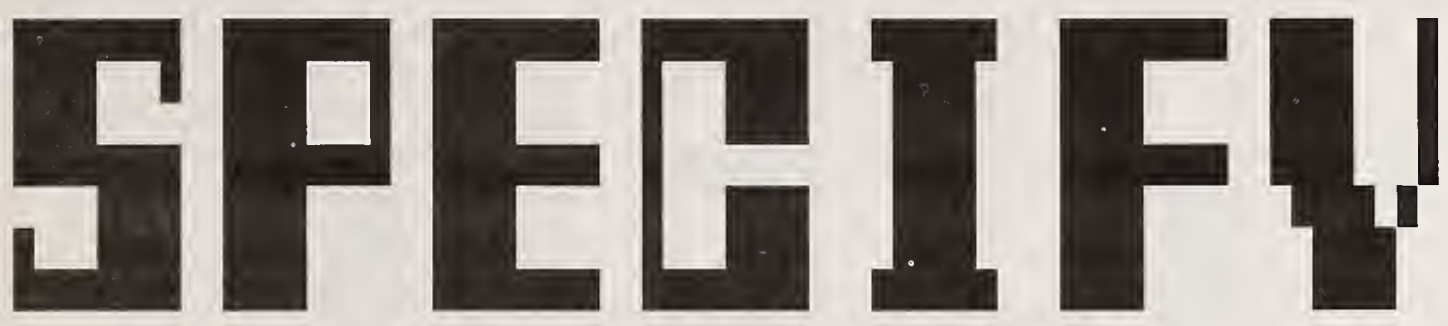

The subroutine allows the user to specify the channel number that the next "n" created channels will be given (see NPDI [3]). Up to 100 channel numbers can be specified at a time. A channel number can be specified more than once with no message given. If a specified channel has already been used, the values in that channel are over-written. If all the channels from a previous SPECIFY command have not been used when a new SPECIFY command is given, the left-over channels from the previous command are NOT used. It is possible for more than one created channel reference $(\$ x x x)$ to point to the same channel and a single channel may, at different points in the execution, contain more than one set of reduced data. It is therefore very important that care be exercised when using this command.

NOTE - THIS CAN BE A VERY DANGEROUS COMMAND. 


\begin{tabular}{c|l|c|c}
\hline Input & Variables & Format & Comments \\
\hline HU11 & $\begin{array}{l}\text { JSPEC(1) X } \\
1<=1<=100\end{array}$ & $\begin{array}{c}\text { EVALU8 } \\
\text { (NPDI } \\
[2])\end{array}$ & $\begin{array}{r}\text { JSPEC - a channel number to be used } \\
\text { when a channel is created, in } \\
\text { order of usage (NPDI [3]). }\end{array}$ \\
\hline
\end{tabular}

Enter Another Command (Data Input H1) 
13.13 Part H, Class U, Subpart $\mathrm{m}$ : Input Specifled by Utility Command STATS
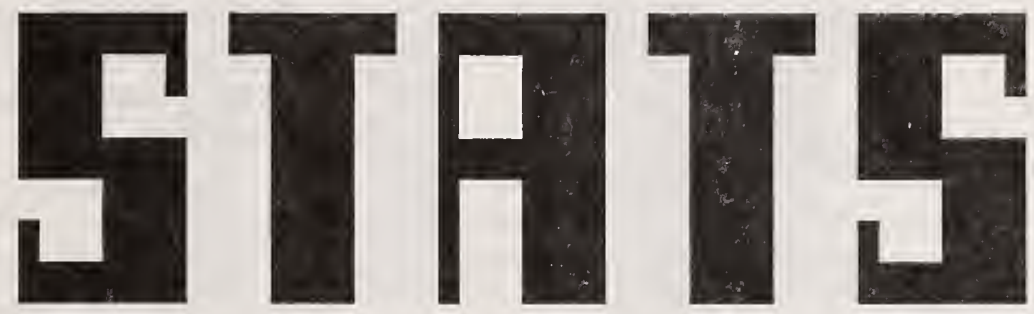

The subroutine calculates various statistics with respect to the values from any particular channe1. It finds the minimum and maximum values and the times at which those values first occur. It calculates the average value for the test. It compares the values from the channel to a constant or the values from some other channel and determines:

1. the first time at which the value of the channel is less than the comparison value and greater than the comparison value, and

2. the total time less than the comparison value, and greater than the comparison value.

In addition, the time range over which the statistics are determined can be specified.

This subroutine does not reduce any raw data and does not create any new channels . 


\begin{tabular}{|c|c|c|c|}
\hline Input & Variables & Format & Comments \\
\hline HUm1 & NSTATS & $\begin{array}{l}\text { open } \\
(\text { NPDI } \\
[1])\end{array}$ & $\begin{array}{l}\text { NSTATS - the number of blocks of chan- } \\
\text { nels for which statistics are } \\
\text { to be determined. Prepare } \\
\text { NSTATS HUm2 inputs. }\end{array}$ \\
\hline Input & Variables & Format & Comments \\
\hline HUm2 & $\begin{array}{l}\text { JCHANL, J CHANH, CMPVAL } \\
\text { or JCOMP, JTIME } \\
{[\text {, TIMELO or ITIMEL }} \\
{[, \text { TIMEHI or ITIMEH]] }} \\
\mathrm{X}\end{array}$ & $\begin{array}{l}\text { EVALU8 } \\
\text { (NPDI } \\
[2])\end{array}$ & $\begin{array}{l}\text { JCHANL - the first channel number in } \\
\text { the block of channels } \\
\text { (NPDI [3]). } \\
\text { JCHANH - the last channel number in the } \\
\text { block of channels (NPDI [3]). } \\
\text { Note that JCHANL and JCHANH } \\
\text { should be determined by the } \\
\text { order of the instrument list } \\
\text { (data inputs B3). If there } \\
\text { is only one channel in the } \\
\text { block, JCHANH should be the } \\
\text { same as JCHANL which should } \\
\text { be the channel. } \\
\text { CMPVAL - a constant comparison value: } \\
\text { JCOMP - the channel number of the } \\
\text { values to be used for } \\
\text { comparison. } \\
\text { JTIME - the time channel number. } \\
\text { TIMELO - the time(s) at which to begin } \\
\text { determining the statistics, } \\
\text { default is time of first scan. } \\
\text { ITIMEL - scan number at which to begin } \\
\text { determining the statistics, } \\
\text { default is } 1 . \\
\text { TIMEHI - the time(s) at which to end } \\
\text { determination of statistics, } \\
\text { default is time of last scan. } \\
\text { ITIMEH - scan number at which to end } \\
\text { determination of statistics, } \\
\text { default is the last scan. } \\
\text { X = } \text { X' - end-of-set mark }\end{array}$ \\
\hline
\end{tabular}

Enter Another Command (Data Input H1) 
13.14 Part H, Class U, Subpart $\mathrm{n}$ : Input Specifled by Utility Command TIME
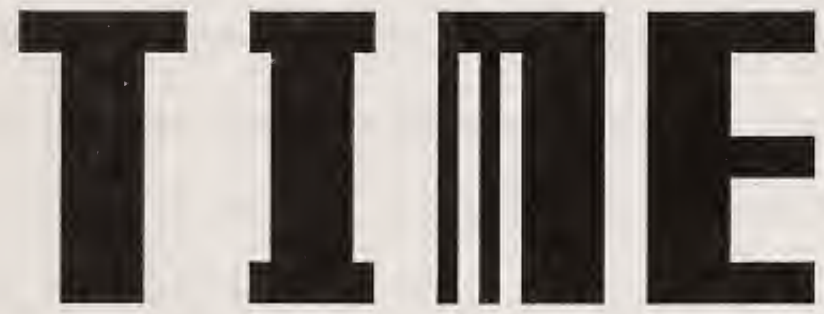

The subroutine can change the readings stored in a specified channel from hours/minutes/seconds format to elapsed seconds, and/or add a time shift. The results may be stored back in the original channel (destroying the old values) or they may be stored in a new channel (saving the old values in the original channe1).

$\mathrm{H} / \mathrm{M} / \mathrm{S}$ Conversion to $\mathrm{S}$

The hours / minutes / seconds to seconds conversion is not needed unless the program expects the time reading to be in seconds format but was recorded in hours / minutes / seconds format. If the program gets the format it expects, the time is automatically converted to seconds.

Time Shift

The time shift is used when "time-zero" occurs before or after the data acquisition system is started. If the event marking the beginning of the test occurs before the start of the data acquisition, the time shift will be a positive value; if it occurs after, the time shift will be a negative value. 
New Channel

The new channel is created automatically by the program at the option of the user. However, it is not always necessary to store the adjusted time in a new channel. If the old values in the original channel are not required, and the size of the data matrix is critical, it is recommended that a new channel not be used.

Note that, alternatively, if a new channel is not needed, the hours / minutes / seconds to seconds conversion and the time shift can be performed without using the TIME command by using appropriate coded part B (instrument identification and conversion coefficient) and part C (reading format) data inputs.

\begin{tabular}{|c|c|c|c|}
\hline Input & Variables & Format & Comments \\
\hline HUnl & $\begin{array}{l}\text { JTIMEO, ITIME, IHMS, } \\
\text { TSHIFT }\end{array}$ & $\begin{array}{l}\text { open } \\
\text { (NPDI } \\
[1])\end{array}$ & 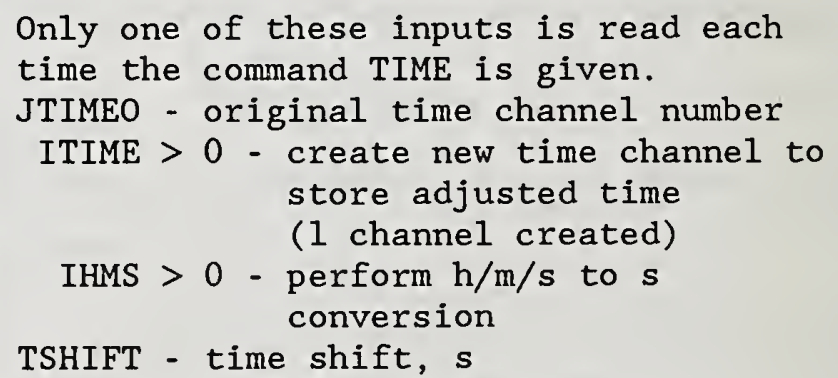 \\
\hline
\end{tabular}

Enter Another Command (Data Input H1) 
14. Data Input for Basic Commands 
14.1 Part H, Class B, Subpart a: Input Specifled by Basic Command GAS\&
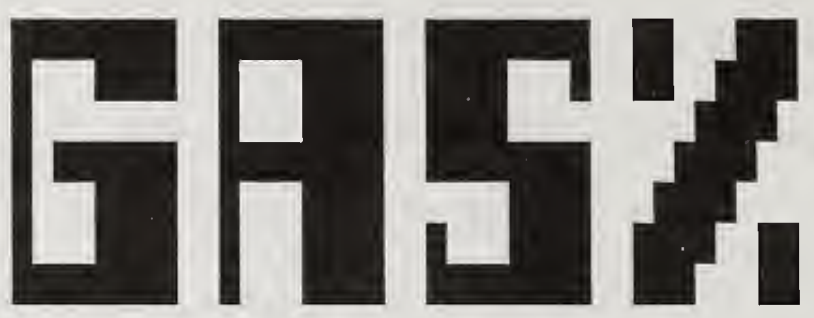

The subroutine calculates the volume percent concentrations of gas from the output of four different types of analyzers.

Types 1 and 2

For analyzer types 1 and 2, the concentration is calculated using a natural $\log$ fit of the calibration curve (actually the inverse of Beer's Law, which is an exponential). The calibration curve is the relationship of the concentration to the analyzer meter reading and not necessarily to the recorded analyzer output. The actual calculation is made by first changing the recorded output to an equivalent meter reading and then using that meter reading in the calibration curve equation to find the concentration:

$$
M=\frac{R-R(0)}{R(s)-R(0)} * M(s)
$$

where $M$ is the calculated meter reading corresponding to output $R, M(s)$ is the known meter reading for known output $R(s)$, and $R(0)$ is the output for zero percent concentration of gas. Then, 


$$
\mathrm{C}=-\mathrm{a} * \ln (1.0-(\mathrm{M} / \mathrm{b}))
$$

where $\mathrm{C}$ is the calculated concentration, $\mathrm{M}$ is the meter reading calculated above, and $a$ and $b$ are the curve fit coefficients.

Type 2 analyzers differ from type 1 analyzers only in that they may use two ranges during a test and, thus, two calibration curves. The range change may be indicated automatically by a voltage change in a dummy channel or it may be indicated by entering the scan number or time of the switch. There are advantages and disadvantages to each type of indicator. The automatic indicator allows an unlimited number of switches between the two ranges but the output voltages must be less than and greater than one volt to indicate the change. If either the scan number or the time is used to indicate the switch, only one switch can be used. In addition, if the time is used, the time channel number must have an ITYPE equal to 1 (see PLOT2 data input B3).

Coefficients for calibration curves can be catalogued in the program. A BLOCK DATA subroutine for this purpose has already been prepared. An example can be found in Appendix $B$.

If the calibration curve you need is not already catalogued, find the coefficients for the curve and enter them with the appropriate data input (data input $\mathrm{HBa} 2.1$ or $\mathrm{HBa} 3.1$ ). 
Type 3

The change in output from type 3 analyzers is linearly proportional to the change in concentration of the gas. Once the slope of the line is found, any concentration may be calculated. To define the slope, two points must be known, typically the "zero" and one other point. The concentration, $C$, for any output $R$ then becomes :

$$
C=\frac{C(s) *(R-R(0))}{R(s)-R(0)}
$$

where $R(0)$ is the output for zero concentration and $R(s)$ is the output for known concentration $\mathrm{C}(\mathrm{s})$.

Type 4

The concentration recorded by type 4 analyzers is proportional to $10 * *(-R / k)$, where $R$ is the recorded output and $k$ is a constant determined by the analyzer characteristics.

To find $k$, two concentrations and their corresponding outputs must be known: 


$$
k=\frac{R(2)-R(1)}{\log (C(1) / C(2))}
$$

where $R(1)$ is the output corresponding to $C(1)$ and $R(2)$ is the output corresponding to $C(2)$. Note that neither $C(1)$ nor $C(2)$ may be zero.

Then the concentration, $C$, for any output $R$ is

$$
C=\frac{C(s)}{10 * *((R-R(s)) / k)}
$$

where $R(s)$ is the known output for $C(s)$ and $k$ is as calculated above. In this program $C(1)$ equals $C(s)$.

For all four types of analyzers, the calculated concentrations (volume percent) replace the raw data values in the data matrix; no new channels are created.

\begin{tabular}{c|c|c|c}
\hline Input & Variables & Format & \multicolumn{1}{c}{ Comments } \\
\hline HBal & NGAS & $\begin{array}{l}\text { open } \\
\text { (NPDI } \\
[1])\end{array}$ & $\begin{array}{c}\text { Only one of these inputs is read each } \\
\text { time the command GAS is given. } \\
\text { NGAS - number of gas analyzers. }\end{array}$ \\
& & & $\begin{array}{l}\text { Prepare NGAS set(s) of HBa2 } \\
\text { through HBa5 inputs }\end{array}$ \\
\hline
\end{tabular}




\begin{tabular}{|c|c|c|c|}
\hline Input & Variables & Format & Comments \\
\hline $\mathrm{HBa} 2.1$ & $\begin{array}{l}\text { JCHAN, ITYPE, IDNO, } \\
\text { ZERO, SPAN, SM } \\
\{, C A, C B\} X\end{array}$ & $\begin{array}{l}\text { EVALU8 } \\
\text { (NPDI } \\
[2])\end{array}$ & $\begin{aligned} \text { JCHAN - } & \text { analyzer channel number } \\
& \text { (NPDI [3]) } \\
\text { ITYPE - } & \text { analyzer type code. Use this } \\
& \text { input format only if ITYPE }=1 \text { - } \\
& \text { single range calibration curve } \\
\text { IDNO - } & \text { curve number of analyzer and } \\
& \text { range to be used } \\
= & 0, \text { if analyzer is not in } \\
& \text { catalog (read input HBa2.2) } \\
\text { ZERO - } & \text { output for zero concentration } \\
& \text { of gas } \\
\text { SPAN - } & \text { output for a known } \\
& \text { concentration of gas } \\
\text { SM - } & \text { meter. reading for span } \\
& \text { concentration } \\
\text { CA,CB - } & \text { calibration curve coefficients. } \\
& \text { Enter these values only if } \\
& \text { IDNO=0. } \\
X= & \text { ' } X^{\prime} \text { - end-of-set mark }\end{aligned}$ \\
\hline $\mathrm{HBa} 2.2$ & SERNO, GAS, RANGE & $\begin{array}{l}\mathrm{A} 8, \mathrm{~A} 8 \\
\mathrm{~A} 5\end{array}$ & $\begin{array}{l}\text { Read this input only if IDNO }=0 \text { (see } \\
\text { input HBa2.1). } \\
\text { SERNO - analyzer serial number } \\
\text { GAS - type of gas analyzed } \\
\text { RANGE - maximum concentration of } \\
\text { gas for analyzer (volume } 8 \text { ) }\end{array}$ \\
\hline Input & Variables & Format & Comments \\
\hline $\mathrm{HBa} 3.1$ & $\begin{array}{l}\text { JCHAN, ITYPE, IDNO1, } \\
\text { IDNO2, LHTYPE, LOHI, } \\
\text { ZERO, SPAN1, SM1 } \\
\text { \{,CA1, CB1\}, SPAN2, } \\
\text { SM2 }\{, \text { CA2, CB2\} X }\end{array}$ & $\begin{array}{l}\text { EVALU8 } \\
\text { (NPDI } \\
[2])\end{array}$ & 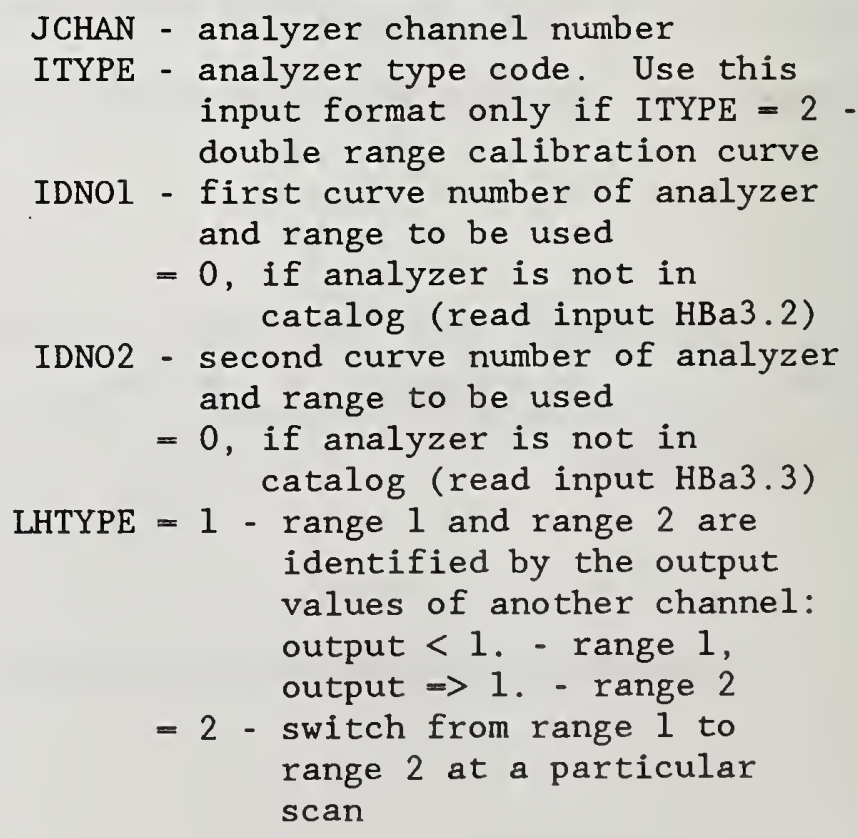 \\
\hline
\end{tabular}




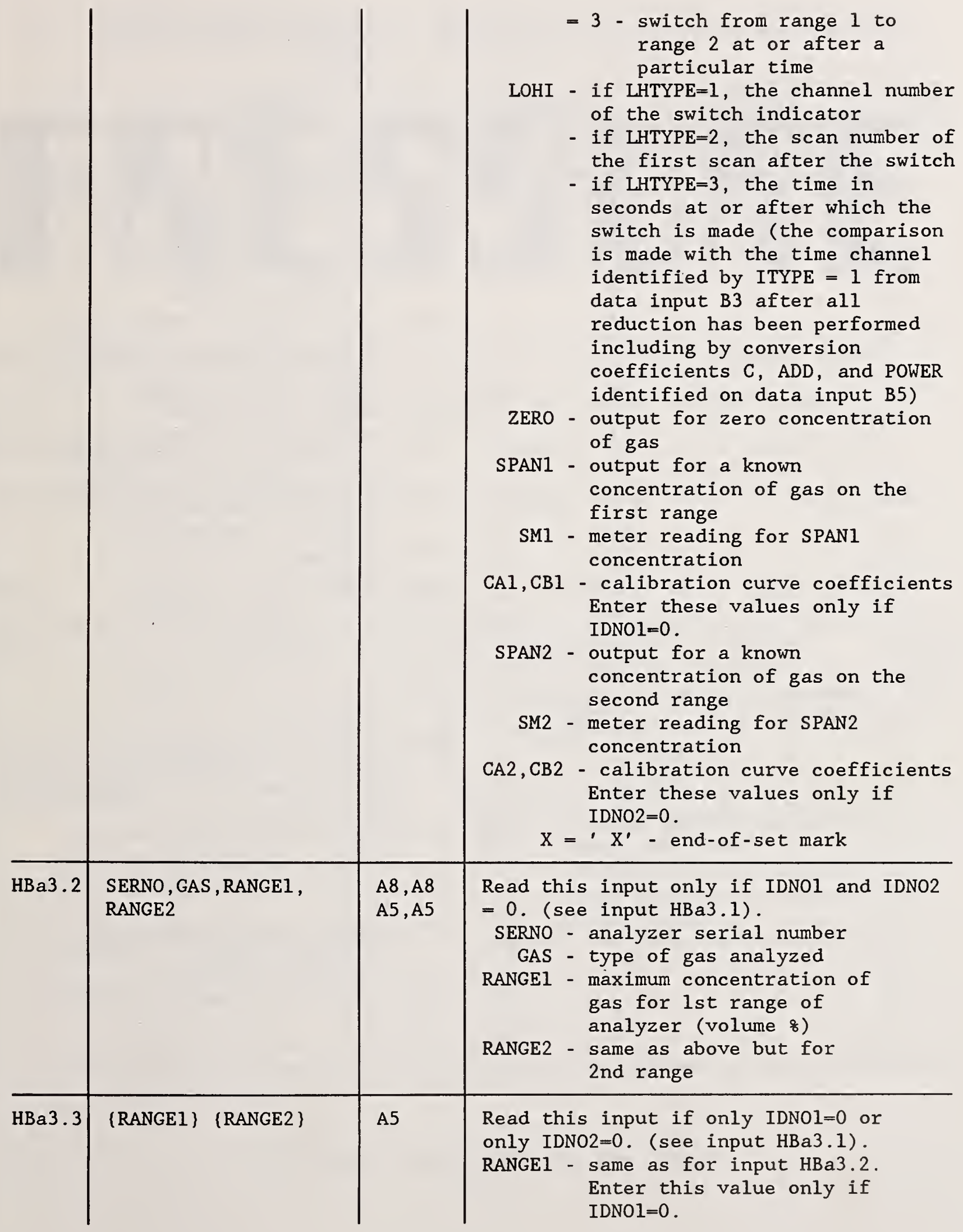




\begin{tabular}{|c|c|c|c|c|}
\hline & & & RANGE2 - & $\begin{array}{l}\text { same as for input } \mathrm{HBa} 3.2 \text {. } \\
\text { Enter this value only if } \\
\text { IDNO2 }=0\end{array}$ \\
\hline Input & Variables & Format & & Comments \\
\hline $\mathrm{HBa} 4$ & $\begin{array}{l}\text { JCHAN, ITYPE [, ZERO] } \\
{[\text {, SPAN], CON } x}\end{array}$ & $\begin{array}{l}\text { EVALU8 } \\
\text { (NPDI } \\
[2])\end{array}$ & $\begin{array}{l}\text { JCHAN } \\
\text { ITYPE } \\
\text { ZERO } \\
\text { SPAN } \\
\text { CON . } \\
\mathrm{X}=\end{array}$ & $\begin{array}{l}\text { - analyzer channel number } \\
\text { (NPDI [3]). } \\
\text { - analyzer type code. Use this } \\
\text { input format only if ITYPE }=3 \\
\text { change in gas concentration } \\
\text { linearly proportional to change } \\
\text { in analyzer output } \\
\text { - output for zero concentration } \\
\text { of gas. Note: if only three } \\
\text { arguments are entered with this } \\
\text { input, ZERo is assumed = 0.0. } \\
\text { - output for a known } \\
\text { concentration of gas. Note: if } \\
\text { only three or four arguments } \\
\text { are entered with this input, } \\
\text { SPAN is set equal to the first } \\
\text { reading of the analyzer. } \\
\text { - span gas concentration } \\
\text { (volume } 8 \text { ) } \\
\text { = X' - end-of-set mark }\end{array}$ \\
\hline Input & Variables & Format & & Comments \\
\hline $\mathrm{HBa} 5$ & $\begin{array}{l}\text { JCHAN, ITYPE, C1, R1, } \\
\text { C2, R2 X }\end{array}$ & $\begin{array}{l}\text { EVALU8 } \\
\text { (NPDI } \\
{[2] \text { ) }}\end{array}$ & $\begin{array}{r}\text { JCHAN } \\
\text { ITYPE } \\
\mathrm{C} 1 \\
\mathrm{R} 1 \\
\mathrm{C} 2 \\
\mathrm{R} 2 \\
\mathrm{X}\end{array}$ & $\begin{array}{l}\text { - analyzer channel number } \\
\text { (NPDI [3]). } \\
\text { - analyzer type code. Use this } \\
\text { input format only if ITYPE }=4 \\
\text { gas concentration proportional } \\
\text { to } 10 * *(-R / k) \\
\text { - known concentration of gas, } \\
\text { volume \& (not equal to zero) } \\
\text { - output for known concentration } \\
\text { C1 } \\
\text { - known concentration of gas } \\
\text { different than C1, volume } 8 \\
\text { (not equal to zero) } \\
\text { - output for known concentration } \\
\text { C2 } \\
\text { - } X^{\prime} \text { - end-of-set mark }\end{array}$ \\
\hline
\end{tabular}

Enter Another Command (Data Input H1) 
14.2 Part H, Class B, Subpart b: Input Specifled by Basic Command PRESSURE
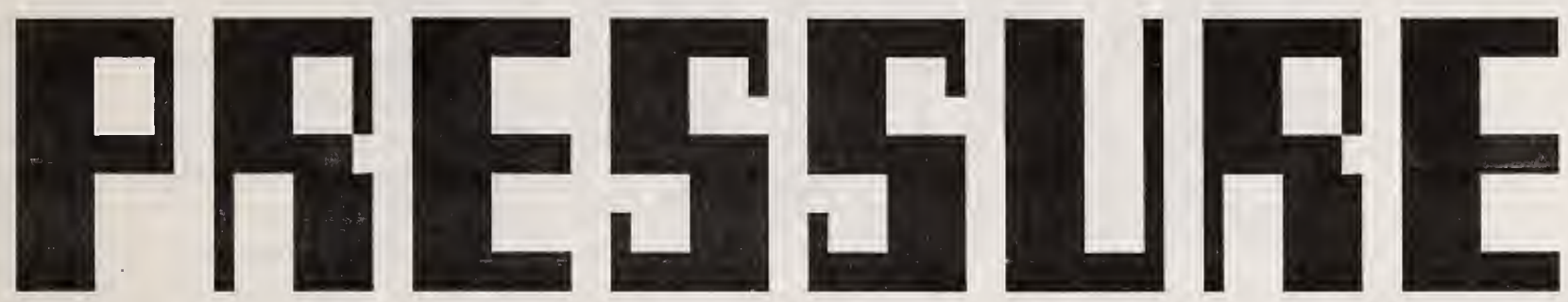

The subroutine calculates static pressure from the output of pressure transducers. A static pressure probe is two sided and senses the difference in pressure between one side and the other. A typical use for the probe is to measure the pressure difference between the inside and outside of a test chamber.

For all the static pressure calculations, the calculated values replace the raw data values in the data matrix; no new channels are created.

\begin{tabular}{|c|c|c|c|}
\hline Input & Variables & Format & Comments \\
\hline $\mathrm{HBbl}$ & NSTAT & $\begin{array}{l}\text { open } \\
\text { (NPDI } \\
[1])\end{array}$ & $\begin{array}{l}\text { Only one of these inputs is read each } \\
\text { time the command PRESSURE is given. } \\
\text { NSTAT - number of channels to be } \\
\text { converted from raw data to } \\
\text { static pressure. Prepare NSTAT } \\
\text { HBb2 input(s) }\end{array}$ \\
\hline
\end{tabular}




\begin{tabular}{|c|c|c|c|}
\hline Input & Variables & Format & Comments \\
\hline $\mathrm{HBb} 2$ & JCHAN , ZERO, CON X & $\begin{array}{c}\text { EVALU8 } \\
\text { (NPDI } \\
[2])\end{array}$ & $\begin{aligned} & \text { JCHAN - } \text { pressure probe channel number } \\
& \text { (NPDI [3]). } \\
& \text { ZERO - output for zero pressure } \text { difference (ambient) } \\
& \text { CON - conversion factor from output } \\
& \text { to static pressure (pascals per } \\
& \text { unit output) } \\
& \mathrm{X}=' \mathrm{X}^{\prime} \text { - end-of-set mark. }\end{aligned}$ \\
\hline
\end{tabular}

Enter Another Command (Data Input H1) 


\subsection{Part H, Class B, Subpart c: Input Specified by Basic Command SMOKE}
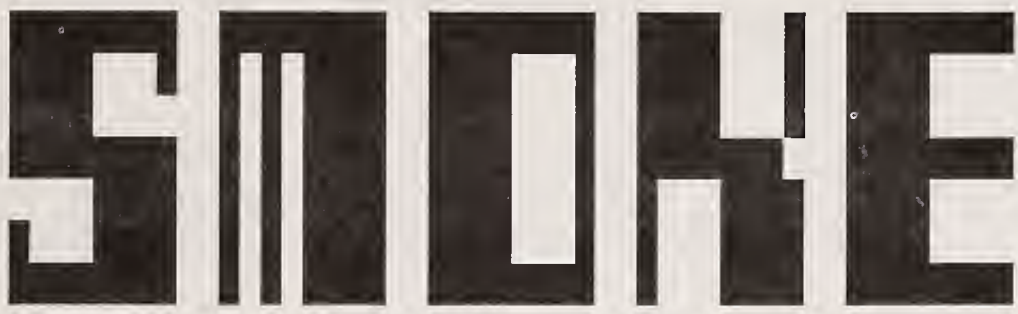

The subroutine calculates the optical density per unit length from the recorded output of a smoke meter. There are three types of relationships between the optical density and the output.

Type 1 - optical density proportional to the $\log$ of the inverse of the fraction of full transmission, output decreasing for transmission decreasing.

Type 2 - $\quad$ same as type 1 but output increasing for transmission decreasing.

Type 3 - optical density linearly proportional to the zero-adjusted output voltage

Type 4 - extinction coefficient linearly proportional to the zero-adjusted output voltage 
For types 1 and 2,

$$
\text { O.D. }=\log (1 / P)
$$

where O.D. is the optical density and $P$ is the fraction of full transmission

$$
P=\frac{R-R(0)}{R(1)-R(0)}
$$

where $R$ is any recorded output, $R(1)$ is the output at full transmission, and $R(0)$ is the output at zero transmission.

Note that the equation for optical density will not allow $P$ equal to zero and, thus, $R$ may not equal $R(0)$. Since, in practice, the meter cannot sense less than one hundredth of one percent of full transmission, that value is assumed equal to zero and for any value less than that the optical density defaults to 5.0 .

For types 3 and 4 ,

$$
S=(R-R(1)) * C
$$

where $S$ is either the optical density (type 3 ) or the extinction coefficient (type 4) and $\mathrm{C}$ is the calibration factor for the smoke meter, 


$$
C=\frac{\text { change in } s}{\text { change in voltage output }}
$$

For all the optical density calculations, the calculated values replace the raw data values in the data matrix; no new channels are created.

\begin{tabular}{c|c|c|c}
\hline Input & Variables & Format & \multicolumn{1}{c}{ Comments } \\
\hline HBCl & NMETER & $\begin{array}{c}\text { open } \\
\text { (NPDI } \\
[1])\end{array}$ & $\begin{array}{l}\text { Only one of these inputs is read each } \\
\text { time the command SMOKE is given. } \\
\text { NMETER - number of smoke meters. } \\
\text { Prepare NMETER HBc2 input }(s)\end{array}$ \\
\hline
\end{tabular}




\begin{tabular}{|c|c|c|c|}
\hline Input & Variables & Format & Comments \\
\hline $\mathrm{HBc} 2$ & $\begin{array}{l}\text { JCHAN, JTYPE }[(, \text { PATH }\} \\
{[, \text { ICONV }[, \text { R } 100} \\
[\{, \mathrm{RO}\}]]]]\{[, \mathrm{CAL}]\} \\
\mathrm{X}\end{array}$ & $\begin{array}{l}\text { EVALU8 } \\
\text { (NPDI } \\
[2])\end{array}$ & 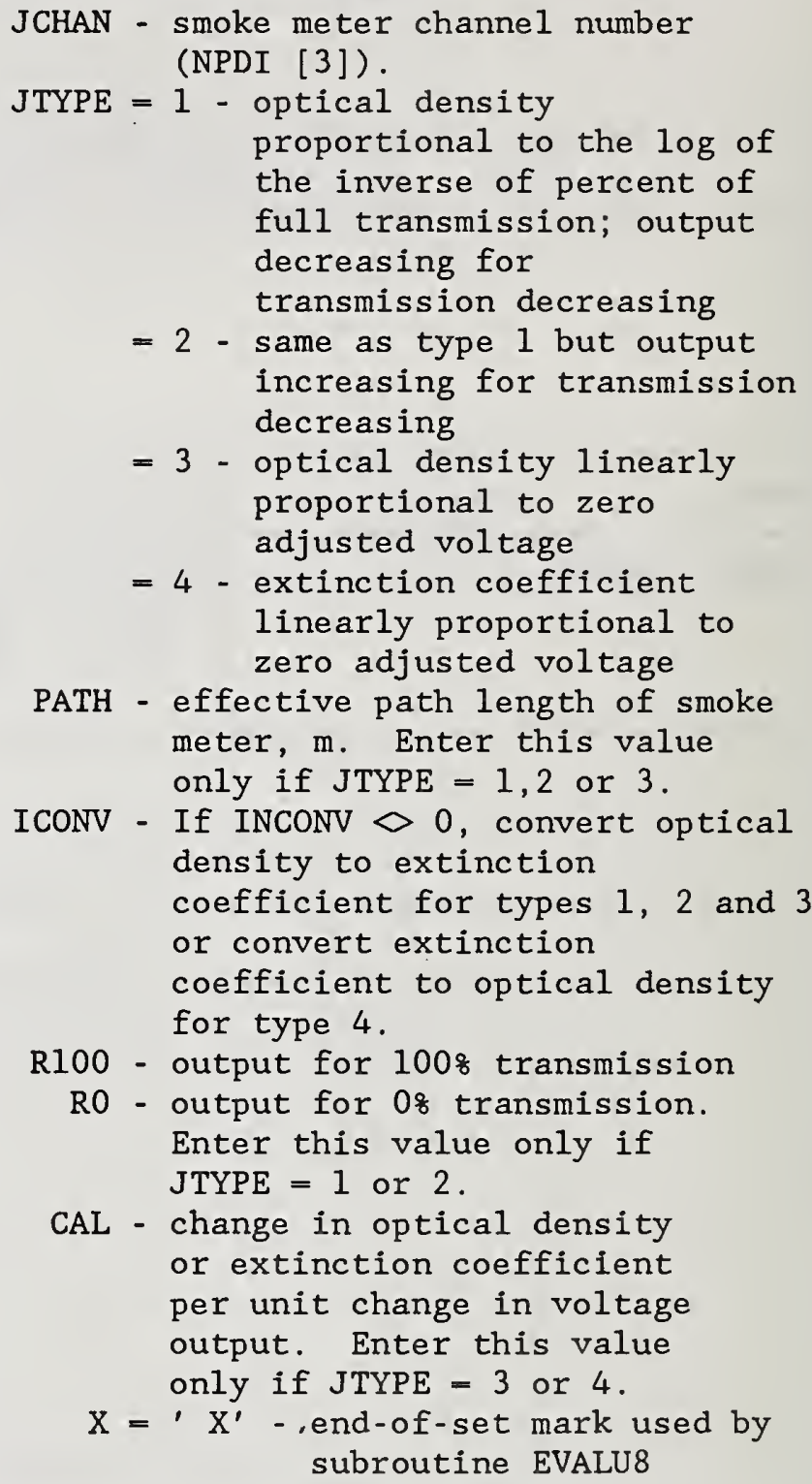 \\
\hline
\end{tabular}

Enter Another Command (Data Input H1) 
14.4 Part H, Class B, Subpart d: Input Specifled by Basic Command THERMOCOUPLE

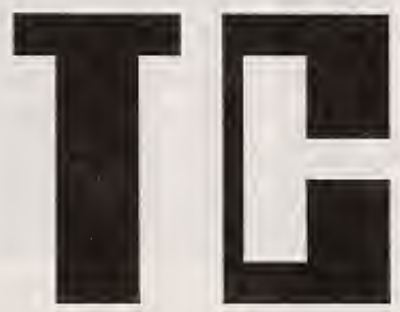

The subroutine calculates the temperature in degrees C (Celsius), F (Fahrenheit), $\mathrm{K}$ (Kelvin), or $\mathrm{R}$ (Rankine) from the thermocouple output voltage using an eightsegment curve fit for seven different types of thermocouples: E, S, J, T, K, B and $\mathrm{R}$.

The instruments to be converted are entered in blocks, identifying only the first and last instruments in the block. A block is a contiguous set of B3 data inputs. Note that the input for this command can be simplified by grouping all the thermocouple channels together in the instrument list (Data Input B3). 


\begin{tabular}{|c|c|c|c|}
\hline Input & Variables & Format & Comments \\
\hline HBdl & NTCGRP & $\begin{array}{r}\text { open } \\
\text { (NPDI } \\
[1])\end{array}$ & $\begin{array}{l}\text { NTCGRP - the number of thermocouple } \\
\text { blocks to be converted. } \\
\text { Prepare NTCGRP HBd2 inputs. }\end{array}$ \\
\hline Input & Variables & Format & Comments \\
\hline $\mathrm{HBd} 2$ & $\begin{array}{l}\text { JLOW, JHI } \\
{[\mathrm{JT}[, \text { ISCALE }]] \mathrm{X}}\end{array}$ & $\begin{array}{l}\text { EVALU8 } \\
\text { (NPDI } \\
[2])\end{array}$ & $\begin{array}{l}\text { JLOW - the first thermocouple } \\
\text { instrument number of the block. } \\
\text { (NPDI [3]). } \\
\text { JHI - the last thermocouple } \\
\text { instrument number of the block. } \\
\text { (NPDI [3]). } \\
\text { JT - the thermocouple type. } \\
\text { i.d. number: } \\
1 \text { - Type E } \\
2 \text { - Type S } \\
3 \text { - Type J } \\
4 \text { - Type T } \\
5 \text { - Type K } \\
6 \text { - Type B } \\
7 \text { - Type R } \\
\text { The default type for missing } \\
\text { or invalid input is } 5 \text { (Type } \mathrm{K} \text { ). } \\
\text { the output temperature units } \\
\text { i.d. number: } \\
1 \text { - }{ }^{\circ} \mathrm{C} \\
2 \text { - }{ }^{\circ} \mathrm{F} \\
3 \text { - }{ }^{\circ} \mathrm{K} \\
4 \text { - }{ }^{\circ} \mathrm{R}\end{array}$ \\
\hline
\end{tabular}

Enter Another Command (Data Input H1) 
14.5 Part H, Class B, Subpart e: Input Specified by Basic Command VELOCITY
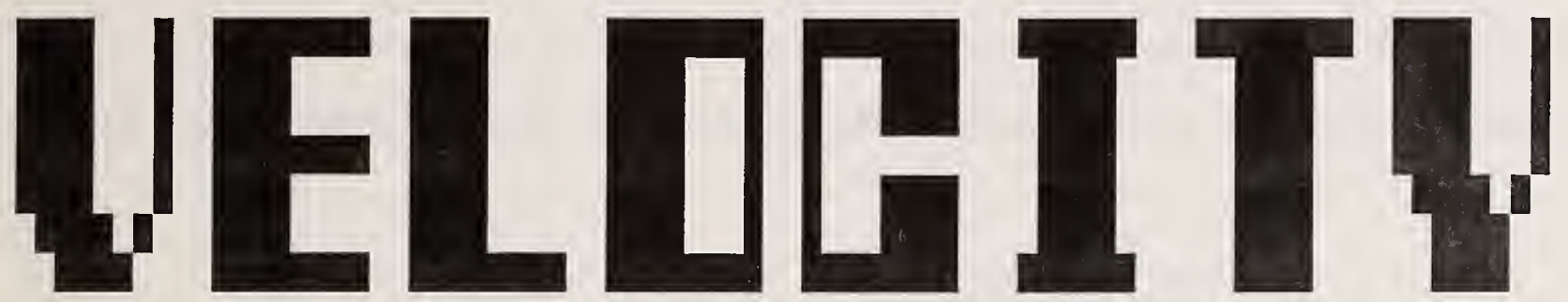

The subroutine calculates the gas velocity from the output of a velocity probe (pressure transducer). There are two kinds of probes: mono-directional (pitot tube) and bi-directional. Essentially, the probes sense the dynamic air pressure on them and the transducers convert it to a voltage output.

\section{Pressure Calculation}

The conversion factor for changing the voltage output to pressure (the sensitivity) must be known (e.g., $10 \mathrm{~V}=1 " \mathrm{H} 20=248.7 \mathrm{~Pa}$ ). The pressure, $\mathrm{P}$, is then

$$
P=(R-R(0)) * S
$$

where $R(0)$ is the output at ambient pressure, $R$ is the recorded output, and $S$ is the sensitivity ( $\mathrm{Pa} /$ output unit). 
Gas Density Calculation

In addition to the pressure, the gas density, $p$, is also necessary. The gas density is directly proportional to the absolute gas temperature: by the gas law

$$
p=\frac{p(0) * T(0)}{T}
$$

where $\mathrm{p}(0)$ and $\mathrm{T}(0)$ are known, related gas density $\left(\mathrm{kg} / \mathrm{m}^{3}\right)$ and temperature $(\mathrm{K})$ and $T$ is the input gas temperature $(K)$. Note that $p(0) * T(0)$ is constant and equal to $353 \mathrm{~kg} * \mathrm{~K} / \mathrm{m}^{3}$.

Input Temperature

The input temperature for the gas density calculation may be from one of three different sources:

1. A single temperature from one, or the average of several, thermocouples located near the velocity probe;

2. An arbitrary, constant temperature supplied by the user;

3. An interpolated temperature from the values of two thermocouples near the velocity probe. 
Velocity Calculation

For mono-directional probes (pitot tubes), the velocity, $v$, is calculated by

$$
\mathrm{v}=(2 . * \mathrm{P} / \mathrm{p}) * * * 0.5
$$

where $P$ is the pressure in pascals $(\mathrm{Pa})$ and $\mathrm{P}$ is the gas density $\left(\mathrm{kg} / \mathrm{m}^{3}\right)$.

$$
\begin{aligned}
& \mathrm{Pa}=\frac{\mathrm{N}}{\mathrm{m}^{2}}=\frac{\mathrm{kg} * \mathrm{~m}}{\mathrm{~s}^{2} * \mathrm{~m}^{2}} \\
& \mathrm{P}=\frac{\mathrm{p}(0) * \mathrm{~T}(0)\left(\mathrm{K} * \mathrm{~kg} / \mathrm{m}^{3}\right)}{\mathrm{T}(\mathrm{K})}=\frac{353}{\mathrm{~T}}\left(\mathrm{~kg} / \mathrm{m}^{3}\right)
\end{aligned}
$$

Substituting the proper units back into the velocity equation yields

$$
\mathrm{v}=0.0753 *(\mathrm{P} * \mathrm{~T}) * 0.5 \mathrm{~m} / \mathrm{s}
$$

The equation for bi-directional probes is similar

$$
\begin{aligned}
\mathrm{v} & =(1.717 * \mathrm{P} / \mathrm{p}) * 0.5 \\
& =0.0698 *(\mathrm{P} * \mathrm{~T}) * 0.5 \mathrm{~m} / \mathrm{s}
\end{aligned}
$$

Note that the bi-directional probes measure velocity in two directions. In this subroutine, which direction is positive and which is negative has no real meaning. However, in subroutine FLORAT the convention is that the positive direction is out of the test chamber and the negative direction is into the test 
chamber. Mono-directional probes should be consistent with any bi-directional probes and/or with each other.

This subroutine replaces the raw data in the data matrix with the calculated gas velocities; no new channels are created.

\begin{tabular}{|c|c|c|c|}
\hline Input & Variables & Format & Comments \\
\hline $\mathrm{HBe} 1$ & NPROBE & $\begin{array}{l}\text { open } \\
\text { (NPDI } \\
[1])\end{array}$ & $\begin{array}{l}\text { Only one of these inputs is read each } \\
\text { time the command VELOCITY is given. } \\
\text { NPROBE - number of velocity probes. } \\
\text { Prepare NPROBE HBe2 input(s) }\end{array}$ \\
\hline Input & Variables & Format & Comments \\
\hline $\mathrm{HBe} 2$ & 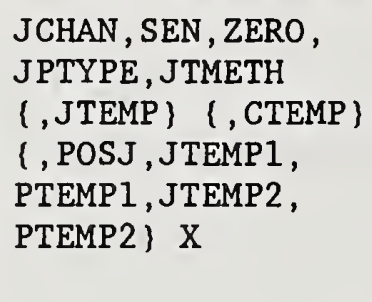 & $\begin{array}{l}\text { EVALU8 } \\
\text { (NPDI } \\
[2])\end{array}$ & $\begin{aligned} \text { JCHAN - velocity probe channel number } \\
\text { (NPDI [3]). } \\
\text { SEN - sensitivity (or calibration) } \\
\text { of transducer (pascals per } \\
\text { output unit) } \\
\text { ZERO - transducer output for no-flow } \\
\text { condition }\end{aligned}$ \\
\hline
\end{tabular}




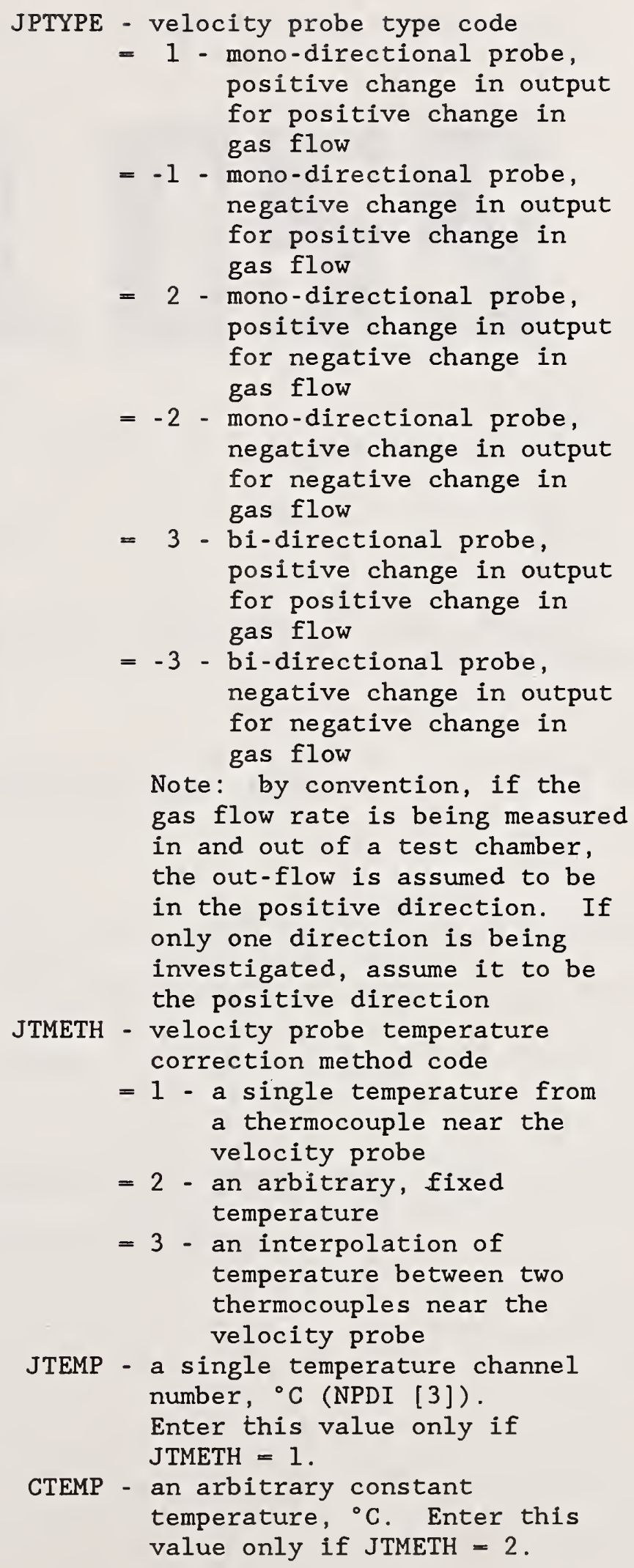




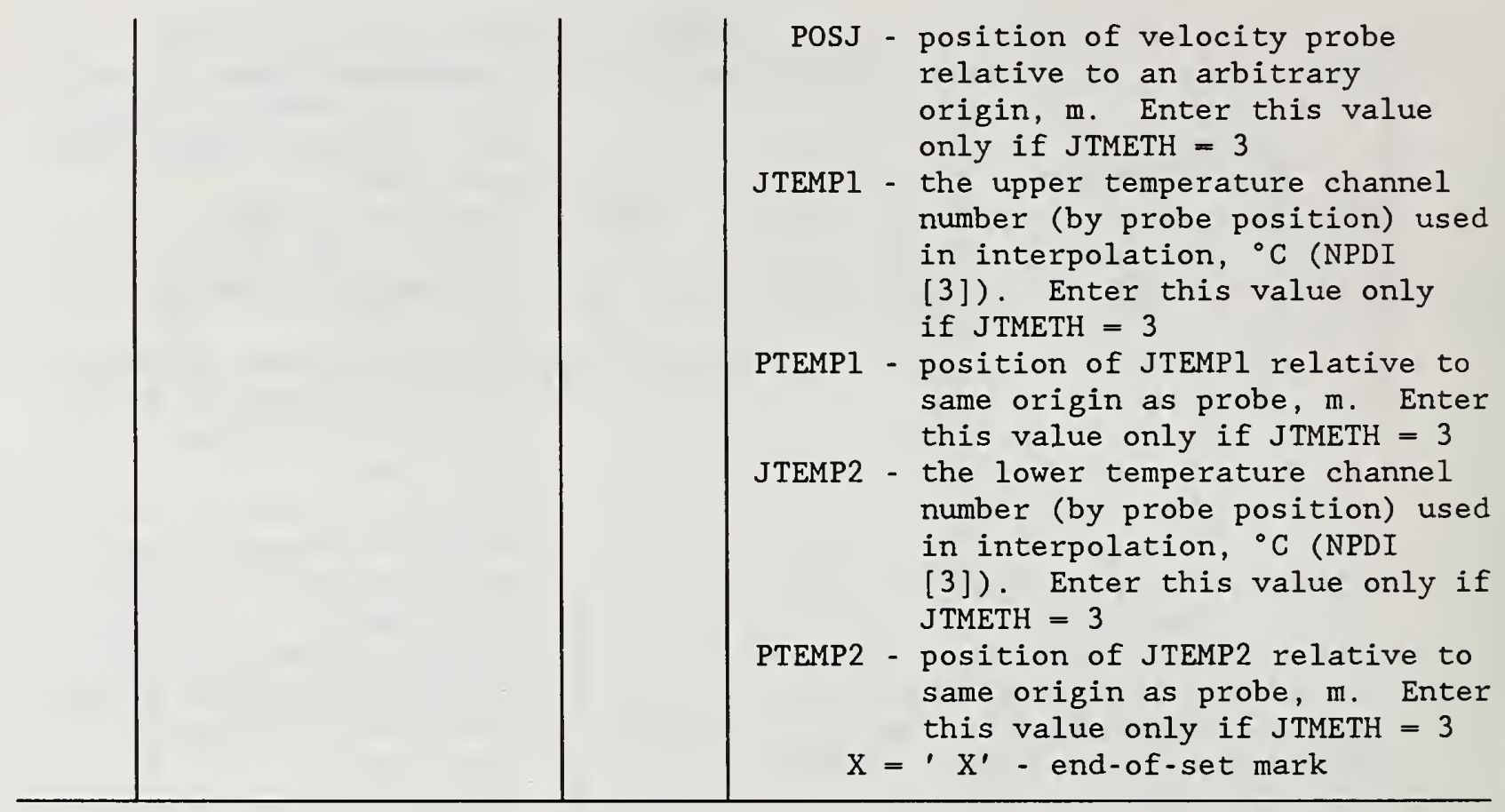

Enter Another Command (Data Input H1) 


\subsection{Part H, Class B, Subpart f: Input Specified by Basic Command WT-LOSS}
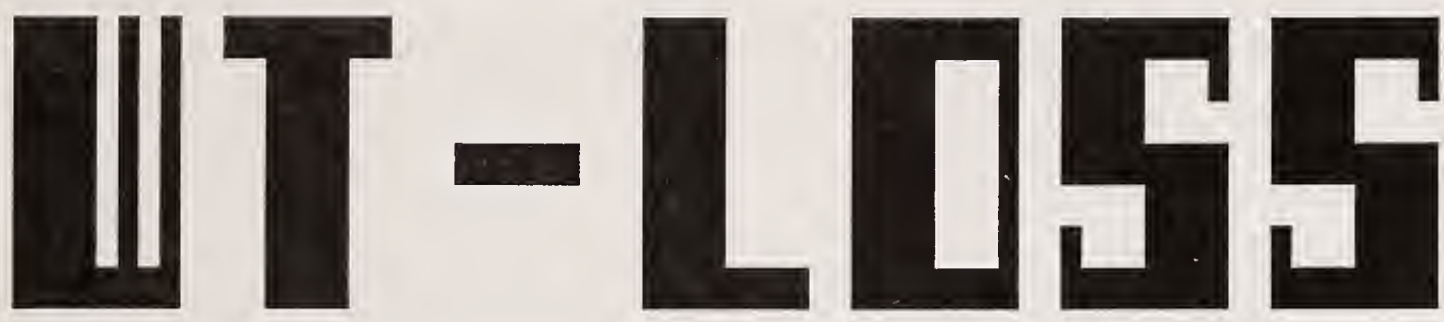

The subroutine calculates the total weight loss of an item that is being weighed by a load cel1.

The change in weight is linearly proportional to the change in output and the total weight loss is defired as

$$
T=C *(R(1)-R)
$$

where $\mathrm{T}$ is the total weight loss $(\mathrm{kg}), \mathrm{R}(1)$ is the output at the beginning of the test (i.e. the output corresponding to the initial weight), $R$ is any output, and $\mathrm{C}$ is the conversion factor from volts to $\mathrm{kg}$.

If the initial weight, W $(\mathrm{kg})$, of the weighed item and the output, $R(0)$, for zero weight are known, C can be calculated by the program as

$$
C=\frac{W}{R(1)-R(0)}
$$

otherwise $\mathrm{C}$ must be input. 
For all the total weight loss calculations, the calculated values replace the raw data values in the data matrix; no new channels are created.

\begin{tabular}{|c|c|c|c|}
\hline Input & Variables & Format & Comments \\
\hline $\mathrm{HBfl}$ & NCHAN & $\begin{array}{l}\text { open } \\
\text { (NPDI } \\
[1])\end{array}$ & $\begin{array}{l}\text { Only one of these inputs is read each } \\
\text { time the command WT-LOSS is given. } \\
\text { NCHAN - number of weight loss channels. } \\
\text { Prepare NCHAN HBf2 input(s) }\end{array}$ \\
\hline Input & Variables & Format & Comments \\
\hline HBf2 & $\begin{array}{l}\text { JCHAN }\{, \text { ZERO, WEIGHT }\} \\
\{, \text { CON }\} x\end{array}$ & $\begin{array}{l}\text { EVALU8 } \\
\text { (NPDI } \\
[2])\end{array}$ & $\begin{aligned} & \text { JCHAN - load cell channel number } \\
& \text { (NPDI [3] ). } \\
& \text { ZERO - } \\
& \text { output for zero weight. } \\
& \text { Enter this value only if it } \\
& \text { and the initial weight are } \\
& \text { known. } \\
& \text { WEIGHT - } \\
& \text { initial total weight of items } \\
& \text { this value only if it and the } \\
& \text { output for zero weight are } \\
& \text { known. } \\
& \text { CON - the output to weight conversion } \\
& \text { factor. Enter this value only } \\
& \text { if ZERO or WEIGHT is unknown. } \\
& X=\text { ' } X^{\prime} \text { - end-of-set mark }\end{aligned}$ \\
\hline
\end{tabular}

Enter Another Command (Data Input H1) 
15. DATA INPUT FOR COMPLEX COMMANDS 
15.1 Part H, Class C, Subpart a: Input Specified by Complex Command BALANCE
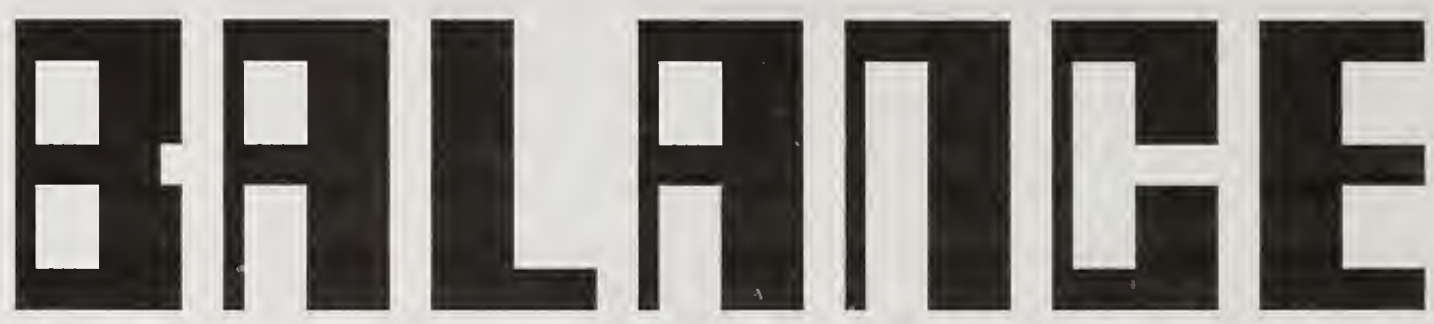

The subroutine solves an energy balance equation to find the rate of heat release

of the system:

$$
\mathrm{E}(\mathrm{i})+\mathrm{Q}^{\prime}-\mathrm{Q}(\mathrm{s})-\mathrm{Q}(0) \mathrm{E}(\mathrm{0})=0
$$

where

$\mathrm{E}(\mathrm{i})$ - the convective energy transfer rate into the system, $\mathrm{kW}$ (equals the product of the mass flow rate and enthalpy into system, calculated in subroutine FLORAT)

$\mathrm{E}(\mathrm{o})$ - the convective energy transfer rate out of the system, $\mathrm{kW}$ (equals the product of the mass flow rate and enthalpy out of system, calculated in subroutine FLORAT)

$\mathrm{Q}(\mathrm{s})$ - total heat loss rate to surfaces, $\mathrm{kW}$ (calculated in subroutine SURFAC)

$\mathrm{Q}(0)$ - total heat loss rate through an opening, $\mathrm{kW}$ (calculated in subroutine RHLOPN)

$\mathrm{Q}^{\prime}$ - rate of heat release of system, $\mathrm{kW}$

Rearranging and solving for the rate of heat release of the system we have:

$$
Q^{\prime}=Q(s)+Q(0)+M(0) * E(0)-M(i) * E(i)
$$


The calculated results are stored in a channel created by the program. The subroutine does not reduce any raw data.

\begin{tabular}{|c|c|c|c|}
\hline Input & Variables & Format & Comments \\
\hline $\mathrm{HCal}$ & $\begin{array}{l}\operatorname{JEIN}(1), \operatorname{JEOUT}(1), \\
\operatorname{JEIN}(2), \operatorname{JEOUT}(2) \\
\ldots, \operatorname{JEIN}(i) \\
\operatorname{JEOUT}(i) \mathrm{X} \\
1<=i<=5\end{array}$ & $\begin{array}{l}\text { EVALU8 } \\
\text { (NPDI } \\
[2])\end{array}$ & $\begin{array}{l}\text { Enter convective energy flow rate } \\
\text { in and flow rate out channel numbers } \\
\text { in pairs. } \\
\text { JEIN - convective energy flow rate } \\
\text { into chamber, kW (NPDI [3]) } \\
\text { JEOUT - convective energy flow rate } \\
\quad \text { out of chamber, kW (NPDI [3]) } \\
\qquad X=' \mathrm{X}^{\prime} \text { - end-of-set mark }\end{array}$ \\
\hline Input & Variables & Format & Comments \\
\hline $\mathrm{HCa} 2$ & $\begin{array}{l}\operatorname{JWALL}(1), \operatorname{JWALL}(2) \\
\ldots, \operatorname{JWALL}(\mathrm{i}) \mathrm{X} \\
1<=1<=10\end{array}$ & $\begin{array}{l}\text { EVALU8 } \\
\text { (NPDI } \\
[2])\end{array}$ & $\begin{aligned} \text { JWALL - } & \text { total radiative rate of heat } \\
& \text { loss to surfaces channel } \\
& \text { number, } \mathrm{kW} \text { (NPDI [3]) } \\
\mathrm{X}= & \mathrm{X}^{\prime}-\text { end-of-set mark }\end{aligned}$ \\
\hline Input & Variables & Format & Comments \\
\hline $\mathrm{HCa} 3$ & $\begin{array}{l}\operatorname{JOPEN}(1), \operatorname{JOPEN}(2) \\
\ldots, \operatorname{JOPEN}(i) \mathrm{X} \\
1<=i<=5\end{array}$ & $\begin{array}{l}\text { EVALU8 } \\
\text { (NPDI } \\
[2])\end{array}$ & $\begin{aligned} \text { JOPEN - total radiative rate of heat } \\
\text { loss through an opening channel } \\
\text { number, } \mathrm{kW} \text { (NPDI [3]) } \\
\mathrm{X}=' \mathrm{X}^{\prime}-\begin{array}{l}\text { end-of-set mark used by } \\
\text { subroutine EVALU8 }\end{array}\end{aligned}$ \\
\hline
\end{tabular}

Enter Another Command (Data Input H1) 
15.2 Part H, Class C, Subpart b: Input Specified by Complex Command FLOW-RATE
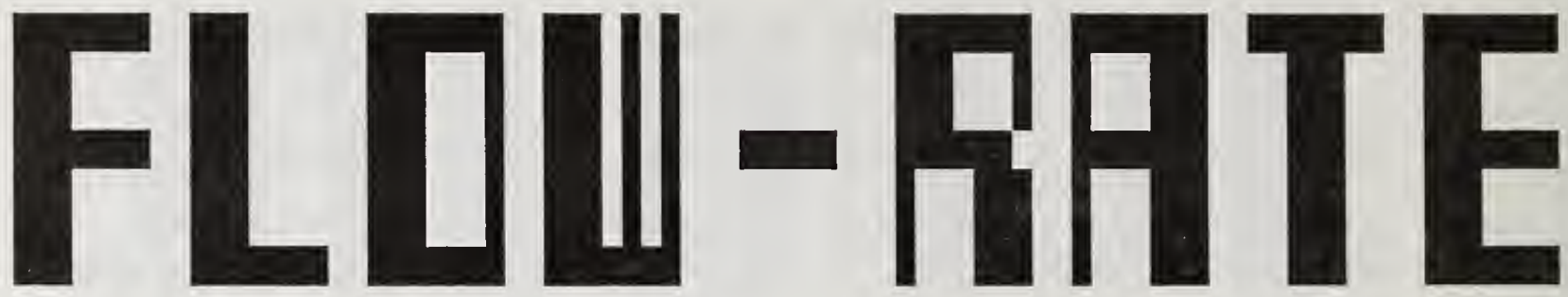

The subroutine makes four separate calculations based on the gas velocity (m/s) profile of an opening in the test chamber: 1) neutral plane height (m) of the opening; 2) volume flow rate $\left(\mathrm{m}^{3} / \mathrm{s}\right)$ in and out of the opening; 3) mass flow rate $(\mathrm{kg} / \mathrm{s})$ in and out of the opening; and 4) convective energy transfer rate (kW) in and out of the opening. The seven different calculated values are all stored in their own channels created by the program. This subroutine does not reduce any raw data.

Neutral Plane

The neutral plane height calculation requires a velocity profile of the opening being investigated. The velocities are checked from top to bottom for gas flow reversal. When reversal is found, the neutral plane height is calculated by interpolating the two velocities and the positions of the velocity probes to find the position of zero velocity (the neutral plane). 


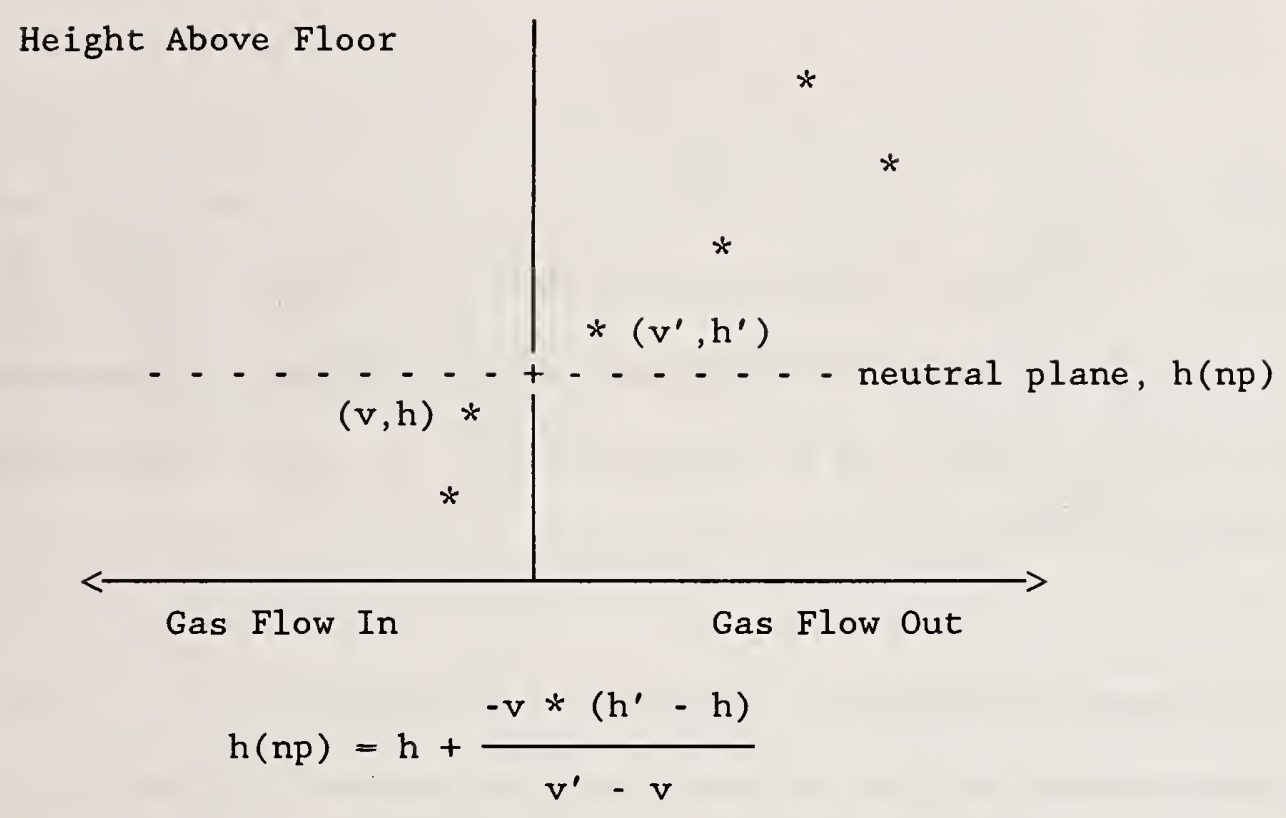

Volume, Mass, and Convective Energy Flow Rates

For all three kinds of calculated flow rates, the flow rate is proportional to the product of the velocity, $v(\mathrm{~m} / \mathrm{s})$, the opening height, $\mathrm{H}(\mathrm{m})$, and the opening width, W(m):

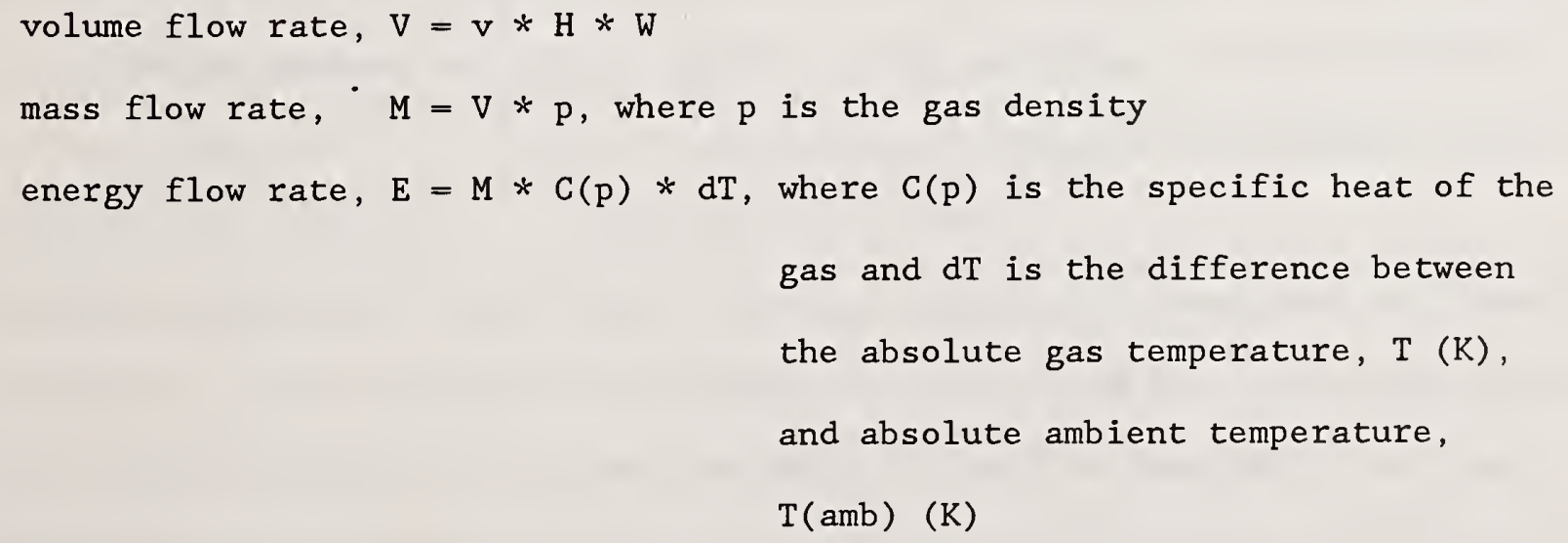


For air,

$$
C(p)=0.9126+2.577 * 10 * *(-4) * T-3.974 * 10 * *(-8) * T * * 2
$$

Both the mass and energy flow rate calculations require the gas temperature to make the calculations (to find $\mathrm{p}$ and $\mathrm{dT}$ respectively). The input temperature may be from three different sources:

1. an arbitrary constant temperature supplied by the user;

2. a single temperature from one, or the average of several, thermocouple(s) located near the velocity probe;

3. an interpolated temperature from the values of two thermocouples near the velocity probe.

When only one velocity in the opening is known, the calculations are made assuming the same gas velocity over the whole area. However, when a velocity profile is used, the opening height is divided into segments calculated by the program and determined by the velocity probe positions. The flow rates for each part are calculated using the opening width, W (m), the segment height, h(i) (m), and the segment gas velocity, $v(i)(\mathrm{m} / \mathrm{s})$.

There are some conventions built in to the default flow coefficient conditions of this subroutine. In particular, the default flow coefficient for the positive direction corresponds to flows of relatively hot gas at relatively high velocities while the default flow coefficient for the negative direction corresponds to 
flows of relatively cool gas at relatively low velocities. Thus the default conditions correspond to in = negative and out = positive.

The user is not restricted to these conventions; however, and may change them with the appropriate choices for the flow coefficients.

Note also that for comparison and plotting purposes, the absolute values of negative flow rates are returned. It is up to the user to decide the convention he wishes to use for in and out $(-,+$ or,+-$)$. Note, however, that the negative value is stored in the first channel created and the positive value in the second.

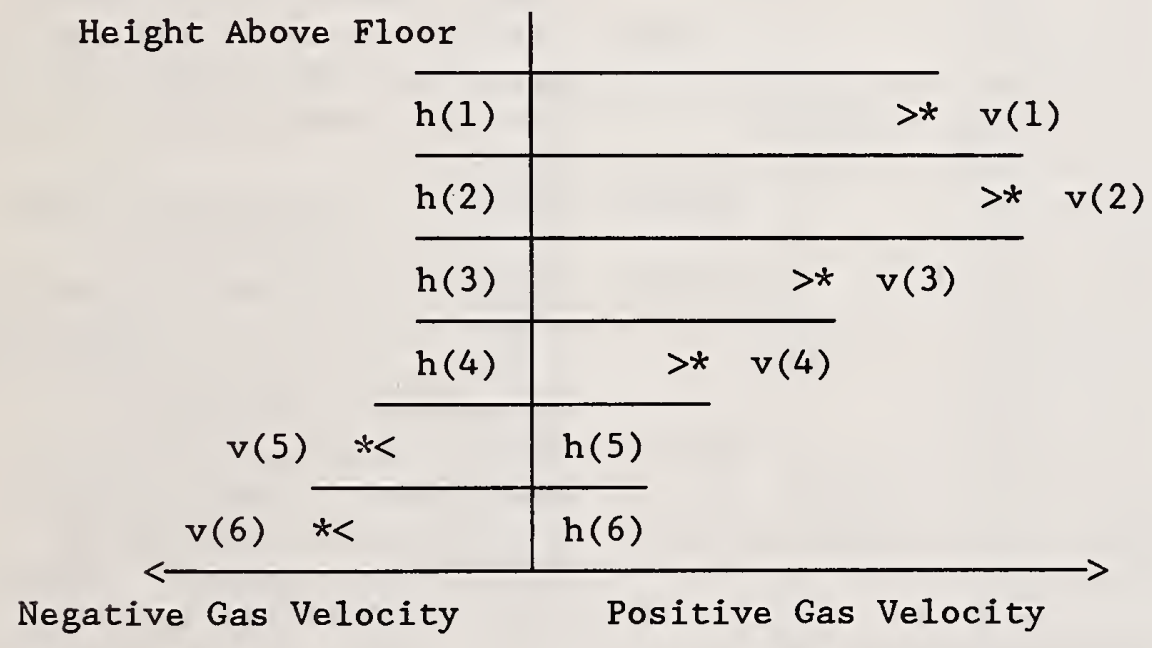




\begin{tabular}{|c|c|c|c|}
\hline Input & Variables & Format & Comments \\
\hline $\mathrm{HCb} 1$ & $\begin{array}{l}\text { NPROBE, INP, IVF, IMF, } \\
\text { IEF, HDOOR (, WDOOR) } \\
{[, \text { FCNEG [, FCPOS ] X X }}\end{array}$ & $\begin{array}{c}\text { EVALU8 } \\
\text { (NPDI } \\
[2])\end{array}$ & 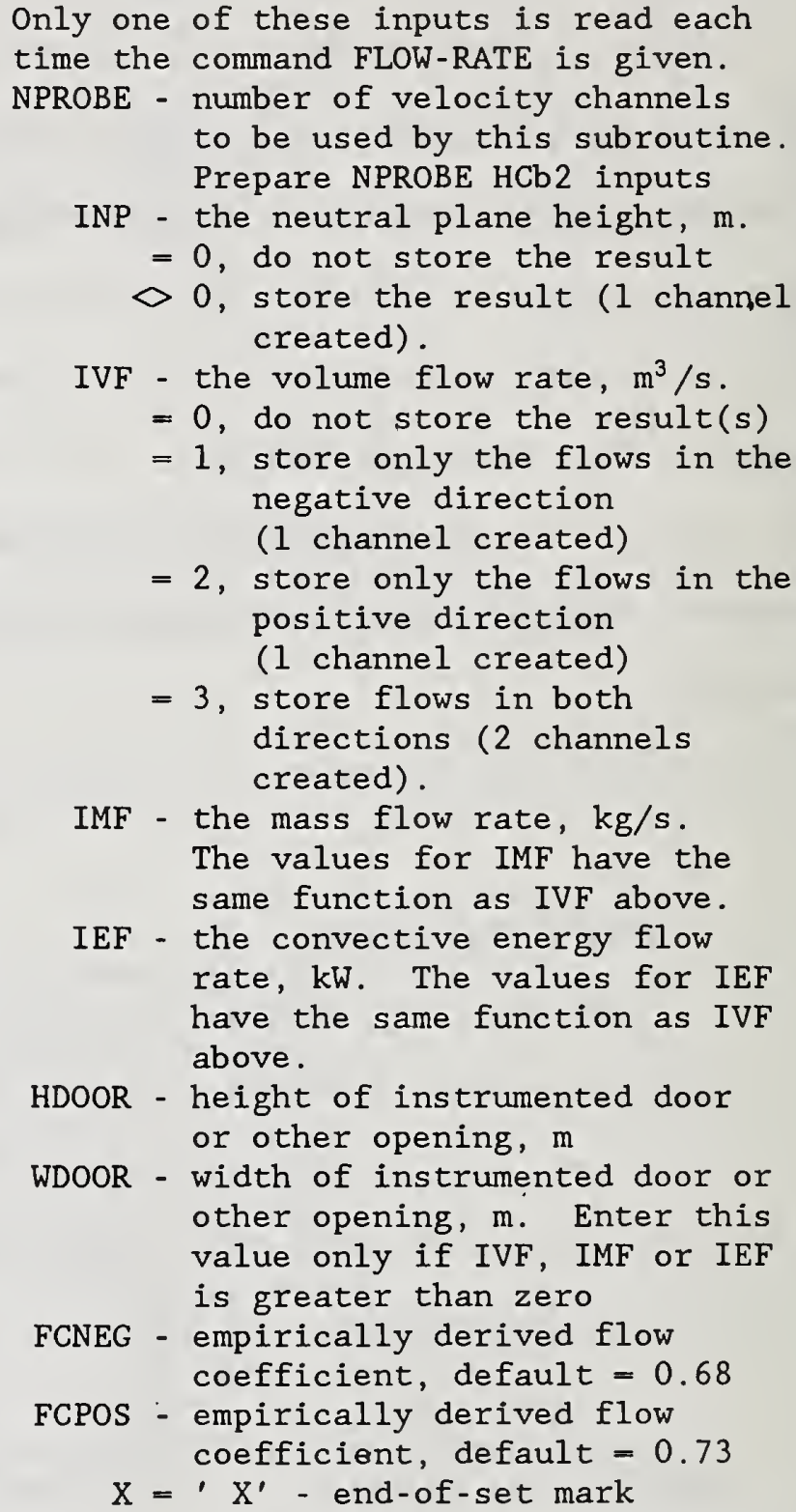 \\
\hline
\end{tabular}




\begin{tabular}{|c|c|c|c|}
\hline Input & Variables & Format & Comments \\
\hline $\mathrm{HCb} 2$ & $\begin{array}{l}\text { JVEL, POSJ \{, CTEMP }\} \\
\{, \text { JTEMP \} \{, JTEMP } 1, \\
\text { POSTC } 1, \text { JTEMP } 2, \\
\text { POSTC } 2\} \text { [, CTAMB or } \\
\text { ITAMB }] \mathrm{X}\end{array}$ & $\begin{array}{c}\text { EVALU8 } \\
\text { (NPDI } \\
[2])\end{array}$ & 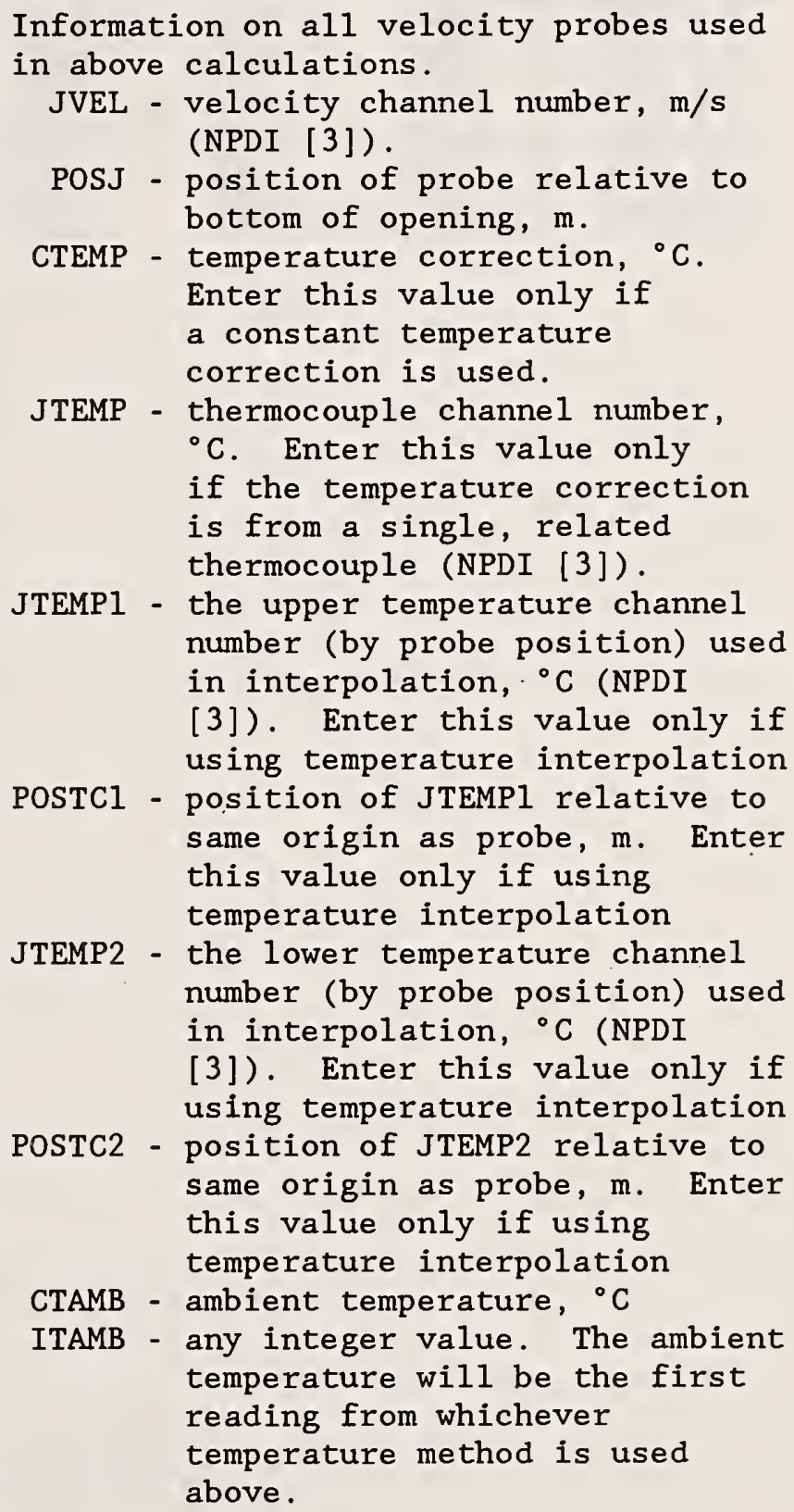 \\
\hline
\end{tabular}




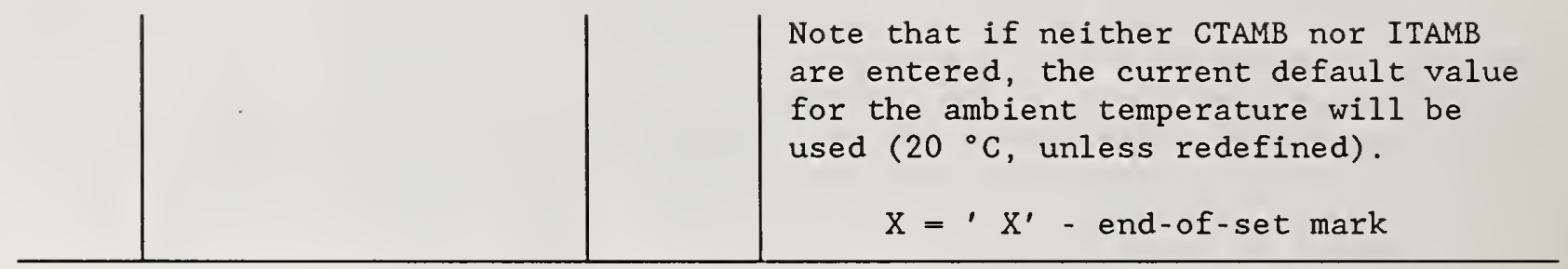

Enter Another Command (Data Input Hl) 

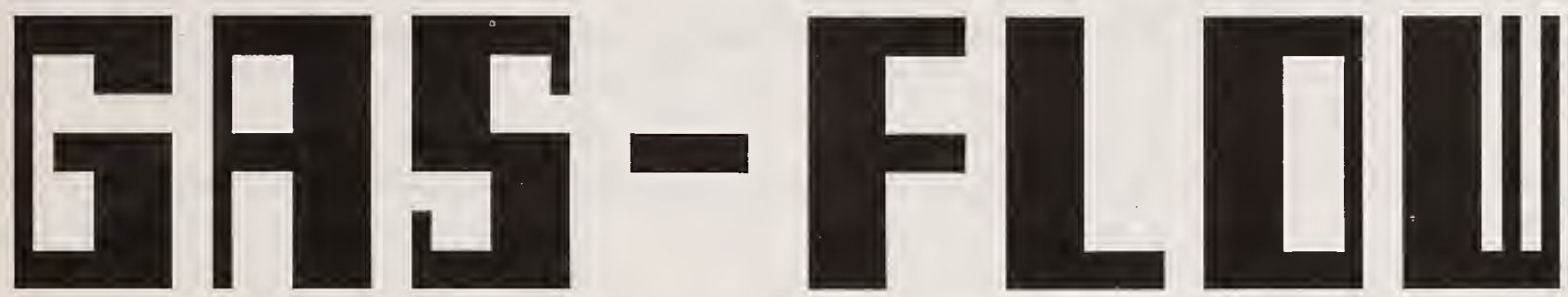

The subroutine calculates the mass flow rate of a gas of known concentration, molecular weight, and velocity through an opening of known area. There are two methods of calculating the mass flow rate: one is for openings where only one gas concentration value is available and the other is where there is more than one value (vertical profile). Both use the same equation to calculate the mass flow rate:

$$
M^{\prime}=\frac{x(g) * W(g) * v(g) * A * T(a m b) * p(a m b)}{W(a) * T(g)}
$$

where

$$
\mathrm{M}^{\prime} \text { - mass flow rate of gas, } \mathrm{kg} / \mathrm{s}
$$

$\mathrm{x}(\mathrm{g})$ - gas concentration expressed as a mole fraction

$\mathrm{v}(\mathrm{g})$ - gas velocity through opening, $\mathrm{m} / \mathrm{s}$

A - area of opening, $\mathrm{m}^{2}$

$\mathrm{T}(\mathrm{amb})$ - ambient temperature, $\mathrm{K}$

$\mathrm{p}(\mathrm{amb})$ - density of air at ambient temperature, $\mathrm{kg} / \mathrm{m}^{3}$

$\mathrm{W}(\mathrm{g})$, W(a) - molecular weight of gas and air

$\mathrm{T}(\mathrm{g})$ - gas temperature, $\mathrm{K}$

When more than one gas probe are used (method 2), the opening is divided into segments, the sizes of which are governed by the positions of the probes. The 
boundary between two probes is simply the halfway point. The total mass flow rate of the gas is the sum of the mass flow rates for the segments. Note that there is provision for the user to select segment sizes if desired.

The calculated values are stored in channels created by the program. This subroutine does not reduce any raw data.

\begin{tabular}{|c|c|c|c|}
\hline Input & Variables & Format & Comments \\
\hline $\mathrm{HCcl}$ & $\begin{array}{l}\text { ICALC, [CTAMB or } \\
\text { JTAMB] } \mathrm{X}\end{array}$ & $\begin{array}{c}\text { EVALU8 } \\
\text { (NPDI } \\
[2])\end{array}$ & 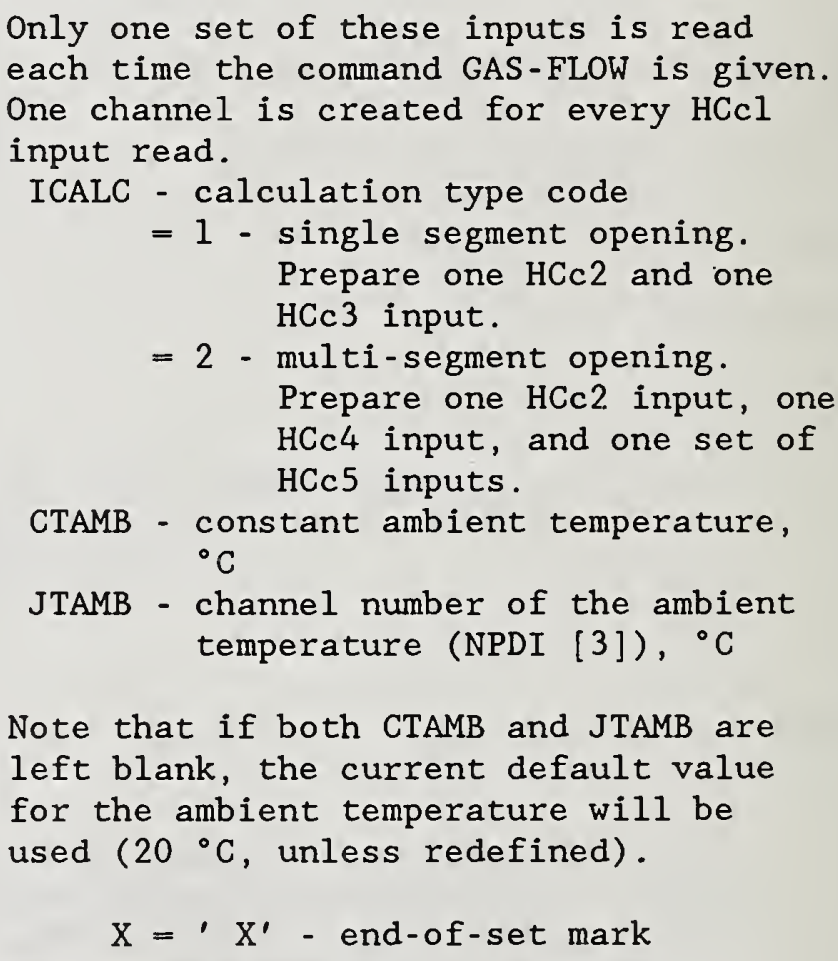 \\
\hline Input & Variables & Format & Comments \\
\hline $\mathrm{HCc} 2$ & IGAS & $\mathrm{A} 20$ & $\begin{aligned} \text { IGAS - a } 20 \text { character name for the } \\
\text { kind of gas to be quantified }\end{aligned}$ \\
\hline
\end{tabular}




\begin{tabular}{|c|c|c|c|}
\hline Input & Variables & Format & Comments \\
\hline $\mathrm{HCc} 3$ & $\begin{array}{l}\text { JGAS , JVEL1, CTEMP or } \\
\text { JTEMP1, AREA, AMWG } \mathrm{X}\end{array}$ & $\begin{array}{c}\text { EVALU8 } \\
\text { (NPDI } \\
[2])\end{array}$ & 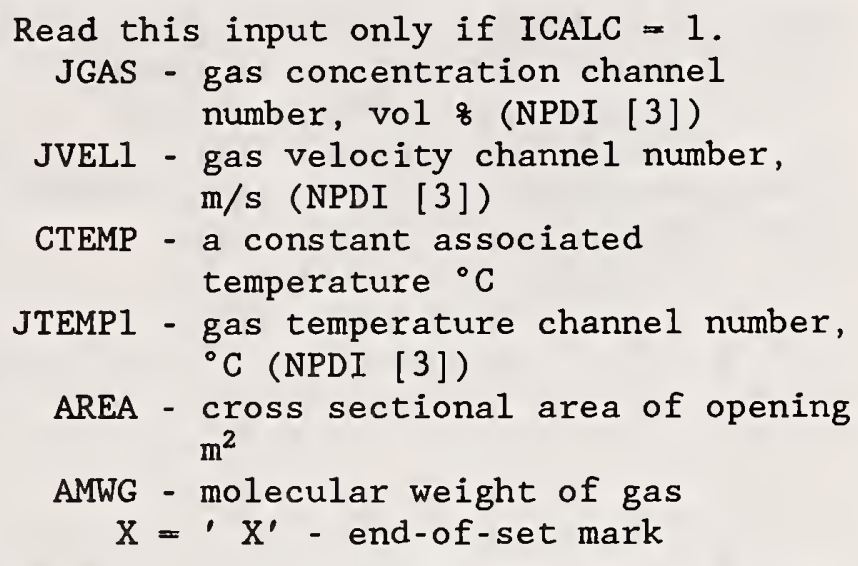 \\
\hline Input & Variables & Format & Comments \\
\hline $\mathrm{HCc} 4$ & $\begin{array}{l}\text { NGAS , HT, WD, JNP, } \\
\text { ISMETH , AMWG } \mathrm{X}\end{array}$ & $\begin{array}{c}\text { EVALU8 } \\
\text { (NPDI } \\
[2])\end{array}$ & 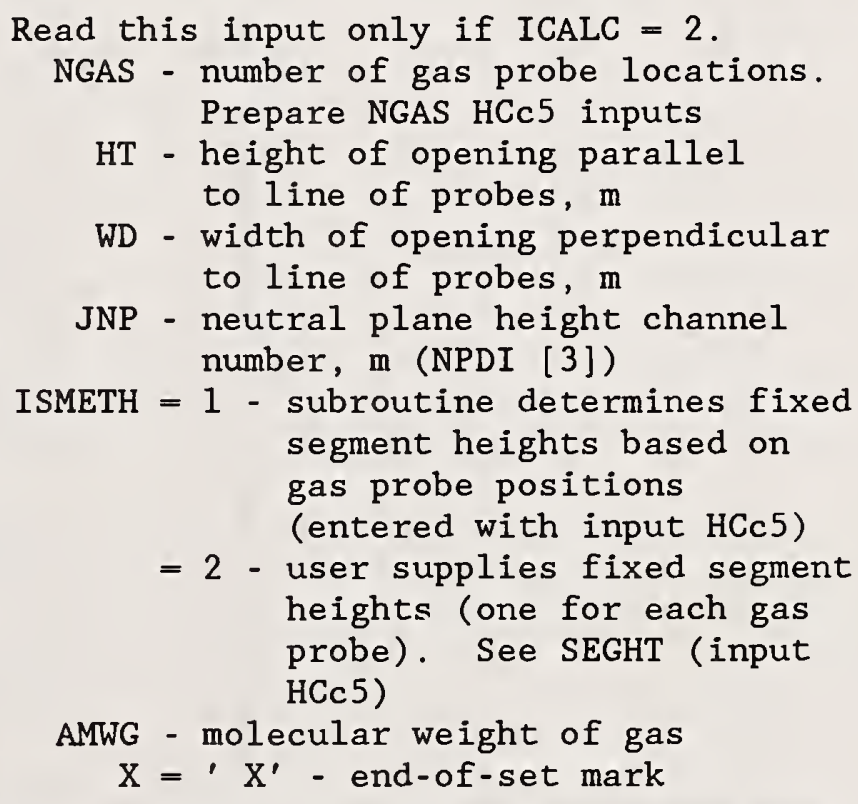 \\
\hline
\end{tabular}




\begin{tabular}{|c|c|c|c|}
\hline Input & Variables & Format & Comments \\
\hline $\mathrm{HCc} 5$ & $\begin{array}{l}\text { JGAS , GASPOS , IVMETH, } \\
\text { ITMETH \{, JVEL\} } \\
\text { \{, JVEL1, VPOS } 1, \text { JVEL2, } \\
\text { VPOS } 2\} \text { \{, CTEMP or } \\
\text { JTEMP \} \{, JTEMP1, } \\
\text { TPOS } 1, \text { JTEMP } 2, \text { TPOS } 2\} \\
\text { \{, SEGHT }\}\end{array}$ & $\begin{array}{c}\text { EVALU8 } \\
\text { (NPDI } \\
[2])\end{array}$ & 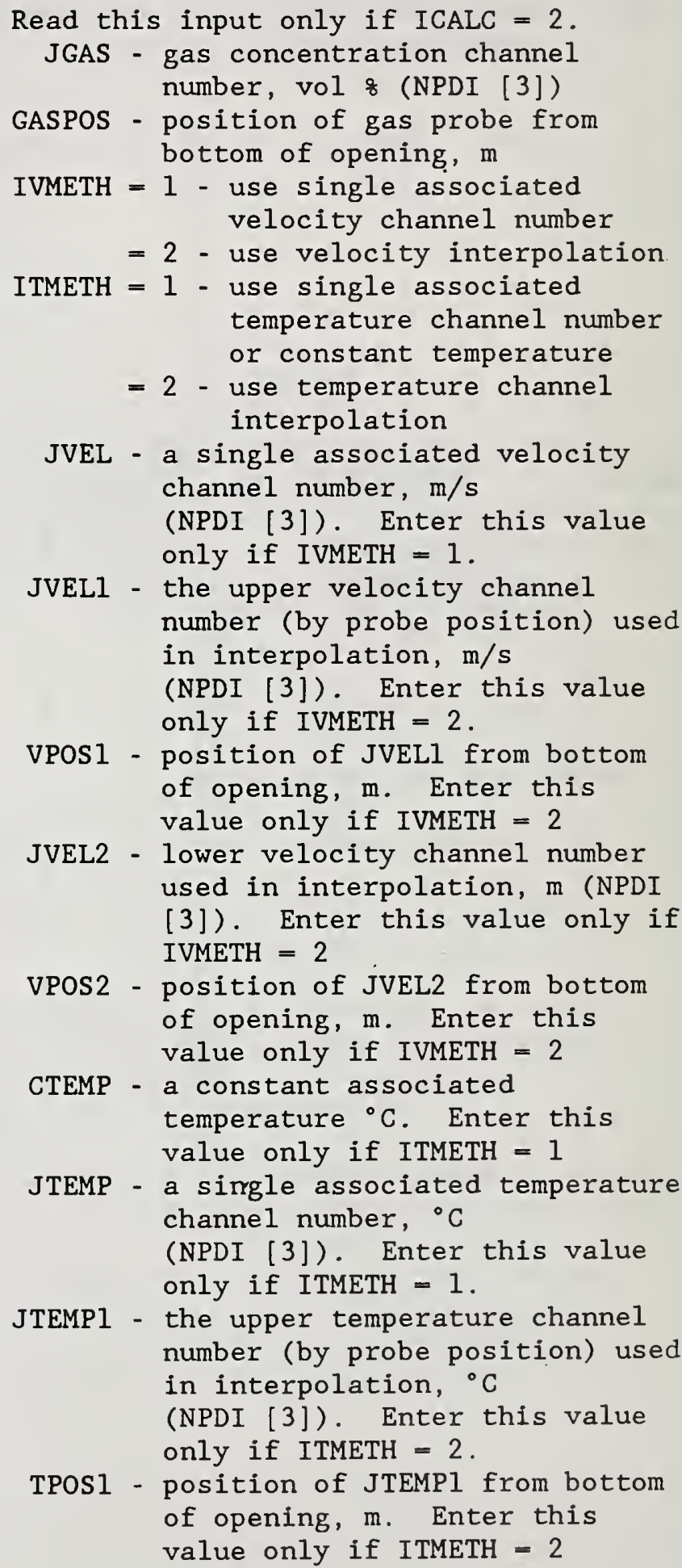 \\
\hline
\end{tabular}




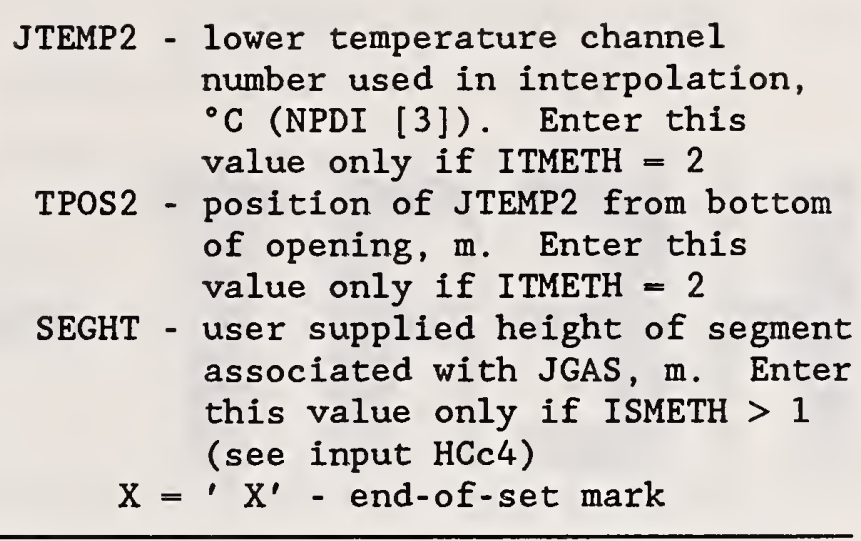

Enter Another Command (Data Input H1) 
15.4 Part H, Class C, Subpart d: Input Specified by Complex Command HEAT-RATE
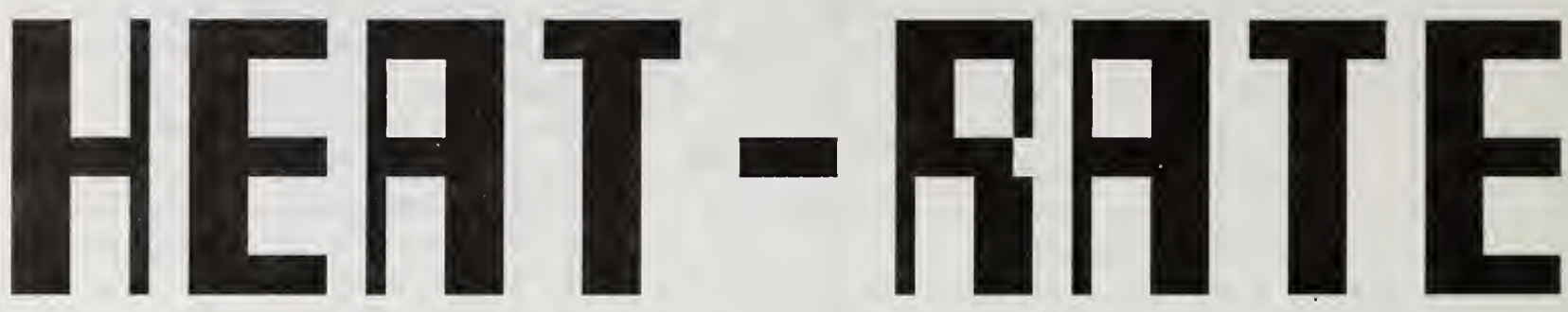

The subroutine calculates the total rate of heat release for a system based on the oxygen depletion of the gas leaving the system ${ }^{3}$. There are five basic methods of calculating the rate of heat release. Some or all of the following input variables are required to make the calculations: oxygen, carbon dioxide, and carbon monoxide gas concentrations (volume percent), exhaust gas velocity $(\mathrm{m} / \mathrm{s})$, exhaust opening (doorway, window, stack, etc.) dimensions (m), neutral plane height $(\mathrm{m})$, exhaust gas temperature $\left({ }^{\circ} \mathrm{C}\right)$, input air volume flow rate $\left(\mathrm{m}^{3} / \mathrm{s}\right)$, and input fuel volume flow rate $\left(\mathrm{m}^{3} / \mathrm{s}\right)$.

The choice of method used to calculate the rate of heat release must be based on test conditions and available information. The five methods are:

1. open system - no restriction on air going into the test chamber; one oxygen concentration, one gas velocity, and one gas temperature measurement in the exhaust gas (from a single probe or from the average of several); the oxygen concentration may or may not be corrected for carbon dioxide concentration.

3 Parker, W. J., Calculations of the Heat Release Rate by Oxygen Consumption for Various Applications, Nat. Bur. Stand., (U. S.), NBSIR 81-2427-1 (March 1982). 
2. the same type calculation as (1) except there are more than one oxygen concentration, gas velocity, and gas temperature measurement in the opening (i.e. a vertical profile of quantities). Essentially, the rate of heat release is calculated for each "segment" represented by an oxygen measurement, then added together to find the total rate of heat release.

3. open system - one oxygen, carbon dioxide, carbon monoxide, gas velocity, and gas temperature measurement; the fuel burning characteristics must be known, i.e. the stoichiometric coefficients of water, carbon dioxide, carbon monoxide, oxygen, and the fuel. The oxygen concentration is always corrected for carbon dioxide and carbon monoxide.

4. the same type calculation as (3) except there is a vertical profile as in type (2).

5. closed system - the input air and fuel are monitored and may be regulated; the outflow concentrations of oxygen, carbon dioxide, and carbon monoxide are known as are the stoichiometric coefficients of water, carbon dioxide, carbon monoxide, oxygen and fuel in the reaction equation.

Methods 1 and 2 use the same equation to calculate the rate of heat release:

$$
\mathrm{Q}^{\prime}=\frac{\mathrm{dO2} * \mathrm{H} * \mathrm{~V} * \mathrm{~A} * \mathrm{~T}(\mathrm{amb})}{\mathrm{T}}
$$

where 


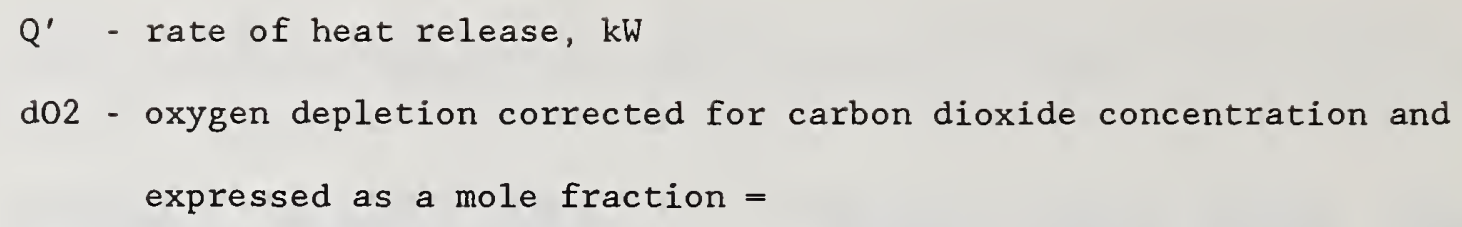

$$
\frac{0.209-[x(02) * 0.01 /(1.0-x(\mathrm{CO} 2) * 0.01)]}{1.0-(x(02) * 0.01) /(1.0-x(\mathrm{CO} 2) * 0.01)}
$$

where $\mathrm{x}(02)$ and $\mathrm{x}(\mathrm{CO} 2)$ are the oxygen and carbon dioxide concentrations, respectively, in volume percent. If the correction for carbon dioxide is not used, the equation for oxygen depletion reduces to

$$
\frac{0.209-\mathrm{x}(02) * 0.01}{1.0-\mathrm{x}(02) * 0.01}
$$

$\mathrm{H}$ - heat of combustion of fuel in terms of a volume of oxygen consumed at STP, $\mathrm{kJ} / \mathrm{m}^{3}$ (default value is $17010 \mathrm{~kJ} / \mathrm{m}^{3}$ )

$\mathrm{v}$ - outflow gas velocity, $\mathrm{m} / \mathrm{s}$

A - opening area, $\mathrm{m}^{2}$

$\mathrm{T}(\mathrm{amb})$ - ambient temperature, $\mathrm{K}$

$\mathrm{T}$ - outflow gas temperature, $\mathrm{K}$

Methods 3 and 4 use a different, more precise but more complex, equation to calculate the rate of heat release: 


$$
\mathrm{Q}^{\prime}=\frac{\mathrm{d} 02 * \mathrm{H} * \mathrm{v} * \mathrm{~A} * \mathrm{~T}(\mathrm{amb})}{\mathrm{T} *[1 .+0.209 *((1 .+\mathrm{a} * \mathrm{dnu}) / \mathrm{nu}(02))]}
$$

where

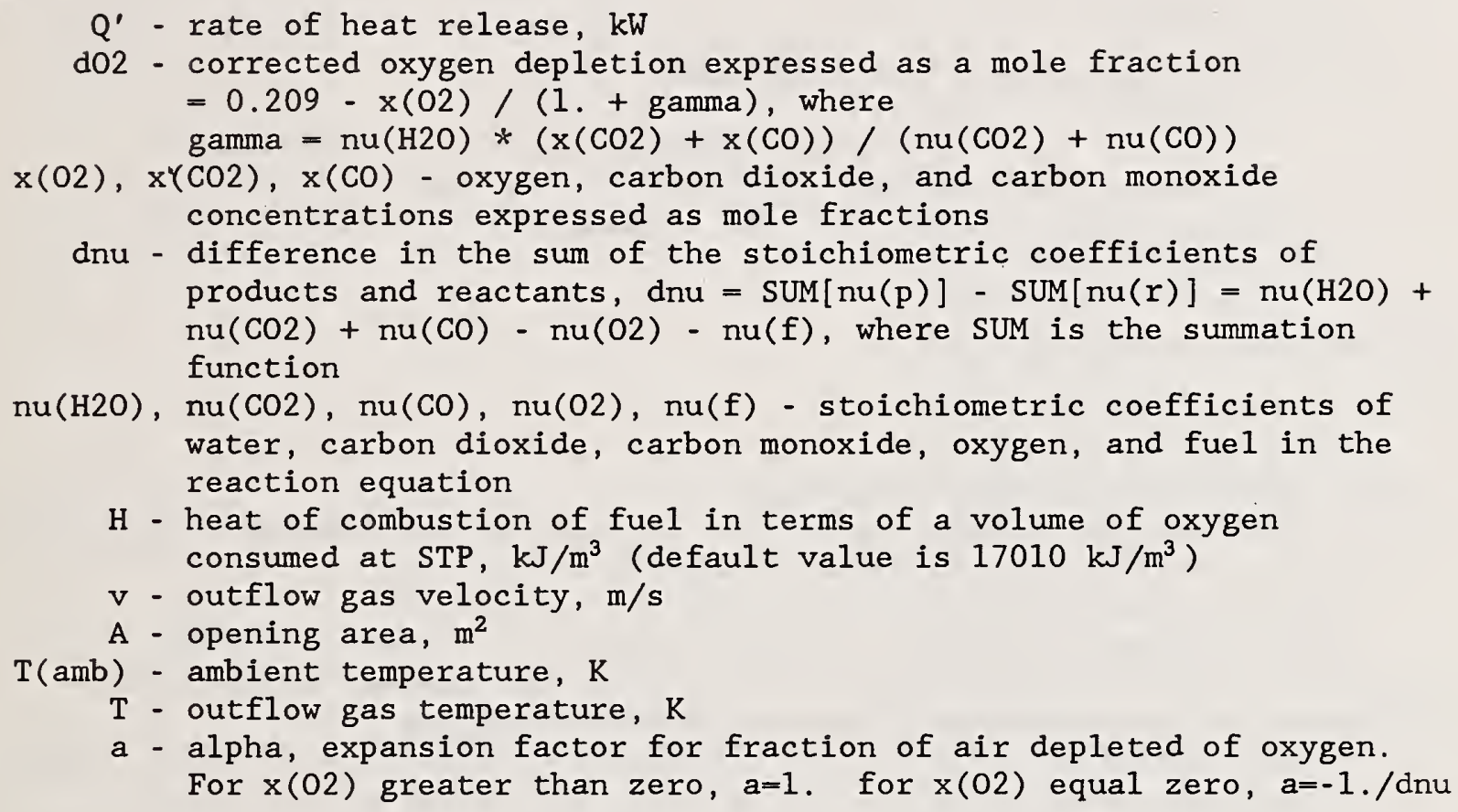


The calculation of the rate of heat release using method 5 rests heavily on the volume flow rates of air and fuel into the system and the oxygen concentration in the exhaust gas:

$$
Q^{\prime}=H * V(a) *\left[0.209-\left(\frac{x(02) * W(a)}{(1+\text { gamma }) * W(g)}+\frac{V(f) * W(f)}{V(a) * W(a)}\right)\right]
$$

where

$$
\begin{aligned}
& \text { Q' - rate of heat release, } \mathrm{kW} \\
& \mathrm{H} \text { - heat of combustion of fuel in terms of a volume of oxygen consumed } \\
& \text { at } \left.\mathrm{STP}, \mathrm{kJ} / \mathrm{m}^{3} \text { (default value is } 17010 \mathrm{~kJ} / \mathrm{m}^{3}\right) \\
& \text { gamma - correction factor for oxygen, } \\
& \text { gamma }=\mathrm{nu}(\mathrm{H} 2 \mathrm{O}) *(\mathrm{x}(\mathrm{CO} 2)+\mathrm{x}(\mathrm{CO})) /(\mathrm{nu}(\mathrm{CO} 2)+\mathrm{nu}(\mathrm{CO})) \\
& \mathrm{x}(\mathrm{O} 2), \mathrm{x}(\mathrm{CO}), \mathrm{x}(\mathrm{CO}) \text { - oxygen, carbon dioxide, and carbon monoxide } \\
& \text { concentrations expressed as mole fractions } \\
& \mathrm{nu}(\mathrm{H} 20) \text {, nu (CO2), nu(CO) - stoichiometric coefficients of water, carbon } \\
& \text { dioxide, and carbon monoxide in the reaction equation } \\
& \mathrm{V}(\mathrm{a}), \mathrm{V}(\mathrm{f}) \text { - temperature adjusted volume flow rate of air and fuel into the } \\
& \text { system, } \mathrm{m}^{3} / \mathrm{s} \\
& \mathrm{W}(\mathrm{a}), \mathrm{W}(\mathrm{f}), \mathrm{W}(\mathrm{g}) \text { - molecular weight of input air, input fuel, and exhaust } \\
& \text { gas }
\end{aligned}
$$

When more than one oxygen probe are used (methods 2 and 4), the opening is divided into segments, the sizes of which are governed by the positions of the probes. The boundary between two probes is simply the halfway point. The total rate of heat release is then the sum of the rates of heat release for the segments. Note that there is provision for the user to select segment sizes if desired.

The calculated values are stored in their own channels created by the program. This subroutine does not reduce any raw data. 


\begin{tabular}{|c|c|c|c|}
\hline Input & Variables & Format & Comments \\
\hline HCdl & $\begin{array}{l}\text { ICALC, [CTAMB or } \\
\text { JTAMB] } \mathrm{X} \\
.\end{array}$ & $\begin{array}{l}\text { EVALU8 } \\
\text { (NPDI } \\
[2])\end{array}$ & 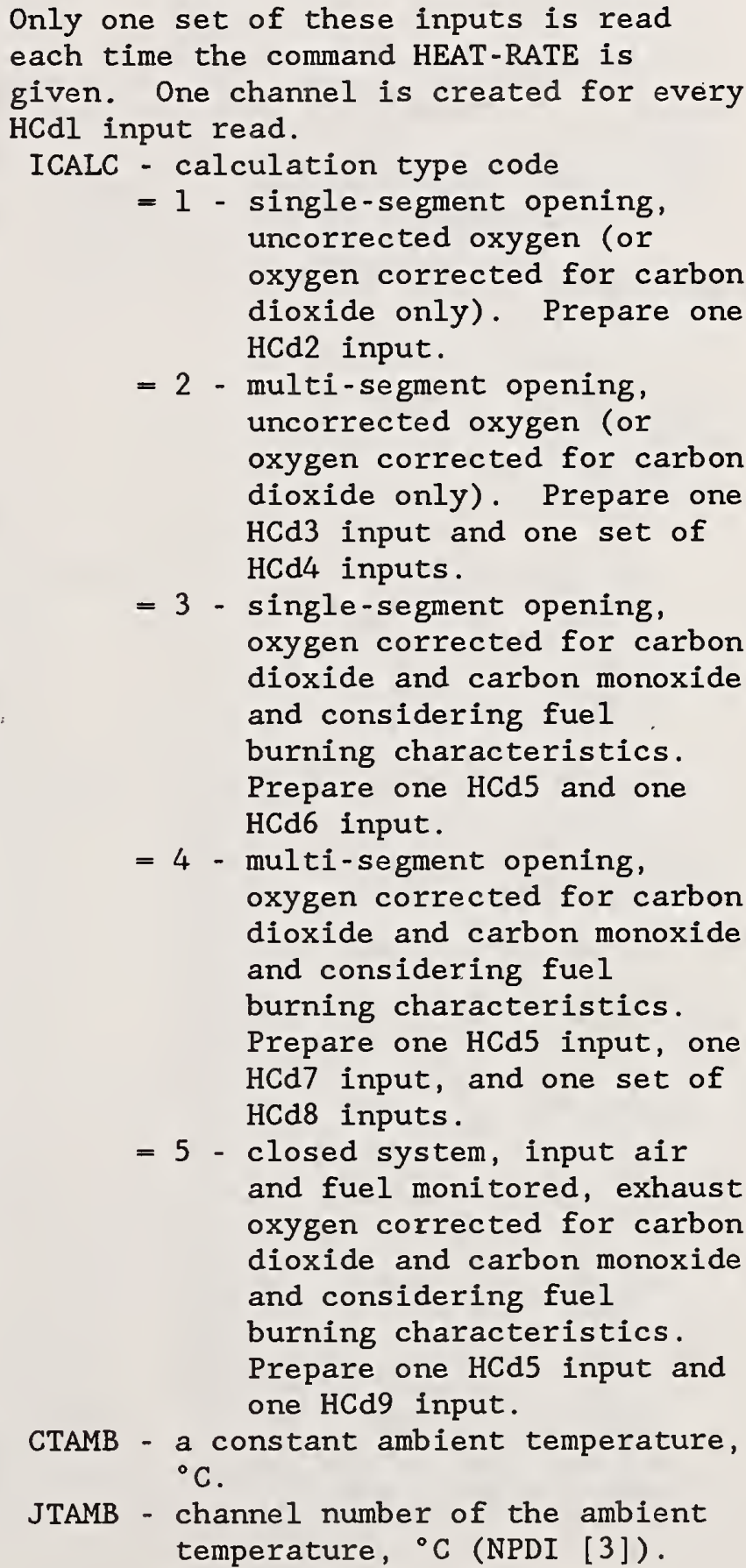 \\
\hline
\end{tabular}




\begin{tabular}{|c|c|c|c|}
\hline & & & $\begin{array}{l}\text { Note that if both CTAMB and JTAMB are } \\
\text { left blank, the current default value } \\
\text { for the ambient temperature will be } \\
\text { used ( } 20^{\circ} \mathrm{C} \text {, unless redefined). } \\
\qquad \mathrm{X}={ }^{\prime} \mathrm{X}^{\prime} \text { - end-of-set mark }\end{array}$ \\
\hline Input & Variables & Format & Comments \\
\hline $\mathrm{HCd} 2$ & $\begin{array}{l}\text { JO2, JVEL1, CTEMP or } \\
\text { JTEMP, AREA, ICORR } \\
\text { (, JCORR }][, \text { HCOM }] \times\end{array}$ & $\begin{array}{l}\text { EVALU8 } \\
\text { (NPDI } \\
{[2] \text { ) }}\end{array}$ & 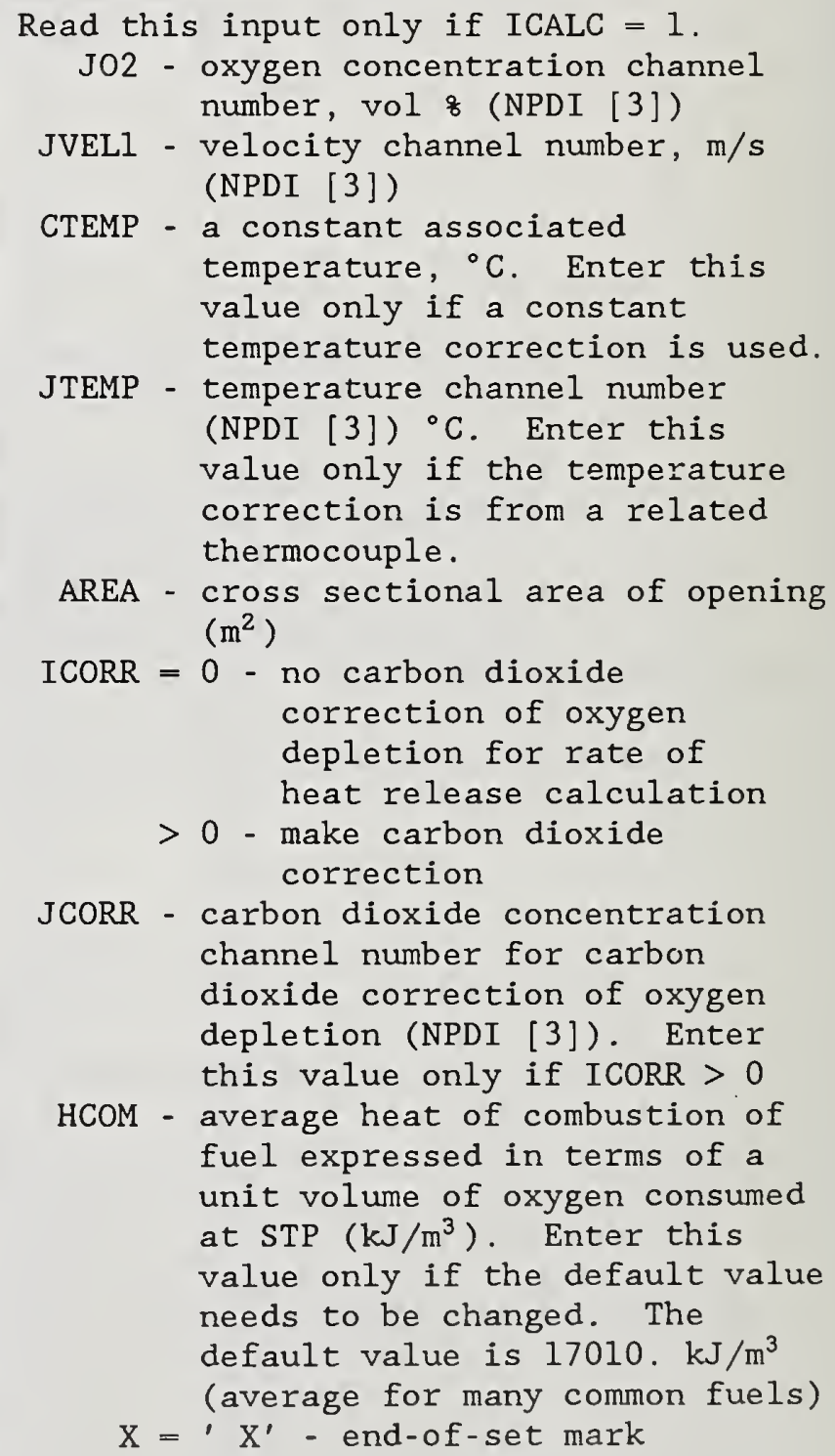 \\
\hline
\end{tabular}




\begin{tabular}{|c|c|c|c|}
\hline Input & Variables & Format & Comments \\
\hline $\mathrm{HCd} 3$ & $\begin{array}{l}\text { NO2 }, \mathrm{HT}, \text { WD , JNP, } \\
\text { ISMETH, ICORR } \\
{[, \text { HCOM }] \mathrm{X}}\end{array}$ & $\begin{array}{l}\text { EVALU8 } \\
\text { (NPDI } \\
[2])\end{array}$ & 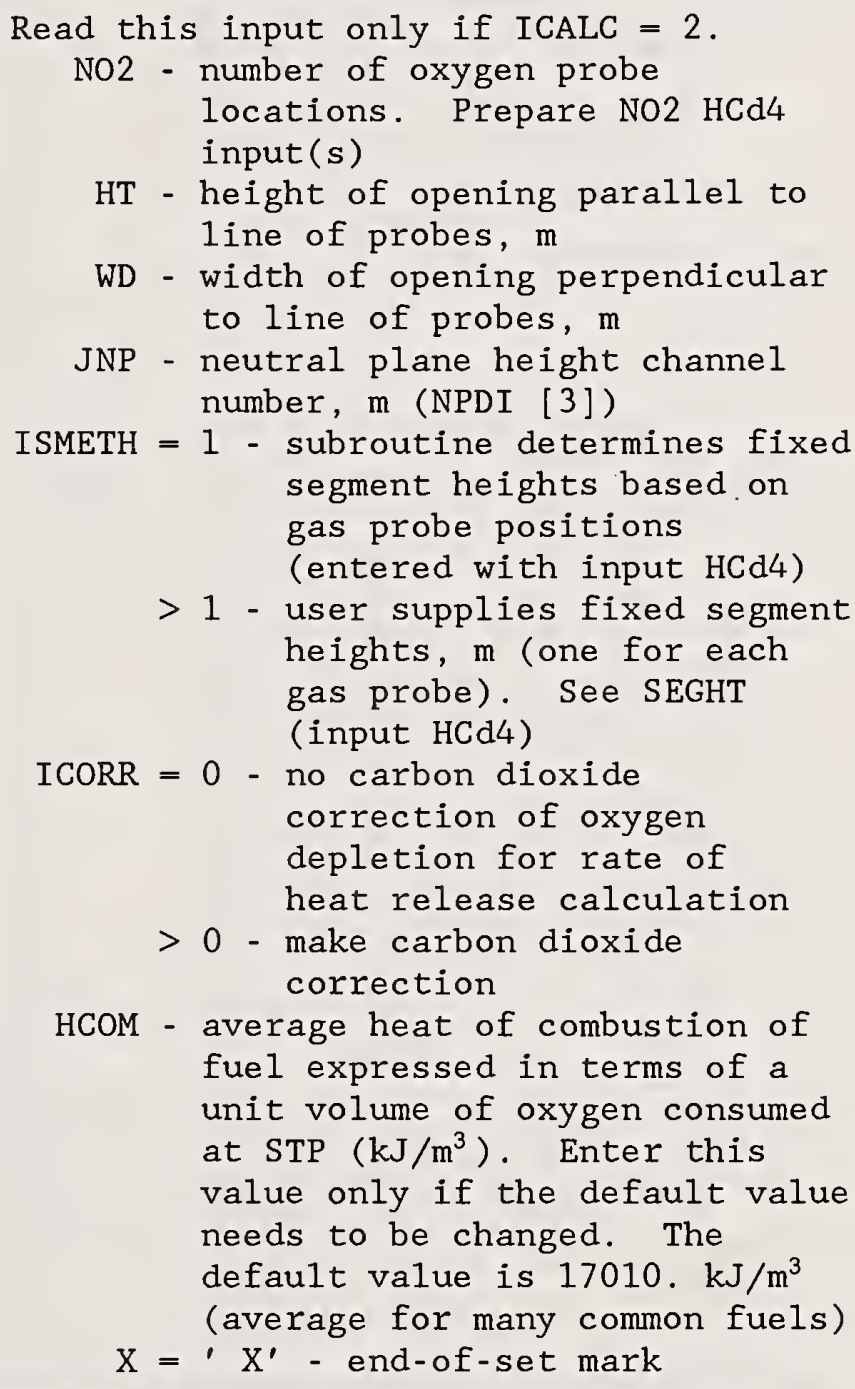 \\
\hline Input & Variables & Format & Comments \\
\hline $\mathrm{HCd} 4$ & $\begin{array}{l}\text { JO2, O2POS, IVMETH, } \\
\text { ITMETH \{, JVEL\} } \\
\text { \{, JVEL1, VPOS } 1, \text { JVEL2, } \\
\text { VPOS } 2\}\{, \text { CTEMP Or } \\
\text { JTEMP \} \{, JTEMP1, } \\
\text { TPOS } 1, \text { JTEMP } 2, \text { TPOS } 2\} \\
\{, \text { SEGHT }\}\{, \text { JCORR }\} \text { X }\end{array}$ & $\begin{array}{l}\text { EVALU8 } \\
\text { (NPDI } \\
[2])\end{array}$ & 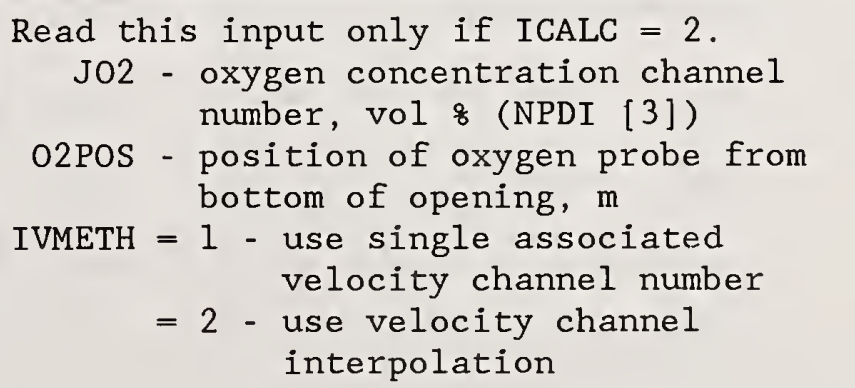 \\
\hline
\end{tabular}




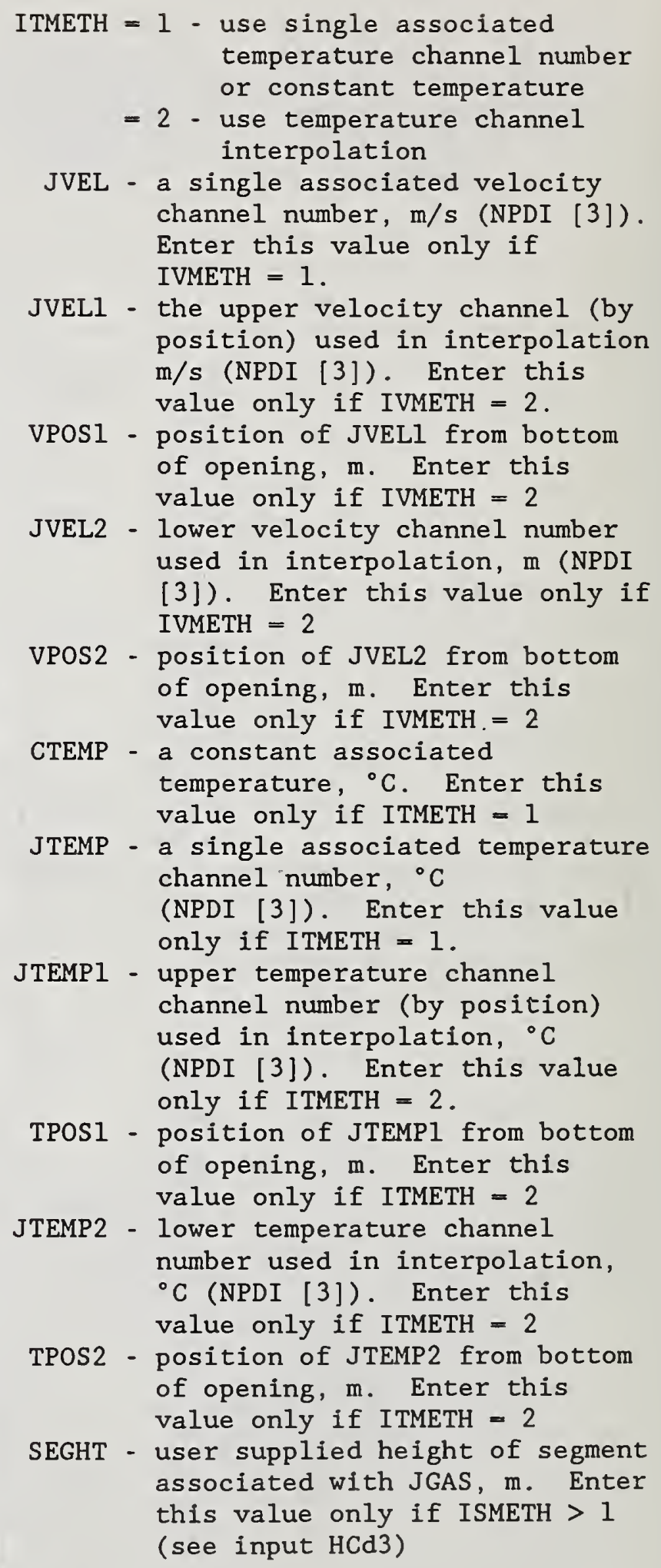

JVEL1 - the upper velocity channel (by position) used in interpolation $\mathrm{m} / \mathrm{s}$ (NPDI [3]). Enter this value only if IVMETH $=2$.

VPOS1 - position of JVEL1 from bottom of opening, m. Enter this value only if IVMETH $=2$

JVEL2 - lower velocity channel number used in interpolation, m (NPDI [3]). Enter this value only if IVMETH $=2$

VPOS2 - position of JVEL2 from bottom of opening, m. Enter this value only if IVMETH. $=2$

CTEMP - a constant associated temperature, ${ }^{\circ} \mathrm{C}$. Enter this value only if ITMETH $=1$

JTEMP - a single associated temperature channel number, ${ }^{\circ} \mathrm{C}$

(NPDI [3]). Enter this value only if ITMETH $=1$.

JTEMP1 - upper temperature channel channel number (by position) used in interpolation, ${ }^{\circ} \mathrm{C}$ (NPDI [3]). Enter this value only if ITMETH $=2$.

TPOS1 - position of JTEMP1 from bottom of opening, m. Enter this value only if ITMETH $=2$

JTEMP2 - lower temperature channe1 number used in interpolation, ${ }^{\circ} \mathrm{C}$ (NPDI [3]). Enter this value only if ITMETH $=2$

TPOS2 - position of JTEMP2 from bottom of opening, $m$. Enter this value only if ITMETH $=2$

SEGHT - user supplied height of segment associated with JGAS, m. Enter this value only if ISMETH $>1$ (see input $\mathrm{HCd} 3$ ) 


\begin{tabular}{|c|c|c|c|}
\hline & & & $\begin{aligned} \text { JCORR - } & \text { carbon dioxide concentration } \\
& \text { channel number for carbon } \\
& \text { dioxide correction of oxygen } \\
& \text { depletion (NPDI [3]). Enter } \\
& \text { this value only if ICORR }>0 \\
& \text { see input HCd3) } \\
X= & X^{\prime} \text { - end-of-set mark }\end{aligned}$ \\
\hline Input & Variables & Format & Comments \\
\hline $\mathrm{HCd} 5$ & $\begin{array}{l}\mathrm{VH} 20, \mathrm{VCO} 2, \mathrm{VCO}, \\
\mathrm{VO} 2, \mathrm{VF}[, \mathrm{HCOM}] \mathrm{X}\end{array}$ & $\begin{array}{l}\text { EVALU8 } \\
\text { (NPDI } \\
[2])\end{array}$ & $\begin{array}{l}\text { Read this input only if ICALC }=3,4 \text { or } \\
5 . \\
\text { VH2O - stoichiometric coefficient of } \\
\text { water in the reaction } \\
\text { VCO2 - coefficient of carbon dioxide } \\
\text { VCO - coefficient of carbon monoxide } \\
\text { VO2 - coefficient of oxygen } \\
\text { VF - coefficient of the fuel } \\
\text { HCOM - average heat of combustion of } \\
\text { fuel expressed in terms of a } \\
\text { unit volume of oxygen consumed } \\
\text { at STP. (kJ/m }{ }^{3} \text { ). Enter this } \\
\text { value only if the default value } \\
\text { needs to be changed. The } \\
\text { default value is } 17010 \text {. } \mathrm{kJ} / \mathrm{m}^{3} \\
\text { (average for many common fuels) } \\
\mathrm{X}=\end{array}$ \\
\hline Input & Variables & Format & Comments \\
\hline $\mathrm{HCd} 6$ & $\begin{array}{l}\mathrm{JO} 2, \mathrm{JCO} 2, \mathrm{JCO}, \mathrm{JVEL} \text {, } \\
\text { CTEMP or JTEMP, } \\
\text { AREA X }\end{array}$ & $\begin{array}{l}\text { EVALU8 } \\
\text { (NPDI } \\
[2])\end{array}$ & 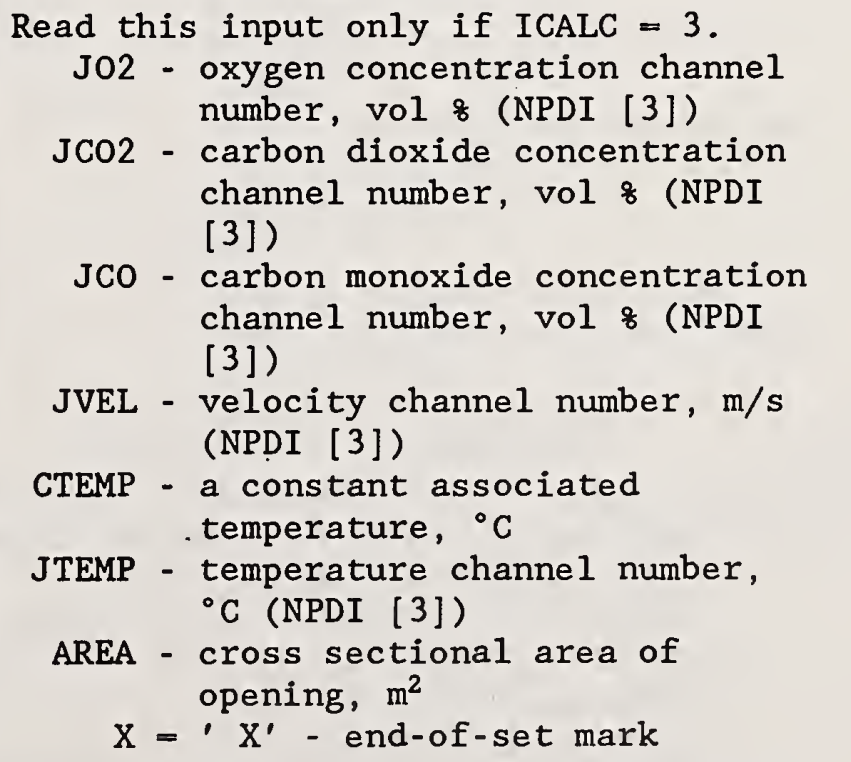 \\
\hline
\end{tabular}




\begin{tabular}{|c|c|c|c|}
\hline Input & Variables & Format & Comments \\
\hline $\mathrm{HCd} 7$ & $\begin{array}{l}\text { NO2, HT, WD, JNP, } \\
\text { JAVFRI, JAVFRO, CATI } \\
\text { or JATI, CATO or } \\
\text { JATO, WF, ISMETH X }\end{array}$ & $\begin{array}{l}\text { EVALU8 } \\
\text { (NPDI } \\
[2])\end{array}$ & 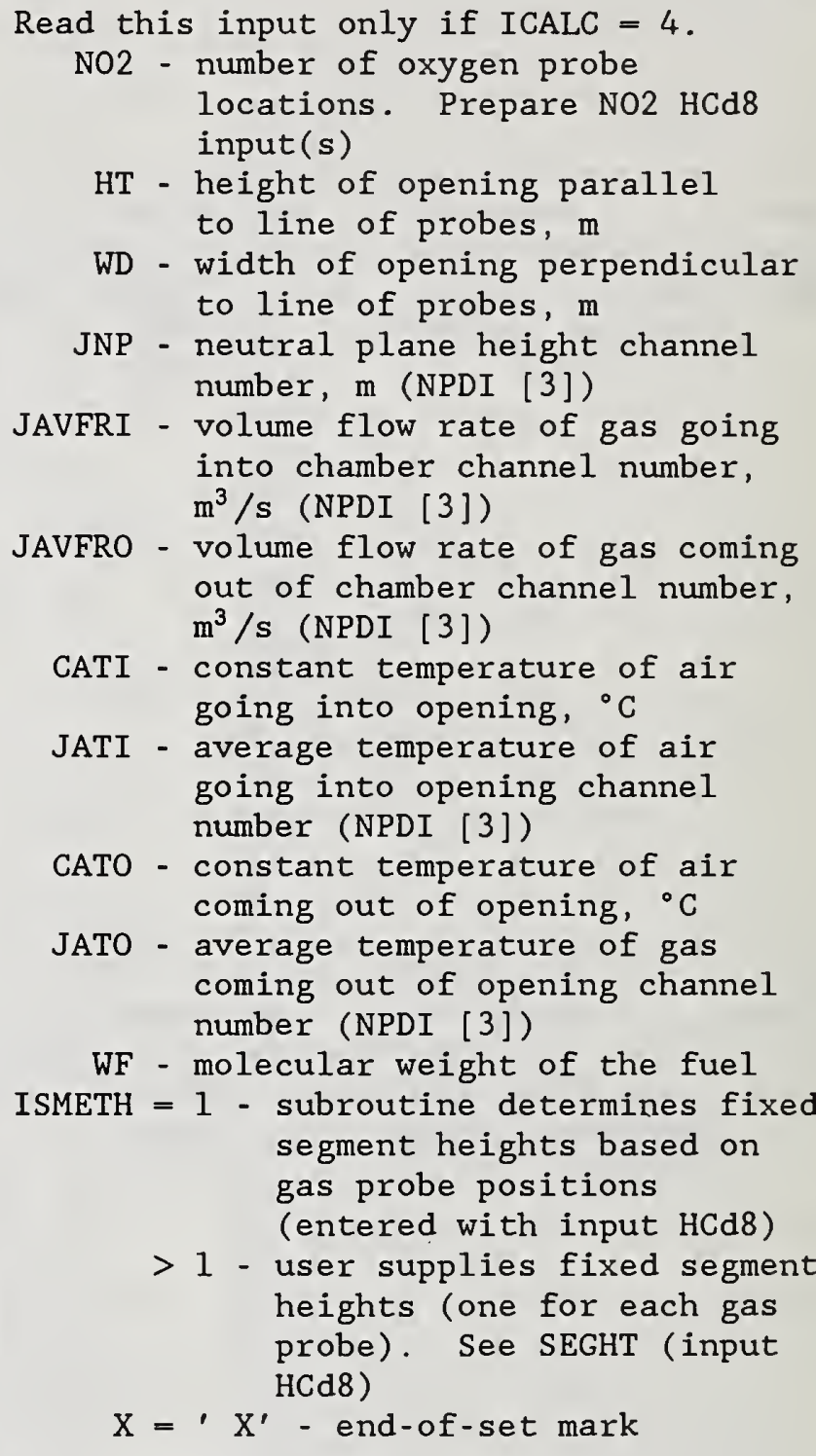 \\
\hline Input & Variables & Format & Comments \\
\hline $\mathrm{HCd} 8$ & $\begin{array}{l}\text { JO2 , JCO2, JCO, GASPOS, } \\
\text { IVMETH, ITMETH \{, JVEL\} } \\
\text { \{, JVEL1, VPOS } 1 \text {, JVEL2, } \\
\text { VPOS } 2 \text { \} \{, CTEMP or } \\
\text { JTEMP \} \{, JTEMP1, } \\
\text { TPOS1, JTEMP2, TPOS } 2\} \\
\text { \{, SEGHT X X }\end{array}$ & $\begin{array}{l}\text { EVALU8 } \\
\text { (NPDI } \\
[2])\end{array}$ & $\begin{aligned} & \text { Read this input only if ICALC }=4 \text {. } \\
& \text { JO2 - oxygen concentration channel } \\
& \text { number, vol \& (NPDI [3]) } \\
& \text { JCO2 - carbon dioxide concentration } \text { channel number, vol \& (NPDI } \\
& {[3] \text { ) } } \\
& \text { JCO - carbon monoxide } \text { concentration channel number, } \\
& \text { vol } \& \text { (NPDI [3]) }\end{aligned}$ \\
\hline
\end{tabular}




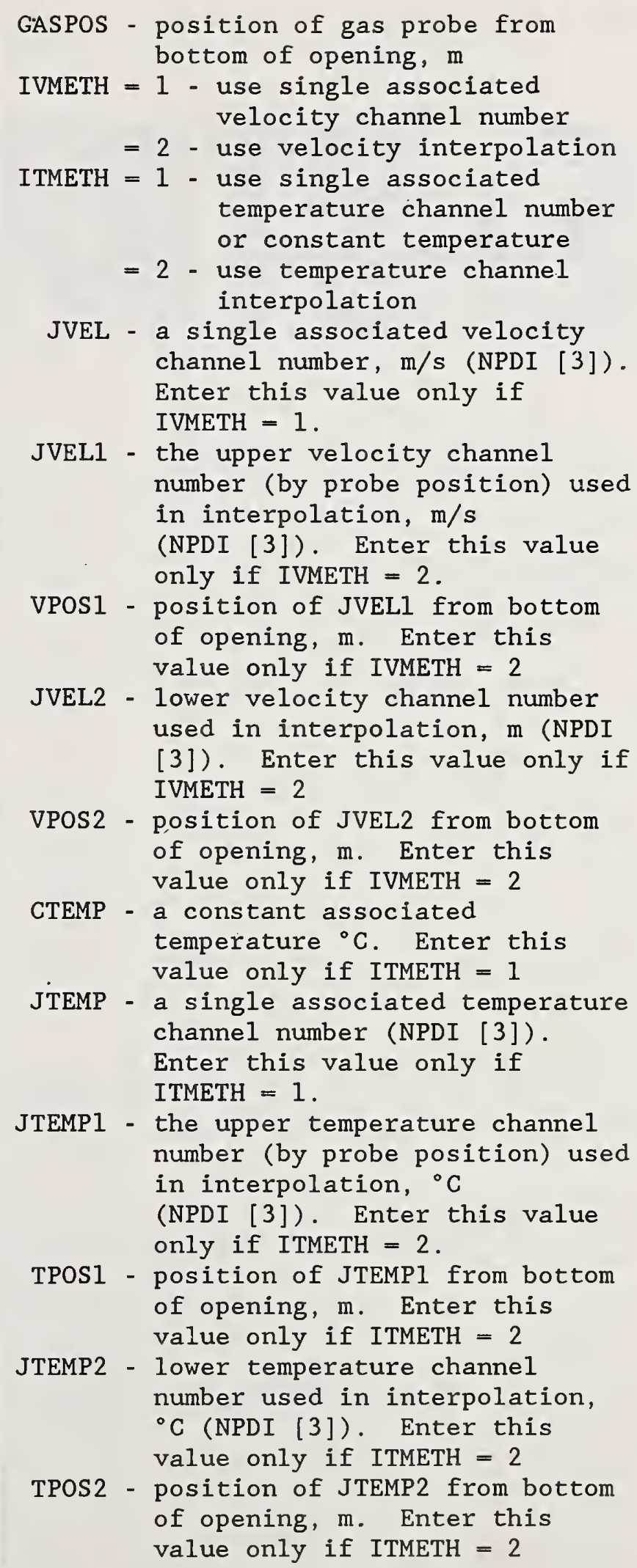




\begin{tabular}{|c|c|c|c|}
\hline & & & $\begin{aligned} & \text { SEGHT - } \text { user supplied height of segment } \\
& \text { associated with JGAS, m. Enter } \\
& \text { this value only if ISMETH }>1 \\
& \text { (see input HCd7) } \\
& \mathrm{X}=\text { ' } \mathrm{X}^{\prime} \text { - end-of-set mark }\end{aligned}$ \\
\hline Input & Variables & Format & Comments \\
\hline $\mathrm{HCd} 9$ & $\begin{array}{l}\mathrm{JO} 2, \mathrm{JCO} 2, \mathrm{JCO}, \mathrm{JVFF}, \\
\mathrm{JVFA}, \mathrm{WF}, \mathrm{CTF} \text { or JTF, } \\
\text { CTA or JTA X }\end{array}$ & $\begin{array}{l}\text { EVALU8 } \\
(\text { NPDI } \\
[2])\end{array}$ & 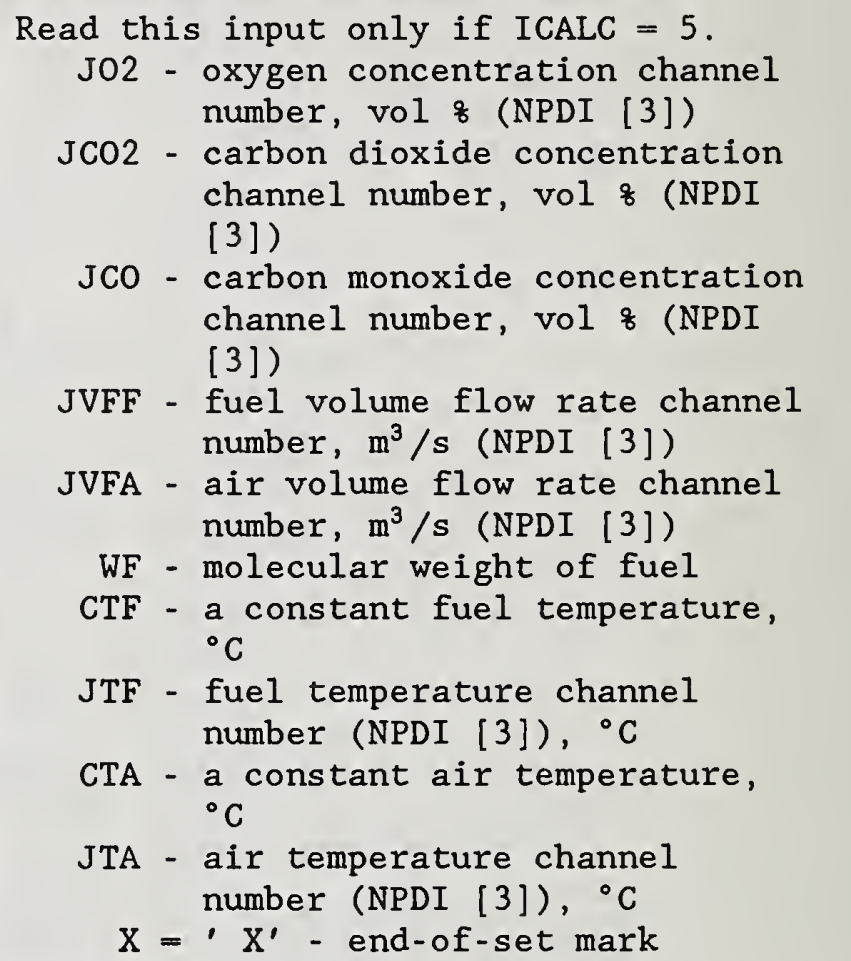 \\
\hline
\end{tabular}

Enter Another Command (Data Input H1) 
15.5 Part H, Class C, Subpart e: Input Specifled by Complex Command HEAT-RATE-2
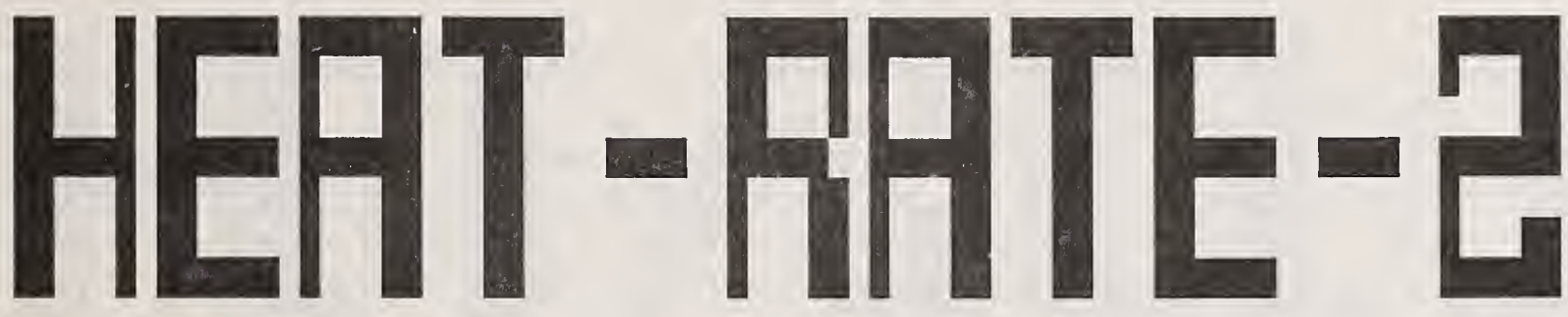

The subroutine calculates the total rate of heat release for a system based on the oxygen depletion and mass flow rate of exhaust gases through an exhaust duct or other exhaust collection device. For the best results, the specific energy and the stoichiometric factor for the fuel being burned should be known. The default values for these parameters are $13100 . \mathrm{kJ} / \mathrm{kg}$ and 1.5 , respectively.

The rate of heat release equation is then

$$
Q^{\prime}=S * \frac{M(02)}{M(a i r)} * m^{\prime} * X
$$

where,

$$
\begin{aligned}
Q^{\prime} \text { - rate of heat release, } \mathrm{kW} \\
\mathrm{S} \text { - } \\
\text { specific energy }(\mathrm{S}=\mathrm{dhc} / \mathrm{r} 0), \mathrm{kJ} / \mathrm{kg}(\text { default }=13100 .) \\
\text { ro - stoichiometric oxygen } / \text { fuel mass ratio } \\
M(02) \text { - molecular weight of oxygen }(=32 .) \\
M(\text { air }) \text { - molecular weight of air }(=28.97) \\
\mathrm{m}^{\prime} \text { - mass flow rate of gases through collection duct, } \mathrm{kg} / \mathrm{s}
\end{aligned}
$$

and, 
$\mathrm{X}$

$[(1-\mathrm{XO} 2-\mathrm{XCO} 2) /(\mathrm{XO} 2(0) *(1-\mathrm{XCO} 2)-\mathrm{XO} 2 *(1-\mathrm{XCO} 2(0)))]+(\mathrm{b}-1)$

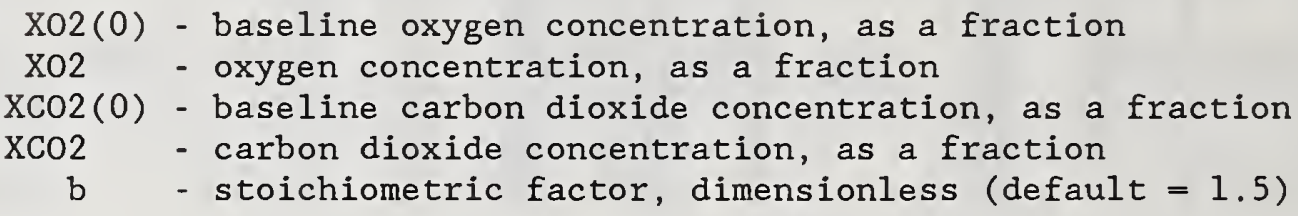

The calculated values are stored in their own channels created by the program. One channel is created each time the command HEAT-RATE- 2 is given. This subroutine does not reduce any raw data.

\begin{tabular}{|c|c|c|c|}
\hline Input & Variables & Format & Comments \\
\hline $\mathrm{HCel}$ & $\begin{array}{l}\text { JO2, CMFR or JMFR, } \\
\text { ICO } 2(, \text { JCO2 }\} \\
{[[, B], \text { SENRGY }] \mathrm{X}}\end{array}$ & $\begin{array}{l}\text { EVALU8 } \\
(\text { NPDI } \\
[2])\end{array}$ & 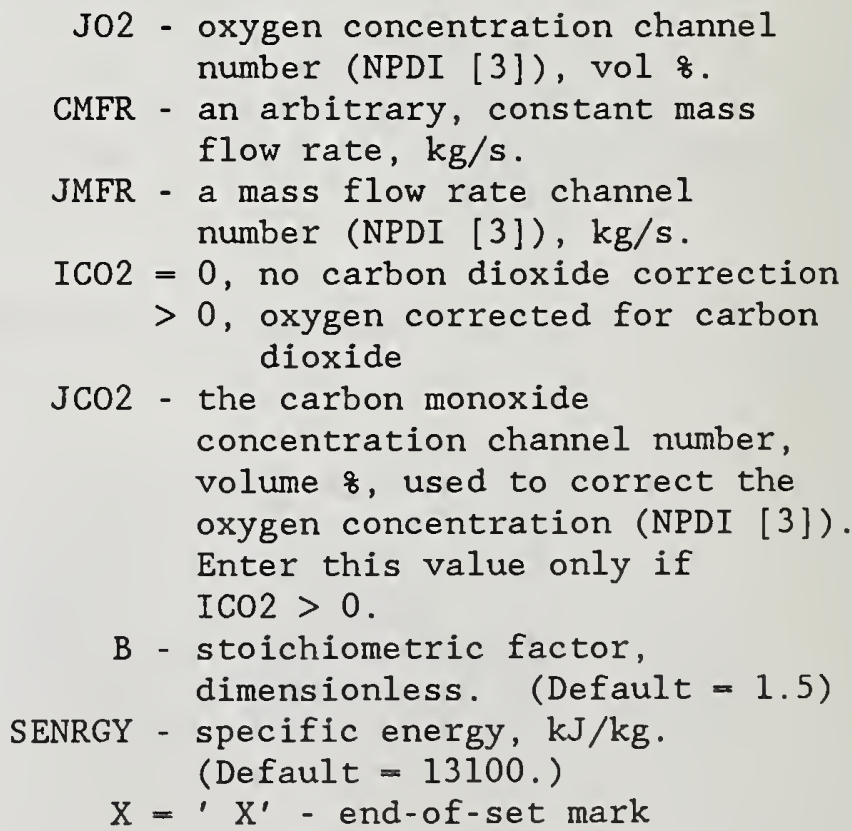 \\
\hline
\end{tabular}

Enter Another Command (Data Input H1) 


\subsection{Part H, Class C, Subpart f: Input Specifled by Complex Command HOT/COLD}
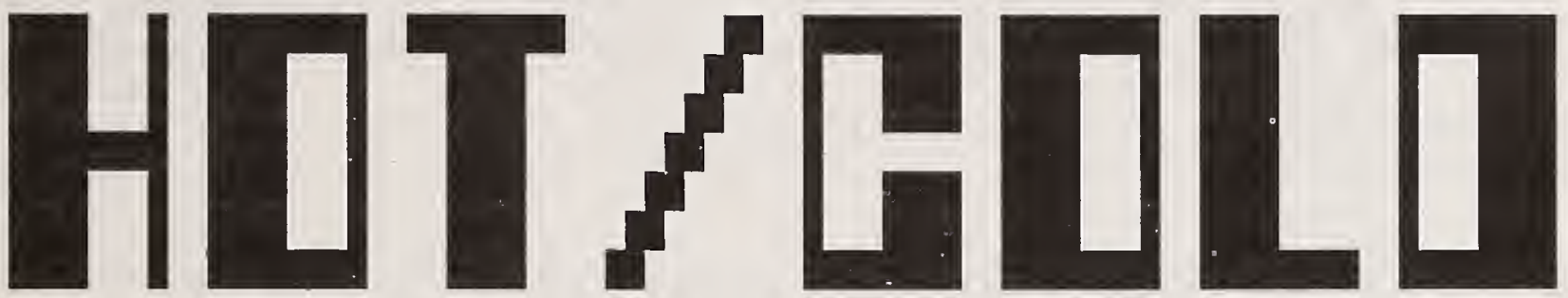

The subroutine finds the height of the hot/cold interface and the average temperatures above and below the interface using a temperature profile of the $\operatorname{gas}^{4}$.

The temperature at the interface is defined to be:

$$
\mathrm{Ti}=\mathrm{T} 1+((\mathrm{Th}-\mathrm{T} 1) * \mathrm{C})
$$

where,

$\mathrm{Ti}$ - the temperature at the interface height

$\mathrm{T} 1$ - the lowest temperature in the profile; (this subroutine uses the temperature of the bottom thermocouple in the profile)

Th - the highest temperature in the profile.

C - an empirical value, less than or equal to 1.0 , used to define the temperature at the interface height

Once the temperature at the interface height is known, the height of the interface is found by interpolating between the pair of profile temperatures that

4 Cooper, L. Y., Harkleroad, M., Quintiere, J. G., and Rinkinen, W. J., An Experimental Study of Upper Hot Layer Stratification in Full-Scale Multiroom Fire Scenarios, J. Heat Trans., Vo1. 104, 741-749 (November 1982). 
bracket the interface temperature. Note that you may request the program to calculate (by extrapolation) the temperature at height $=0.0$ and that that temperature and position are than available to the algorithm for finding the interface height.

Once the interface height is known, the average temperatures above and below it are calculated.

The calculated interface height, average upper gas temperature, and average lower gas temperature are stored in channels created by the program, at the option of the user. This subroutine does not reduce any raw data. Any units may be used for temperature and position as long as they are consistent among themselves. Only one set of HCf inputs is read each time the command HOT/COLD is given. 


\begin{tabular}{|c|c|c|c|}
\hline Input & Variables & Format & Comments \\
\hline $\mathrm{HCfl}$ & $\begin{array}{l}\text { IHT; IHOT, ICOLD, } \\
\text { ROOMHT, [IXTRAP, ] } \\
{[\text { PCT] X }}\end{array}$ & $\begin{array}{l}\text { EVALU8 } \\
\text { (NPDI } \\
[2])\end{array}$ & $\begin{array}{c}\text { IHT }>0 \text { - } \begin{array}{c}\text { store the calculated } \\
\text { interface height. One } \\
\text { channel is created. }\end{array} \\
\text { IHOT }>0 \text { - } \begin{array}{r}\text { store the calculated } \\
\text { temperature of the gases } \\
\text { above the interface }\end{array} \\
\text { ICOLD }>0 \text { - } \begin{array}{r}\text { store the calculated } \\
\text { temperature of the gases } \\
\text { below the interface }\end{array} \\
\text { ROOMHT - the height of the ceiling at } \\
\text { the point in line with the } \\
\text { temperature profile }\end{array}$ \\
\hline Input & Variables & Format & Comments \\
\hline HCf2 & $\begin{array}{l}\operatorname{JTEMP}(1), \operatorname{JTEMP}(2) \\
\ldots, \operatorname{JTEMP}(i) \times \\
1<i<=25\end{array}$ & $\begin{array}{l}\text { EVALU8 } \\
\text { (NPDI } \\
[2])\end{array}$ & $\begin{array}{l}\text { JTEMP - thermocouple channel number } \\
\text { (NPDI [3]). } \\
\text { Thermocouples may be in any } \\
\text { order. The positions, entered } \\
\text { with data input HCf3 below, must } \\
\text { be in the same order. } \\
\mathrm{X}={ }^{\prime} \mathrm{X}^{\prime} \text { - end-of-set mark }\end{array}$ \\
\hline Input & Variables & Format & Comments \\
\hline $\mathrm{HCf} 3$ & $\begin{array}{l}\operatorname{POS}(1), \operatorname{POS}(2), \ldots \\
\operatorname{POS}(i) X \\
1<i<=25\end{array}$ & $\begin{array}{l}\text { EVALU8 } \\
\text { (NPDI } \\
[2])\end{array}$ & $\begin{array}{l}\text { POS - height of the thermocouple in } \\
\text { the corresponding position on } \\
\text { data input HCf } 2 \text {. } \\
\mathrm{X}=\text { ' } \mathrm{X}^{\prime} \text { - end-of-set mark }\end{array}$ \\
\hline
\end{tabular}

Enter Another Command (Data Input HI) 
15.7 Part H, Class C, Subpart $\mathrm{g}$ : Input Specifled by Complex Command MASS-FLOW
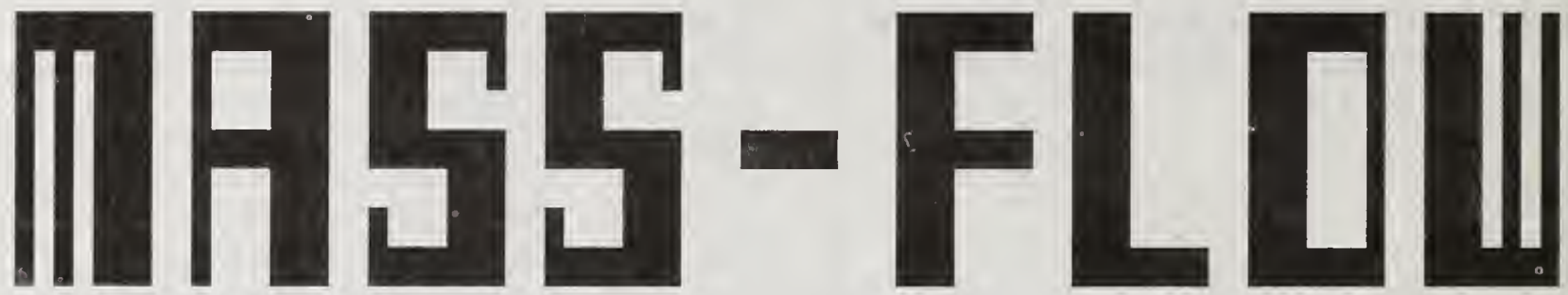

The subroutine calculates the height of the neutral plane from the temperature profile at the room opening and one static pressure probe and the mass flow rate of hot gas in and out of the fire room based only on the gas temperature and opening dimensions 5

The neutral plane is found by solving the following equation for "Hnp":

$$
\mathrm{dP}+\mathrm{g} * \text { rho } * \operatorname{SUM}[(1 .-(\mathrm{Ta} / \mathrm{T})) * \mathrm{dH}]=0.0
$$

where,

dP: pressure ( $\mathrm{Pa}$ ) at an arbitrarily chosen height, "Hp" (m)

g: acceleration due to gravity $=9.8 \mathrm{~m} / \mathrm{s}^{2}$

rho: density of air ( $\mathrm{kg} / \mathrm{cu} \mathrm{m}$ ) at temperature "Ta"

Ta: absolute ambient temperature (K)

$\mathrm{T}$ : absolute temperature $(\mathrm{K})$ at some height, " $\mathrm{H}$ " (m), in interior of room, where $\mathrm{Hp}<=\mathrm{H}<=\mathrm{Hnp}$

5 Lee, B. T., Effect of Ventilation on the Rates of Heat, Smoke, and Carbon Monoxide Production in A Typical Jail Cell Fire, Nat. Bur. Stand., (U. S.), NBSIR 82-2469 (March 1982).

6 Lee, B. T., Effect of Wall and Room Surfaces on the Rates of Heat, Smoke, and Carbon Monoxide Production in A Park Lodging Bedroom Fire, Nat. Bur. Stand., (U. S.), NBSIR 85-2998 (February 1985). 
$\mathrm{dH}$ : segment height $(\mathrm{m})$, which is at most twice the accuracy of the calculation

SUM: the summation function over the range $\mathrm{Hp}$ to $\mathrm{Hnp}$ by $\mathrm{dH}$

Hnp: the neutral plane height (m)

Once the neutral plane height is calculated, the mass flow rates are calculated using the following equation:

Mdot $=\mathrm{C} * \mathrm{~W} *$ rho $* \mathrm{Ta} * \operatorname{SQRT}(2 \mathrm{~g}) * \operatorname{SUMd}[\operatorname{SQRT}(1 / \mathrm{Td} * \operatorname{SUMi}[(1 / \mathrm{Ta}-1 / \mathrm{Ti}) * \mathrm{dHi}]) * \mathrm{dHd}]$

where,

Mdot: mass flow rate $(\mathrm{kg} / \mathrm{s})$

C: flow coefficient; defaults are 0.68 for inflow and 0.73 for outflow

W: the width of the opening (m)

rho: density of air ( $\mathrm{kg} / \mathrm{cu} \mathrm{m}$ ) at temperature "Ta"

Ta: absolute ambient temperature (K)

g: acceleration due to gravity $=9.8 \mathrm{~m} / \mathrm{s}^{2}$

SQRT: the square root function

dHd: segment height in doorway (m)

$\mathrm{Td}$ : absolute temperature (K) at some height, " $\mathrm{H}$ " (m) in doorway

Ti: absolute temperature $(K)$ at some height, " $H "$ (m) in interior

$\mathrm{dHi}$ : segment height in interior (m)

SUMd: the summation function over the range

Hnp to zero by -dHd for in-flow and

Hnp to Hdoor by dHd for out-flow

SUMi: the summation function over the range

Hnp to $\mathrm{H}$ by - dHi for in-flow and

Hnp to $\mathrm{H}$ by dHi for out-flow

Hdoor: the height of the opening (m)

Hnp: the height of the neutral plane (m)

The results are stored in channels created by the program. This subroutine does not reduce any raw data. 


\begin{tabular}{|c|c|c|c|}
\hline Input & Variables & Format & Comments \\
\hline $\mathrm{HCgl}$ & $\begin{array}{l}\text { WDOOR, HDOOR, HINT, } \\
\text { INP, IMFI, IMFO, } \\
\text { CPR or JPR, PPR, } \\
\text { CTAMB or JTAMB, } \\
{[, \text { FCI [, FCO }} \\
{[, \text { HACC]]] X }}\end{array}$ & $\begin{array}{c}\text { EVALU8 } \\
\text { (NPDI } \\
[2])\end{array}$ & 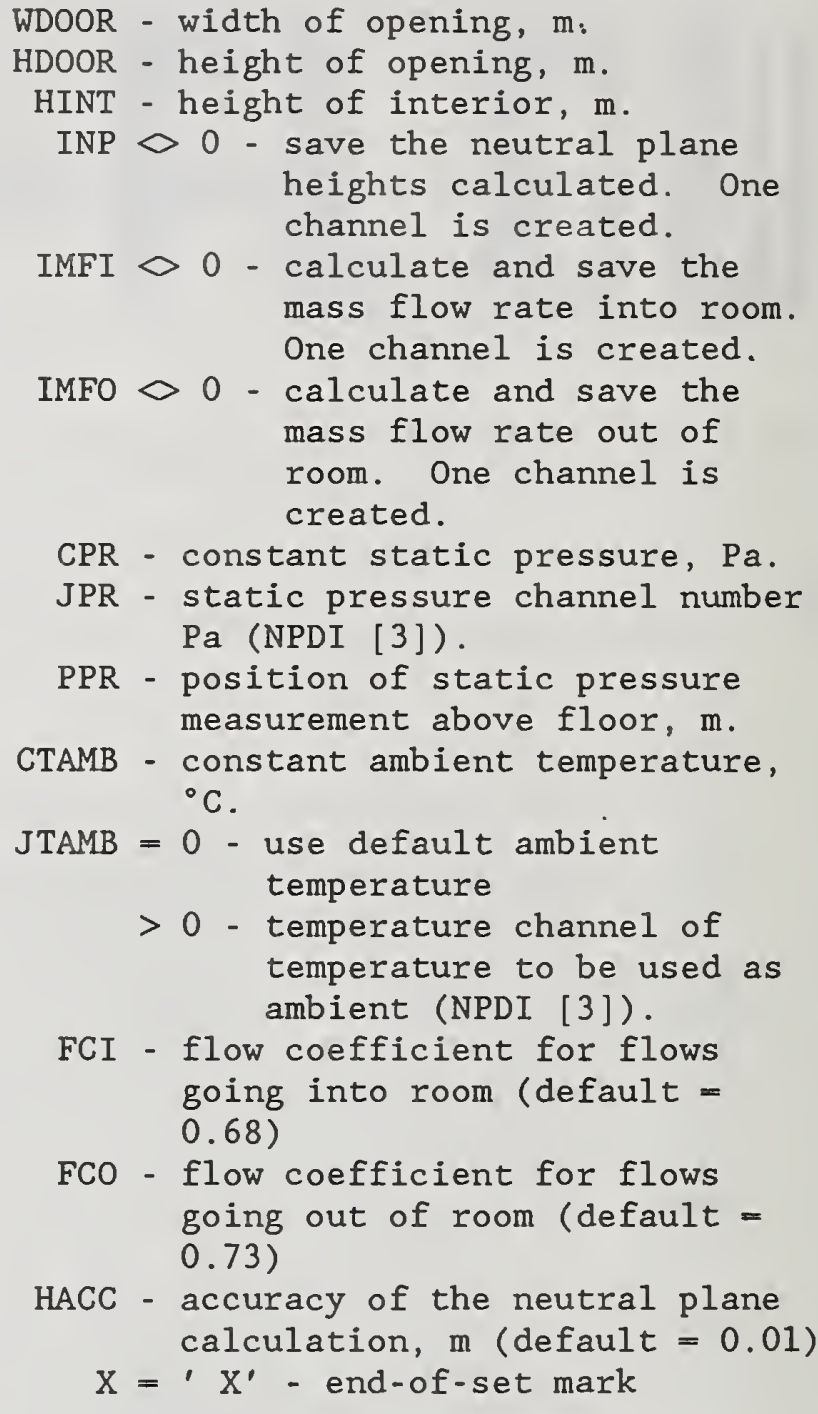 \\
\hline Input & Variables & Format & Comments \\
\hline $\mathrm{HCg} 2$ & $\begin{array}{l}\operatorname{JTCD}(1), \operatorname{JTCD}(2), \ldots \\
\operatorname{JTCD}(i) \mathrm{X} \\
1<=i<=50\end{array}$ & $\begin{array}{l}\text { EVALU8 } \\
\text { (NPDI } \\
[2])\end{array}$ & $\begin{array}{c}\text { JTCD - doorway thermocouple channel } \\
\left.\text { number, }{ }^{\circ} \mathrm{C} \text { (NPDI }[3]\right) \\
\mathrm{X}={ }^{\prime} \mathrm{X}^{\prime} \text { - end-of-set mark }\end{array}$ \\
\hline Input & Variables & Format & Comments \\
\hline $\mathrm{HCg} 3$ & $\begin{array}{l}\mathrm{PD}(1), \mathrm{PD}(2), \ldots \\
\mathrm{PD}(\mathrm{i}) \mathrm{X} \\
1<=\mathrm{i}<=50\end{array}$ & $\begin{array}{l}\text { EVALU8 } \\
\text { (NPDI } \\
[2])\end{array}$ & $\begin{aligned} \text { PD - doorway thermocouple positions } \\
\text { (height above floor) of above } \\
\text { thermocouples in same order, } m \text {. } \\
X=' X^{\prime} \text { - end-of-set mark }\end{aligned}$ \\
\hline
\end{tabular}




\begin{tabular}{|c|c|c|c|}
\hline Input & Variables & Format & Comments \\
\hline $\mathrm{HCg} 4$ & $\begin{array}{l}\operatorname{JTCI}(1), \operatorname{JTCI}(2), \ldots \\
\operatorname{JTCI}(i) X \\
1<=1<=50\end{array}$ & $\begin{array}{l}\text { EVALU8 } \\
\text { (NPDI } \\
[2])\end{array}$ & $\begin{array}{c}\text { JTCI - interior thermocouple channel } \\
\text { number, }{ }^{\circ} \mathrm{C} \text { (NPDI [3]). } \\
\mathrm{X}={ }^{\prime} \mathrm{X}^{\prime} \text { - end-of-set mark }\end{array}$ \\
\hline Input & Variables & Format & Comments \\
\hline $\mathrm{HCg} 5$ & $\begin{array}{l}P I(1), P I(2), \ldots \\
P I(i) X \\
1<i<=50\end{array}$ & $\begin{array}{l}\text { EVALU8 } \\
(\text { NPDI } \\
[2])\end{array}$ & $\begin{aligned} \text { PI - interior thermocouple positions } \\
\text { (height above floor) of above } \\
\text { thermocouples in same order, } m . \\
X=' X^{\prime} \text { - end-of-set mark }\end{aligned}$ \\
\hline
\end{tabular}

Enter Another Command (Data Input H1) 


\subsection{Part H, Class C, Subpart h: Input Specified by Complex Command MASS-FLOW-2}
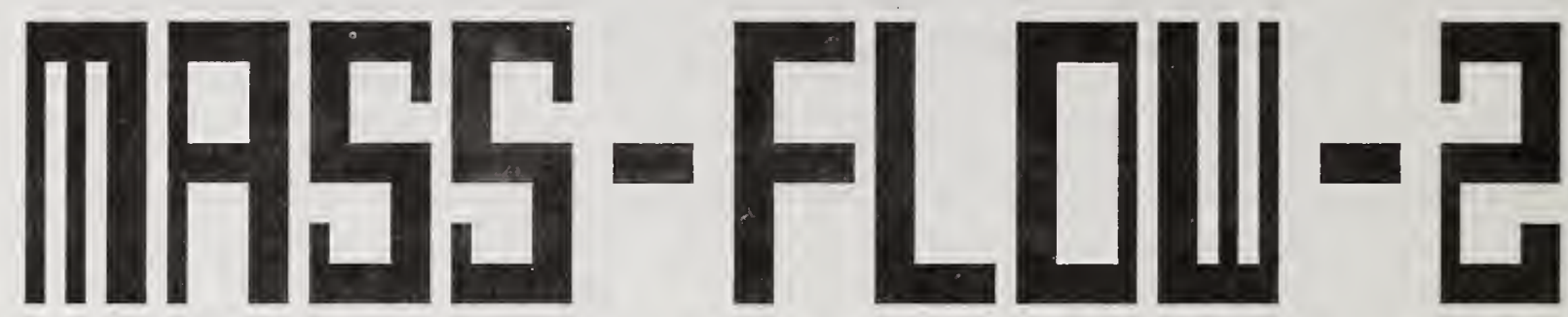

The subroutine is very similar to the one used for the command MASS-FLOW, except that the neutral plane height is an input value instead of a calculated value. The mass flow rate of gas in and out of the fire room is still based on the gas temperature and the opening dimensions.

The mass flow rates are calculated using the following equation:

Mdot $=\mathrm{C} * W * \operatorname{rho} * \mathrm{Ta} * \operatorname{SQRT}(2 \mathrm{~g}) * \operatorname{SUMd}[\operatorname{SQRT}(1 / \mathrm{Td} * \operatorname{SUMi}[(1 / \mathrm{Ta}-1 / \mathrm{Ti}) * \mathrm{dHi}]) * \mathrm{dHd}]$

where,

Mdot: mass flow rate $(\mathrm{kg} / \mathrm{s})$

C: flow coefficient; defaults are 0.68 for inflow and 0.73 for outflow

$\mathrm{W}$ : the width of the opening (m)

rho: density of air ( $\mathrm{kg} / \mathrm{cu} \mathrm{m}$ ) at temperature "Ta"

Ta: absolute ambient temperature (K)

$\mathrm{g}$ : acceleration due to gravity $=9.8 \mathrm{~m} / \mathrm{s}^{2}$

SQRT: the square root function

dHd: segment height in doorway ( $m$ )

Td: absolute temperature $(K)$ at some height, " $H "(m)$ in doorway

Ti: absolute temperature $(K)$ at some height, " $H "(m)$ in interior

dHi: segment height in interior ( $m$ )

SUMd: the summation function over the range Hnp to zero by -dHd for in-flow and

Hnp to Hdoor by dHd for out-flow 
SUMi: the summation function over the range

Hnp to $\mathrm{H}$ by -dHi for in-flow and

Hnp to $\mathrm{H}$ by $\mathrm{dHi}$ for out-flow

Hdoor: the height of the opening (m)

Hnp: the height of the neutral plane (m)

The results are stored in channels created by the program. This subroutine does not reduce any raw data.

\begin{tabular}{|c|c|c|c|}
\hline Input & Variables & Format & Comments \\
\hline $\mathrm{HCh} 1$ & $\begin{array}{l}\text { WDOOR, HDOOR, HINT, CNP } \\
\text { or JNP, IMFI, IMFO, } \\
\text { CTAMB or JTAMB, } \\
{[, \text { FCI [,FCO }} \\
{[, \text { HACC ] ] X }}\end{array}$ & $\begin{array}{c}\text { EVALU8 } \\
\text { (NPDI } \\
[2])\end{array}$ & $\begin{aligned} \text { WDOOR - width of opening, m. } \\
\text { HDOOR - height of opening, m. } \\
\text { HINT - height of interior, m. } \\
\text { CNP - constant neutral plane height, } \\
\text { m. } \\
\text { JNP - neutral plane height channel } \\
\text { number, m (NPDI [3]). } \\
\text { IMFI > } 0 \text { - calculate and save the } \\
\quad \text { mass flow rate into room. } \\
\text { IMFO > } 0 \text { - calculate and save the } \\
\quad \text { mass flow rate out of } \\
\quad \text { room. One channel is } \\
\quad \text { created. } \\
\text { CPR - constant static pressure, Pa. } \\
\text { JPR - static pressure channel number, } \\
\text { Pa (NPDI [ } 3 \text { ]). } \\
\text { PPR - position of static pressure } \\
\text { measurement above floor, m. } \\
\text { CTAMB - constant ambient temperature, } \\
\text { JC. } \\
\text { JTAMB = } 0 \text { - use default ambient } \\
\text { temperature } \\
>\text { o - temperature channel of } \\
\text { temperature to be used as } \\
\text { FCI - flow coefficient for flows } \\
\text { going into room (default = } \\
0.68 \text { ) }\end{aligned}$ \\
\hline
\end{tabular}




\begin{tabular}{|c|c|c|c|}
\hline & & & $\begin{array}{l}\text { FCO - flow coefficient for flows } \\
\text { going out of room (default }= \\
0.73 \text { ) } \\
\text { HACC - accuracy of the neutral plane } \\
\text { calculation, } m \text { (default }=0.01) \\
X=' X^{\prime} \text { - end-of-set mark }\end{array}$ \\
\hline Input & Variables & Format & Comments \\
\hline $\mathrm{HCh} 2$ & $\begin{array}{l}\operatorname{JTCD}(1), \operatorname{JTCD}(2), \ldots \\
\operatorname{JTCD}(i) \times \\
1<=i<=50\end{array}$ & $\begin{array}{l}\text { EVALU8 } \\
\text { (NPDI } \\
[2])\end{array}$ & $\begin{array}{c}\text { JTCD - doorway thermocouple channel } \\
\text { number, }{ }^{\circ} \mathrm{C} \text { (NPDI [3]). } \\
\mathrm{X}=' \mathrm{X}^{\prime} \text { - end-of-set mark }\end{array}$ \\
\hline Input & Variables & Format & Comments \\
\hline $\mathrm{HCh} 3$ & $\begin{array}{l}\mathrm{PD}(1), \mathrm{PD}(2), \ldots \\
\mathrm{PD}(\mathrm{i}) \mathrm{X} \\
1 .<=i<=50\end{array}$ & $\begin{array}{l}\text { EVALU8 } \\
\text { (NPDI } \\
[2])\end{array}$ & $\begin{aligned} \text { PD - doorway thermocouple positions } \\
\text { (height above floor) of above } \\
\text { thermocouples in same order, } m \text {. } \\
X=' X^{\prime} \text { - end-of-set mark }\end{aligned}$ \\
\hline Input & Variables & Format & Comments \\
\hline $\mathrm{HCh} 4$ & $\begin{array}{l}\operatorname{JTCI}(1), \operatorname{JTCI}(2), \ldots \\
\operatorname{JTCI}(i) \mathrm{X} \\
1<i<=50\end{array}$ & $\begin{array}{l}\text { EVALU8 } \\
\text { (NPDI } \\
[2])\end{array}$ & $\begin{array}{c}\text { JTCI - interior thermocouple chaninel } \\
\text { number, }{ }^{\circ} \mathrm{C} \text { (NPDI [3]) } \\
\mathrm{X}=' \mathrm{X}^{\prime} \text { - end-of-set mark }\end{array}$ \\
\hline Input & Variables & Format & Comments \\
\hline HCh5 & $\begin{array}{l}\mathrm{PI}(1), \operatorname{PI}(2), \ldots \\
\operatorname{PI}(i) X \\
1<i<=50\end{array}$ & $\begin{array}{l}\text { EVALU8 } \\
\text { (NPDI } \\
[2])\end{array}$ & $\begin{aligned} \text { PI - interior thermocouple positions } \\
\text { (height above floor) of above } \\
\text { thermocouples in same order, } m . \\
X=' X^{\prime} \text { - end-of-set mark }\end{aligned}$ \\
\hline
\end{tabular}

Enter Another Command (Data Input H1) 
15.9 Part H, Class C, Subpart 1: Input Specifled by Complex Command MASS-FLOW-3

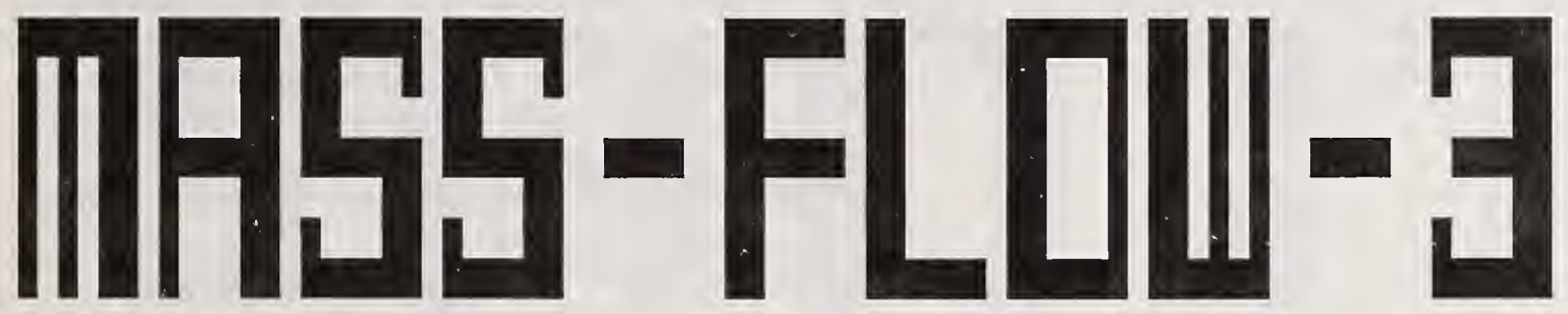

The subroutine calculates the mass flow rate of gas through an opening where the gas flow is in only one direction and the velocity, temperature, and area perpendicular to the flow are known. It is particularly well suited for calculations in an exhaust duct.

The equation for the mass flow rate is

$$
\mathrm{m}^{\prime}=\mathrm{c} * \mathrm{~V} * \mathrm{~A} * \text { rho } *(\mathrm{Ta} / \mathrm{T})
$$

where,

$\mathrm{m}^{\prime}$ - mass flow rate of gas, $\mathrm{kg} / \mathrm{s}$

$c$ - empirical flow coefficient, default $=1.0$

$\mathrm{V}$ - gas velocity, $\mathrm{m} / \mathrm{s}$

A - cross sectional area of the duct (perpendicular to the direction of gas flow, $\mathrm{m}^{2}$

rho - density of air at temperature "Ta", $\mathrm{kg} / \mathrm{m}^{3}$

$\mathrm{Ta}$ - absolute ambient temperature, default $=293.15 \mathrm{~K}(20 \mathrm{C})$

$\mathrm{T}$ - absolute temperature of gas, $\mathrm{K}$

The calculated results are stored in a channel created by the program. One channel is created each time the command MASS-FLOW-3 is given. The subroutine does not reduce any raw data. 


\begin{tabular}{|c|c|c|c|}
\hline Input & Variables & Format & Comments \\
\hline HCil & $\begin{array}{l}\text { JVEL, AREA, JTEMP or } \\
\text { CTEMP [, C [, CTAMB or } \\
\text { JTAMB] ] X }\end{array}$ & $\begin{array}{l}\text { EVALU8 } \\
\text { (NPDI } \\
[2])\end{array}$ & 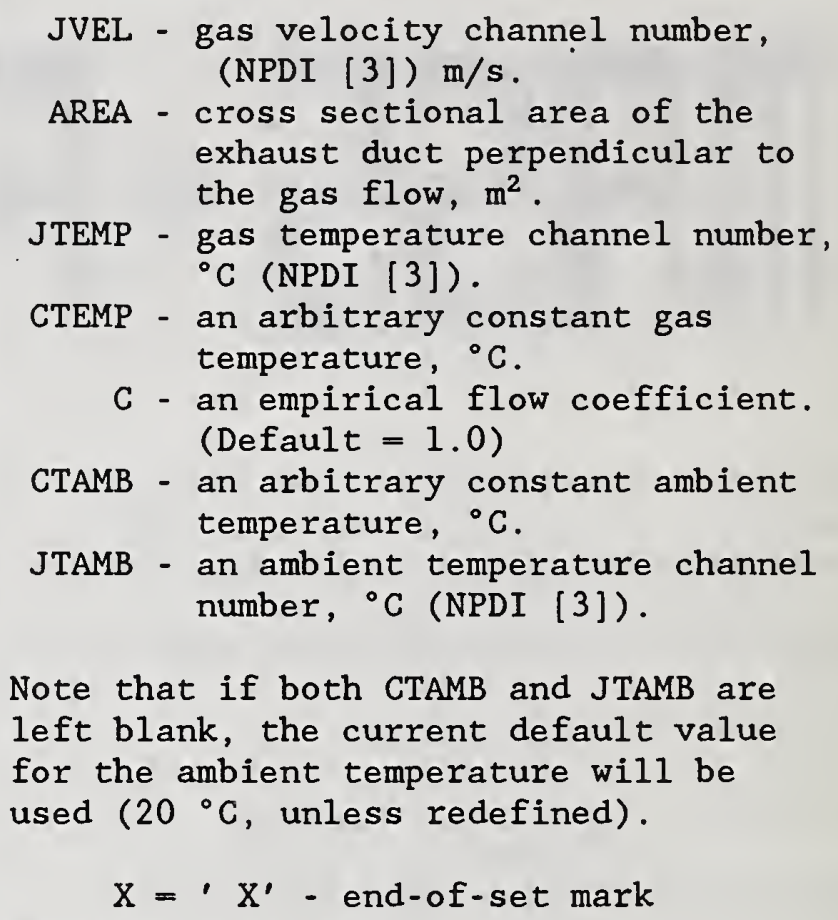 \\
\hline
\end{tabular}

Enter Another Command (Data Input H1) 
15.10 Part H, Class C, Subpart J: Input Specifled by Complex Command STATIC
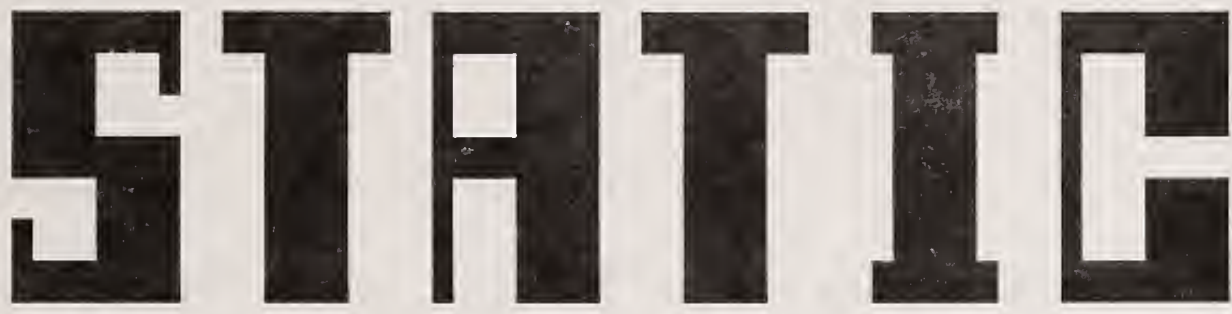

The subroutine uses static pressure measurements in conjunction with some other test parameters, such as temperature, to calculate various quantities of interest.

Generally, if more than one probe is used they are arranged such that a pressure "profile" of the room from top to bottom can be ascertained. In addition, the profile makes it possible to calculate gas velocities through openings in the chamber, the neutral plane and thermal discontinuity heights in the openings, and the interior gas temperature in the chamber.

The standard unit for pressure is the pascal ( $\mathrm{Pa}$ ). The calculated velocities, heights, and temperatures are in meters per second (m/s), meters (m), and degrees Celsius $\left({ }^{\circ} \mathrm{C}\right)$, respectively.

Gas Velocities

The gas velocity, $v(\mathrm{~m} / \mathrm{s})$, through an opening at a given height, $z(\mathrm{~m})$, can be 
calculated from the static pressure at height $z$ and the average local gas temperature:

$$
\mathrm{v}(\mathrm{z})=(2 * \mathrm{dP}(\mathrm{z}) / \mathrm{p}(\mathrm{z})) * * .5
$$

where $\operatorname{dP}(z)$ is the pressure difference at height $z$ with respect to ambient static pressure ( $\mathrm{Pa}$ ) and $\mathrm{p}(\mathrm{z})$ is the density of the gas $\left(\mathrm{kg} / \mathrm{m}^{3}\right)$ at height $\mathrm{z}$. Using the gas law:

$$
p(z)=p(0) * T(0) / T(z)
$$

where $T(z)$ is the absolute average local temperature $(K)$ and $p(0)$ and $T(0)$ are constant, arbitrarily chosen gas density and temperature $\left(p(0)=1.197 \mathrm{~kg} / \mathrm{m}^{3}\right.$, $T(0)=295(K)$. The velocity equation then becomes

$$
\begin{aligned}
\mathrm{v} & =[2 * \mathrm{~T}(\mathrm{z}) * \mathrm{dP}(\mathrm{z}) /(\mathrm{p}(0) * \mathrm{~T}(0))] * * .5 \\
& =.07526 *(\mathrm{~T}(z) * \mathrm{dP}(\mathrm{z})) * * .5
\end{aligned}
$$

Neutral Plane and Thermal Discontinuity Heights

To find the neutral plane and thermal discontinuity heights from the static pressure "profile", two least square straight lines are found: one for the probes above the neutral plane (positive pressure difference with ambient), one for the probes below the neutral plane (negative pressure difference with ambient). The Y-axis intercept for the former yields the neutral plane height; 
the intersection of the two yields the thermal discontinuity height. In addition, once the thermal discontinuity height is found, the first equation can be rearranged and evaluated to find the static pressure at that height.

The equations for the two lines are of the form:

$$
\begin{aligned}
& z=a * d P+b \text { and } \\
& z^{\prime}=c * d P^{\prime}+d
\end{aligned}
$$

where $z$ and $z^{\prime}$ are the heights above the floor and $d P$ and $d P^{\prime}$ are the pressure differences with respect to ambient static pressure at those heights.

The equations for the coefficients are:

$n * \operatorname{SUM}[d P(i) * z(i), i=1, n]-\operatorname{SUM}[d P(i), i=1, n] * \operatorname{SUM}[z(i), i=1, n]$

$a=$

$n * \operatorname{SUM}[\operatorname{dP}(i) * * 2, i=1, n]-\operatorname{SUM}[d P(i), i=1, n] * * 2$

$b=\frac{\operatorname{SUM}[z(i), i=1, n]-a * \operatorname{SUM}[d P(i), i=1, n]}{n}$

$c=\frac{n^{\prime} * \operatorname{SUM}\left[d P^{\prime}(i) * z^{\prime}(i), i=1, n^{\prime}\right]-\operatorname{SUM}\left[d P^{\prime}(i), i=1, n^{\prime}\right] * \operatorname{SUM}\left[z^{\prime}(i), i=1, n^{\prime}\right]}{n^{\prime} * \operatorname{SUM}\left[d P^{\prime}(i) * * 2, i=1, n^{\prime}\right]-\operatorname{SUM}\left[d P^{\prime}(i), i=1, n^{\prime}\right] * * 2}$

$d=\frac{\operatorname{SUM}\left[z^{\prime}(i), i=1, n^{\prime}\right]-c * \operatorname{SUM}\left[d P^{\prime}(i), i=1, n^{\prime}\right]}{n^{\prime}}$

where $\mathrm{n}$ and $\mathrm{n}^{\prime}$ are the number of probes above and below the neutral plane, respectively, and SUM is the summation function. The neutral plane height, 
$z(n p)$, equals $b$. The thermal discontinuity height occurs at the height where dP $=d P^{\prime}=d P(t d)$ and $z=z^{\prime}=z(t d)$. Then, solving the two equations,

$$
\begin{aligned}
& z(t d)=a * d P(t d)+b \quad \text { and } \\
& z(t d)=c * d P(t d)+d
\end{aligned}
$$

simultaneously for the thermal discontinuity height yields

$$
z(t d)=\frac{(b * c)-(a * d)}{(c-a)}
$$

Rearranging the first equation and evaluating at height $z(t d)$ yields the pressure at the thermal discontinuity height:

$$
\begin{aligned}
& z(t d)=a * d P(t d)+b \\
& d P(t d)=b * z(t d) / a
\end{aligned}
$$

Interior Gas Temperatures

The interior gas temperature $\mathrm{T}\left({ }^{\circ} \mathrm{C}\right)$ at a given height $\mathrm{z}$ is calculated from the difference in pressure between height $z$ and the thermal discontinuity height and the difference in position between the two heights.

$$
T(z)=\frac{T(a m b)}{1-(D P /(G * P(a m b) * D Z))}-273.15
$$


where $D P=d P(z)-d P(t d), D Z=z-z(t d), G$ is the acceleration due to gravity $\left(=9.806 \mathrm{~m} / \mathrm{s}^{2}\right)$, and $\mathrm{T}(\mathrm{amb})$ and $\mathrm{p}(\mathrm{amb})$ are the ambient gas temperature $(\mathrm{K})$ and density $\left(\mathrm{kg} / \mathrm{m}^{3}\right)$.

The calculated values are stored in channels created by the program. This subroutine does not reduce any raw data. 


\begin{tabular}{|c|c|c|c|}
\hline Input & Variables & Format & Comments \\
\hline $\mathrm{HCj} 1$ & $\begin{array}{l}\text { NPROBE, IVEL }\{, \text { JTAVG }\} \text {, } \\
\text { INPTD }\{, \text { HEIGHT }\} \\
\text { ITEMP }[, \text { CTAMB or } \\
\text { JTAMB }] \mathrm{X}\end{array}$ & $\begin{array}{l}\text { EVALU8 } \\
\text { (NPDI } \\
[2])\end{array}$ & 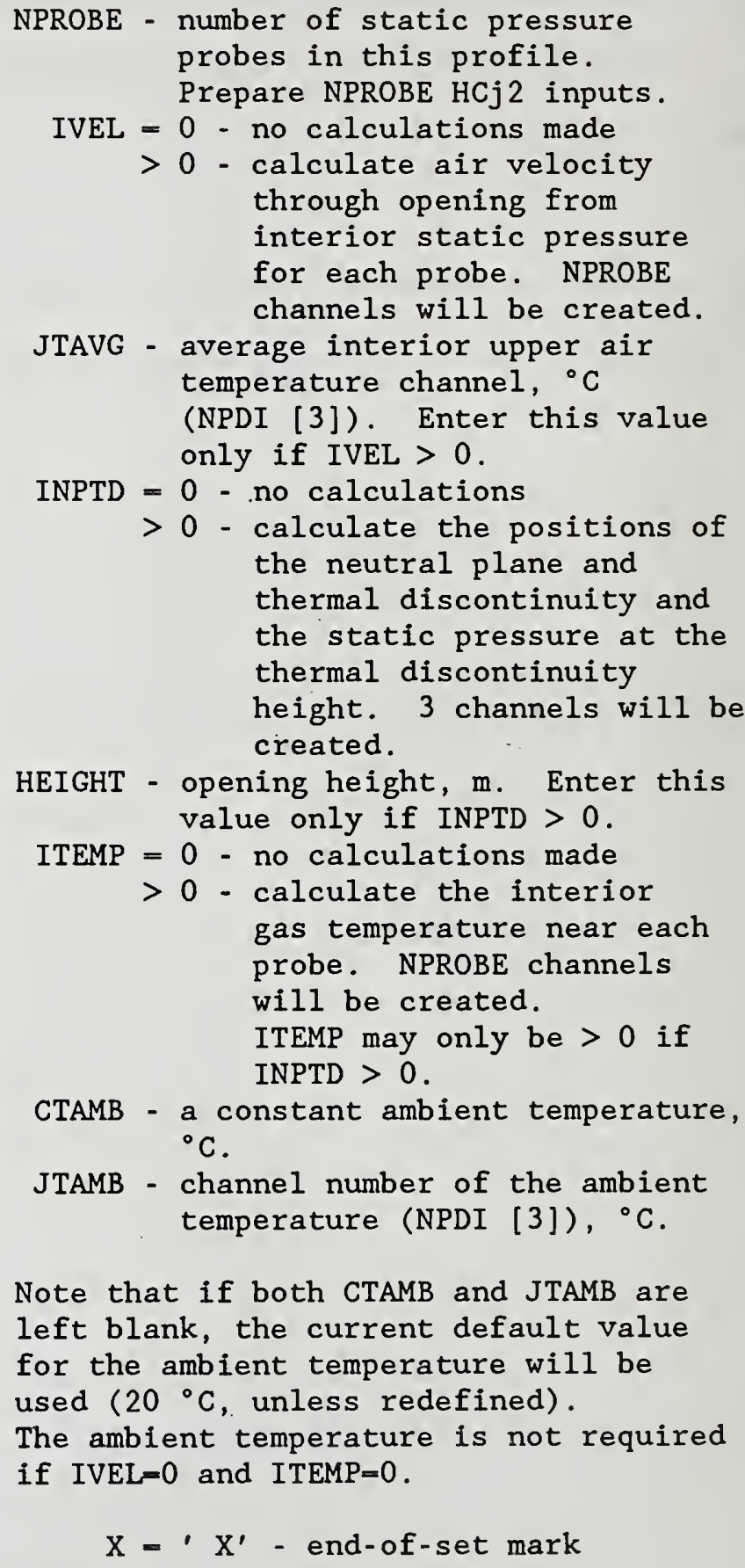 \\
\hline
\end{tabular}




\begin{tabular}{|c|c|c|c|}
\hline Input & Variables & Format & Comments \\
\hline $\mathrm{HCj} 2$ & JCHAN, POS (, JTOPEN $X$ & $\begin{array}{c}\text { EVALU8 } \\
\text { (NPDI } \\
[2])\end{array}$ & $\begin{aligned} \text { JCHAN - } & \text { static pressure channel number, } \\
& \text { Pa (NPDI [3]). } \\
\text { POS - } & \text { position of probe relative to } \\
& \text { floor, } m . \\
\text { JTOPEN - } & \text { corresponding opening } \\
& \text { thermocouple channel (NPDI [3]) } \\
& \text { Enter this value only if } \\
& \text { IVEL }>\text { (see input HCj1). } \\
X= & ' \mathrm{X}^{\prime}-\text { end-of-set mark }\end{aligned}$ \\
\hline
\end{tabular}

Enter Another Command (Data Input H1) 
15.11 Part H, Class C, Subpart k: Input Specifled by Complex Command SURFACE
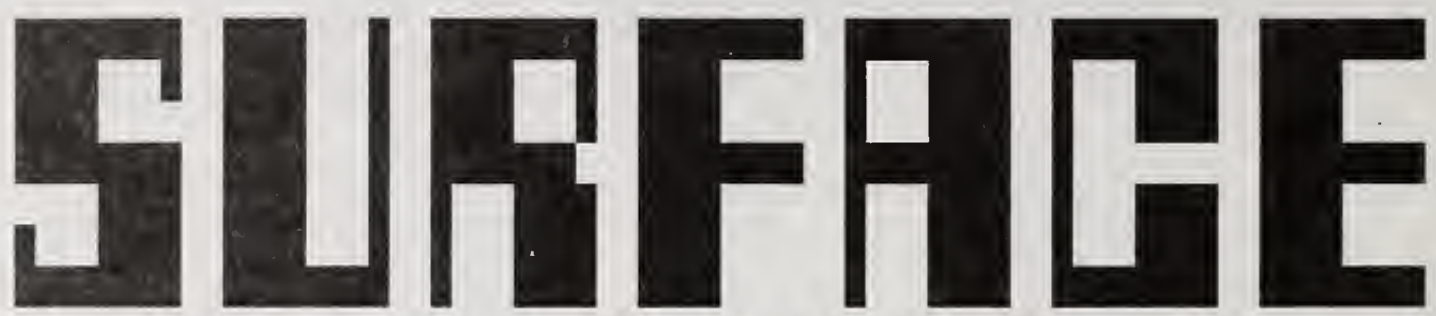

The subroutine calculates the average and total heat loss rate and the incident heat flux to a semi-infinite surface (such as a wall or ceiling) from the surface temperature and material characteristics ${ }^{7}$. The three equations are related to each other and are as follows:

$$
\begin{aligned}
q(a, j)= & k / 2 *(p i / a) * * 0.5 * \frac{(T-T(0))}{(t(j)-t(j-1)) * * 0.5}- \\
& \operatorname{SUM}[q(a, i) *((t(j)-t(i-1)) * * 0.5-(t(j)-t(i)) * * 0.5), i=1, j-1] \\
q(t, j)= & q(a, j) * A \\
q(j)= & q(a, j)+e * s *(T * * 4)
\end{aligned}
$$

where

$$
\begin{aligned}
& q(a, j) \text { - average heat loss rate per unit area, } \mathrm{kW} / \mathrm{m}^{2} \text {, at time step } \mathrm{j} \\
& \mathrm{q}(t, j) \text { - total heat loss rate, } \mathrm{kW} \text {, at time step } \mathrm{j} \\
& \mathrm{q}(\mathrm{j}) \text { - incident heat flux, } \mathrm{kW} / \mathrm{m}^{2} \text {, at time step } \mathrm{j} \\
& \mathrm{k} \text { - thermal conductivity of surface, } \mathrm{kW} / \mathrm{m} *{ }^{\circ} \mathrm{C} \\
& \mathrm{pi} \text { - ratio of the radius squared to the area of a circle }=3.14159 \\
& \mathrm{a} \text { - alpha, thermal diffusivity of the surface material, } \mathrm{m}^{2} / \mathrm{s} \\
& \mathrm{T}(0) \text { - initial surface temperature, } \mathrm{K}
\end{aligned}
$$

7 Fang, J. B., and Breese, J. N., Fire Development in Residential Basement Rooms, Nat. Bur. Stand., (U. S.), NBSIR 80-2120 (October 1980). 


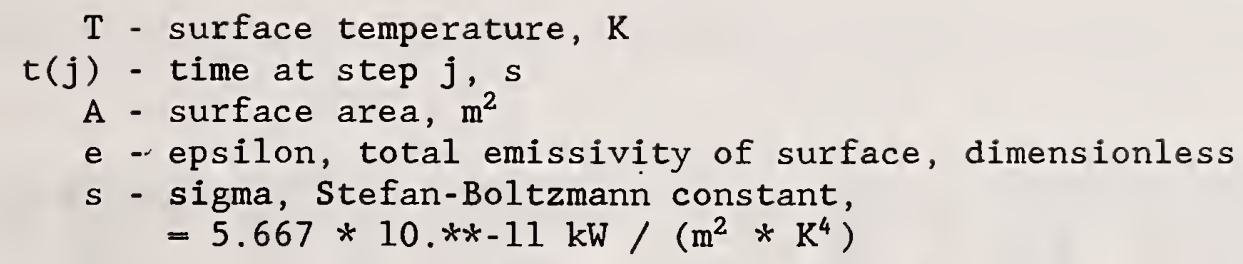

All three calculations are made at the same time and each is stored in its own channel created by the program. This subroutine does not reduce any raw data.

\begin{tabular}{|c|c|c|c|}
\hline Input & Variables & Format & Comments \\
\hline $\mathrm{HCk} 1$ & $\begin{array}{l}\text { IWTYPE, AREA, CTEMP or } \\
\text { JTEMP, JTIME [, TCONA, } \\
\text { TCONB, ALPHA, EPSIS ], } \\
\text { IAHLR, ITHLR, ITNHF } \\
\text { [, CTAMB or JTAMB] X }\end{array}$ & $\begin{array}{c}\text { EVALU8 } \\
\text { (NPDI } \\
{[2]}\end{array}$ & 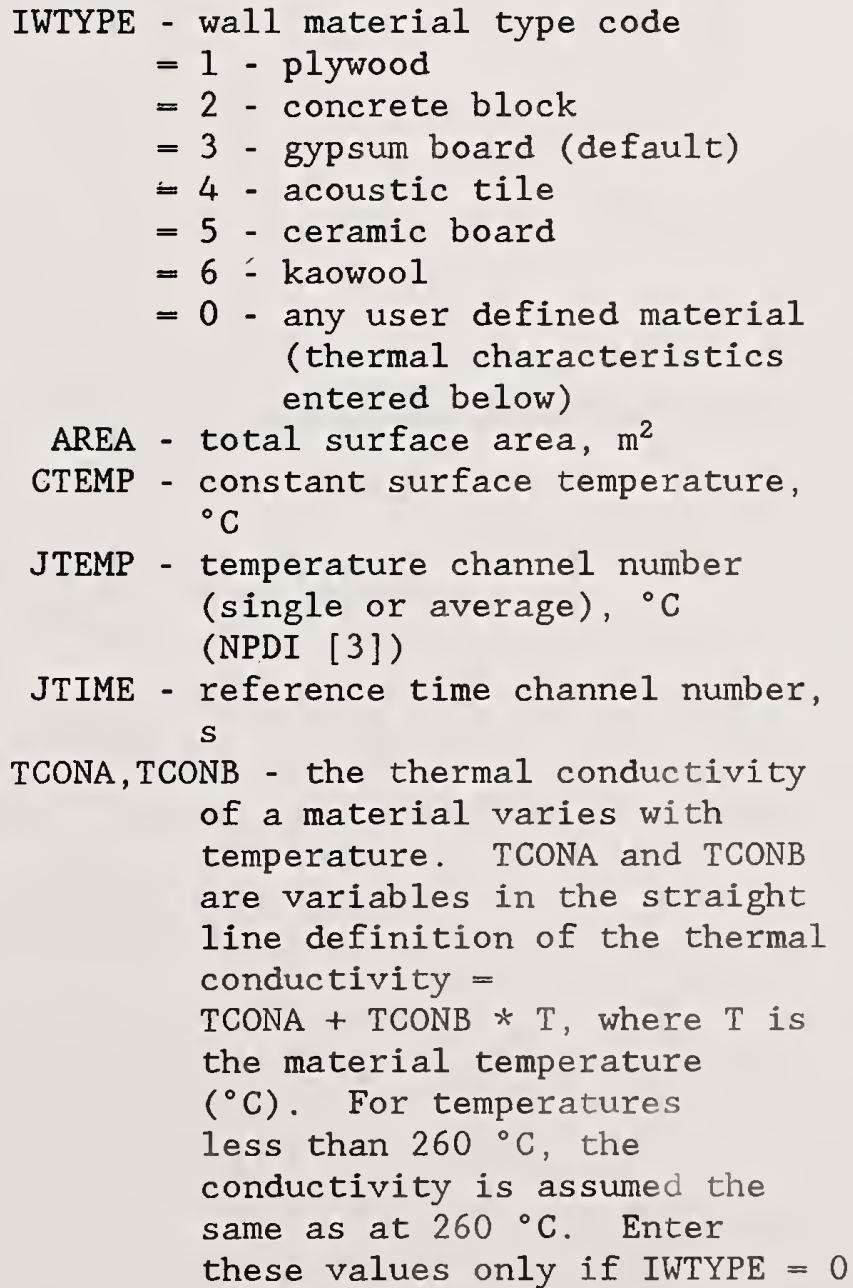 \\
\hline
\end{tabular}




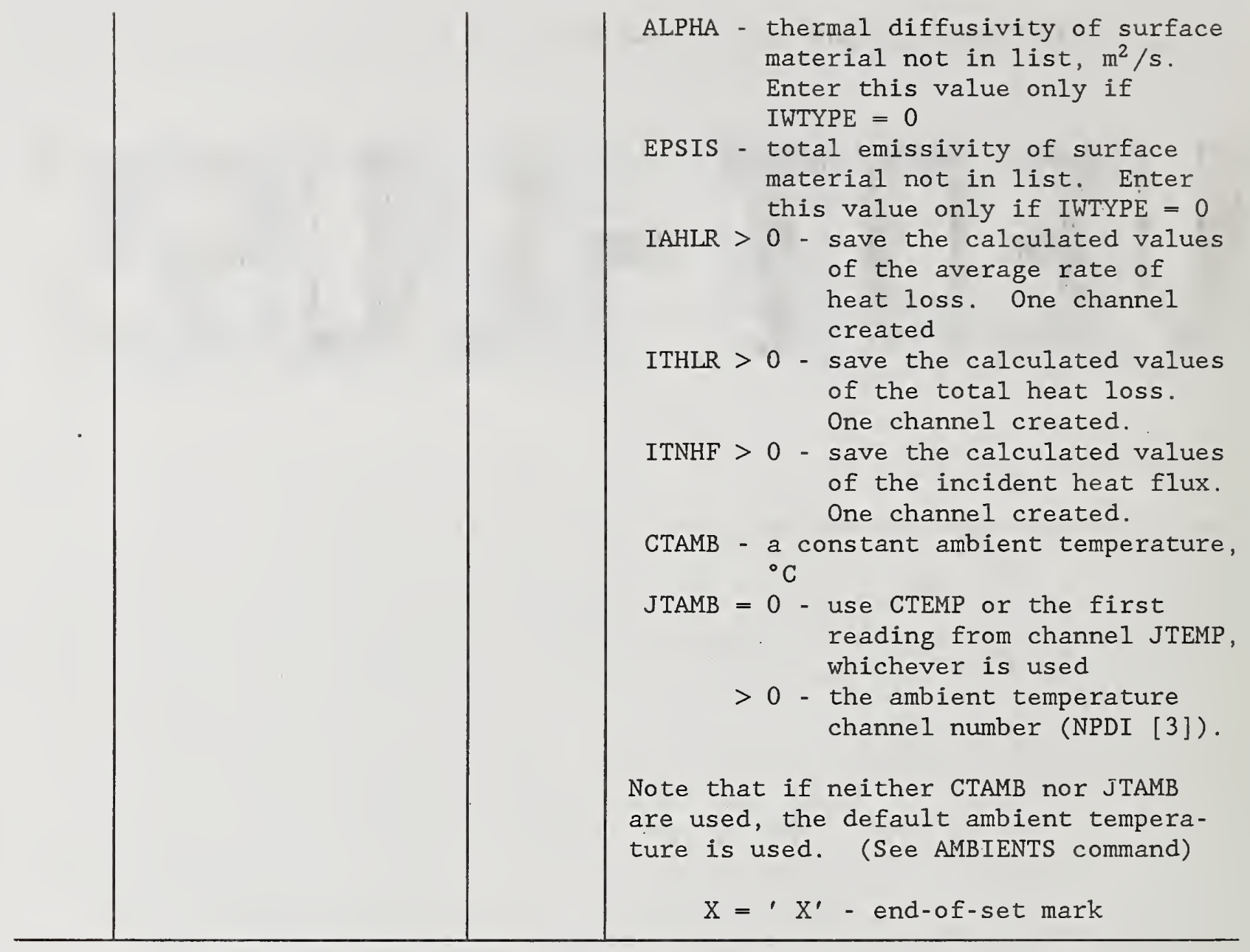

Enter Another Command (Data Input H1) 


\subsection{Part H, Class C, Subpart 1: Input Specifled by Complex Command VENT-LOSS}
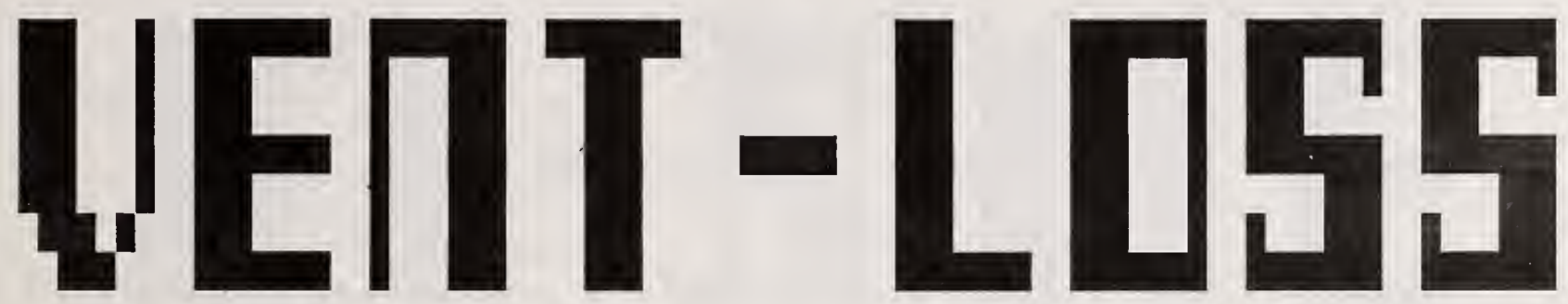

The subroutine calculates the radiative heat loss rate through an opening based on the temperature in the opening. The equation is as follows:

$$
Q^{\prime}=s * e * A *(T * * 4-T(a m b) * * 4)
$$

where

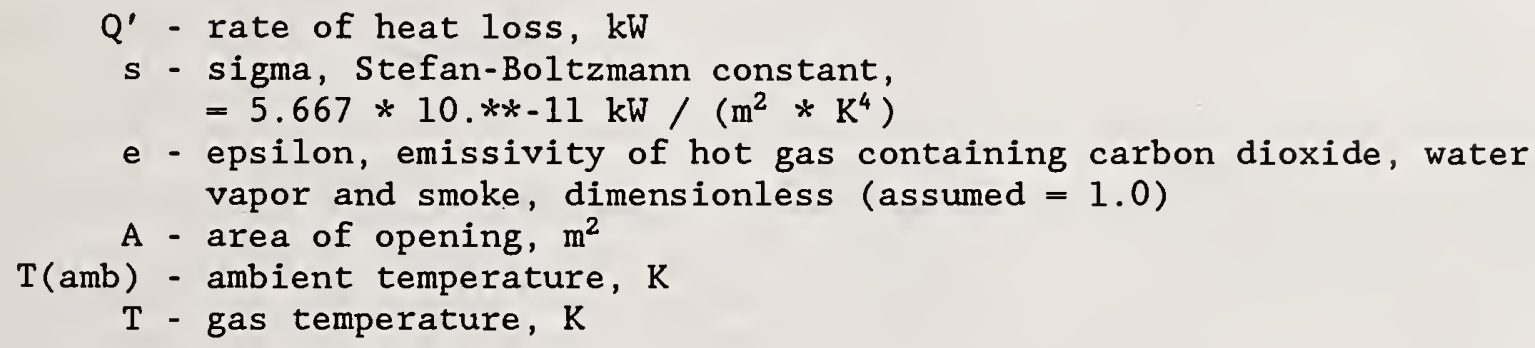

If a temperature profile is used (i.e. more than one thermocouple in the opening), the opening is divided into segments. The heat loss rate for each segment is calculated and added together to get the total.

The calculated results are stored in a channel created by the program. This subroutine does not reduce any raw data. 


\begin{tabular}{|c|c|c|c|}
\hline Input & Variables & Format & Comments \\
\hline $\mathrm{HCll}$ & $\begin{array}{l}\text { OPENWD, OPENHT, } \\
\text { [CTAMB or JTAMB] } X\end{array}$ & $\begin{array}{l}\text { EVALU8 } \\
(\text { NPDI } \\
[2])\end{array}$ & $\begin{array}{l}\text { One channel is created each time the } \\
\text { command VENT-LOSS is given. } \\
\text { OPENWD - width of the opening } \\
\text { perpendicular to the string of } \\
\text { thermocouples, } \mathrm{m}\end{array}$ \\
\hline Input & Variables & Format & Comments \\
\hline $\mathrm{HC} 12$ & $\begin{array}{l}\operatorname{JTEMP}(i) X \\
1<=i<=30\end{array}$ & $\begin{array}{l}\text { EVALU8 } \\
\text { (NPDI } \\
[2])\end{array}$ & $\begin{aligned} \text { JTEMP - } & \text { single or average temperature } \\
& \text { channel number, }{ }^{\circ} \mathrm{C} \\
& (\mathrm{NPDI}[3]) \\
\mathrm{X}= & \left(\mathrm{X}^{\prime}-\text { end-of-set mark }\right.\end{aligned}$ \\
\hline Input & Variables & Format & Comments \\
\hline $\mathrm{HC} 13$ & $\begin{array}{l}\operatorname{TMPLOC}(j) X \\
2<=j<=i\end{array}$ & $\begin{array}{l}\text { EVALU8 } \\
\text { (NPDI } \\
[2])\end{array}$ & $\begin{array}{l}\text { Enter this input only if } 2 \text { or more } \\
\text { temperature channels were entered above. } \\
\text { TMPLOC - the height of the temperature } \\
\text { reading (m) of the above } \\
\text { in the same order } \\
X=\text { ' } \mathrm{X} \text { ' - end-of-set mark }\end{array}$ \\
\hline
\end{tabular}

Enter Another Command (Data Input H1) 


\subsection{Part H, Class C, Subpart m: Input Specifled by Complex Command WT-RATE}
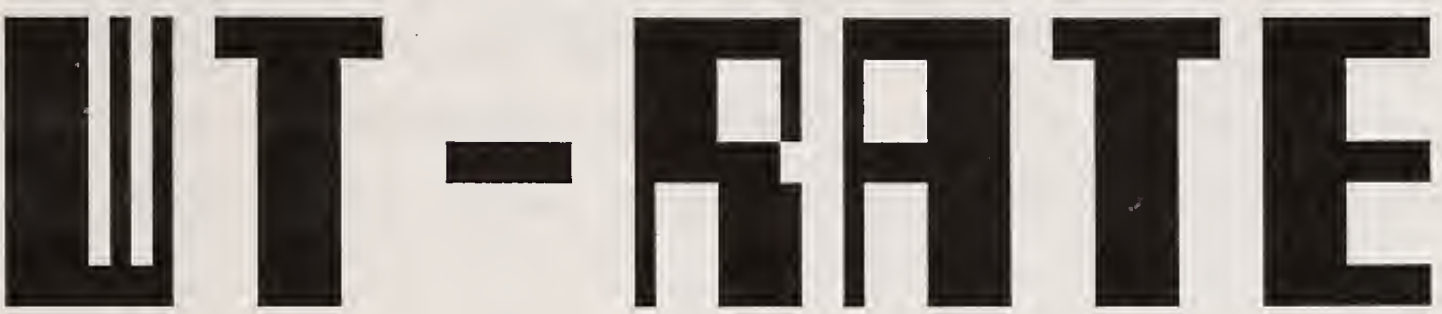

The subroutine makes two different calculations based on the total weight loss of an item: percent weight loss and rate of weight loss. Each of the calculations can be called individually. The calculated results are stored in their own channels created by the program. This subroutine does not reduce any raw data.

Percent Weight Loss

The percent weight loss is simply the total weight loss divided by the initial weight:

$$
\text { 8WL }=\frac{100 * \mathrm{~T}}{\mathrm{~W}}
$$


Rate of Weight Loss

The rate of weight loss $(\mathrm{kg} / \mathrm{s})$ is calculated by finding the least squares straight line fit of five adjacent points on the total weight loss curve. The rate of weight loss at the center point then, is simply the slope of the line:

$$
W^{\prime}=\frac{N * \operatorname{SUM}[t(i) * T(i), i=a, b]-\operatorname{SUM}[t(i), i=a, b] * \operatorname{SUM}[T(i), i=a, b]}{N * \operatorname{SUM}[t(i) * * 2, i=a, b]-(\operatorname{SUM}[t(i), i=a, b]) * * 2}
$$

where $\mathrm{W}^{\prime}$ is the rate of weight $\operatorname{loss}(\mathrm{kg} / \mathrm{s}), T$ is the total weight loss (kg) at time $t(s), N$ is the number of points fit (currently 5 ) and SUM is the summation function. In general (except near the end points), if I is the point of interest, then $a=I-2$ and $b=I+2$.

By dropping the "oldest" point and adding a new one, the slope can be found efficiently at every point.

Note that to be able to calculate the rate of weight loss, the corresponding time channel must be available. 


\begin{tabular}{|c|c|c|c|}
\hline Input & Variables & Format & Comments \\
\hline $\mathrm{HCml}$ & $\begin{array}{l}\text { JCHAN , NPWL }\{\text {, WEIGHT }\} \\
\text { NRWL }\{, \text { JTIME }\} X\end{array}$ & $\begin{array}{c}\text { EVALU8 } \\
\text { (NPDI } \\
[2])\end{array}$ & 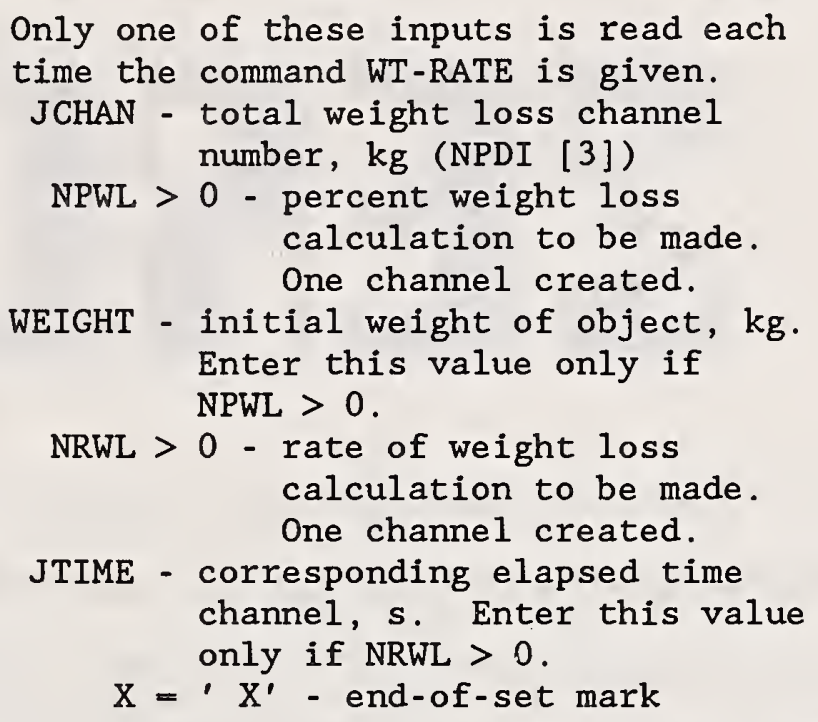 \\
\hline
\end{tabular}

Enter Another Command (Data Input H1) 
15.14 Part H, Class C, Subpart n: Input Specifled by Complex Command ZERO-TC
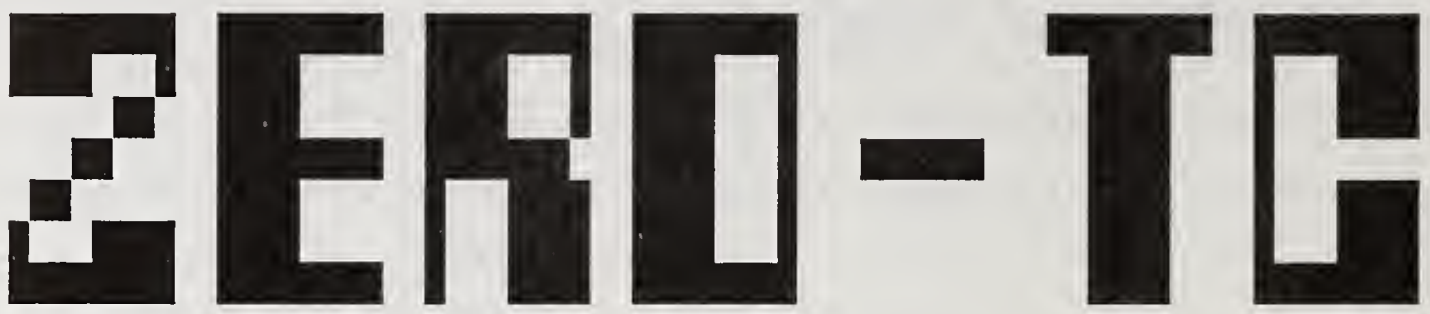

The subroutine finds the least squares fit of temperatures from various sized thermocouples and calculates the temperature for any other given size of thermocouple asing the derived coefficients. Typically, the temperature is calculated for a zero diameter thermocouple.

The evaluated equation is of the form:

$$
\mathrm{T}(\mathrm{e})=\mathrm{A} 0+\mathrm{A} 1 * \mathrm{D}(\mathrm{e})
$$

where $T(e)$ is the calculated temperature for a thermocouple of diameter $D(e)$, and $\mathrm{AO}$ and $\mathrm{Al}$ are the derived coefficients from the least squares fit:

$$
\begin{aligned}
& A 1=\frac{\operatorname{SUM}(D(i) * T(i), i=1, N)-(\operatorname{SUM}(D(i)) * \operatorname{SUM}(T(i)), i=1, N) / N}{\operatorname{SUM}(D(i) * * 2, i=1, N)-(\operatorname{SUM}(D(i), i=1, N)) * * 2 / N} \\
& A 0=\frac{\operatorname{SUM}(T(i), i=1, N)}{N}-A 1 * \frac{\operatorname{SUM}(D(i), i=1, N)}{N}
\end{aligned}
$$

where $D(i)$ and $T(i)$ are the thermocouple diameter and its related temperature, $N$ 
is the number of thermocouples, and SUM is the summation function. Note that at least two thermocouples must be input.

The calculated temperature is stored in a channel created by the program. This subroutine does not reduce any raw data. Any units may be used for the diameters and temperatures as long as they are consistent within a group.

\begin{tabular}{|c|c|c|c|}
\hline Input & Variables & Format & Comments \\
\hline $\mathrm{HCnl}$ & NGRP & $\begin{array}{c}\text { open } \\
\text { (NPDI } \\
{[1] \text { ) }}\end{array}$ & $\begin{array}{l}\text { Only one of these inputs is read each } \\
\text { time ZDIAM is called. } \\
\text { NGRP - number of groups of } \\
\text { thermocouples to be fit. } \\
\text { Prepare NGRP sets of HCn } 2 \\
\text { inputs. (NGRP channels created } \\
\text { one for each group.) }\end{array}$ \\
\hline Input & Variables & Format & Comments \\
\hline $\mathrm{HCn} 2$ & $\begin{array}{l}{[\operatorname{EVDIAM},] \operatorname{DIAM}(1)} \\
\operatorname{TEMP}(1), \operatorname{DIAM}(2) \\
\operatorname{TEMP}(2), \ldots, \operatorname{DIAM}(i) \\
\operatorname{TEMP}(i) \mathrm{X} \\
1<=i<=25\end{array}$ & $\begin{array}{c}\text { EVALU8 } \\
\text { (NPDI } \\
[2])\end{array}$ & $\begin{array}{l}\text { EVDIAM - diameter for which the derived } \\
\text { fit is evaluated (default, if } \\
\text { omitted, is zero) } \\
\text { DIAM - thermocouple diameter } \\
\text { TEMP - thermocouple channel number } \\
\text { (NPDI [3]). } \\
X=' \mathrm{X}^{\prime} \text { - end-of-set mark }\end{array}$ \\
\hline
\end{tabular}

Enter Another Command (Data Input $\mathrm{Hl}$ ) 
Appendix A

Sample Set of Input Data for RAPID 
To aid users in preparing input data from the execution of RAPID, a sample set of data that has been used to perform calculations on data collected by an automatic data acquisition system is presented on the following pages. A detailed description of each data input in the data set is presented to give the user an idea of the placement and function of the various data inputs used to perform calculations with RAPID. The information is divided into three columns. In column 1, the identifying data input number as indexed in this report and throughout the computer program is shown. In column 2, a detailed description of the variables read from the line of input and their values is presented. Column 3 shows the data input itself as it. would be used as input for RAPID. Note that many spaces may occur between data inputs in Column 3 . These multiple blank lines are only to allow a complete description of the data set and would not be Included in an input data flle for RAPID. A listing of the same data set exactly as it would look to execute RAPID is included at the end of this appendix. 
:

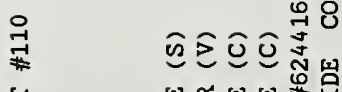

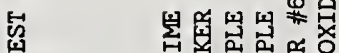

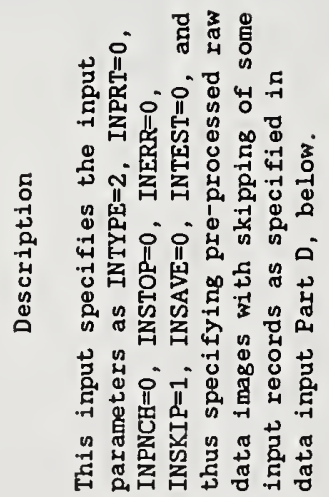

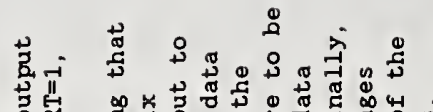
等

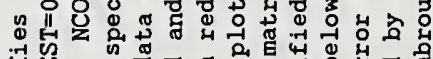

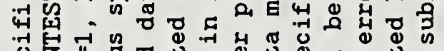

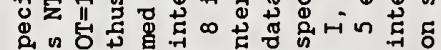

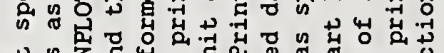

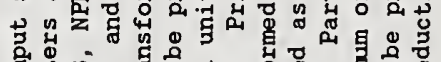

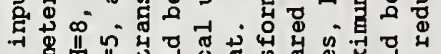
n

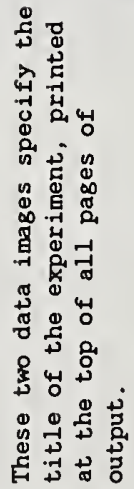

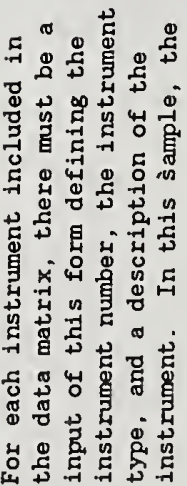

㢣苟 ج

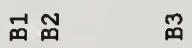


品

है

స్

角苑

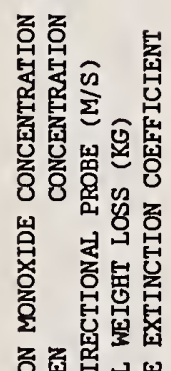

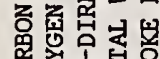

急它它题

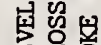

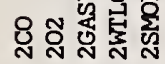

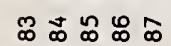

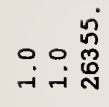

苟

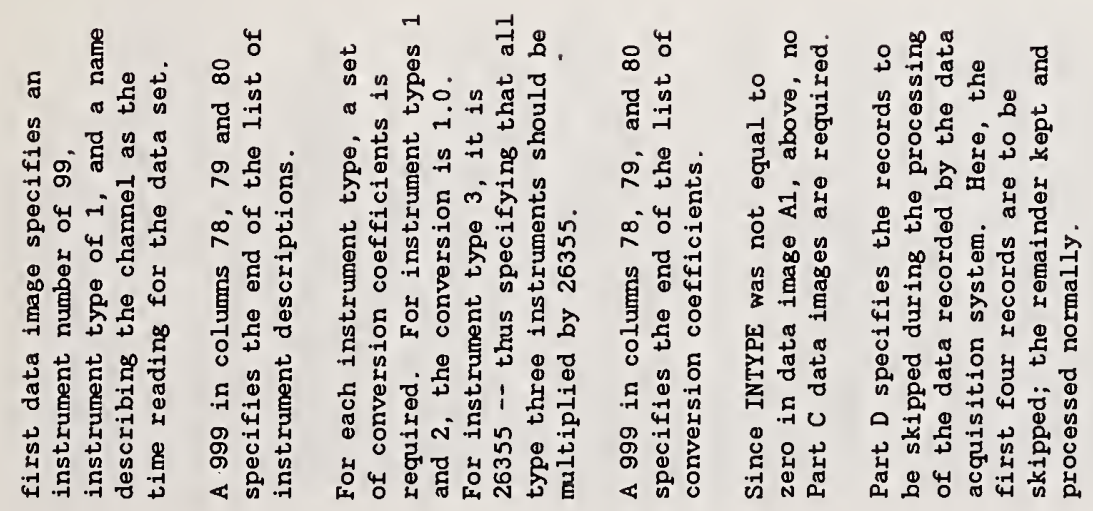

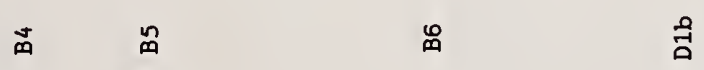



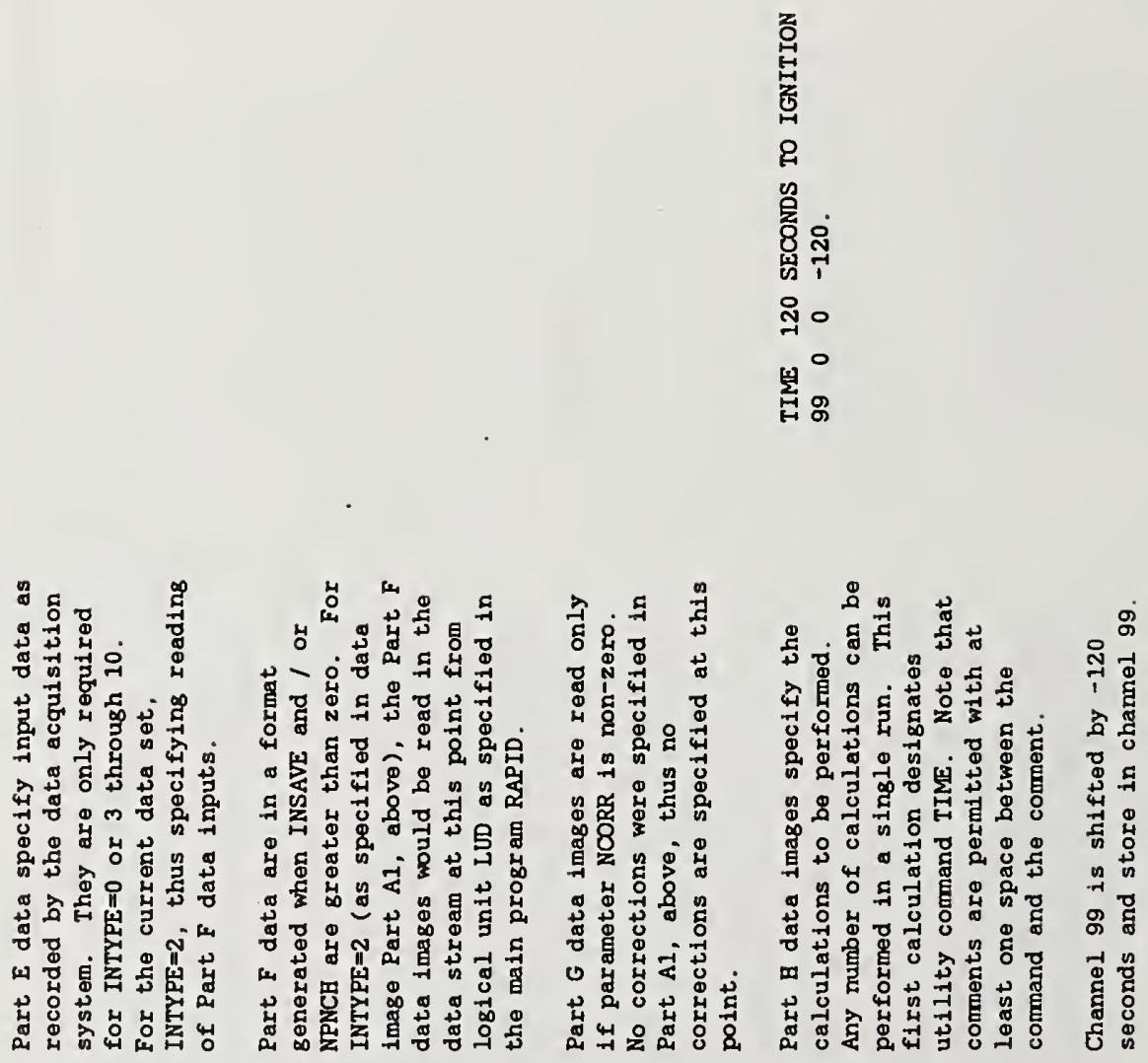

证

藏䆛 


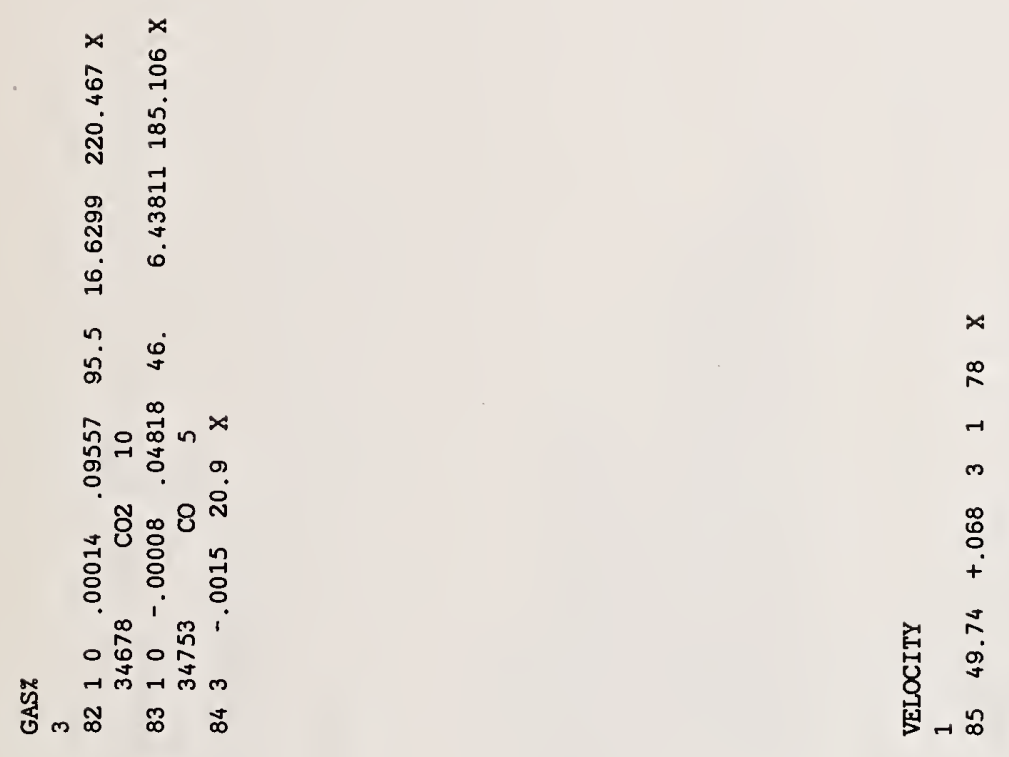

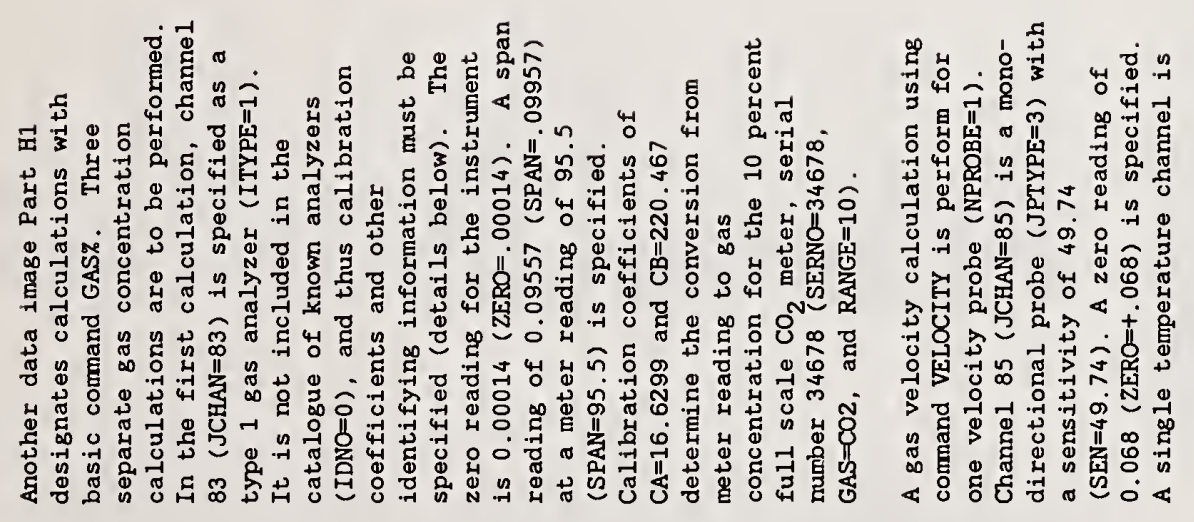

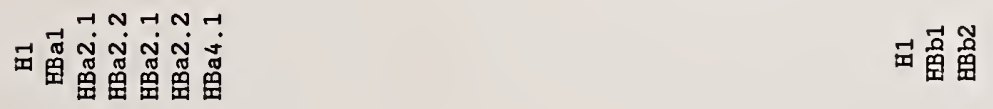




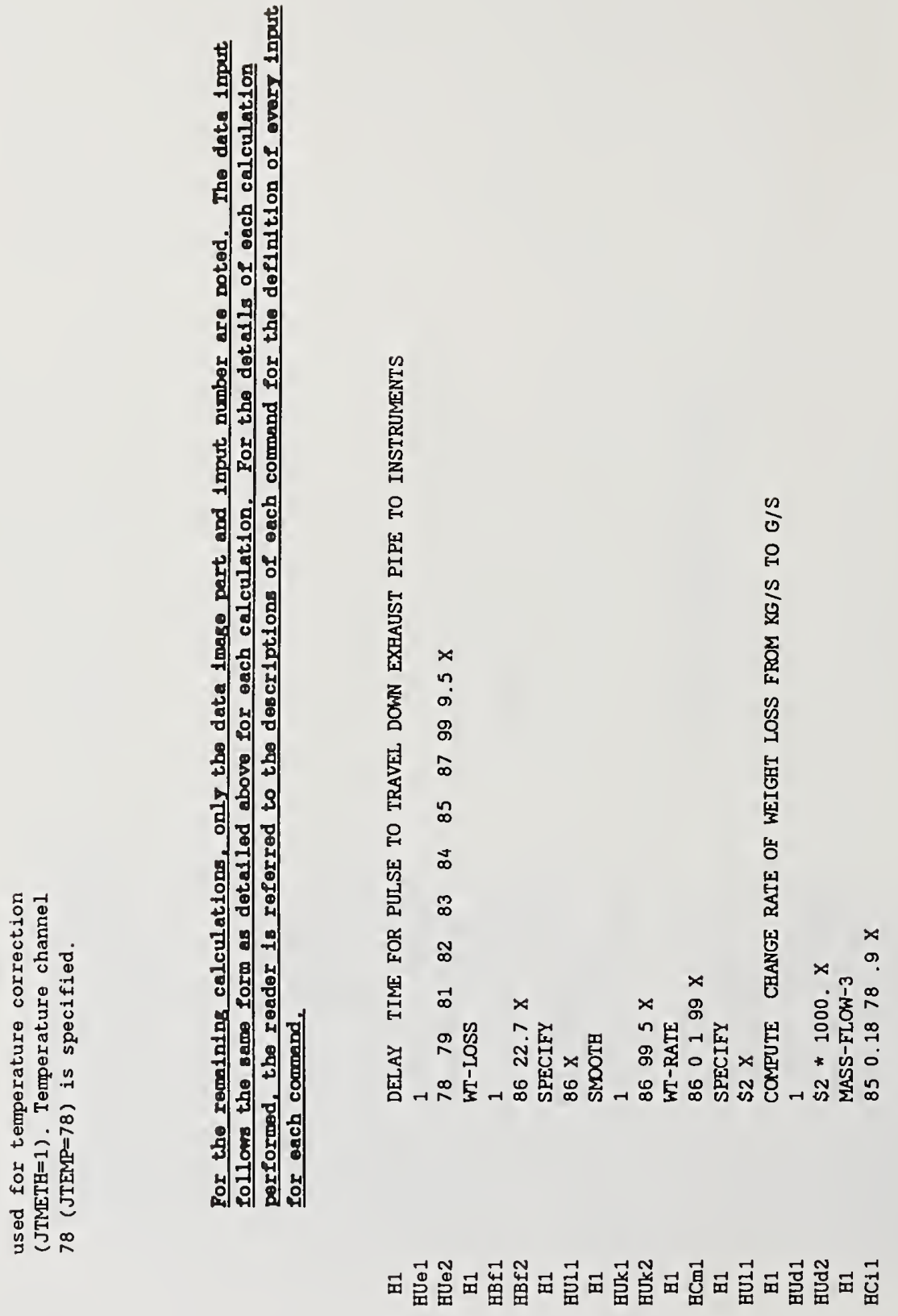




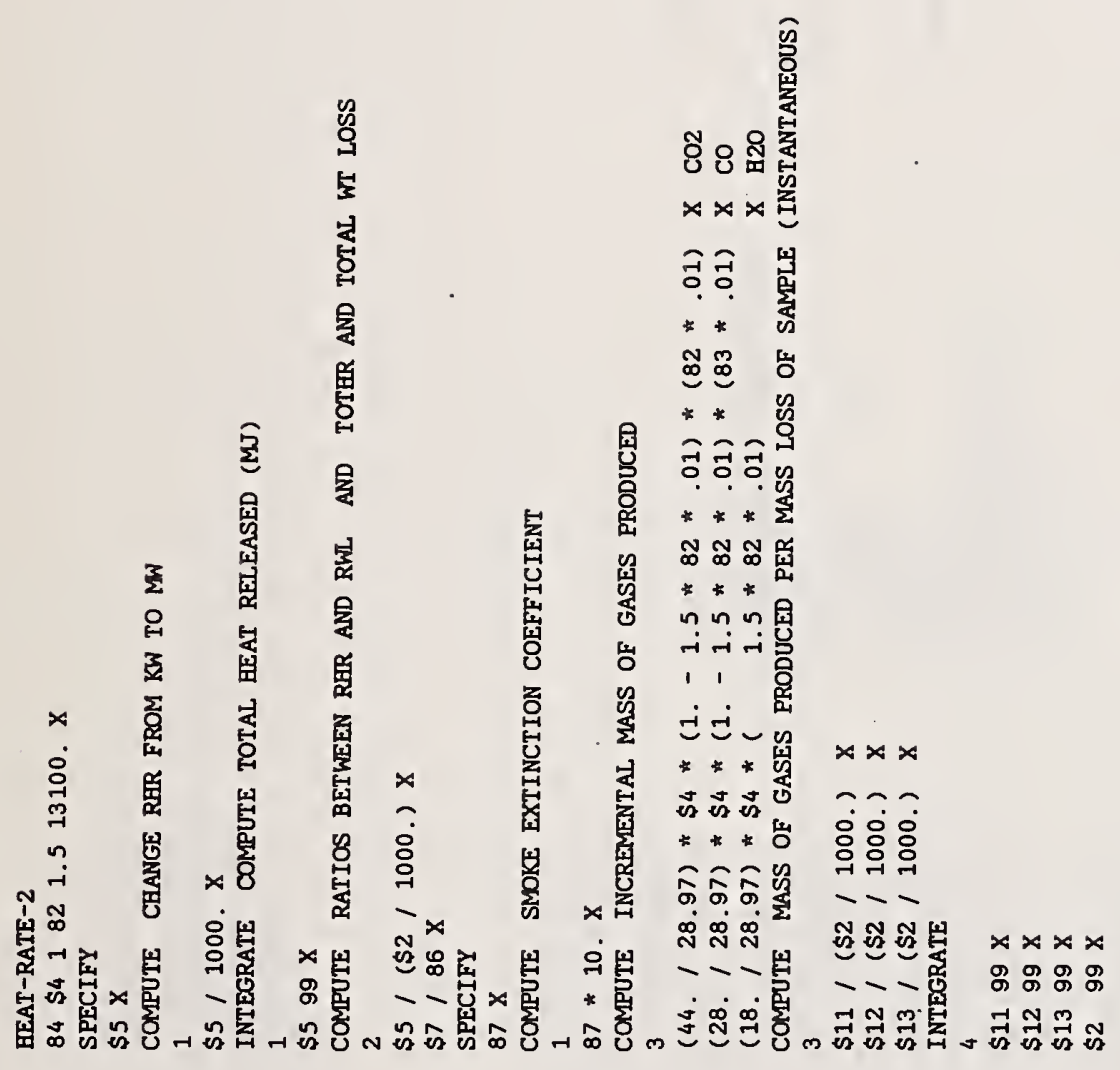

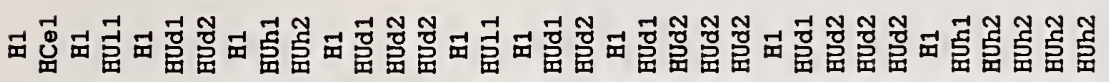



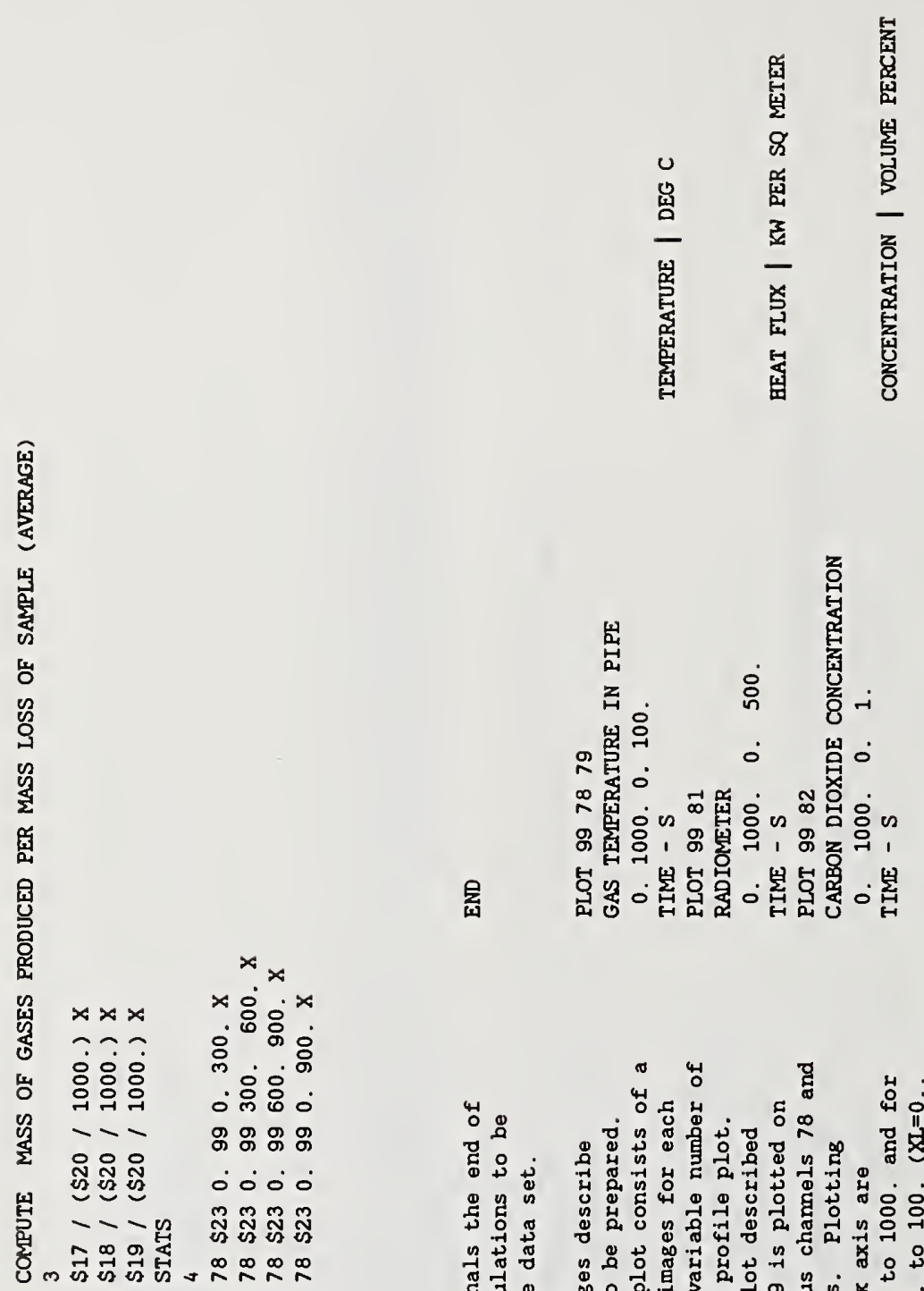

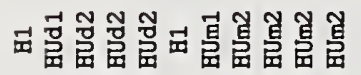
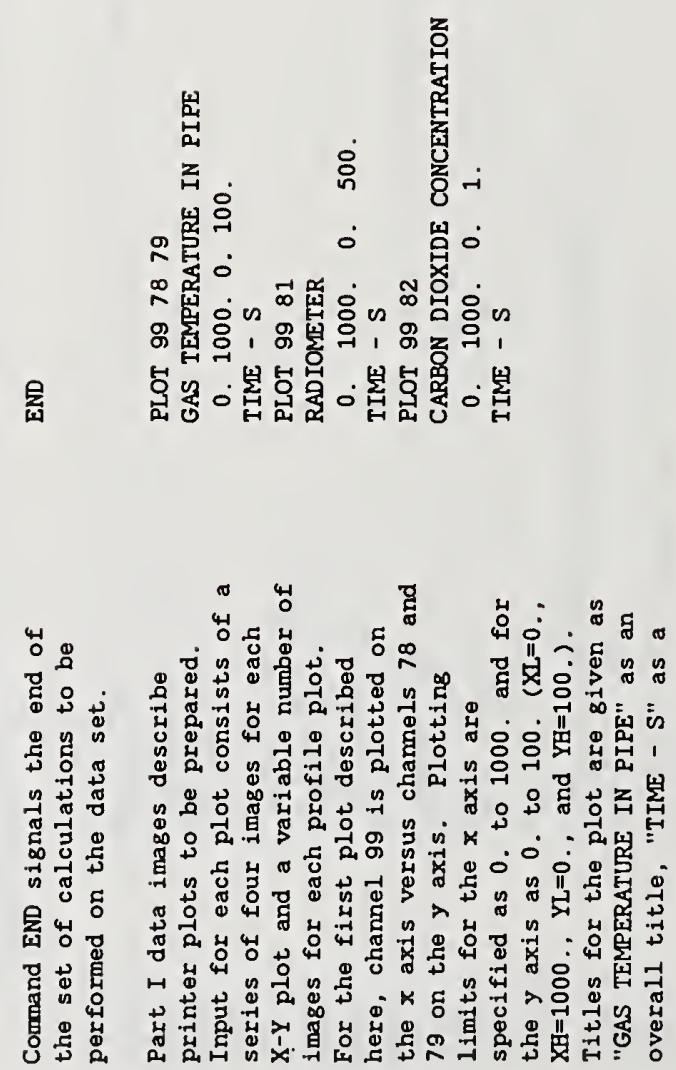

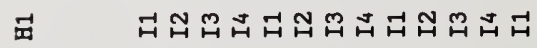




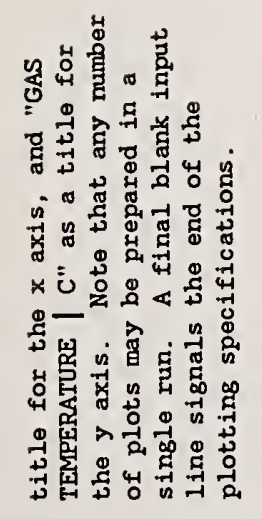


Listing of Input Data Set for RAPID 
$\begin{array}{llllllll}2 & 0 & 0 & 0 & 0 & 1 & 0 & 0 \\ 0 & 1 & 8 & 1 & 0 & 5 & & \end{array}$

FURNITURE CALORIMETER TEST \#110 85.0806

FAN SPEED TEST

99 1TIME ELAPSED TIME (S)

80 2MARKEREVENT MARKER (V)

78 2TC THERMOCOUPLE (C)

79 2TC THERMOCOUPLE (C)

81 3RADMTRRADIOMETER \#624416 (KW/SQ M)

$822 \mathrm{CO} 2$ CARBON DIOXIDE CONCENTRATION \#34678 SPAN 9.428 (VOL 8 )

$832 \mathrm{CO}$ CARBON MONOXIDE CONCENTRATION \#34753 SPAN $1.82 \%$ (VOL 8 )

84202 OXYGEN CONCENTRATION (VOL \&)

85 2GASVELBI-DIRECTIONAL PROBE (M/S)

86 2WTLOSSTOTAL WEIGHT LOSS (KG)

87 2SMOKE SMOKE EXTINCTION COEFFICIENT

1.0

1.0

26355 .

$\operatorname{SKIP}=(\mathrm{S} 1) 4$

TIME 120 SECONDS TO IGNITION

$99000-120$.

GAS 8

3

$\begin{array}{lllllllll}82 & 1 & 0 & .00014 & .09557 & 95.5 & 16.6299 & 220.467 & \mathrm{X}\end{array}$

$34678^{\circ} \mathrm{CO} 2 \quad 10$

$\begin{array}{llllllll}83 & 1 & 0 & -.00008 & .04818 & 46 . & 6.43811 & 185.106 \mathrm{X}\end{array}$

$34753 \quad$ CO 5

$\begin{array}{llll}84 & 3 & -.0015 & 20.9 \quad \mathrm{X}\end{array}$

VELOCITY

1

$85 \quad 49.74+.068 \quad 3 \quad 178 \quad X$

DELAY TIME FOR PULSE TO TRAVEL DOWN EXHAUST PIPE TO INSTRUMENTS 1

$\begin{array}{lllllllllll}78 & 79 & 81 & 82 & 83 & 84 & 85 & 87 & 99 & 9.5 & \mathrm{X}\end{array}$

WT - LOSS

1

$8622.7 \mathrm{X}$

SPECIFY

$86 \mathrm{X}$

SMOOTH

1

$86995 \mathrm{X}$

WT-RATE

$\begin{array}{lllll}86 & 0 & 1 & 99 & \mathrm{X}\end{array}$

SPECIFY

$\$ 2 \mathrm{X}$

COMPUTE CHANGE RATE OF WEIGHT LOSS FROM KG/S TO G/S

1

$\$ 2 * 1000 . \mathrm{X}$

MASS - FLOW - 3 


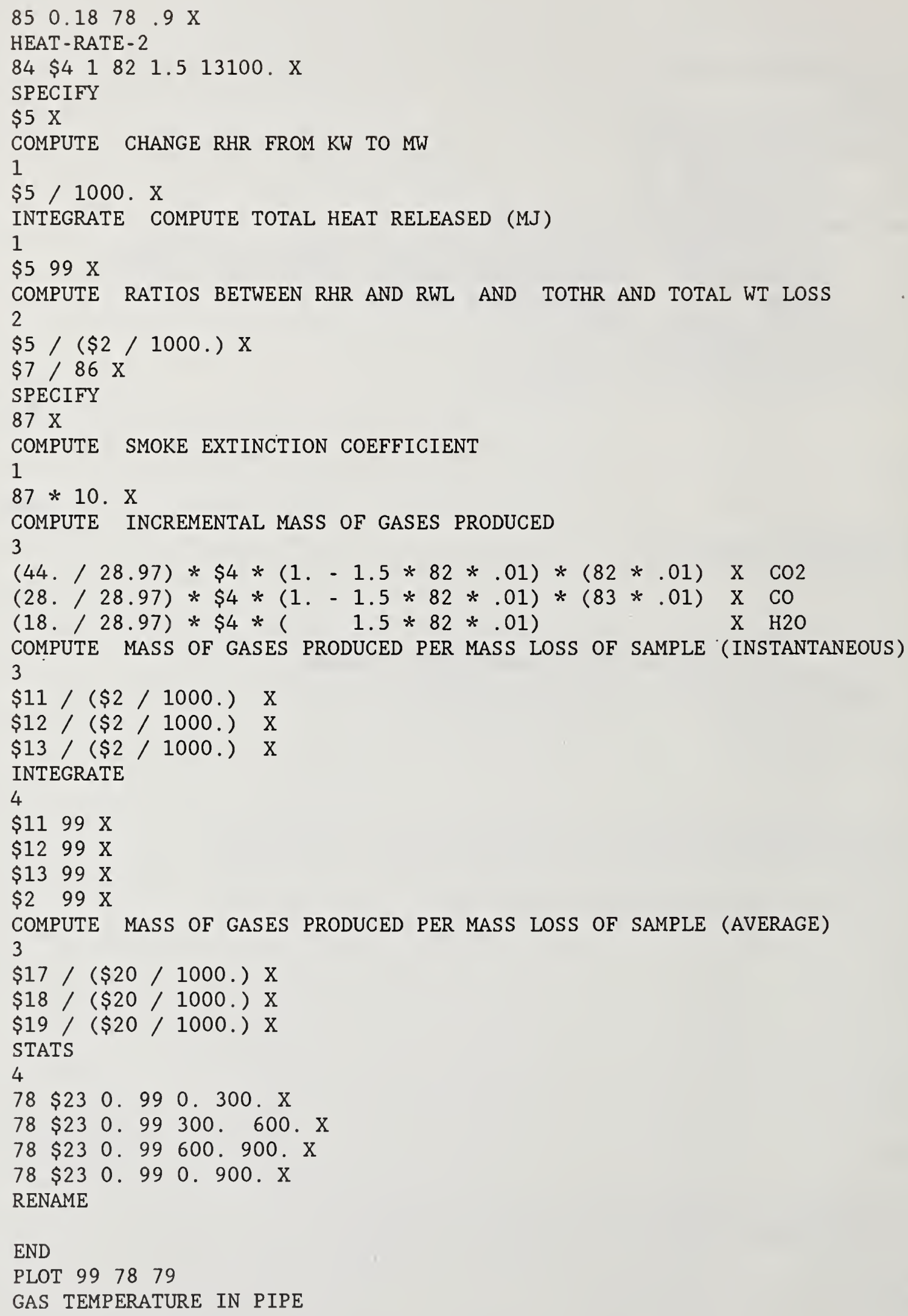


0. 1000. 0. 100 .

TIME - $\mathrm{S}$

PLOT 9981

RADIOMETER

0. 1000. 0. 500 .

TIME - $\mathrm{S}$

PLOT 9982

CARBON DIOXIDE CONCENTRATION

0 . 1000. 0. 1 .

TIME - $\mathrm{S}$

PLOT 9983

CARBON MONOXIDE CONCENTRATION

0 . 1000. 0. 0.1

TIME - $\mathrm{S}$

PLOT 9984

OXYGEN CONCENTRATION IN PIPE

0 . 1000. 10. 22.5

TIME - S

PLOT 9985

GAS VELOCITY THROUGH PIPE

0 . 1000. 0. 25.

TIME - $S$

PLOT 9986

TOTAL WEIGHT LOSS OF COMBUSTIBLES

0 . 1000 . 0. 25 .

TIME - S

PLOT $99 \$ 02$

RATE OF WEIGHT LOSS

0 . 1000. -10.90 .

TIME - S

PLOT $99 \$ 05$

RATE OF HEAT RELEASE THROUGH PIPE

0. 1000. 0. 0.1

TIME - S

PLOT $99 \$ 7$

TOTAL HEAT RELEASED

0 . 1000. 0. 10 .

TIME - S

PLOT $99 \$ 8 \$ 9$

INSTANTANEOUS AND AVERAGE HEAT RELEASED PER KG OF SAMPLE BURNED

0 . 1000. 0. 250.

TIME - S

PLOT $99 \$ 14 \$ 15 \$ 16$

MASS OF $\mathrm{CO} 2$, CO, AND H2O PRODUCED PER MASS OF SAMPLE BURNED (INSTANTANEOUS)

0.1000 .0 .10 .

TIME - S

PLOT $99 \$ 21 \$ 22 \$ 23$

MASS OF CO2, CO, AND H2O PRODUCED PER MASS OF SAMPLE BURNED (AVERAGE)

0.1000 .0 .10 .

TIME - S
TEMPERATURE | DEG C

HEAT FLUX | KW PER SQ METER

CONCENTRATION | VOLUME PERCENT

CONCENTRATION | VOLUME PERCENT

CONCENTRATION | VOLUME PERCENT

VELOCITY | METERS PER S

WEIGHT LOSS | KG

RATE OF WEIGHT LOSS | GRAMS PER S

RATE OF HEAT RELEASE | MW

TOTAL HEAT RELEASED | MJ

MEGAJOULES PER KILOGRAM

KG PER KG

KG PER KG 
Appendix B

Using RAPID on the CFR Minicomputer 
This appendix provides details specifically on the use of RAPID on the CFR Perkin - Elmer 3252 Minicomputer. The process will be similar on other computers, with different operating systems commands to load and execute the programs.

\section{Using the Program}

On the 3252, RAPID exists in three versions (for three different maximum data set sizes). The program RAPID has a data set size of 100 columns by 100 rows. RAPIDB has a larger data set size of 400 by 400 . A third version, RAPIDH has a data set size of 400 by 2000 . To run RAPID, load one of the versions, assigned the appropriate logical units and start the program as:

$*$ LOAD RAPID (or RAPIDB or RAPIDH)

*AS $5,<$ RAPIDinputdatacardfile $>$

*AS $6,<$ RAPIDprintedoutputfile>

*AS $7,<$ RAPIDdatasystemdatafile $>$

*START

where <RAPIDinputdatacardfile> is the set of input data as detailed in the NBS report, <RAPIDprintedoutputfile> is the file where printed output from the program is to be written (which may, of course, be the printer PR:), and <RAPIDdatasystemdatafile $>$ is the file of data collected by the data acquisition system. Up to three additional, optional logical units may be required depending upon the values of three variables read from the input data 
set on logical unit 5 (variable INPNCH specifies a logical unit to write a file of data as recorded by the data acquisition system, INSAVE specifies a logical unit to write a file of data as recorded by the data acquisition system in a format which may be easily and quickly read in future RAPID runs, and NPNCH specifies a logical unit to write a file of the transformed data once all calculations have been performed). These logical units must be preassigned prior to entering the START command from MTM.

\section{But. It Can Be Easler Than That}

To make execution of the program easier, a number of CSS files have been created. Before describing them, it is necessary to detail a few conventions assumed in the use of the CSS files. A number of extensions for file names are assumed within the CSS files. A list follows.

.DTA Data file containing the raw unformatted data as recorded by the data acquisition system.

.FRD

Data file containing formatted raw data prepared from the data acquisition system file (the .DTA file) by specifying INSAVE non zero on RAPID data card Al.

.CRD Data file containing the input data for the execution of RAPID .

.RED Data file of the transformed data written once all calculations have been preformed on the data. 
A naming convention for the filenames is assumed in the CSS files as well. Each test is identified by a two character test series identification followed by up to six alphanumeric characters to uniquely identify the test within a test series. One way we have found particularly convenient is to use the date of the test in the form YYMMDD. Thus, the filename FC850806 would identify a test in the FC series (for Furniture Calorimeter) performed on August 6, 1985.

Execution of RAPID is performed in two steps. In the first, a formatted raw data file is prepared with one run of RAPID to produce a .FRD file from a .DTA file. To do this, a cSS call is entered:

*FRD <testseries $>,<$ filename $>,<$ printedoutput $>,<$ versionofRAPIDtouse $>$

where <testseries> is the two letter designation of the series of tests to which this data set belongs, <filename> is the name of the specific test being reduced (without extensions), <printedoutput> specifies the destination of the printed output (usually PR: or C:), and <versionofRAPIDtouse> is either left blank (to use the smallest version of RAPID) or B or $H$ to use the larger versions.

Once the FRD file is created, another CSS call can be used to create all files with extensions as outlined above: 
$*$ RAPID <filename>, <versionofRAPID touse>

If printed output is desired (normally the printout from the execution is left in the file <filename>.SAV), it can be routed to the printer by

$*$ PRINT $<$ filename $>$ SAV, VFC

\section{Other Niceties to Make Your Life With RAPID Easier}

One more program and CSS is available to annotate a list of RAPID input cards with created instrument numbers and locations is available. It's use has proven invaluable when creating (and especially modifying) an input data set. To use is, simply enter

*CCLIST <filename $>$, printedoutput>

and you will get a two column listing with the created channels and their numbers on the left hand side and a formatted listing of the input data set on the right.

\section{Gas Analysis Conversion Constants}

A number of gas analyzers are predefined in the program and are available to 
the command GAS: by number alone as detailed in Section 14.1. A listing of the predefined analyzers and their constants are shown below:

\begin{tabular}{|c|c|c|c|c|c|c|}
\hline $\begin{array}{l}\mathrm{v} \\
\mathrm{e}\end{array}$ & $\begin{array}{l}\text { Serial } \\
\text { Number }\end{array}$ & Make & Gas & Range & a & $\mathrm{b}$ \\
\hline $\begin{array}{l}1 \\
2 \\
3\end{array}$ & $\begin{array}{l}3351 \\
8312 \\
8313\end{array}$ & $\begin{array}{l}\text { Lira } \\
\text { Lira } \\
\text { Lira }\end{array}$ & $\begin{array}{l}\mathrm{CO} 2 \\
\mathrm{CO} 2 \\
\mathrm{CO}\end{array}$ & $\begin{array}{l}20.0 \% \\
20.08 \\
10.08\end{array}$ & $\begin{array}{l}35.6728 \\
64.0867 \\
22.5739\end{array}$ & $\begin{array}{l}232.667 \\
372.973 \\
278.821\end{array}$ \\
\hline $\begin{array}{l}4 \\
5 \\
6\end{array}$ & $\begin{array}{l}30760 \\
30761 \\
31497\end{array}$ & $\begin{array}{l}\text { Lira } \\
\text { Lira } \\
\text { Lira }\end{array}$ & $\begin{array}{l}\mathrm{CO} \\
\mathrm{CO} \\
\mathrm{CO} 2\end{array}$ & $\begin{array}{r}10.08 \\
10.08 \\
4.08\end{array}$ & $\begin{array}{l}17.8165 \\
17.4194 \\
7.42968\end{array}$ & $\begin{array}{l}232.728 \\
229.156 \\
239.724\end{array}$ \\
\hline $\begin{array}{l}7 \\
8 \\
9\end{array}$ & $\begin{array}{r}32369 \\
100203 \\
100203\end{array}$ & $\begin{array}{l}\text { Lira } \\
\text { Beckman } \\
\text { Beckman }\end{array}$ & $\begin{array}{l}\mathrm{CO} \\
\mathrm{CO} 2 \\
\mathrm{CO} 2\end{array}$ & $\begin{array}{l}2.08 \\
0.58 \\
2.58\end{array}$ & $\begin{array}{r}3.05138 \\
.836754 \\
1.49959\end{array}$ & $\begin{array}{l}208.020 \\
222.762 \\
123.019\end{array}$ \\
\hline $\begin{array}{l}10 \\
11 \\
12\end{array}$ & $\begin{array}{l}100203 \\
100203 \\
100324\end{array}$ & $\begin{array}{l}\text { Beckman } \\
\text { Beckman } \\
\text { Beckman }\end{array}$ & $\begin{array}{l}\mathrm{CO} 2 \\
\mathrm{CO} 2 \\
\mathrm{CO}\end{array}$ & $\begin{array}{r}5.08 \\
20.08 \\
0.18\end{array}$ & $\begin{array}{l}6.57108 \\
14614.9 \\
22.2749\end{array}$ & $\begin{array}{l}187.330 \\
73115.0 \\
22316.4\end{array}$ \\
\hline $\begin{array}{l}13 \\
14 \\
15\end{array}$ & $\begin{array}{l}100324 \\
100324 \\
100324\end{array}$ & $\begin{array}{l}\text { Beckman } \\
\text { Beckman } \\
\text { Beckman }\end{array}$ & $\begin{array}{l}\text { CO } \\
\text { CO } \\
\text { CO }\end{array}$ & $\begin{array}{l}0.58 \\
1.08 \\
5.08\end{array}$ & $\begin{array}{l}.334504 \\
2.76620 \\
1209.37\end{array}$ & $\begin{array}{l}128.746 \\
327.558 \\
24229.0\end{array}$ \\
\hline $\begin{array}{l}16 \\
17 \\
18\end{array}$ & $\begin{array}{l}300634 \\
300634 \\
300635\end{array}$ & $\begin{array}{l}\text { Beckman } \\
\text { Beckman } \\
\text { Beckman }\end{array}$ & $\begin{array}{l}\mathrm{CO} 2 \\
\mathrm{CO} 2 \\
\mathrm{CO}\end{array}$ & $\begin{array}{r}2.5 \% \\
15.0 \% \\
1.0 \%\end{array}$ & $\begin{array}{l}7.52544 \\
12.2465 \\
6.34414\end{array}$ & $\begin{array}{l}353.735 \\
141.164 \\
685.198\end{array}$ \\
\hline $\begin{array}{l}19 \\
20 \\
21\end{array}$ & $\begin{array}{r}300635 \\
30759 \\
32062\end{array}$ & $\begin{array}{l}\text { Beckman } \\
\text { Lira } \\
\text { Lira }\end{array}$ & $\begin{array}{l}\mathrm{CO} \\
\mathrm{CO} \\
\mathrm{CO}\end{array}$ & $\begin{array}{r}7.08 \\
10.0 \% \\
2.0 \%\end{array}$ & $\begin{array}{l}5.00492 \\
17.1453 \\
2.71598\end{array}$ & $\begin{array}{l}132.479 \\
226.150 \\
191.773\end{array}$ \\
\hline $\begin{array}{l}22 \\
23 \\
24\end{array}$ & $\begin{array}{l}32371 \\
34537 \\
34539\end{array}$ & $\begin{array}{l}\text { Lira } \\
\text { Lira } \\
\text { Lira }\end{array}$ & $\begin{array}{l}\mathrm{CO} 2 \\
\mathrm{CO} \\
\mathrm{CO} 2\end{array}$ & $\begin{array}{l}20.08 \\
15.08 \\
20.08\end{array}$ & $\begin{array}{l}39.0345 \\
20.5896 \\
29.3901\end{array}$ & $\begin{array}{l}249.152 \\
193.337 \\
202.437\end{array}$ \\
\hline $\begin{array}{l}25 \\
26 \\
27\end{array}$ & $\begin{array}{l}34677 \\
34865 \\
34540\end{array}$ & $\begin{array}{l}\text { Lira } \\
\text { Lira } \\
\text { Lira }\end{array}$ & $\begin{array}{l}\mathrm{CO} 2 \\
\mathrm{CO} 2 \\
\mathrm{CO} 2\end{array}$ & $\begin{array}{l}10.0 \% \\
10.0 \% \\
20.0 \%\end{array}$ & $\begin{array}{l}16.7002 \\
13.7266 \\
32.8684\end{array}$ & $\begin{array}{l}221.373 \\
193.402 \\
219.574\end{array}$ \\
\hline $\begin{array}{l}28 \\
29 \\
30\end{array}$ & $\begin{array}{l}34391 \\
34538 \\
32372\end{array}$ & $\begin{array}{l}\text { Lira } \\
\text { Lira } \\
\text { Lira }\end{array}$ & $\begin{array}{l}\mathrm{CO} \\
\mathrm{CO} \\
\mathrm{CO} 2\end{array}$ & $\begin{array}{l}10.08 \\
15.08 \\
20.08\end{array}$ & $\begin{array}{l}17.6194 \\
20.0793 \\
29.7035\end{array}$ & $\begin{array}{l}230.505 \\
189.892 \\
203.110\end{array}$ \\
\hline
\end{tabular}




\begin{tabular}{|c|c|c|c|c|c|c|}
\hline $\begin{array}{l}\mathrm{v} \\
\mathrm{e}\end{array}$ & $\begin{array}{l}\text { Serial } \\
\text { Number }\end{array}$ & Make & Gas & Range & a & $\mathrm{b}$ \\
\hline 31 & 34678 & Lira & $\mathrm{CO} 2$ & 10.08 & 16.6299 & 220.467 \\
\hline 32 & 34753 & Lira & $\mathrm{CO}$ & 5.08 & 6.4381 & 185.106 \\
\hline 33 & 103522 & Beckman & $\mathrm{CO} 2$ & 2.58 & 4.4600 & 231.000 \\
\hline 34 & 31445 & Lira & $\mathrm{CO} 2$ & 20.08 & 37.3761 & 237.640 \\
\hline 35 & 32098 & Lira & $\mathrm{CO}$ & 1.08 & 1.2718 & 182.966 \\
\hline 36 & 100203 & Beckman & $\mathrm{CO} 2$ & $5.0 \%$ & 6.3243 & 181.815 \\
\hline 37 & 100324 & Beckman & $\mathrm{CO}$ & 1.08 & 2.1355 & 261.877 \\
\hline 38 & 101403 & Beckman & $\mathrm{CO} 2$ & 5.08 & 6.1889 & 8.972 \\
\hline 39 & 101403 & Beckman & $\mathrm{CO} 2$ & 20.08 & 12.3116 & 6.180 \\
\hline 40 & 101404 & Beckman & $\mathrm{CO}$ & 1.08 & 2.4985 & 15.073 \\
\hline 41 & 101404 & Beckman & $\mathrm{CO}$ & 5.08 & 2.5896 & 5.774 \\
\hline
\end{tabular}




\section{Appendix C \\ Selected Listings from the Program}

Only two routines would normally be changed by the user, the main program RAPID and block data subprogram CRVFIT. In the main program, the user may adjust the number of rows and columns in the data arrays to match the size of the data set under consideration. Subprogram CRVFIT allows the user to maintain a catalog of gas analysis equipment which can be referenced by number, without entering calibrations and identifications for the analyzers at each execution of the program. 


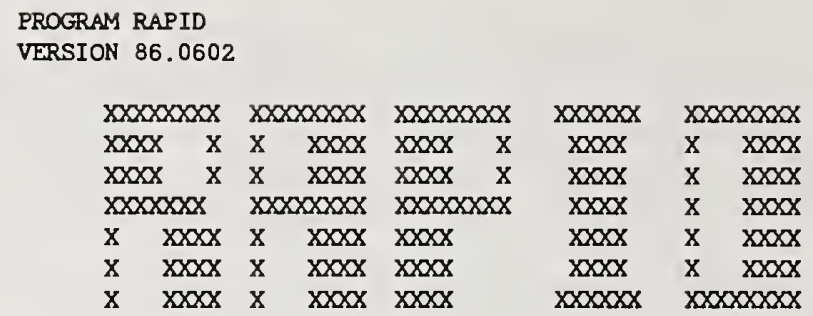

\section{RAPID CONPILS IIME PARAMETERS}

IRON: MAXIMUN KUMBER OF RONB (SCANS) II TER INPUT DATA

HCOL: MAXIMUM MUNBRER OF COLUNAS (INSTRUMENTS) TO BB PROCESSSED

MAXPLI: MAXIMUY TIUMRER OF CURVES TO BE FLOTTED OF A SINGE CURVE MAXCIL: MAXIMUM YRABER OF INSTRUMEATS RECORDED BY TEE DATA SYSTEY

LUIN: LOGICAI UNIT FROM WEICH CARD IMMGES ARB RRAD

LUOUT: LOGICAL UNIT TO WEICE PRINT IMAGES ARB SENT

LUDATA: LOGICAL UNIT FROM WEICE TEST DATA ARE ENTERRED

INTEGER OUTDIM, PLTDIM

PAPAMTIER (KRON=400, KCOi 400 )

PARAMETER (MAXPLT-11)

PARAMETER (MAXCLL -200$)$

PARAMETER (OUTDIM=18*MAXCNL+160)

PARAMETER (NPTS=MAXPLT ${ }^{*} N O W+2$ )

PARAMETER (PLTDIM $=2 \star$ MAXPL T)

PARAMETER (LUIN-5, LUOUT=6, LUDATA-7)

CHARACTER VERSN*27, NAME (NCOL)*66, IPN (PL TDIM)*6, IOUT (OUTDIM)

CBARACTER IKSP $(80)$, JCHN (MAXPLT)*6, KHPRT (NCOL)*3

INTEGER $\operatorname{ATSCAN}(2$, NCOL)

DIMENSION REED (NROW, NCOL), KH(NCOL), ITYPE (NCOL) , C (NCOL), ADD (NCOL) DIMENSION X (NROW, MAXPLT), Y (NROW, MAXPLT), XP3 (NPTS), YP3 (NPTS) DIMENSION MAXR (NCOL) , ICHRS (320), MCNL (MAXCNL), IPC (PLTDIM), XR (NROW) DIMENSION YR (NROW), JM(PLTDIM), ISKIP (320), POWER (NCOL)

DIMENSION IXR (NROW), IYR (NROW), RMAX (NCOL), RMIN (NCOL) , RAVG (NCOL) EQUIVALENCE (IXR, XR), (IYR, YR)

COMON /ERRORS/ ICRD, ISEG

COMON /IO/ LUI, LUO, LUD

EQUIVALENCE (X,XP3), ( $Y, Y P 3)$

LUI $=$ LUIN

LUO=LUOUT

LUD=LUDATA

VERSN IS USED FOR IDENTIFICATION PURPOSES ONLY,

TO IDENTIFY THE VERSION OF RAPID IN USE

VERSN='PE: $324286.0602(400,400)^{\prime}$

VERSION 85.1009: 1) ADDED CODE FOR SUBROUTINE COMBIN

2) REVISED SUBROUTINE HTNCLD.

DEFAULT PERCENTAGE IS NOW 15. OPTION FOR EXTRAPOLATING BOTTOM TWO 


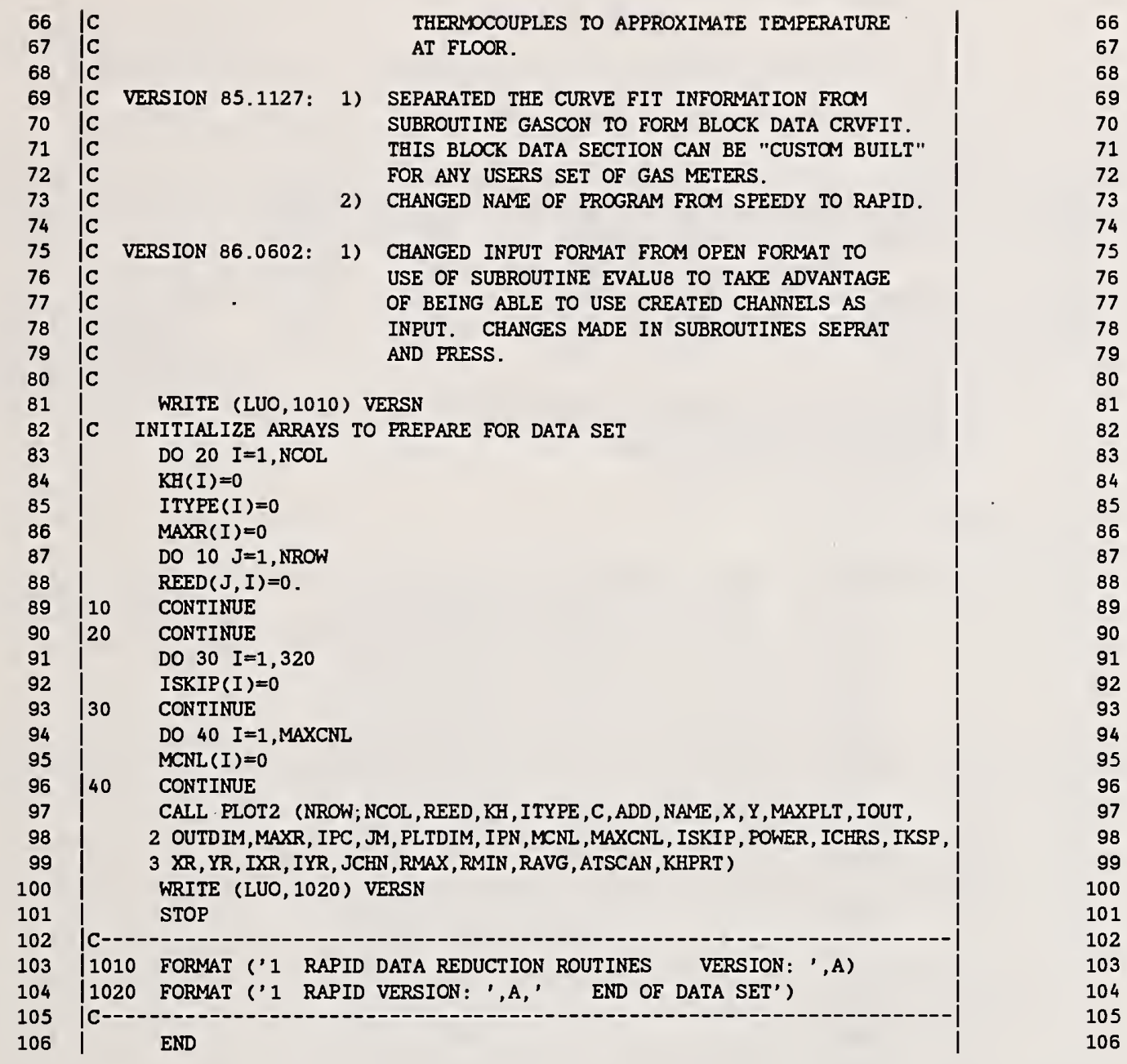


BLOCK DATA CRVFIT

\begin{tabular}{|c|c|c|c|c|c|c|c|c|}
\hline \multicolumn{2}{|c|}{$x \times 0 \times x \times x \times x$} & \multicolumn{2}{|c|}{$X X X X X X X X X$} & $x x x x$ & $x$ & $x \times D X X X X X$ & $x x x x x x$ & $x \times x \times x \times x x$ \\
\hline$x$ & $x x x x$ & $x x x x$ & $\mathrm{x}$ & $x x x x$ & $x$ & $x x x x$ & $x x x x$ & $x x x x$ \\
\hline $\mathrm{x}$ & $x x x x$ & $x x x x$ & $\mathrm{x}$ & $x x x x$ & $x$ & $x x x x$ & $x x x x$ & $x x x x$ \\
\hline$x$ & & $x x x x$ & $x x x$ & $x x x x$ & $x$ & $x x x \times x \times x \times x$ & $x x x x$ & $x x x x$ \\
\hline$x$ & $x x x x$ & $x$ & $x x x x$ & $x \times x x$ & $x$ & $x \times x x$ & $x x x x$ & $x x x x$ \\
\hline$x$ & $x x x x$ & $x$ & $x x x x$ & $x x x \times 2$ & & $x x x x$ & $x x x x$ & $x x x x$ \\
\hline & $x x x x$ & $\mathrm{x}$ & $x x x x$ & $x x x x$ & & $x x x x$ & $x x x x x x$ & $x x x x$ \\
\hline
\end{tabular}

CHARACTER SERNO $(50) * 8, \operatorname{GAS}(50) * 8, \operatorname{RANGE}(50) * 5$

DIMENSION CA(50), CB(50)

COMMON /CRVIDS/ SERNO, GAS, RANGE

COMON /CRVFTS/ CA, CB,NINS

Ic

C CURVE FIT CATALOG

DATA (SERNO(I), GAS(I), RANGE(I), CA(I), CB(I), $\quad I=1,10$ )

$1 /, 3351^{\prime}$, , CO2', 20.0', 35.6728, 232.667 ,

$2,8312^{\prime}, ' \mathrm{CO}^{\prime}{ }^{\prime},{ }^{\prime}, 20.0^{\prime}, 64.0867,372.973$

3 ' $8313^{\prime}$, ' CO CO ', 10.0', 22.5739, 278.821,

4 ' 30760',' CO ', ' 10.0', 17.8165, 232.728,

5 ' 30761',' CO ', ' 10.0', 17.4194, 229.156,

$6{ }^{\prime} 31497^{\prime}, ' \operatorname{CO} 2{ }^{\prime}, '$ ' 4.0', 7.42968, 239.724,

7 ' 32369', ' co ', ' 2.0', 3.05138, 208.020,

8 ' 100203',' $\operatorname{CO2}, ', 0.5 \prime, .836754,222.762$,

9 ' 100203',' $\mathrm{CO} 2$ ', ' 2.5', 1.49959, 123.019,

* ' 100203',' CO2 ', ' 5.0', 6.57108, 187.330/

DATA (SERNO(I), GAS(I), RANGE(I), CA(I), CB(I), I=11,20)

$1 /$ ' 100203',' $\mathrm{CO} 2$ ', '20.0', 14614.9, 73115.0,

2 ' 100324',' CO ', ' 0.1', 22.2749, 22316.4,

3 ' $100324^{\prime}$, ', Co ', ' $0.5^{\prime}, .334504,128.746$,

$4{ }^{\prime} 100324^{\prime}, '$ CO ', ' $1.0^{\prime}, 2.76620,327.558$,

5 ' 100324',' CO ',' $5.0^{\prime}, 1209.37,24229.0$,

$6{ }^{\prime} 300634^{\prime}, ' \quad \operatorname{CO} 2{ }^{\prime}, ' 2.5^{\prime}, 7.52544,353.735$,

7 ' 300634',' CO2 ', ' 15.0', 12.2465, 141.164,

8 ' 300635',' CO ', ' 1.0', 6.34414,685.198,

9 ' 300635',' CO ', ' 7.0', 5.00492, 132.479,

* '30759',' co ', ' 10.0', 17.1453, 226.150/

DATA (SERNO(I), GAS(I), RANGE(I), $\operatorname{CA}(I), \quad C B(I), \quad I=21,30$ )

$1 /$ '32062',' CO ', ' 2.0', 2.71598, 191.773,

2 ' 32371', $\operatorname{co2}$ ', '20.0', 39.0345, 249.152,

3 ' 34537',' CO ', ' 15.0', 20.5896, 193.337,

4 '34539',' $\mathrm{CO} 2$ ', '20.0', 29.3901, 202.437,

5 ' 34677', $7^{\prime}$ CO2 ', ' 10.0', 16.7002, 221.373,

$6,34865^{\prime}, \mathrm{CO}^{\prime},{ }^{\prime}, 10.0^{\prime}, 13.7266,193.402$,

7 ' 34540',' $\operatorname{CO} 20^{\prime}, ' 20.0^{\prime}, 32.8684,219.574$,

8 ' 34391',' CO ', ' 10.0', 17.6194, 230.505,

9 ' 34538',' CO ', '15.0', 20.0793, 189.892,

* ' 32372',' CO2 ', ' 20.0', 29.7035, 203.892/

DATA (SERNO(I), GAS(I), RANGE(I), CA(I), $C B(I), \quad I=31,40$ )

$1 l^{\prime} 34678^{\prime}, ' \mathrm{CO}^{\prime}$ ', ' 10.0', 16.6299, 220.467,

2 ' 34753', ' CO ', ' 5.0', 6.4381, 185.106,

3 , 103522,', CO2 ', ' 2.5', 4.4600, 231.000,

4 , 31445', $, \quad \operatorname{CO} 2, ', 20.0$ ', 37.3761, 237.640,

5 ' 32098',' CO ', ' 1.0', 1.2718, 182.966,

6 ' 100203',' $\mathrm{CO} 2$ ', ' 5.0', 6.3243, 181.815,

7 ' 100324',' CO ', ' 1.0', 2.1355, 261.877,

8 ' 101403',' $\mathrm{CO} 2, ', 5.0^{\prime}, 6.1889,8.972$,

9 ' 101403', ${ }^{\prime}, 2^{\prime}, ', 20.0^{\prime}, 12.3116,6.180$,

* ' 101404',' $\infty \quad$ ', ' 1.0', 2.4985, 15.073/

DATA (SERNO(I), GAS(I), RANGE(I), CA(I), $\quad C B(I), \quad I=41,41$ )

$1 I^{\prime} 101404^{\prime}, ' C O{ }^{\prime}, 0^{\prime} 5.0^{\prime}, 2.5896,5.774 /$

DATA NINS /41/

END 
1. PUBLICATION OR REPORT NO. NBS/SP-722
2. Performing Organ. Report Nod 3. Publication Date

August 1986

4. TITLE AND SUBTITLE

A User's Guide for RAPID,

Reduction Algorithms for the Presentation of Incremental Fire Data

5. AUTHOR(S)

J. N. Breese and R. D. Peacock

6. PERFORMING ORGANIZATION (If joint or other than NBS, see instructions)

7. Contract/Grant No.

NATIONAL BUREAU OF STANDARDS

DEPARTMENT OF COMMERCE

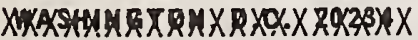

GAITHERSBURG, MD 20899

8. Type of Report \& Period Covered

Final

9. SPONSORING ORGANIZATION NAME AND COMPLETE ADDRESS (Street, City, State, ZIP)

Same as I tem 6.

10. SUPPLEMENTARY NOTES

Library of Congress Catalog Card Number 86-600565

Document describes a computer program; SF-185, FIPS Software Summary, is attached.

11. ABSTRACT (A 200-word or less factual summary of most significant information. If document includes a significant

bibliography or literature survey, mention it here)

The Voluminous amount of data than can be collected by automatic data acquisition systems during large scale fire tests requires the use of a digital computer for the reduction of data. RAPID is a stand-alone program specifically designed to convert raw instrument voltages collected during such tests into meaningful units. The reduced data can also be used alone or in combinations to obtain quantities that require more than minimal data reduction. The program is written with the ability to accept data from a user defined data acquisition system, with the ability to check the correctness of data included. Through the use of input data provided by the user, the data can be converted into meaningful scientific units. The data can then be presented in tabular or printer plot form, or stored for further processing.

This user's guide provides detailed instructions for the use of the program.

12. KEY WORDS (Six to twelve entries; alphabetical order; capitalize only proper names; and separate key words by semicolons) Computer program; data reduction; data acquisition; fire tests

\section{AVAILABILITY}

[X] Unlimited

$\square$ For Official Distribution. Do Not Release to NTIS

[X Order From Superintendent of Documents, U.S. Government Printing Office, Washington, D.C. 20402.

Order From National Technical Information Service (NTIS), Springfield, VA, 2216I
14. NO. OF

PRINTED PAGES

195

15. Price 



\section{Periodical}

Journal of Research-The Journal of Research of the National Bureau of Standards reports NBS research and development in those disciplines of the physical and engineering sciences in which the Bureau is active These include physics, chemistry, engineering, mathematics, and computer sciences. Papers cover a broad range of subjects, with major emphasis on measurement methodology and the basic technology underlying standardization. Also included from time to time are survey articles on topics closely related to the Bureau's technical and scientific programs. Issued six times a year.

\section{Nonperiodicals}

Monographs-Major contributions to the technical literature on various subjects related to the Bureau's scientific and technical activities.

Handbooks-Recommended codes of engineering and industrial practice (including safety codes) developed in cooperation with interested industries, professional organizations, and regulatory bodies.

Special Publications-Include proceedings of conferences sponsored by NBS, NBS annual reports, and other special publications appropriate to this grouping such as wall charts, pocket cards, and bibliographies.

Applied Mathematics Series-Mathematical tables, manuals, and studies of special interest to physicists, engineers, chemists, biologists, mathematicians, computer programmers, and others engaged in scientific and
technical work.

National Standard Reference Data Series-Provides quantitative data on the physical and chemical properties of materials, compiled from the world's literature and critically evaluated. Developed under a worldwide program coordinated by NBS under the authority of the National Standard Data Act (Public Law 90-396).

NOTE: The Journal of Physical and Chemical Reference Data (JPCRD) is published quarterly for NBS by the American Chemical Society (ACS) and the American Institute of Physics (AIP). Subscriptions, reprints, and supplements are available from ACS, 1155 Sixteenth St., NW, Washington, DC 20056.

Building Science Series-Disseminates technical information developed at the Bureau on building materials, components, systems, and whole structures. The series presents research results, test methods, and performance criteria related to the structural and environmental functions and the durability and safety

characteristics of building elements and systems.

Technical Notes-Studies or reports which are complete in themselves but restrictive in their treatment of a subject. Analogous to monographs but not so comprehensive in scope or definitive in treatment of the subject area. Often serve as a vehicle for final reports of work performed at NBS under the sponsorship of other government agencies.

Voluntary Product Standards-Developed under procedures published by the Department of Commerce in Part 10, Title 15, of the Code of Federal Regulations. The standards establish nationally recognized requirements for products, and provide all concerned interests with a basis for common understanding of the characteristics of the products. NBS administers this program as a supplement to the activities of the private sector standardizing organizations.

Consumer Information Series-Practical information, based on NBS research and experience, covering areas of interest to the consumer. Easily understandable language and illustrations provide useful background knowledge for shopping in today's technological marketplace.

Order the above NBS publications from: Superintendent of Documents, Government Printing Office, Washington, DC 20402.

Order the following NBS publications-FIPS and NBSIR's-from the National Technical Information Service, Springfield, VA 2?161.

Federal Information Processing Standards Publications (FIPS PU B)-Publications in this series collectively constitute the Federal Information Processing Standards Register. The Register serves as the official source of information in the Federal Government regarding standards issued by NBS pursuant to the Federal Property and Administrative Services Act of 1949 as amended, Public Law 89-306 (79 Stat. 1127), and as implemented by Executive Order 11717 (38 FR 12315, dated May 11, 1973) and Part 6 of Title 15 CFR (Code of Federal Regulations).

NBS Interagency Reports (NBSIR)—A special series of interim or final reports on work performed by NBS for outside sponsors (both government and non-government). In general, initial distribution is handled by the sponsor; public distribution is by the National Technical Information Service, Springfield, VA 22161, in paper copy or microfiche form. 
U.S. Department of Commerce

National Bureau of Standards

Gaithersburg. MD 20899

Official Business

Penalty for Private Use $\$ 300$ 